\title{
ZDRAVJE STAROSTNIKOV HEALTH OF THE ELDERLY
}

\section{Proceedings}




\section{Uredniški odbor Založbe Univerze na Primorskem}

Gregor Pobežin, UP Fakulteta za humanistične študije Vito Vitrih, UP FAMNIT in UP IAM

Silva Bratož, UP Pedagoška fakulteta

Simon Kerma, UP Fakulteta za turistične študije - Turistica Ana Petelin, UP Fakulteta za vede o zdravstvu Janko Gravner, University of California, Davis Krstivoje Špijunović, Učiteljski fakultet Užice Miloš Zelenka, Jihočeská univerzita v Českých Budějovicích in Univerzita Konštantína Filozofa v Nitre Jonatan Vinkler, Založba Univerze na Primorskem Alen Ježovnik, Založba Univerze na Primorskem 
zdravje starostnikov health of the elderly 


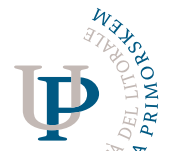

UNIVERS 5

UNIVERT UP $^{\text {U }}$

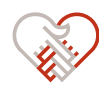

$F_{A C O T A D}$

Univerza na Primorskem . Fakulteta za vede o zdravju Università del Litorale . Facoltà di scienze della salute University of Primorska . Faculty of Health Sciences 


\section{Zdravje starostnikov Health of the Elderly}

Edited by Ana Petelin 



\section{Contents}

Sanela Aljija, Tamara Arh, Jasna Kovač, Urška Ugovšek

7 Self-care promotion program for people with heart failure Liridon Avdylaj, Ines Dujc

13 Effects of music therapy on patients with dementia: A systematic review

Mandy Bade, Anita Hökelmann, Jörn Kaufmann, Volkmar Leßmann, Patrick Müller, Kathrin Rehfeld, Notger Müller

25 Investigations of adult neuroplasticity as an effect of long-term physical activity in old age

Kristina Batič, Marjetka Gomboc

33 The effect of physiotherapy on the mobility of patients with cognitive impairment

Urša Cankar, Saša Kenig

43 The effect of non-nutritive sweetener on lipid metabolism in liver cells

Tilen Dolinar, Saša Kastelic, Andreja Kvas

53 Nutrition of the elderly with atherosclerosis

Kemal Ejub, Alen Mahmutović, Valentina Syla, Andrej Starc

61 Nutrition support teams in social care institutions

Simona Hvalič-Touzery, Vesna Dolničar

71 Attitudes towards smart technologies among older people and their informal carers in Slovenia

Anže Jurček, Mojca Urek

81 Integrating the needs of LGBT+ older adults into health and social care education 
Tjaša Kamnik, Mojca Jevšnik

89 A study on the experiences of hygiene requirements among older persons during the COVID-19 epidemic

Andrej Kirbiš

97 Is the ICT use for health purposes in Slovenia linked to better health?

Adriana Kozina, Valentina Rok, Andrej Starc

105 Apps that help the elderly with dementia

Adriana Kozina, Jožica Čehovin Zajc, Marija Milavec Kapun

113 Use of personal protective equipment during the COVID-19 epidemic in nursing homes - a students' perspective

Katja Kramberger, Darja Barlič-Maganja

123 Elderly and dietary supplements: Benefits and Risks

Marjeta Logar Čuček

131 The impact of oral cancer on the quality of life of older patients

Tatjana Pokrajac

143 Prevention and rehabilitation in the context of long-term care (LTC) in Slovenia

Liza Privošnik, Maša Sedej Knezović, Lara Šinkovec, Andrej Starc

157 Comparison of applications used to help the elderly

Kristina Rakuša Krašovec

167 The importance of educating older adults with diabetes

Valerija Rotar, Tamara Poklar Vatovec

175 Quality of life of the elderly in intergenerational cooperation and learning programs

Tjaša Šarić ${ }^{1}$, Karin Kramberger ${ }^{2}$

183 The influence of the covid-19 epidemic on the incidence of depression in the elderly in a reference dispensary

Karin Šik Novak, Zala Jenko Pražnikar

191 The gut microbiota in the elderly

Mateja Šimec

199 Recognizing the importance of nutrition counseling for the elderly with COPD in primary care

Jasna Špehar, Dajana Glavan, Dijana Došen, Andrej Starc

207 Elderly's attitude towards information communication technology

Felicita Urzi, Sandra Potušek, Laura lacolina, Elena Bužan

215 Association between dietary nutrient intake and sarcopenia in older adults 


\title{
Self-care promotion program for people with heart failure
}

\author{
Sanela Aljija, Tamara Arh, Jasna Kovač, Urška Ugovšek \\ University of Ljubljana, Faculty of Health Sciences, Ljubljana, Slovenia \\ sanela.a94@gmail.com; arh.tamara1995@gmail.com; jasna.kovac24@gmail.com; ugovseku@gmail.com
}

\begin{abstract}
Introduction: Statistics show that heart failure is a major public health problem, and in the population that continues to remain, the disease will only increase. Self-care includes activities performed by the patient to maintain life, healthy functioning, and well-being. Self-care in heart failure can be defined as a decision-making process that influences measures that maintain physiological stability, facilitate the perception of symptoms and the response to them. Coping with heart failure is often complicated, because it involves a complex treatment regimen. Methods: A descriptive method of working with a review of Slovenian and foreign literature using the Cochrane Library, CINAHL, PubMed and MedNar. The Google Scholar web browser was also used to search the literature. We were looking for literature that was published from 2010 to 2020 , the focus was on more recent literature. Results: Preventive activities in self-care measures reduce direct and indirect health care expenditure, so hospitalization is increased due to the health-related quality of life of patients. With different coping strategies (selective denial, goal setting) patients with heart failure achieved a better clinical outcome. In the future, we can expect a big increase in the need for appropriate therapeutic tools and approaches, in connection with heart failure. Above all, the need for education, self-care control and therapy titration. Solutions that will allow patients with heart failure to be treated appropriately are needed. Discussion and conclusions: Heart failure is a medical condition with frequent hospitalizations, high mortality, and high treatment costs. It is extremely important to involve patients in health education programs that encourage them to take active care of their health, to acquire the necessary knowledge and skills, and to form a positive attitude and behavioural patterns for a healthy lifestyle. Only through the joint action of all stakeholders in the field of health, the
\end{abstract}


economy, the non-governmental sector and others can we achieve better

health for all of us.

Keywords: heart failure, health promotion, self-care, self-management

\section{Introduction}

Heart failure (HF) is a common cardiovascular disease associated with high morbidity, mortality, and hospital admission. Heart failure is a major public health problem, the incidence of which is increasing. Current treatment of a patient with HF requires a multidisciplinary approach and includes four areas of care related to biomedical care, psychosocial care, self-care or self-management, and palliative care. The disease requires daily self-care, which is a major part of successful disease management. Self-management and self-care in HF refer to how the individual is responsible for the active management of daily activities such as compliance and regular use of medications, weight monitoring, and lifestyle change. Many factors can affect a person's ability to independently manage $\mathrm{HF}$, these include the socioeconomic status of the patient, the level of health literacy, access to ongoing family support, educational interventions, and the care model in a given health system (Cui et al., 2019).

Self-care includes activities performed by the patient to maintain life, healthy functioning, and well-being. Koirala and colleagues (2020) believe that the ability to perform self-care activities can improve both self-sufficiency and self-care management. The goal of self-care in HF is to improve the health outcomes of patients and to maintain the symptoms of HF in order to avoid avoidable complications. Optimal self-care includes proper medication, adherence to dietary instructions and a healthy lifestyle, monitoring of symptoms, taking appropriate measures to manage symptoms, and regular collaboration with healthcare professionals. Through these activities and measures, self-care helps to reduce direct and indirect health care expenditure, reduces hospitalizations and increases the health-related quality of life of patients.

\section{Methods}

We used a descriptive method of work; a review of Slovenian and English literature was made. Data for were selected from May 2021 to June 2021. Literature was searched in the Cochrane Library, CINAHL, PubMed and MedNar databases using the following keywords: heart failure, self-management, heart failure AND education. The Google Scholar web browser was also used to search the literature. The age of literature was limited from 2010 to 2021, the emphasis was on more recent literature. Articles with full access to the text related to the topic of heart failure were included. The exclusion criteria were: articles that did not have a complete article structure, articles that did not relate to the topic. In addition, the relevance of the content was also a selection criterion. 21 articles were reviewed, of which 10 articles were excluded according to the exclusion criteria. Articles that were not in Slovene or English were also excluded. 
The collected literature is professionally, substantively and topically related to the title of the work.

\section{Results}

Coping with HF is complex, as it often involves a complex treatment regimen. Patients with HF should follow dietary and exercise recommendations and should actively engage with the health facility (Gu et al., 2020).

Statistics confirm SP as a major public health problem, and in the population that remains, the disease will only increase. Promoting self-care and disease management through improved education and follow-up of people with HF can reduce the possibility of hospital admission, improve patient outcomes, and reduce healthcare-related costs, which remains essential in this population (Hart et al., 2020). If patients do not follow self-care activities, such as taking therapy regularly or weighing regularly, the symptoms of HF can obviously worsen.

Between 2004 and 2012, Lainščak and colleagues (2019) in Slovenia recorded 2,430,748 hospitalizations due to illness, of which 158,303 (6\%) with HF. The final sample of hospitalizations included 156,859 hospitalizations with SP.

A recent review showed that drug compliance ranges between 20 and $58 \%$. Patients should be advised to always take medication, even when they are feeling well, as this is due to effective treatment. It is most effective for people with HF to prepare therapy at home in containers or tablets for the next day, so that they do not forget to take medication (Rabelo et al., 2007).

We will educate patients and their relatives about heart failure and empower them to perform self-care, such as: Education about their medications and how to manage heart failure, changing eating habits, improving strength and mobility, daily exercise, monitoring vital signs and symptoms of heart failure, management of aggravated symptoms, proper use of devices to monitor blood pressure, heart rate and weight. Indicators of health and well-being of patients: reduced symptoms of the disease (decompensation symptoms), blood pressure and pulse within normal limits (normotension and normocardia), improved well-being of an individual with HF, reduced fear of self-care activity.

The aim is to reduce the burden of cardiovascular diseases among the Slovenian population, because cardiovascular diseases represent an important public health problem. However, the participation of the population is important for the success of the program, as a key change is the lifestyle of the people.

\section{Discussion}

The goal is to create a motivational model for the implementation of self-care as a method to improve their own well-being and strengthen their health - emphasis on people with heart failure and their relatives, and sports opportunities for everyone else. The goal is to increase knowledge about heart failure, 
and about self-care in doing so. In addition, the aim is to increase cooperation between organizations and groups of individuals, and to increase the number of transmitters of information through promotional activities and influential people, thereby increasing the number of politicians who support the proposed policy changes. A program to promote self-care in people with heart failure would achieve a higher quality of life for elderly who face such problems.

The advantages of the project are, above all, urging the elderly population to better self-care heart failure activity. Through these activities and measures, self-care helps to reduce direct and indirect health care expenditure, reduces hospitalizations and increases the health-related quality of life.

Opportunities for active participation in various sports activities, learning about diets and a healthy diet, which is crucial in managing and reducing symptoms. Individuals have the opportunity to talk individually with experts in the field. The program offers empowerment to heart failure sufferers as well as their relatives or close people, and can also lead to improved health, well-being and, consequently, the quality of life of individuals with HF and their relatives.

\section{Conclusions}

Heart failure is a medical condition with frequent hospitalizations, high mortality, and high treatment costs. Due to better treatment of acute conditions in cardiology and the aging of the population, the prevalence of heart failure is increasing, which is the only condition in cardiology whose burden is increasing. Therefore, important health education programs that encourage individuals (individual approach) or groups of the population (group approach) to begin to actively care for their health, acquire the necessary knowledge and skills, and develop positive attitudes and behavioural patterns for a healthy lifestyle.

Only through the joint action of all stakeholders in the field of healthcare, the economy, the non-governmental sector and others can we achieve better health for all of us.

\section{References}

CUI, X., ZHOU, X., MA, L., SUN, T., BISHOP, L., GARDINER, F.W., WANG, L., (2019). A nurse-led structured education program improves self-management skills and reduces hospital readmissions in patients with chronic heart failure: a randomized and controlled trial in China. Rural and Remote Health 19(2): 1-8. doi: https://doi.org/10.22605/RRH5270

GU, J., YIN, Z.F., ZHANG, H.L., FAN, Y.Q., ZHANG, J.F., WANG, C.Q., (2020). Characteristics and outcomes of transitions among heart failure categories: a prospective observational cohort study. ESC Heart Fail 7(2): 61625. doi: 10.1002/ehf2.12619. 
HART, J., NUTT, R., (2020). Improving inpatient education and follow-up in patients with heart failure: a hospital-based quality improvement project. Nurs Econ 38(2): 74-85. Available at: https://mdsoar.org/handle/11603/10795 [9.5.2020]

HENNING, R.J., (2020). Diagnosis and treatment of heart failure with preserved left ventricular ejection fraction. World J Cardiol 12(1): 7-25. doi: 10.4330/wjc.v12.i1.7.

KAMATH, D.Y., BHUVANA, K.B., DHIRAJ, R.S., XAVIER, D., VARGHESE, K., SALAZAR, L.J., GRANGER, C.B. et al., (2020). Patient and caregiver reported facilitators of self-care among patients with chronic heart failure: report from a formative qualitative study. Wellcome Open Res 5(10): 1-16. doi: 10.12688/wellcomeopenres.15485.2.

KOIRALA, B., BUDHATHOKI, C., DENNISON-HIMMELFARB, C.R., BHATTARAI, P., DAVIDSON, P.M., 2020. The self-care of heart failure index: A psychometric study. J Clin Nurs 29(3-4): 645-652.

LAINŠČAK, M., OMERSA, D., SEDLAR, N., ANKER, S., FARKAŠLAINŠČAK, J., (2019). Heart failure prevalence in the general population: SOBOTA-HF study rationale and design. ESC Heart Failure, ISSN 2055-5822, 2019, vol. 6, iss., str. https://onlinelibrary.wiley.com/doi/epdf/10.1002/ehf2.12496, doi: 10.1002/ehf2.12496.

LAMBRECHT, A., HARDT, R., 2019. Herzinsuffizienz im Alter: Aktuelle Empfehlungen mit Blick auf die überarbeitete Nationale VersorgungsLeitlinie Chronische Herzinsuffizienz. Z Gerontol Geriatr 52(7): 701-712. Doi: 10.1007/s00391-019-01617-0.

MARTI, C.N., FONAROW, G.C., ANKER, S., YANCY, C., VADUGANATHAN, M., GREENE, S,. et al., 2019. Medication dosing for heart failure with reduced ejection fraction. Eur J Heart Fail 21(3): 286-96. doi: 10.1002/ejhf.1351.

RABElO, E.R., Aliti, G.B., DOMINGUES, F.B., RUSCHEL, K.B., BRUN, A.O., 2007. What to teach to patients with heart failure and why: the role of nurses in heart failure clinics. Rev. Latino-Am. Enfermagem 15(1): 165170. https://doi.org/10.159o/So104-11692007000100024.

SUN, J., ZHANG, Z.W., MA, Y.X., LIU, W., WANG, C.Y., 2019. Application of self-care based on full-course individualized health education in patients with chronic heart failure and its influencing factors. World J Clin Cases 7(16): 2165-2175. doi: 10.12998/wjcc.v7.i16.2165. 



\title{
Effects of music therapy on patients with dementia: A systematic review
}

\author{
Liridon Avdylaj, Ines Dujc \\ Izola General Hospital, Izola, Slovenia \\ liridon.avdylaj@gmail.com; ines.dujc@gmail.com
}

\begin{abstract}
Introduction: A high percentage (20\% to $40 \%$ ) of residents in nursing homes care and patients in acute hospitals suffering from dementia develop neuropsychiatric symptoms such as anxiety, depression, agitation, apathy and delusions. Neuropsychiatric symptoms are complex, stressful and challenging to manage, which increase caregiver's burden and the cost associated with dementia care. This systematic literature review aims to investigate the effects of music therapy on neuropsychiatric symptoms of patients with dementia. Methods: A literature search was performed in databases: MEDLINE, Wiley Online Library, CINHAL and ScienceDirect. The search keywords included dementia, music therapy, neuropsychiatric symptoms, anxiety, depression. The search was limited to scientific articles; only articles in English language; only systematic reviews; articles published from January 2011 to January 2021; articles with full text available; articles about residents, who were clinically diagnosed with dementia; articles on study intervention: music therapy; outcomes of study: reported at least one effect of music therapy on neuropsychiatric symptoms; reviews were required to have an AMSTAR rating of five points or greater. Results: We screened 3257 titles, only 12 articles, involving in total 5.978 patients, met the inclusion criteria for review. Overall, the studies showed that music therapy has a significant impact on decreasing neuropsychiatric symptoms of people with dementia. Some of studies found out that there were no significant improvements on cognition or daily functioning and the results on quality of life were ambiguous. Discussion and conclusions: Music therapy is beneficial and improves neuropsychiatric symptoms of people with dementia, therefore it could be a powerful treatment strategy in the future. However further randomized studies are still needed.
\end{abstract}

Keywords: dementia, music therapy, neuropsychiatric symptoms, depression, anxiety. 


\section{Introduction}

Dementia is a syndrome caused by a brain disease that can be chronic or progressive (World Health Organization, 2020). A large proportion (from $20 \%$ to $40 \%)$ of residents of nursing homes and patients in hospitals suffering from dementia develop neuropsychiatric symptoms, such as violent behavior, agitation, wandering, socially inappropriate behavior, eating disorders, anxiety, depression, apathy, insomnia, delusions, misidentification, and hallucinations (Aarsland, 2020).

Demographic aging is a global process resulting from improved healthcare over the last century. There are more than 10 million new cases of dementia worldwide each year, i.e. one new case every 3.2 seconds (Alzheimer's disease international, 2020; Alzheimer's Association, 2021).

Dementia is also a major economic burden because treatment costs are high. Treatment includes costs attributable to informal care (unpaid care for family and others), direct costs of social care (provided by professionals), and direct costs of healthcare (cost of treating dementia and other conditions in primary and secondary care) (Castro et al., 2010; Gustavsson et al., 2010).

The treatment of patients with dementia is holistic. Both pharmacological and non-pharmacological treatments are important. However, there is now a wide range of non-pharmacological strategies to treat neuropsychiatric symptoms. Among these strategies, music therapy is worth mentioning. According to the World Federation for Music Therapy, music therapy is "the use of music and/or musical elements (sound, rhythm, melody, and harmony) by a qualified music therapist, with a client or group, in a process designed to facilitate and promote communication, relationships, learning, mobilization, expression, organization, and other relevant therapeutic objectives to meet physical emotional, mental, social and cognitive needs". Some studies indicated a beneficial effect on reducing the anxiety of patients with dementia (Svansdottir and Snaedal, 2006, Goddaer and Abraham, 1994; Moroi et al., 2008; Nomi et al., 2005; Tabloski et al., 1995; Tsuchiya, 2003) and a few studies also indicated moderate increase a cognitive function (Miura et al., 2005). On the other hand, some studies reported that music therapy did not have a significant effect on agitated behaviors in those with dementia (Sung et al., 2012).

\section{Methods}

A literature search was performed in databases.

\section{Search strategy and selection criteria}

A literature search was conducted in following databases: MEDLINE, Willey Online Library, CINHAL and ScienceDirect. The search keywords included dementia, music therapy, neuropsychiatric symptoms, anxiety, depression. Databases were searched using the Boolean operators to find the results (dementia AND music therapy AND neuropsychiatric symptoms OR anxiety OR depres- 
sion). The search was limited to scientific articles; only articles in English language; only systematic reviews; articles published from January 2011 to January 2021; articles with full text available; articles about residents who were clinically diagnosed with dementia; articles on study intervention: music therapy; outcomes of study: reported at least one effect of music therapy on neuropsychiatric symptoms; reviews were required to have an AMSTAR rating of five points or greater (Table 1 ).

Table 1: Inclusive and exclusive criteria

\begin{tabular}{|c|c|c|}
\hline Criteria & Inclusion criteria & Exclusion criteria \\
\hline Topic & $\begin{array}{l}\text { Effect of music therapy on de- } \\
\text { creasing neuropsychiatric symp- } \\
\text { toms of patients with dementia }\end{array}$ & $\begin{array}{l}\text { Other types of therapy on de- } \\
\text { creasing neuropsychiatric symp- } \\
\text { toms of patients with dementia }\end{array}$ \\
\hline Population & $\begin{array}{l}\text { Residents or patients who were } \\
\text { clinically diagnosed with de- } \\
\text { mentia }\end{array}$ & $\begin{array}{l}\text { Residents or patients with other } \\
\text { pathologies or matters }\end{array}$ \\
\hline Types of study & Only systematic reviews & Other study design \\
\hline Time frame & $1.1 .2011-1.1 .2021$ & Published before 1.1. 2011 \\
\hline Language & English only articles & Articles in other languages \\
\hline Available in electronic databases & articles with full text available & Incompletely accessible articles \\
\hline Outcomes & $\begin{array}{l}\text { reported at least one effect of mu- } \\
\text { sic therapy on neuropsychiatric } \\
\text { symptoms }\end{array}$ & No outcomes/unclear effect \\
\hline Rating tool & $\begin{array}{l}\text { Five points or greater by AM- } \\
\text { STAR }\end{array}$ & Less than five points by AMSTAR \\
\hline
\end{tabular}

Legend: AMSTAR-A Measurement Tool to Assess systematic reviews.

\section{Study identification and selection}

Without the use of pre-defined exclusion criteria, we obtained 9.327 titles. Of these, the most articles were in the Medline database, namely 3.263, the second database with the most articles was Willey Online Library 1.054 articles, in the CINHAL there were 872 articles, and the least results were in the ScienceDirect database, there were 520 articles. After applying such as time limit, removal of duplicates, full availability of text and articles in English, the number of results was reduced to 549 articles. We further removed an additional 127 articles based on analysis of article titles and/or abstracts due to population, which did not include residents or patients who were clinically diagnosed with dementia, thus removing and additional 100 articles. In addition, 64 additional articles were excluded because we could not accurately understand or the effect of music therapy was unclear. We removed an additional 15 articles because authors use other types of non-pharmacological therapy on decreasing neuropsychiatric symptoms of patients with dementia. At finally phase we evaluated twenty articles with a Measurement Tool to Assess systematic review (AMSTAR). Only twelve articles met other inclusion criteria and get more than five points or greater by AMSTER. 
Twelve articles included in the systematic review of the literature met all the set inclusion criteria. Articles that were in line with the purpose and goal of our systematic review were evaluated with a Measurement Tool to Assess systematic review (AMSTAR) (Table 2). A total of 5,978 patients participated in all studies included in our review. The PRISMA approach () was used to show the course of the literature review (Figure 1) (Moher et al., 2015). We further imported the results into the Zotero program, which is a research tool that also enables the organization, storage of resources, management and citation of our references.

\section{Results}

We identified and analysed 12 articles (Ueda et al., 2013; Ing-Randolph et al., 2015; Fusar-Poli et al., 2018; Gomez-Romero et al., 2017; Sherriff et al., 2017; Rezende Alexio et al., 2017; Zhang et al., 2016; Mercadal-Brotons and Alcantara-Silva., 2019; Bartfy et al., 2019; Li et al., 2019; Long Lam et al., 2020; Morales et al., 2020) showed on (Table 2).

\section{Table 2: Overview of studies}

\begin{tabular}{|c|c|c|c|c|c|}
\hline Reference & Type of study & Study goal & Sample size & Research findings & AMSTAR \\
\hline Ueda et al., 2013 & $\begin{array}{l}\text { A systematic } \\
\text { review }\end{array}$ & $\begin{array}{l}\text { Investigate the } \\
\text { effects of music } \\
\text { therapy on be- } \\
\text { havioural and } \\
\text { psychological } \\
\text { symptoms, cog- } \\
\text { nitive function, } \\
\text { and activities } \\
\text { of daily living } \\
\text { in patients with } \\
\text { dementia. }\end{array}$ & 617 & $\begin{array}{l}\text { The effect of therapy is } \\
\text { effective for the man- } \\
\text { agement of behav- } \\
\text { ioural and psychologi- } \\
\text { cal symptoms. }\end{array}$ & $11 / 11$ \\
\hline $\begin{array}{l}\text { Ing- Randolph } \\
\text { et al., } 2015\end{array}$ & $\begin{array}{l}\text { Systematic } \\
\text { review }\end{array}$ & $\begin{array}{l}\text { To review the } \\
\text { using group } \\
\text { music interven- } \\
\text { tion to reduce } \\
\text { dementia-asso- } \\
\text { ciated anxiety, } \\
\text { the delivery of } \\
\text { such interven- } \\
\text { tions. }\end{array}$ & $\begin{array}{l}361 \text { people clin- } \\
\text { ically diagnosed } \\
\text { with demen- } \\
\text { tia, the age of } \\
\text { subjects ranged } \\
62.7-99 \text { years }\end{array}$ & $\begin{array}{l}\text { Group music inter- } \\
\text { vention to treat de- } \\
\text { mentia-associated } \\
\text { anxiety is a promising } \\
\text { treatment. However, } \\
\text { the small number of } \\
\text { studies and the large } \\
\text { variety in methods } \\
\text { and definitions lim- } \\
\text { it our ability to draw } \\
\text { conclusions. }\end{array}$ & $9 / 11$ \\
\hline
\end{tabular}


The aim is to

ascertain the

conclusions of scientific publi-

Gomez-Romero A systematic et al., 2017 review

cations regarding the benefits of music therapy on behavioural problems elderly patients

with dementia.

To analysed the efficacy of music therapy in elderly demen-

Zhang et al., 2016

A systematic review of literature tia patients, and

if so where music therapy can be used at firstline non-pharmacological treatment.

The effect of music therapy on cognitive functions in patients with dementia.

$\begin{array}{ll}2018 & \begin{array}{l}\text { review of liter- } \\ \text { ature }\end{array}\end{array}$

Rezende Alexio et al., 2017

A systematic review of literature
Assessing the efficacy of music therapy in the neuropsychiatric symptoms of people with dementia.
404 subjects diagnosed with dementia.
Music therapy is ben-

eficial and improves behaviour disorders, anxiety and agitation $9 / 11$ in subjects diagnosed with dementia.
1757 adults with dementia
The meta-analysis suggested that music therapy had positive effects on disruptive behaviour and anxiety and positive trend for cognitive function, depression and quality of life.
$11 / 11$

It is possible to affirm that the positive effect of music therapy on $9 / 11$ cognitive impairments in dementia.

\section{0}

In general, studies in-

641 elderly dicated the efficacy of with uncatego- music therapy on the rized demen- decline of depression, tia, $A D$, vascu- agitation and anxiety. lar dementia, There were heterogemixed dementia neity of interventions, in mild, mod- methodological deerate and sever sign and instruments stages. of evaluation among studies.

Music delivery was

To establish whether music therapy improves neu-

Sherriff et al.,

A systematic review of literature adults with de- ropsychiatric symptoms in mentia and/or delirium in the general hospital. feasible and have a positive effect on some aspects of neuropsychiatric symptoms in various set-

239 patients clinically diagnosed with dementia. tings, but the studies was generally small at high risk of bias and did not use recognized frameworks for evaluating complex interventions. 
Determine the effectiveness of music therapy on reduc-

Hui-Chi Li et A systematic real., 2019 view of literature ing depression for people with dementia during different intervention intervals.
Music therapy interventions can effectively reduce people depression in people with dementia. The importance of music therapists in music therapy interventions.
The results of the sources analyzed show that active music therapy seems to be safe

To provide clinical recommendation regarding music therapy interventions on patients with non-Alzheimer disease dementia.
136 patients. 15 patients were diagnosed with dementia. and effective treatment for all tyoes of dementia. However, it is recommended that future studies contemplate and highlight

the diversity of symp-

toms and course of the disease of the different types of demen$10 / 11$ $\begin{array}{ll}\text { tons and Alan- } & \text { view } \\ \text { tara-Silva., 2019 } & \text { ature }\end{array}$

A systematic retia in order to identify and better understand the music therapy interventions best suited for each of them

Overall, the studies showed a significant

To examines the effects of music therapy

Bartfay et al., A systematic re- on behaviourview of liter- al psychologiature cal symptoms of dementia and the quality of life.
Approximately 1872 patients clinically diagnosed with dementia. impact on mitigating agitation, reducing BPSD and improving memory, cognition, QOL, and decreasing anxiety and symptoms associated with depression.

Music therapy could be a powerful treatment strategy. It is necessary to developed clinical tri-

Effect of music therapy on cognitive function, quality of Morales et al., A systematic review of literature life, and/or depressive state in people living with dementia. als aimed to design standardized protocols depending on the nature or stage of dementia so that they can be applied together with current cognitive-behavioural and pharmacological therapies. 


\begin{tabular}{llll} 
& & $\begin{array}{l}\text { Effects of mu- } \\
\text { sic therapy on } \\
\text { patients with } \\
\text { dementia to } \\
\text { evaluate its po- } \\
\text { tential benefits } \\
\text { on dementia. }\end{array}$ & No data \\
2020 & $\begin{array}{l}\text { Music therapy could } \\
\text { improve verbal fluen- } \\
\text { cy and reduce anxie- } \\
\text { ty, depression, and ap- } \\
\text { athy to patients living } \\
\text { view of liter- } \\
\text { ature }\end{array}$ & $\begin{array}{l}\text { with dementia. There } \\
\text { dose not appear to be } \\
\text { proven benefits on } \\
\text { memory, daily func- } \\
\text { tion, or overall quali- } \\
\text { ty of life }\end{array}$ \\
\hline
\end{tabular}

\section{Discussion}

Nowadays, there is a growing incidence of this disease in the population all around the world, and, therefore, it is important to develop treatments and activities to relieve its symptoms. To reach that assumption, we performed this overview which identified 12 systematic reviews including 228 studies reporting on outcomes of music therapy on at least one neuropsychiatric symptom to patients with dementia. These reviews addressed components that are important for this intervention to be successful, like for example range of different types of music therapy, the intervention length, the number of sessions per week, and the person who conducted music therapy.

Some of the analyzed studies found out that music therapy can alleviate anxiety and depression. Gomez-Romero et al., 2017, found that different types of music therapy (active technique, passive listening, or combined technique) are beneficial for improving anxiety. The results of a study by author Ueda et al., 2013 indicate that music therapy reduced anxiety and depression in people with dementia. However, they were unable to clarify what type of music therapy. Regarding the effects of the intervention type, the singing intervention seemed to produce moderate effects on behavior and anxiety. The listening intervention might produce somewhat more effects on the outcomes of behavior, depression, and anxiety. In the study by Alexio et al., 2017, receptive "relaxation" music therapy is a method that probably better reduces neuropsychiatric symptoms. Studies of authors Zhang et al., 2016, and Long Lam et al., 2020, also showed that music therapy had positive effects on disruptive behavior and anxiety but also a positive trend for cognitive function, depression, and quality of life.

A systematic review from author Long Lam et al., 2020, showed that the effect of music therapy on patients living with dementia suggested significant improvements in verbal and language fluency, alleviation of BPSD including anxiety and depression and reduced levels of apathy. These findings are generally in line with previous reports on the potential benefits of music therapy in improving the behavioral symptoms in patients living with dementia (Zhang et al., 2016; Gomez-Romero et al., 2017). However, this study suggests that the music therapy field significantly improves the overall aspects of cognition (such as 
memory, orientation, and registration), agitation, daily functioning, and the quality of life living with dementia. A systematic review with meta-analyses from authors Fusar-Poli et al., 2018, aimed at providing an overview of the possible effects of music therapy on cognitive functions in patients with dementia. Results confirm the conclusions of previous reviews which did not find any significant improvement in global cognition (Chang et al., 2015; Lie et al 2015; Ueda et al., 2013). They did also not find any positive effect of music therapy on domains like cognitive functions, such as attention, language, memory, and perceptual-motor skills.

A study by Li et al., 2019, showed that the intervention length and number of sessions per week of music therapy is very important to reduced depression of people with dementia. The meta-analysis revealed that music therapy was significantly associated with decreasing the degree of depression for medium-term intervention (six to 12 weeks). No significant differences in depressive levels were found between music therapy and control groups in short-term interventions (three or four weeks). The effects of medium-term music therapy may contribute to improved depression in people with dementia while shortterm intervention may not. Another similar meta-analysis study suggested that short-term music therapy might not be able to improve cognitive function for people with dementia (Li HC et al., 2015).

The definition of music therapy specifies that sessions must be guided by a qualified music therapist. A majority of analyzed studies showed that the involvement of music therapists significantly reduced neuropsychiatric symptoms (Li et al., 2019; Gomez-Romero et al., 2017; Ueda et al., 2013; Fusar-Poli et al., 2018; Alexio et al., 2017; Sherriff et al., 2017).

Our systematic review includes a relatively large number of subjects and studies. Therefore, we can summarize that music therapy has a significant impact on decreasing neuropsychiatric symptoms of people with dementia. Some studies found out that there were no significant improvements in cognition or daily functioning and the results on quality of life were ambiguous.

\section{Conclusions}

Music therapy is beneficial and improves neuropsychiatric symptoms of people with dementia. Therefore, it could be a powerful treatment strategy in the future. However further randomized studies are still needed.

\section{References}

AARSLAND, D., 2020. Epidemiology and Pathophysiology of Dementia-Related Psychosis. J Clin Psychiatry. vol. 81, no. 5, pp. 1-10.

ALZHEIMER'S DISEASE INTERNATIONAL, n. d. Dementia statistics [online]. [viewed 10 June 2021]. Available from: https://www.alzint.org/ about/dementia-facts-figures/dementia-statistics/ 
BARTFAY, W.-J., ALI M., HORSBURGH, S., DUFF-WOSKOSKY, A., and EARLE, J., 2019. A Systematic Review of the Literature for the Effects of Music on Dementia Patients. Gerontology \& Geriatric Research. vol. 1, no. 1, pp. 1-12.

CASTRO, D.-M., DILLON, C., MACHNICKI, G. and ALLEGRI F.-R., 2010. The economic cost of Alzheimer's disease: Family or public health burden?. Dement Neuropsychol. vol. 4, no. 4, pp. 262-267.

FUSAR-POLI, L., BIELENINIK, L., BRONDINO, N., XI JING, C. and GOLD, C., 2018. The effect of music therapy on cognitive functions in patients with dementia: a systematic review and meta-analysis. Aging and mental health. vol. 22, no. 9, pp. 1103-112.

GODDAER, J. and ABRAHAM I.- L. 1994. Effects of relaxing music on agitation during meals among nursing home residents with severe cognitive impairment. Arch Psychiatr Nurs. vol. 8, no. 3, pp. 150-158.

GOMEZ ROMEROA, M., JIMENEZ PALOMARES, M., RODRIGUEZ MANSILLAC, J., FLORES NIETOC, A., GARRIDO ARDILA, E.-M. and GONZALEZ LOPEZ ARZA, M.-V., 2017.Benefits of music therapy on behaviour disorders in subjects diagnosed with dementia: A systematic review Neurología. no. 32, pp. 253-263.

GUSTAVSSTON, A., JONSSON, L., RAPP, T., REYNISH, E., OUSSET, P.-J., ANDRIEU, S., CANTET, C., WINBLAD, B., VELLAS, B. and WIMO, A., 2010. Differences in resource use and costs of dementia care between European countries: baseline data from the ICTUS study. J Nutr Health Aging

HUI-CHI, LI., HSIU HUNG, W., CHU YUN, L., TAI BEEN, C., YU HUA, and I, L., 2019. The effect of music therapy on reducing depression in people with dementia: A systematic review and meta-analysis. Geriatric Nursing. no. 40, pp. $510-516$.

ING-RANDOLPH, A.-R., PHILLIPS, R.-L. and WILLIMAS, B.-A., 2015. Group music interventions for dementia-associated anxiety: A systematic review. International Journal of Nursing Studies. no. 52, pp. 1775-1784.

LONG LAM, H., WAI TAK, V.-L., ISMAIL, L. and WONG, Y.-W., Effects of Music Therapy on Patients with Dementia-A Systematic Review. Geriatrics. vol. 5 no. 62, pp. 1-14.

MERCADAL BROTONS M. and ALCANTARA SILVA, T.-R., 2019. Music Therapy for Non-Alzheimer's Disease Dementia: A systematic review. $J$ Alzheimers Neurodegener. vol. 5, no, 1, pp. 1-10.

MIURA, H., KANAYAMA, Y., MOGI, N. and ENDO, H., 2005. Effect and significance of music therapy on elderly persons with mild dementia. Japanese Journal of Music Therapy, vol. 5 pp. 48-57. 
MORENO MORALES, C., CALERO, R., MORENO MORALES, P. and PINTADO, C., 2020. Music Therapy in the Treatment of Dementia: A Systematic Review and Meta-Analysis. Front. Med. vol. 7 pp. 1-11.

MOROI, K., YAGUNCHI, K., YASUNAGA, A., OOKUBO, T. and ABE, A., 2007. A sudy of the effects of music therapy fort he elderly with mild-dementia. Tokai University, School of Health Sciencs. vol. 12 pp. 7-14.

NOMI, A., HOSOYA, M., MIHARA, Y., KOTOH, A. and MIHARA, E., 2005. Effects of music therapy for dementia: reducing behavioral problem. Tsusyo Care. vol. 3, 63-68.

REZENDE ALEIXO, M.-A., SANTOS, L.-R. and NASCIMENTO DOURADO, M.-C., 2017. Efficacy of music therapy in the neuropsychiatric symptoms of dementia: systematic review. Bras Psiquiatr. vol. 66, no. 1, pp. 5261.

SHERRIFF, C., MATHEWS, J., REYNISH, E.-L. and SHENKIN, S.-D., 2017. Music Therapy for Neuropsychiatric Symptoms in the General Hospital: a systematic literature review. Music \& Medicine. vol. 9, no. 4, pp. 217-226.

SUNG, H., LEE, W., LI, T. and WATSON, R., 2012 A group music intervention using percussion instruments with familiar music to reduce anxiety and agitation of institutionalized older adults with dementia. Int J Geriatr Psychiatry. no. 27, pp. 621-627.

SUNG, H.C., LEE, W.L., LI, T.L. and WATSON, R., 2012. A group music intervention using percussion instruments with familiar music to reduce anxiety and agitation of institutionalized older adults with dementia. International Journal of Geriatric Psychiatry, vol. 27, no. 6. pp. 621-627.

SVANSDOTTIR, H.-B. and SNAEDAL, J. 2006. Music therapy in moderate and severe dementia of Alzheimer's type: a case-control study. Int Psychogeriatr. vol. 18, no. 4, pp. 613-621.

TABLOSKI, P.A., MCKINNON-HOWE, L. and REMINGTON, R., 1995. Effect of calming music on the level of agitation in cognitively impaired nursing home residents. American Journal of Alzheimer's Disease and Other Dementias, vol. 8 pp. 10-15.

TOMOMI, U., YOSHIMI, S., MAI, S. and SHIN INCHI, I., 2013. Effects of music therapy on behavioral and psychological symptoms of dementia: A systematic review and meta-analysis. Ageing Research Reviews. no. 12, pp. 628-641.

TSUCHYIA, J.-K., BYRNE, M. and MORTENSEN, B.-P., 2003. Risk factors in relation to an emergence of bipolar disorder: a systematic review. Bipolar Disord. vol. 5, no. 4, pp. 231-242. vol. 14, no. 8, pp. 648-654.

WORLD HEALTH ORGANIZATION., 2021. Dementia [online]. [viewed o4 september 2021]. Available from: https://www.who.int/news-room/factsheets/detail/dementia 
YINGSHI, Z., JIAYI, C., LI, A., FUHAI, H., TIANSHU, R., HONGDA, M. and QINGCHUN, Z. 2017. Does music therapy enhance behavioral and cognitive function in elderly dementia patients? A systematic review and meta-analysis. Ageing Research Reviews. no. 35, pp. 1-12.

ZHANG, Y., CAI, J., AN, L., HUI, F., REN, T., MA, H. and ZHAO, Q., 2016. Does music therapy enhance behavioral and cognitive function in elderly demenita patients? A systematic review and meta-analysis. Ageing Research Reviews, vol. 35, no. 2017. pp. 1-11. 



\title{
Investigations of adult neuroplasticity as an effect of long-term physical activity in old age
}

\author{
Mandy Bade', Anita Hökelmann', Jörn Kaufmann', Volkmar Leßmann', \\ Patrick Müller', Kathrin Rehfeld', Notger Müller² \\ 1 Otto von Guericke University Magdeburg, Magdeburg, Germany \\ ${ }^{2}$ German Center for Neurodegenerative Diseases in Magdeburg, Magdeburg, Germany \\ mandy.bade@med.ovgu.de; anita.hoekelmann@ovgu.de; joern.kaufmann@med.ovgu.de;
} volkmar.lessmann@med.ovgu.de; patrick.mueller@dzne.de; kathrin.rehfeld@ovgu.de; notger.mueller@dzne.de

\begin{abstract}
Introduction: The growing number of elderly people in the population is accompanied by an increased prevalence of chronic diseases, e.g. dementia, which will confront the healthcare system with major challenges in the future. Therefore, appropriate interventions are needed to support healthy aging combined with a high quality of life. The potential of the adult organism for neuronal plasticity, induced by longterm physical activity, was examined in an interdisciplinary project on aging research from neuroscientific, physiological, neuropsychological and sports science perspectives. Methods: In a longitudinal study with 20 healthy elderly people $(\mathrm{M}=72.65, \mathrm{SD}=4.31$ years $)$ the influence of endurance and strength training as well as dance training on brain structure, BDNF, memory, balance ability and endurance performance was investigated. Measurements were performed before the start of the training phase, after 6 months, 18 months and 5 years. Structural MRI scans (FSL segmentation), blood analyses, the Verbal Learning and Memory Test (VLMT), Limits of Stability Test (LoS) and Physical Working Capacity Test 130 (PWC 130) were conducted. Results: In both groups, we observed an increased volume in the left amygdala $(\mathrm{F}(3,36)$ $=3.760, \mathrm{p}=.019, \mathrm{f}=.56)$, a maintenance of BDNF concentration in blood plasma, an improvement in balance ability according to LoS in terms of reaction time $(\mathrm{F}(3,42)=6.379, \mathrm{p}=.001, \mathrm{f}=.67)$, movement velocity $(\mathrm{F}(3,42)=4.925, \mathrm{p}=.005, \mathrm{f}=.59)$, endpoint $(\mathrm{F}(1.83,25.58)=9.221$, $\mathrm{p}=.001, \mathrm{f}=.81)$, maximum dislocation $(\mathrm{F}(3,42)=12.476, \mathrm{p}<.001, \mathrm{f}=$ $.94)$ and direction control $(\mathrm{F}(3,42)=6.542, \mathrm{p}=.001, \mathrm{f}=.68)$ as well as a stabilization of the performance in PWC 130. Memory performance improved significantly in the dance group with regard to recognition performance $\left(\mathrm{X}^{2}(3, \mathrm{~N}=8)=12.197, \mathrm{p}=.007\right)$. Discussion and conclusions: The neuroplasticity effect was confirmed as a result of both training measures based on neurostructural, molecular, cognitive, coordinative
\end{abstract}


and conditional adaptation phenomena in the adult organism. The study showed that a long-term physically active lifestyle leads to preservation of performance and thus to a higher quality of life as well as autonomy in old age. It should be emphasized that only dance training contributed to cognitive performance enhancement.

Keywords: neuroplasticity, cognition, dance, seniors, dementia prevention

\section{Introduction}

Demographic change, characterized by low birth rates and simultaneously rising life expectancy, has arrived in Germany long ago. "Every second person in Germany today is older than 45 and every fifth person is older than 66" (Federal Statistical Office, 2020). In the future, a further increase in the number of senior citizens and a decline in the working-age population can be expected. The challenges for the health care system and the provision of care require the development of appropriate interventions that support healthy aging combined with a high quality of life and autonomy in old age. Physical activity and cognitive training are interventions that have been shown in the past to be promising methods to positively influence age-related structural and functional brain changes, and thus the prevalence of dementia. A combination of both methods seems to be the most effective. Sportive dance training represents such a combination, as it combines conditional, coordinative, cognitive and emotional contents (Müller et al., 2017, Rehfeld et al., 2017, Rehfeld et al., 2018).

Our aim was to investigate the influence of different physical activities on neurostructural, molecular, neuropsychological and motor parameters in healthy elderly people aged 60 to 85 years in the long-term course. A distinction is made between sportive dance training and fitness training (endurance and strength training). The longitudinal study is one of the few to examine the long-term effects of different training methods on the complex performance structure of healthy elderly people and therefore plays an essential role in the research focus on dementia prevention.

\section{Methods}

The longitudinal investigation is based on a randomized study design. In 2012, study participants were randomly assigned to either an intervention group (sportive dance training) or an active control group (fitness training). After six months of intervention, the first posttest was conducted. After another 12 months of training, posttest 2 was performed. Finally, a last posttest was completed about 5 years after the start of the first tests. Over the course of the 5-year longitudinal study, the sample size decreased from the original 62 subjects to 20 subjects (ten subjects per group). The measurements included neurostructural, molecular, neuropsychological and motor tests. The aim of the longitudinal study was to examine the development of the above-mentioned parame- 
ters of the sportive dance group and the active control group in the long-term course of about 5 years. An inactive control group was not included because numerous studies have already shown that physical inactivity leads to accelerated age-correlated decline processes (Erickson et al., 2011). In addition, it is ethically questionable to encourage people to be physically inactive for a longer period.

Only cognitively healthy subjects were included in the study. Inclusion criteria were a minimum score of 26 on the Mini-Mental Status Test (MMST) of Folstein, Folstein \& McHugh (1990). Further inclusion criteria were a minimum age of 60 years and MRI suitability (no metallic implants, pacemakers, tinnitus, tattoos, use of centrally acting drugs, claustrophobia and neurological diseases such as stroke or Parkinson's disease).

In the intervention group, the training of conditional and, in particular, coordinative abilities were in focus, as well as the memorization and recall of acyclic, non-automated movement combinations. The fitness training, on the other hand, emphasized conditional skills such as strength and endurance, which were characterized by cyclic, automated, and alternating movements (Rehfeld, 2016). Both exercise interventions had the same conditions regarding the use of music as well as the implementation of the training in a group to keep possible psychosocial and emotional effects constant in the two groups. The training duration, intensity and frequency were almost identical in both training groups. The structure of the training sessions in a warm-up, main and cooldown part were also the same in both groups. The sportive dance training included different genres, such as line dance, jazz dance, Latin dance, rock'n'roll and square dance, which changed monthly. The training concept was based on a balance between learning new acyclic movement patterns and consolidating them through repetition and recall. Due to the variety of coordination of partial body movements, new multimodal sensory and motor stimuli were created continuously. The combinations of mostly unknown step patterns and arm movements had to be memorized, recalled and reproduced under the pressure condition of the dynamic-rhythmic structure of time. The memorization of movement sequences and the recall of these to specific musical structures under time pressure and the permanent relearning of movement sequences under constant conditional stress underline the high cognitive demand in sportive dance training. In addition to time pressure, rhythm, positioning and precision pressure are further pressure conditions of dancing. Spatial orientation, balance (change of one-legged stances, permanent shifting of the body's center of gravity), directional ability (due to changes of place and direction as well as turns), coupling ability (through the combination of arm and leg movements) and speed were also trained. In the fitness training, the 60-minute main part was divided equally (20 minutes each) into endurance training on the bicycle ergometer, strength training with small equipment and flexibility training. In this training program, we intentionally kept the coordinative demands of the exercises as low as possible. 
Structural volume changes of the brain were quantified using magnetic resonance imaging (MRI). A Siemens MAGNETOM Verio 3 Tesla magnetic resonance imaging scanner was used to collect the imaging data for this study. Based on high-resolution T1-weighted MR images, the amygdala volumes were estimated separately for each hemisphere using the segmentation and registration tool FIRST, which is part of the FMRIB's Software Library (FSL) (Patenaude et al., 2011). Blood samples, which were always collected in the morning in a fasting state, were analyzed using an ELISA kit (Enzyme Linked Immuno Sorbent Assay) and tested for neutrophins (specifically BDNF). BDNF concentrations in blood plasma, blood serum, and whole blood were determined, as well as the ratio of blood serum to plasma BDNF concentrations. Long-term regular physical activity and moderate to intense exercise induce an increase in BDNF receptors in brain regions responsible for motor activity and prevent neurodegeneration (Erickson et al., 2011). To measure memory performance, the Verbal Learning and Memory Test (VLMT) was performed. This test measures the performance of verbal declarative episodic memory (Helmstaedter et al., 2001). Balance ability was assessed using the limits of stability (LoS) test. This measures numerous movement characteristics related to the subject's ability to swing voluntarily to different positions in space and briefly maintain balance at these positions. The test includes reaction time, movement speed, maximum deflection and endpoint deflection, as well as directional control. The Physical Working Capacity Test 130, a step load test on a bicycle ergometer, was used to evaluate the conditional capacity endurance. The performance parameters of the PWC 130 were absolute performance in watts and relative performance in watts per kilogram of body weight.

\section{Results}

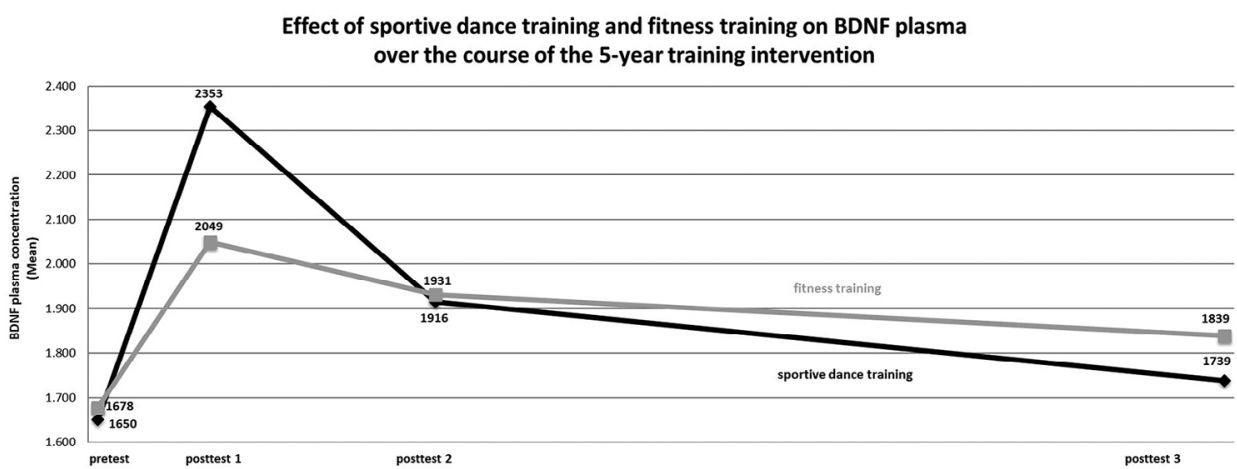

\section{Figure 1: Effect of sportive dance training and fitness training on BDNF plasma over the course of the 5-year training intervention}

The volume of the left amygdala increased significantly over the five-year training period $\left(\mathrm{F}(3,36)=3.760, \mathrm{p}=.019\right.$, partial $\left.\eta^{2}=.24\right)$. Cohen's effect size 
f was .56 , corresponding to a strong effect. According to post-hoc tests with Bonferroni correction, there was a trend toward an increase in volume in the left amygdala from posttest 1 to posttest $2(p=.085)$. There were no significant group differences. Furthermore, it was shown that BDNF concentration in blood plasma remained stable over the five-year training period $(\mathrm{F}(3,45)=$ 2.591, $\mathrm{p}=.064$, partial $\left.\eta^{2}=.15\right)$. No significant group differences were present.

In addition, it was revealed that the Corrected Recognition Performance in the VLMT was significantly improved over the five-year training period in the sportive dance group (Chi-Square $(3)=12.197, \mathrm{p}=.007, \mathrm{n}=8$ ) and remained stable in the fitness training group (Chi-Square(3) $=3.387, \mathrm{p}=.336, \mathrm{n}=9$ ). No significant group differences were found.

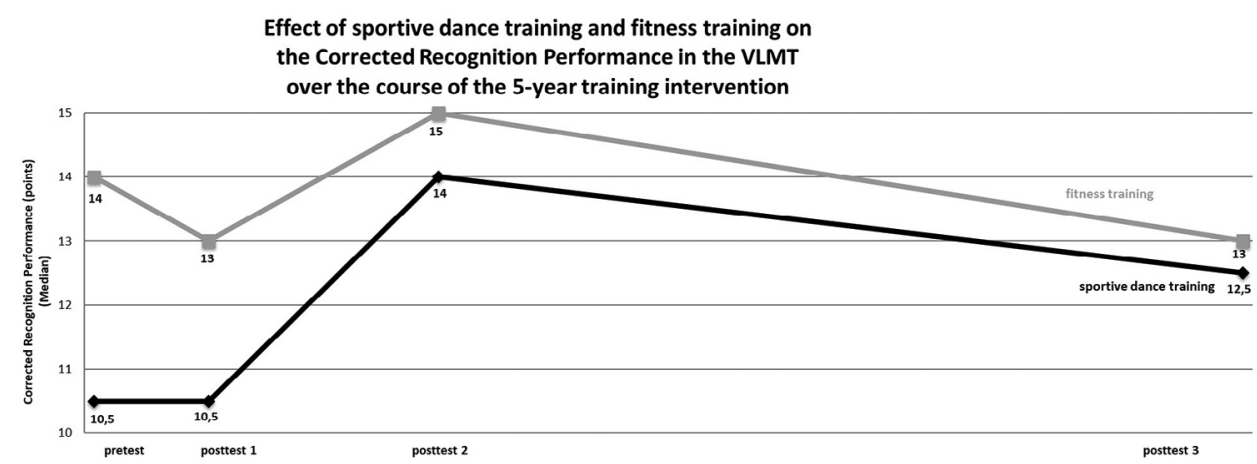

Figure 2: Effect of sportive dance training and fitness training on the Corrected Recognition Performance in the VLMT over the course of the 5-year training intervention

Moreover, it was shown that the "reaction time" in the LoS was significantly improved during the five-year training phase $(\mathrm{F}(3,42)=6.379, \mathrm{p}=.001$, partial $\eta^{2}=.31$ ). Cohen's effect size $\mathrm{f}$ is .67 , representing a strong effect. There were no significant group differences. The "speed of movement" in the LoS was also significantly increased during the five-year training period $(\mathrm{F}(3,42)=$ 4.925, $\mathrm{p}=.005$, partial $\eta^{2}=.26$ ). Cohen's effect size $\mathrm{f}$ was .59 , reflecting a strong effect. No significant group differences were observed. Furthermore, the "endpoint" in the LoS demonstrated a significant increase over the five-year training period $\left(\mathrm{F}(1.83,25.58)=9.221, \mathrm{p}=.001\right.$, partial $\left.\eta^{2}=.40\right)$. Cohen's effect size $\mathrm{f}$ was .81 , indicating a strong effect. There were no significant group differences. The "maximum deflection" in the LoS was also significantly enhanced $(\mathrm{F}(3,42)$ $=12.476$, $\mathrm{p}<.001$, partial $\eta^{2}=.47$ ). Cohen's effect size f was .94 , which corresponded to a strong effect. No significant group differences were present. 


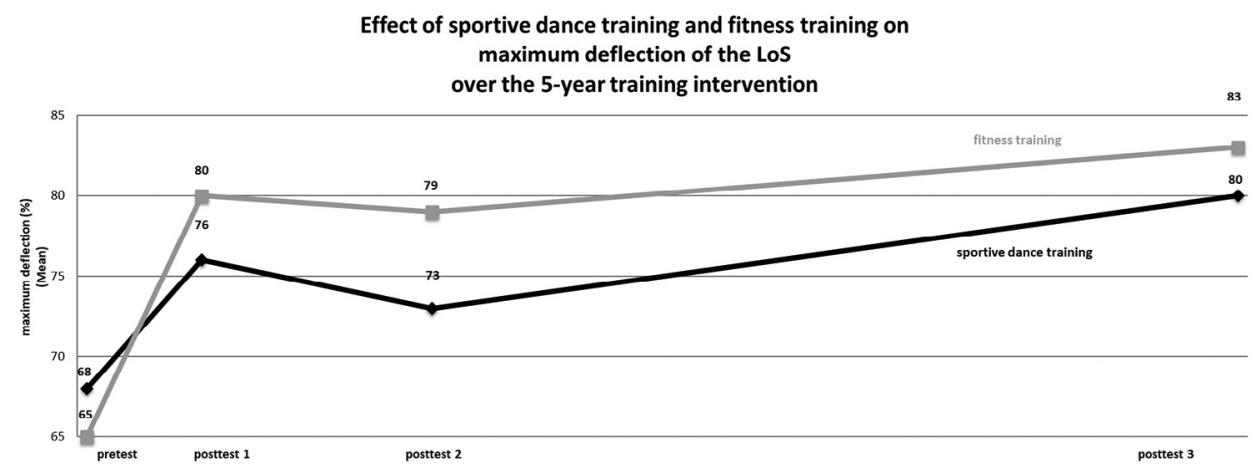

Figure 3: Effect of sportive dance training and fitness training on maximum deflection of the LoS over the 5-year training intervention

Finally, also with regard to "directional control" in the LoS, it could be shown that performance significantly increased from the second to the third measurement time point and significantly decreased again from the third to the fourth measurement time point $\left(\mathrm{F}(3,42)=6.542, \mathrm{p}=.001\right.$, partial $\left.\eta^{2}=.32\right)$. Cohen's effect size f was .68, corresponding to a strong effect. No significant group differences were present. Lastly, it was shown that absolute performance in watts of PWC 130 remained stable over the five-year training period in both the dance group (Chi-Square $(3)=4.846, \mathrm{p}=.183, \mathrm{n}=6$ ) and the fitness training group (Chi-Square $(3)=.360, \mathrm{p}=.948, \mathrm{n}=8$ ). There were no significant group differences. In addition, it was observed that relative performance in PWC 130 maintained stability $\left(\mathrm{F}(3,36)=1.189, \mathrm{p}=.328\right.$, partial $\left.\eta^{2}=.09\right)$. There have been no significant group differences. In both groups, conditional adaptations occurred in terms of stabilization of endurance performance over a 5 -year period.

\section{Discussion}

The present article reflects the main results of the longitudinal study. In the neurostructural and molecular area, a high heterogeneity of the results was observed. In the neuropsychological domain of the longitudinal study, there was a high homogeneity of results, which was characterized by a largely demonstrated maintenance of performance and an absence of group differences. An exception was the improvement of the corrected recognition performance in the sportive dance group. In the motor area of the longitudinal analysis, a maintenance of endurance performance and numerous improvements in balance ability were found.

\section{Conclusions}

Positive effects of sportive dance training as well as fitness training on neurostructural and molecular parameters in older adults during the five-year training intervention were found exclusively in left amygdala volume in both 
groups. Significant group differences were not detectable in the neurostructural and molecular domains. Beneficial effects on neuropsychological parameters were observed only in corrected recall (verbal memory) in the sportive dance group. Regarding motor parameters, positive effects on balance ability were demonstrated in both groups. Thus, it can be summarized that both the conditional-coordinative training dance and the purely conditional training of endurance and strength have a positive effect on neurostructural, neuropsychological as well as motor performance parameters in elderly people and can contribute to the preservation of motor and cognitive functions in old age. Therefore, a physically active lifestyle leads to maintaining quality of life and autonomy in old age.

\section{References}

ERICKSON, K. I., VOSS, M. W., PRAKASH, R. S., BASAK, C., SZABO, A., CHADDOCK, L., KIM, J. S., HEO, S., ALVES, H., WHITE, S. M., WOJCICKI, T. R., MAILEY, E., VIEIRA, V. J., MARTIN, S. A., PENCE, B. D., WOODS, J. A., MC AULEY, E. \& KRAMER, A. F. (2011). Exercise training increases size of hippocampus and improves memory. Proceedings of the National Academy of Sciences of the United States of America, 108 (7), 3017-3022.

FOLSTEIN, M. F., FOLSTEIN, S. E. \& MC HUGH, P. R., 1990. Mini-MentalStatus-Test. Weinheim: Beltz Test.

HELMSTAEDTER, C., LENDT, M. \& LUX, S., 2001. Verbaler Lern- und Merkfähigkeitstest. Göttingen: Beltz Test-GmbH.

MÜLLER, P., REHFELD, K., SCHMICKER, M., HÖKELMANN, A., DORDEVIC, M., LESSMANN, V., BRIGADSKI, T., KAUFMANN, J. \& MÜLLER, N. G. (2017). Evolution of neuroplasticity in response to physical activity in old age: the case for dancing. Frontiers in Aging Neuroscience, 9, 56.

PATENAUDE, B., SMITH, S.M., KENNEDY, D. \& JENKINSON, M. A. (2011). Bayesian Model of Shape and Appearance for Subcortical Brain Segmentation. NeuroImage, 56(3):907-922.

REHFELD, K., 2016. Zum Einfluss eines sportiven Tanztrainings und eines multimodalen Bewegungstrainings auf die Gehirnstruktur sowie auf kognitive und motorische Leistungen bei Senioren (Dissertation, Sportwissenschaft). Punkt um FILM, Biederitz.

REHFELD, K., LÜDERS, A., HÖKELMANN, A., LESSMANN, V., KAUFMANN, J., BRIGADSKI, T., MÜLLER, P. \& MÜLLER, N. G. (2018). Dance training is superior to repetitive physical exercise in inducing brain plasticity in the elderly. PLOS ONE, 13 (7), e0196636.

REHFELD, K., MÜLLER, P., AYE, N., SCHMICKER, M., DORDEVIC, M., KAUFMANN, J. HÖKELMANN, A. \& MÜLLER, N. G. (2017). Dancing or fitness sport? The effects of two training programs on hippocampal plasticity and balance abilities in healthy seniors. Frontiers in Human Neuroscience, 11, 305. 



\title{
The effect of physiotherapy on the mobility of patients with cognitive impairment
}

\author{
Kristina Batič, Marjetka Gomboc \\ University Psychiatric Clinic Ljubljana, Ljubljana, Slovenia \\ kristina.batic@psih-klinika.si; marjeta.gomboc@gmail.com
}

\begin{abstract}
Introduction: Good mobility is crucial for achieving a good quality of life among the elderly. Factors that affect mobility include aging, disease, and injury, but also cognitive decline. A common reason for admitting an elderly person to hospital care are complications associated with the factors mentioned above. Being admitted to the hospital causes additional stress among the elderly, which in practice manifests itself as a risk factor for reduced mobility during hospitalization. The aim of the present study was to determine the effect of a 14-day physical therapy aiming at maintaining or improving the patient's mobility. Methods: We used a quantitative retrospective design. The study included 36 patients, 25 of whom were women ( $73.5 \%)$ and 9 were men $(26.5 \%)$. They were divided into 3 groups, based on the number of points each individual achieved in the Mini-Mental State Examination test (MMSE). They were grouped according to the guidelines of validated Slovenian version of MMSE as follows: 23-19 points - mild cognitive impairment (17 patients), $18-11$ points - moderate cognitive impairment (12 patients) and 10 points or less - severe cognitive impairment ( 5 patients). Patients included in the study were admitted to the Gerontopsychiatric Unit of the University Psychiatric Clinic Ljubljana between October 2020 and April 2021. Inclusion criteria were: aged 60 years or older, confirmed cognitive decline with MMSE, and inclusion in the physical therapy. Exclusion criteria included: worsening of chronic disease, acute deterioration of health or a fall during hospitalization. To assess the patient's mobility, we used the de Morton Mobility Index (DEMMI). Due to the abnormal distribution of the analysed data, the Wilcoxon signed-rank test was used to examine the differences between the first and second assessment with the DEMMI test. The statistical significance of $\mathrm{p}<0.05$ was taken into account. Results: In the second assessment, the results of the DEMMI test in all three groups improved. The most visible
\end{abstract}


improvement is observed in the group with a moderate cognitive decline (18 $\leq$ MMSE $\leq 11$ points), which is statistically significant $(\mathrm{p}=0.005)$. A statistically significant improvement was also observed in the group with mild cognitive impairment ( $19 \leq \mathrm{MMSE} \leq 23$ points $)(\mathrm{p}=0.005)$. The improvement in the second assessment with the DEMMI test, which is evident in the group with severe cognitive impairment, is not statistically significant $(\mathrm{p}=0.109)$. Discussion and conclusions: Existing research shows the importance of adequate physiotherapy treatment of people with cognitive impairment. Our research has also shown that targeted physical therapy preserves or even improves the mobility of people with cognitive impairment, regardless of the degree of the latter.

Keywords: cognitive impairment, mobility, physiotherapy

\section{Introduction}

The world's population is ageing. In 2020, there were 727 million people aged 65 and above. Over the next 30 years, the world's population aged 65 and above is expected to more than double and reach more than 1.5 billion by 2050 (UN, 2020). At the same time, there is also an increasing number of people suffering from dementia. In 2020, there were 50 million people worldwide with dementia. By 2050, that number is expected to rise to 152 million (Alzheimer's disease International, 2020). Due to the ageing of the world's population, the World Health Organization (WHO, 2021) emphasises the importance of improving the lives of older adults and healthy aging. According to the WHO (2020), healthy aging is »the process of improving or maintaining functional abilities that enable wellbeing in older age « (WHO, 2020). Functional abilities include mobility. Mobility is an umbrella term for changing and maintaining body position (e.g. lying down, sitting, getting up) or moving in a position (e.g. moving in a lying position from one side to the other) or from one place to another. It also involves moving to different locations (e.g., at home) or moving using different means of transportation (MKF, 2006).

In the elderly, the key factor for maintaining a good quality of life is preserving good mobility (Le Grow et al., 2013). However, ageing is often associated with reduced mobility and decreased functional (Mahmood Khan, 2017) and cognitive abilities (Murman, 2015). These changes are closely related. Recent researchers (Pedersen et al., 2014; de Melo Borges et al., 2015) argue that the elderly with mild cognitive impairment show more mobility limitations compared to the elderly with intact cognition. In addition to the decline in cognitive abilities, the factors influencing mobility in the elderly are reduced physical activity, obesity, decreased muscle strength, balance disorders and various chronic diseases (Brown et Flood, 2013). The predominant chronic diseases associated with reduced mobility in older adults include hypertension, osteoarthritis, cardiovascular disease, cancer, respiratory disease, diabetes, and stroke (Manini, 2011). Moreover, the occurrence of sarcopenia in old age and the associated decrease in muscle mass and muscle strength also causes problems with 
balance and walking (Marques et Queiros, 2018), which can lead to mobility limitations (Cruz-Jentoft et al., 2019) and to a higher incidence of falls (Yeung et al., 2019). These problems often lead to hospitalisation of older adults, which is an additional risk factor for reduced mobility in the elderly (Surkan et Gibson, 2018) especially in people with cognitive decline (Hartley et al, 2017).

In addition to cognitive decline, reduced mobility is one of the main risk factors for falls among the elderly (Terrosso et al., 2014). The risk of falling is almost three times higher in older adults with moderate to severely reduced mobility compared to those without any restraints (Musich et al., 2018), while in older adults with dementia, the risk of falling is two times higher than in the elderly with intact cognition (Allali et al., 2017). Both reduced mobility and cognitive decline lead to a decrease in an individual's independence in performing activities of daily living (ADLs) (Heiland et al. 2016; Mograbi et al., 2017) and increase mortality (Frith et al., 2015; Bergland et al., 2017).

Previous research shows a positive effect of exercise on cognitive abilities, maintaining mobility and independence in performing ADLs in people with dementia (Liu et al., 2020). Furthermore, therapeutic exercise improves strength, balance, walking, and endurance in people with mild cognitive impairment (Lam et al., 2018), which shows the relevance of including people with cognitive impairment in physiotherapy treatment. In addition, a higher frequency of physiotherapy treatments during hospitalisation shortens the length of stay, improves functional status and increases independence with ADLs upon discharge (Hartley et al., 2016).

However, the effect of physiotherapy treatment on people with cognitive impairment remains insufficiently researched. The aim of our research is to investigate the effect of a 14-day physiotherapy treatment on the mobility of hospitalised patients with cognitive decline.

\section{Methods}

A retrospective quantitative pilot research was conducted. The research included patients admitted to Gerontopsychiatric Unit of the University Psychiatric Clinic Ljubljana between October 2020 and April 2021. Inclusion criteria were age 60 and above, cognitive decline confirmed by Mini Mental State Exam (MMSE) and inclusion to physiotherapy treatment. The exclusion criteria were exacerbation of a chronic disease and acute health deterioration.

The De Morton Mobility Index (DEMMI) was used to assess mobility. It is a standardised measuring instrument used to assess 15 items, including mobility in bed, mobility on a chair, static balance, dynamic balance and walking. Eleven items were evaluated with a 2-point scale, and the remaining four with a 3-point scale. The maximum that an individual could have achieved is 19 raw points that were converted into interval-level DEMMI points. Minimum of o points means complete dependence while 100 points means complete independence in mobility (de Morton et al., 2008). Braun et al. (2018) confirmed 
that the DEMMI test has satisfactory psychometric characteristics for assessing older adults with cognitive decline.

The Slovenian version of the Mini-Mental State Exam (MMSE) was used to assess cognitive function. A 30-point questionnaire assessed orientation, attention, memory, language and visual-spatial skills. According to the score obtained, the patients were divided in three groups: intact cognition $(20-24$ points), mild cognitive impairment ( 23 - 19 points), moderate cognitive impairment (18 - 11 points) and severe cognitive impairment (10 points or less) (Granda et al., 2003).

Physiotherapy treatment was customised according to individual's needs and abilities. It included individual exercises, strength exercises, and exercises to improve static and dynamic balance and coordination, transfer training and walking training. Tests and physiotherapy treatment were performed on the premises of the Gerontopsychiatric Unit of the University Psychiatric Clinic Ljubljana. For each patient, mobility was assessed twice; firstly before enrolment in physiotherapy treatment and secondly after 14 days of physiotherapy treatment.

The anonymised data used in the study was obtained from physiotherapy treatment records. The Commission for Ethical Issues at the University Psychiatric Clinic Ljubljana approved the use of data on the $24^{\text {th }}$ of May 2021. The protection of personal data has been ensured. It was used for research and publishing purposes only.

The data was edited in Microsoft Office Excel 2016 (Microsoft Corporation, New York, USA) and exported for statistical analysis to IBM SPSS Statistics for Windows 25.0 (IBM Corporation, Armonk, New York, USA). Descriptive statistics were given as count (with percentage) or mean (with standard deviation). Shapiro-Wilk test showed the data distribution of the first ( $\mathrm{p}=$ o.018) and second ( $\mathrm{p}=0.026)$ DEMMI test was abnormal. To determine the differences between the first and second DEMMI test the Wilcoxon test was used. Statistical significance was set at p-value $<0.05$.

\section{Results}

In the period between October 2020 and April 2021, 146 patients were tested twice. More precisely, 55 patients $(38 \%)$ were enrolled to physiotherapy treatment.1 patient ( $2 \%$ ) was younger than 60,16 patients $(29 \%)$ did not conclude MMSE or MMSE did not confirm cognitive decline, 4 patients (7\%) experienced exacerbation of chronic disease or acute health deterioration. The remaining 34 patients (62\%) were divided into three groups according to the degree of cognitive impairment: mild cognitive impairment (17 patients, $50 \%$ ), moderate cognitive impairment (12 patients, $35 \%$ ) and severe cognitive impairment (5 patients, $15 \%$ ).

Table 1 shows there were 25 women (73.5 \%) and 9 men $(26.5 \%)$ included in the sample. All three groups had similar representation of women and 
men. The mean age of the patients included in the study was $79.18 \pm 8.67$ years, with patients with severe cognitive decline being the oldest on average $(84,60$ \pm 2.61 ), followed by patients with mild cognitive decline $(79,47 \pm 8.75)$ and patients with moderate cognitive decline (76.50 \pm 9.52$)$.

Table 1: Sample's characteristics

\begin{tabular}{lcccc} 
Group & $\begin{array}{c}\text { Severe } \\
\text { cognitive decline } \\
(N=5)\end{array}$ & $\begin{array}{c}\text { Moderate } \\
\text { cognitive decline } \\
(N=12)\end{array}$ & $\begin{array}{c}\text { Mild } \\
\text { cognitive decline } \\
(N=17)\end{array}$ & $\begin{array}{c}\text { Total } \\
(N=34)\end{array}$ \\
$\begin{array}{l}\text { Age in years } \\
\begin{array}{l}\text { M } \pm \text { SD } \\
(\min -\max )\end{array}\end{array}$ & $\begin{array}{c}84.60 \pm 2.61 \\
(81-88)\end{array}$ & $\begin{array}{c}76.50 \pm 9.52 \\
(60-90)\end{array}$ & $\begin{array}{c}79.47 \pm 8.75 \\
(61-97)\end{array}$ & $\begin{array}{c}79.18 \pm 8.67 \\
(60-97)\end{array}$ \\
\hline $\begin{array}{l}\text { Women N } \\
(\%)\end{array}$ & $3(60 \%)$ & $9(75 \%)$ & $13(76.5 \%)$ & $25(73.5 \%)$ \\
\hline Men N $(\%)$ & $2(40 \%)$ & $3(25 \%)$ & $4(23.5 \%)$ & $9(26.5 \%)$ \\
\hline
\end{tabular}

Legend: $M=$ mean, $S D=$ standard deviation, $N=$ number

The results of the descriptive statistics and the difference between the first and second DEMMI tests in all three groups and Wilcoxon signed-ranked test are shown in Table 2 . In the first assessments, the patients with mild cognitive impairment achieved on average the highest scores (51.47 \pm 22.53 points), followed by the patients with moderate cognitive impairment $(49.50 \pm 19.22$ points). On average, patients with severe cognitive decline (45.80 \pm 23.91 points) achieved the lowest scores in the first assessment.

Table 2: Descriptive statistics of the first and the second DEMMI test and Wilcoxon signed-ranked test

\begin{tabular}{lccc} 
& $\begin{array}{c}\text { DEMMI } \\
\text { Points }(M \pm S D)\end{array}$ & $\begin{array}{c}\text { DEMMI 2 } \\
\text { Points }(M \pm S D)\end{array}$ & p-value \\
\hline Severe cognitive decline & $45.80 \pm 23.91$ & $54.20 \pm 9.37$ & 0.109 \\
\hline $\begin{array}{l}\text { Moderate cognitive de- } \\
\text { cline }\end{array}$ & $49.50 \pm 19.22$ & $63.08 \pm 23.26$ & 0.005 \\
\hline Mild cognitive decline & $51.47 \pm \mathbf{2 2 . 5 3}$ & $65.94 \pm 12.65$ & 0.005 \\
\hline Total & $49.94 \pm 21.03$ & $63.21 \pm 18.09$ & $<0.001$ \\
\hline
\end{tabular}

Legend: $M=$ mean, $S D=$ standard deviation, $D E M M I=$ de Morton Mobility Index

The results of the second DEMMI test improved in all three groups. The greatest improvement was seen in the group with mild cognitive decline. On the other hand, the smallest improvement was observed in the group with severe cognitive decline. The SD of DEMMI test scores in both first and second tests do not exceed $25 \%$ of the $\mathrm{M}$, indicating small differences in mobility within each group.

The results of Wilcoxon signed-ranked test showed statistically significant differences between the results of the first and the second DEMMI test in 
the group with moderate cognitive decline $(\mathrm{p}=0.005)$ and mild cognitive decline $(\mathrm{p}=0.005)$. In addition, a statistically significant difference between the first and the second DEMMI test was shown in the analysis of the whole sample $(\mathrm{p}<\mathrm{o.001})$. In the group with severe cognitive decline, we were unable to confirm a statistically significant difference between the first and the second DEMMI test $(\mathrm{p}=0.109)$.

\section{Discussion}

This research retrospectively examined the effect of physiotherapy treatment on the mobility of older adults with different stages of cognitive decline hospitalised in the Gerontopsychiatric Unit at the University Psychiatric Clinic Ljubljana. In addition, we wanted to determine whether the effect of physiotherapy treatment differs depending on the degree of cognitive decline.

Previous research showed that smaller cognitive impairment is associated with better mobility of an individual (Buchman et al., 2011; Pedersen et al., 2014; De Melo Borges et al., 2015). Our findings confirmed that the highest average score on DEMMI test was achieved by the group with a mild cognitive impairment, followed by the group with a moderate cognitive impairment. The group with a severe cognitive impairment achieved the lowest average score on the DEMMI test. After 14 days of physiotherapy treatment, there was a statistically significant improvement in mobility in the whole sample at the second assessment $(\mathrm{p}<\mathrm{o.001})$. Additionally, the average results of the second DEMMI test were higher in individual groups. The greatest and statistically significant progress in mobility was observed in the group with a mild cognitive impairment $(\mathrm{p}=0.005)$, followed by the group with a moderate cognitive impairment $(\mathrm{p}=0.005)$. The smallest amount of progress, which was not statistically significant, was shown in the group with severe cognitive impairment $(\mathrm{p}=$ o.109). Less progress in more cognitively impaired individuals can be attributed to poorer understanding of instruction (Machiels et al., 2017), poorer performance of complex motor tasks (Wu et al., 2015), and complex ADLs (Perneczky et al., 2006). Furthermore, our findings coincide with those indicated in several research previously conducted, reporting a positive effect of physiotherapy treatment on improving the functional abilities of individuals with cognitive decline (Kovacs et al., 2013; Lam et al., 2018; Gomboc, 2019).

There are important limitations in our research as we included only a small nonrepresentative sample of 34 patients with varying degrees of cognitive impairment. A larger sample would reduce the possibility of random errors in the analysis. In addition, cooperation of a person with cognitive impairment varies daily, which is a challenge in working with people with cognitive decline. In order to better understand the effect of physiotherapy treatment, we suggest further research should be conducted in this field. Prospective research is needed to determine whether the frequency and the duration of physiotherapy treatment plays an important role in mobility outcome. 
Despite limitations of our research, our findings prove positive effect of physiotherapy treatment on the mobility of people with cognitive impairment. Although, the improvement in the group with severe cognitive impairment was not statistically significant, we argue with great certainty that individual physiotherapy treatment customised according to individual's needs and abilities improves an individual's mobility regardless of the degree of cognitive decline.

\section{Conclusions}

Mobility and cognitive decline are closely related phenomena that affect the quality of life of the elderly. The demographic ageing and the increase in the number of elderly people with cognitive difficulties indicate an increasing need to maintain the functional abilities and mobility of these individuals. An additional risk factor to reduce mobility is hospitalisation, which is more common in people with cognitive decline. The inclusion of hospitalised elderly people in physiotherapy treatment has been shown to improve their mobility. Therefore, it is crucial to maintain the mobility and functional abilities of hospitalized individuals with cognitive decline.

\section{References}

ALLALI, G., LAUNAY, C.P., BLUMEN, H.M., CALLISAYA, M.L., DE COCK, A.M., KRESSING, R.W., SRIKANTH, V., STEINMETZ, J.P., VERGHESE, J., BEAUCHET, O. and CONSORTIUM, B., 2017. Falls, Cognitive Impairment, and Gait Performance: Results From the GOOD Initiative. Journal of the American Medical Directors Association, vol. 18, no. 4, pp. $335-340$.

ALZHEIMER'S DISEASE INTERNATIONAL, 2020. Numbers of people with dementia worldwide [online]. [viewed 30 April 2021]. Available from: https://www.alzint.org/u/numbers-people-with-dementia-2017.pdf

BERGLAND, A., JORGENSEN, L., EMAUS, N. and STRAND, B.H., 2017. Mobility as a predictor of all-cause mortality in older men and women: 11.8 year follow-up in the Tromsø study [online]. BMC Health Services Research, vol. 17, no. 22. [viewed 16 May 2021] Available from: https://doi. org/10.1186/s12913-016-1950-O

BRAUN, T., GRUNEBERG, C., THIEL, C. and SCHULZ, R.J., 2018. Measuring mobility in older hospital patients with cognitive impairment using the de Morton Mobility Index [online]. BMC Geriatrics. vol. 18, no. 100. [viewed 20 May 2021] Available from: https://doi.org/10.1186/s12877-018o780-9

BROWN, C.J. and FLOOD, K.L., 2013. Mobility limitation in the older patient: a clinical review. The Journal of the American Medical Association, vol. 310, no. 11, pp. $1168-1177$.

BUCHMAN, A.S., BOYLE, P.A., LEURGANS, S.E., BARNES, L.L. and BENNETT, D.A., 2011. Cognitive function is associated with the development 
of mobility impairments in community-dwelling elders. American Journal of Geriatric Psychiatry, vol. 19, no. 6, pp. $571-580$.

CRUZ-JENTOFT, A.J. and SAYER, A.A., 2019. Sarcopenia [online]. The Lancet, vol. 393, no. 10191, pp. 2636 - 2646. [viewed 15 May 2021] Available from: https://doi.org/10.1016/So140-6736(19)31138-9

DE MELO BORGES, S., RADANOVIC, M. and FORLENZA, O.C., 2015. Functional mobility in a divided attention task in older adults with cognitive impairment. Journal of Motor Behavior, vol. 47, no. 5, pp. $378-385$.

DE MORTON, N.A., DAVIDSON, M. and KEATING, J.L., 2008. The de Morton Mobility Index (DEMMI): An essential health index for an ageing world [online]. Health and Quality of Life Outcomes, vol. 6, no., 63. [viewed 5 May 2021] Available from: https://doi.org/10.1186/1477-7525-6-63

FRITH, E., ADDOH, O., MANN, J.R., WINDHAM, B.G. and LOPRINZI, P.D., 2017. Individual and Combined Associations of Cognitive and Mobility Limitations on Mortality Risk in Older Adults. Mayo Clinic Proceedings, vol. 92, no. 10, pp. $1494-1501$.

GOMBOC, M., 2019. The influence of regular physiotherapy treatment on the functionality of patients admitted to the unit for gerontopsychiatry at the University Psychiatric Clinic Ljubljana. In: ALZHEIMER EUROPE, ed. Making valuable connections: Abstract book / 29th Alzheimer Europe Conference, The Hague, 23 - 25 October 2019. The Hague: Alzheimer Europe, pp. 69.

GRANDA, G., MLAKAR, J. and VODUŠEK, D.B., 2003. Kratek preizkus spoznavnih sposobnosti - umerjanje pri preiskovancih, starih od 55 do 75 let (I). Zdravstveni vestnik, vol. 72, no. 10, pp. 575 - 581.

HARTLEY, P., ADAMSON, J., CUNNINGHAM, C., EMBLETON, G. and ROMERO-ORTUNO, R., 2016. Higher Physiotherapy Frequency Is Associated with Shorter Length of Stay and Greater Functional Recovery in Hospitalized Frail Older Adults: A Retrospective Observational Study. The Journal of Frailty and Aging, vol. 5, no. 2, pp. $121-125$.

HARTLEY, P, GIBBSIN, N., SAUNDERS, A., ALEXANDER, K., CONROY, E., DIXON, R., LANG, J., LUCKETT, J., LUDDINGTON, T. and ROMERO-ORTUNO, R., 2017. The association between cognitive impairment and functional outcome in hospitalised older patients: a systematic review and meta-analysis. Age and Ageing, vol. 46, no. 4, pp. $559-567$.

HEILAND, E.F., WELMER, A.K., WANG, R., SANTONI, G., ANGLEMAN, S., FRATIGLIONI, L. and QUI, C., 2016. Association of mobility limitations with incident disability among older adults: a population-based study. Age and Ageing, vol. 45, no. 6, pp. 812 - 819 .

KOVACS, E., JONASNE, I.S., KAROCZI, C.K., KORPOS, A. and GONDOS, T., 2013. Effects of a multimodal exercise program on balance, functional mobility and fall risk in older adults with cognitive impairment: a randomized controlled single-blind study. European Journal of Physical and Rehabilitation Medicine, vol. 49, no. 5, pp. $639-648$. 
LA GROW, S., YEUNG, P, TOWERS, A., ALPASS, F. and STEPHENS, C., 2013. The impact of mobility on quality of life among older persons. Journal of Aging and Health, vol. 25, no. 5, pp. $723-736$.

LAM, F.H.M., HUANG, M.Z, LIAO, L.R., CHUNG, R.C.K., KWOK, T.C.Y.K. and PANG, M.Y.C. 2018. Physical exercise improves strength, balance, mobility, and endurance in people with cognitive impairment and dementia: a systematic review. Journal of Physiotherapy, vol. 64, no. 1, pp. $4-15$.

LIU, I.T., LEE, W.J, LIN, S.Y., CHANG, S.T., KAO, C.L. and CHENG, Y.Y., 2020. Therapeutic Effects of Exercise Training on Elderly Patients With Dementia: A Randomized Controlled Trial. Archives of Physical Medicine and Rehabilitation, vol. 101, no. 5, pp. $762-769$.

MACHIELS, M., METZELTHIN, S.F., HAMERS, J.P.H. and ZWAKHALEN, S.M.G., 2017. Interventions to improve communication between people with dementia and nursing staff during daily nursing care: A systematic review. International Journal of Nursing Studies, vol. 66, pp. $37-46$.

MAHMOOD KHAN, R., 2018. Mobility impairment in the elderly. InovAiT, vol. 11, no. 1, pp. $14-19$.

MANINI, T., 2011. Development of physical disability in older adults. Current Aging Science, vol. 4, no. 3, pp. $184-191$.

MARQUES, A. and QUEIROS, C., 2018. Frailty, Sarcopenia and Falls. In: HERTZ, K. and SANTY-TOMILSON, J., ed. Fragility Fracture Nursing: Holistic Care and Management of the Orthogeriatric Patient [online]. Cham: Springer. [viewed 15 May 2021] Available from: https://www.ncbi. nlm.nih.gov/books/NBK543821/

MEDNARODNA KLASIFIKACIJA FUNKCIONIRANJA, ZMANJŠANE ZMOŽNOSTI IN ZDRAVJA (MKF), 2006. Gibanje. In: MORAVEC BERGER, D., ed., Mednarodna klasifikacija funkcioniranja, zmanjšane zmožnosti in zdravja. Ljubljana: Inštitut za varovanje zdravja Republike Slovenije, Inštitut RS za rehabilitacijo, pp. 138 - 148.

MOGRABI, D.C., MORRIS, R.G., FICHMAN, H.C:,FARIA, C.A., SANCHEZ, M.A., RIBEIRO, P.C.C. and LOURENCO, R.A., 2017. The impact of dementia, depression and awareness on activities of daily living in a sample from a middle-income country. International Journal of Geriatric Psychiatry, vol. 33, no. 6 , pp. $807-813$.

MURMAN, D., 2015. The Impact of Age on Cognition. Seminars in Hearing, vol. 36, no. 3, pp. $111-121$.

MUSICH, S., WANG, S.S., RUIZ, J., HAWKINS, K. and WICKER, E., 2018. The impact of mobility limitations on health outcomes among older adults. Geriatric Nursing, vol. 39, no. 2, pp. $162-169$.

PEDERSEN, M.M., HOLT, N.E., GRANDE, L., KURLINSKI, L.A., BEAUCHAMP, M.K., KIELY, D.K., PETERSEN, J., LEVEILlE, S. and BEAN, J.F., 2014. Mild Cognitive Impairment Status and Mobility Performance: An Analysis From the Boston RISE Study. The journals of gerontology. 
Series A, Biological sciences and medical sciences, vol. 69, no. 12, pp. 15111518.

PERNECZKY, R., POHL, C., SORG, C., HARTMANN, J., KOMOSSA, K., ALEXOPOULOS, P., WAGENPFEIL, S. and KURZ, A., 20o6. Complex activities of daily living in mild cognitive impairment: conceptual and diagnostic issues. Age and Ageing, vol. 35, no. 3, pp. $240-245$.

SURKAN, M.J. and GIBSON, W, 2018. Interventions to Mobilize Elderly Patients and Reduce Length of Hospital Stay. Canadian Journal of Cardiology, vol. 34, no. 7, pp. $881-888$.

TERROSO, M., ROSA, N., MARQUES, A.T. and SIMOES, R., 2014. Physical consequences of falls in the elderly: a literature review from 1995 to 2010 [online]. European Review of Aging and Physical Activity, vol. 11, pp. 51 - 59. [viewed 15 May 2021] Available from: https://doi.org/10.1007/s11556O13-0134-8

UNITED NATIONS DEPARTMENT OF ECONOMIS AND SOCIAL AFFAIRS, POPULAION DIVISION, 2020. World Population Ageing 2020 Highlights: Living arrangements of older persons [online]. [viewed 19 April 2021]. Available from: https://www.un.org/development/desa/pd/ sites/www.un.org.development.desa.pd/files/undesa_pd-2020_world_ population_ageing_highlights.pdf

WORLD HEALTH ORGANISATION, 2021. Decade of Healthy Ageing 2021 - 2030 [online]. [viewed 5 May 2021]. Available from: https://www.euro. who.int/en/health-topics/Life-stages/healthy-ageing/news/news/2021/o1/ decade-of-healthy-ageing-2021-2030

WORLD HEALTH ORGANISATION, 2020. Ageing: Healthy ageing and functional ability [online]. [viewed 5 May 2021]. Available from: https:// www.who.int/westernpacific/news/q-a-detail/ageing-healthy-ageing-and-functional-ability

WU, Q., CHAN, J.S.Y. and YAN, H.J., 2015. Mild cognitive impairment affects motor control and skill learning. Reviews in the Neurosciences, vol. 27, no. 2, pp. $197-217$.

YEUNG, S.S.Y., REIJNIERSE, E.M., PHAM, V.K., TRAPPENBURG, M.C., LIM, W.K., MESKERS, C.G.M. and MAJER, A.B., 2019. Sarcopenia and its association with falls and fractures in older adults: A systematic review and meta-analysis. Journal of Cachexia, Sarcopenia and Muscle, vol. 10, no. 3, pp. $485-500$. 


\title{
The effect of non-nutritive sweeteners on lipid metabolism in liver cells
}

\author{
Urša Cankar, Saša Kenig \\ University of Primorska, Faculty of Health Sciences, Polje 42, 6310 Izola, Slovenia \\ ursa.cankar1@gmail.com, sasa.kenig@fvz.upr.si
}

\begin{abstract}
Introduction: The use of non-nutritive sweeteners is common in the elderly population, since they often want to avoid sugar intake, as it is also recommended. Additionally, due to the widespread use of sweeteners in a variety of food products, the consumers are sometimes unaware of their consumption. Although they are generally safe to consume, there is also evidence supporting the opposite. In animal models, they have been shown to increase serum triglycerides and fasting insulin levels and interfere with the levels of adipogenic proteins, when consumed regularly. The exact mechanisms are not known. Here, we investigated the effects of the selected sweeteners on the lipid metabolism in human liver cells. Methods: Four sweeteners available on the Slovenian market were selected, namely erythritol, stevia and two commercially available mixed sweeteners Huxol Original (containing sodium cyclamate, sodium saccharin) and Natreen Classic (containing cyclamate, saccharin and thaumatin). Using RTPCR we studied the effect on the expression of genes related to lipid metabolism, and measured the accumulation of OilRed O stained lipid droplets in HepG2 liver cell line exposed to the highest non-cytotoxic concentration of each tested compound for $24 \mathrm{~h}$. All experiments were performed both in the presence and absence of sodium palmitate. Results: Natreen, stevia and erythritol caused an approximately 2 -fold up-regulation of perilipin-2. In addition, Huxol caused more than 8-fold up-regulation of diacyilglycerol-O-acyltranferase, whereas erythritol suppressed its expression. Further, increased expressions of carnitine palmitoyltransferase 1 and 2 were detected for all sweeteners, when palmitate was present in the media. The accumulation of lipid droplets was significantly increased when palmitate was added to the media, but there was no further increase with the addition of the sweeteners. Discussion and conclusions: Treatment of liver cells with the selected
\end{abstract}


non-nutritive sweeteners did not reflect in altered lipid accumulation.

However, the observed changes in gene expression point to their

important impact on lipid metabolism. As genes related to the beta-

oxidation as well as those related to the fat storage were up-regulated,

long-term effects should be further investigated to confirm their safe use

in terms of liver health.

Keywords: non-nutritive sweeteners, fatty liver disease, gene expression

\section{Introduction}

In the elderly population the use of non-nutritional sweeteners is particularly common. The reason lies in the fact that they follow recommendations and avoid sugar intake. On the other hand, it is important for them to keep the food palatable, since sufficient caloric intake is otherwise hard to achieve. Additionally, due to the widespread use of sweeteners in a variety of food products, the consumers are sometimes unaware of the consumption (Sylvetsky and Rother, 2016). In general, sweeteners are safe to consume (Butchko et al., 2002), but there is also evidence supporting the opposite. In contrast to the common expectation, they do not lower body weight and do not even prevent its gain, and glucose levels may also be elevated (Swithers, 2016). Numerous observational studies also suggest an association with metabolic syndrome which includes non-alcoholic fatty liver disease, but there may be a possible association with obesity (Green and Syn, 2019). In animal models, they have been shown to increase serum triglycerides and fasting insulin levels and interfere with the levels of adipogenic proteins, when consumed regularly. Rats which consumed drinks sweetened by aspartame for two months, had increased visceral fat and other characteristics of metabolic syndrome, including hyper-glycemia, increased serum triglycerides and increased low-density and very low-density lipoproteins compared to rats which consumed water (Lebda, 2017). In the same study the levels of leptin were higher, the expression of peroxisomal proliferating receptor decreased and the elevated serum transaminase indicated liver damage. It has been known for a while that sweeteners are not metabolically inert, and further research is needed to elucidate the mechanisms by which sweeteners can promote metabolic effects (Pepino, 2015). In the present study we investigated the effects of the selected sweeteners on the lipid metabolism in human liver cells.

\section{Methods}

Four sweeteners available on the Slovenian market were selected, namely erythritol, stevia and two commercially available mixed sweeteners Huxol Original (containing sodium cyclamate, sodium saccharin) and Natreen Classic (containing cyclamate, saccharin, thaumatin). The analyses were performed in vitro on a HepG2 cell line. HepG2 cells represent a liver cell line derived from human hepatoblastoma, which has been found to express a whole range of liver-spe- 
cific metabolic functions and is therefore an excellent model for studying the central role of the liver in lipid metabolism (Javitt, 1990). The study began with the cultivation of adherent HepG2 liver cells and exposing them to the four different sweeteners to determine cytotoxic concentrations. In the following experiments, the cells were exposed to the highest non-cytotoxic concentration of each tested compound for 24 hours. We examined the effect of sweeteners on the expression of five genes related to lipid metabolism using quantitative polymerase chain reaction (RT-PCR). The genes were: acetyl-CoA carboxylase alpha (ACACA), carnitine palmitoyltransferase $1 \mathrm{~A}(\mathrm{CPT} 1 \mathrm{~A})$, carnitine palmitoyltransferase 2 (CPT2), diacylglycerol O-acyltransferase 2 (DGAT2) and perlipin 2 (PLIN2). We also measured the accumulation of OilRed $\mathrm{O}$ stained lipid droplets in the HepG2 liver cell line. All experiments were performed both in the presence and absence of sodium palmitate.

\section{Results \\ Gene expression analysis}

The cytotoxic effect of selected sweeteners at different concentrations on HepG2 cells after 24 hours of exposure was first studied. All concentrations of erythritol sweetener solution from 0.02 to $2 \mathrm{mg} / \mathrm{ml}$ were found to have a slight proliferative effect on cells. Similar to erythritol, three concentrations of Natreen Classic sweetener solution, $2 \mathrm{mg} / \mathrm{ml}, 1 \mathrm{mg} / \mathrm{ml}$ and $0.2 \mathrm{mg} / \mathrm{ml}$, had a proliferative effect on cells. On the other hand, rebaudioside A (active compound in Stevia Sugarel) at concentrations of $2 \mathrm{mg} / \mathrm{ml}$ and $1 \mathrm{mg} / \mathrm{ml}$ had a cytotoxic effect on cells, while none of the tested concentrations of Huxol Original had either positive or negative effect on cell viability.

Based on the obtained data, further analyses were performed with the highest non-cytotoxic concentration. The following concentrations were used: $2 \mathrm{mg} / \mathrm{mL}$ for Erythritol, Huxol Original and Natreen Classic and $0.2 \mathrm{mg} / \mathrm{ml}$ for Stevia Sugarel. Analysis of fat accumulation-related gene expression was performed for five genes: ACACA, DGAT2, PLIN2, CPT1A and CPT2. Gene expression was tested in cells grown in control medium (source of glucose) and medium with added palmitate (source of glucose and fatty acid). Analysis was performed by RT-PCR, checking the relative expression for each of the selected genes relative to the $18 \mathrm{~S}$ rRNA gene. The results showed increased expression of four of the five genes. ACACA gene expression was below the detection limit in most of the analysed samples.

The results of the CPT1A expression analysis showed that sweeteners, with the exception of one sample (stevia), increased its expression, as shown graphically in Figure 1. The following changes in gene expression occurred between cells in medium with sweeteners and cells in control medium without additives: sweetener Natreen Classic 2.2 \pm 0.7 -fold up-regulation, sweetener Erythritol 3.0 \pm 0.8 -fold up-regulation, sweetener Huxol Original 4.8 \pm 0.7 -fold up-regulation, sweetener Stevia Sugarel $0.7 \pm 0.2$-fold down-regulation. Palmi- 


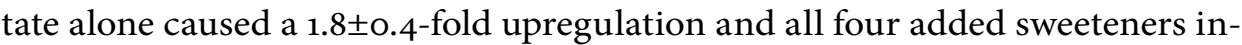
duced further upregulation of the CPT1A. When comparing cells in the medium with palmitate alone and cells with added sweetener and palmitate, Stevia Sugarel showed the most prominent effect. A distinct change in CPT1A expression was observed, while stavia without the presence of palmitate caused a slight downregulation $(\mathrm{F}=0.7 \pm 0.2)$, with the addition of palmitate, CPT1A expression markedly increased $(\mathrm{F}=6.3 \pm 1.1)$.

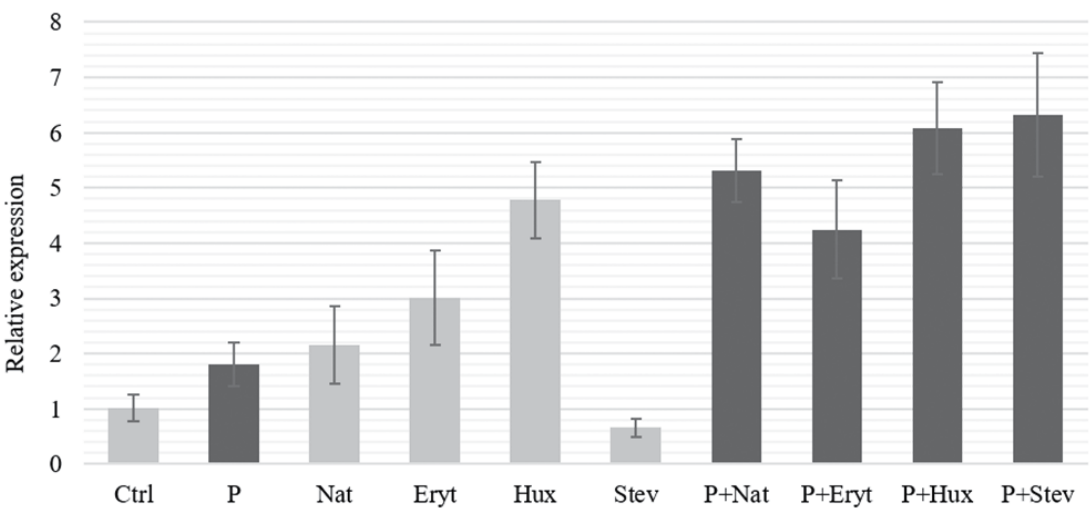

Figure 1: Relative expression of the CPT1A gene in medium, medium with added palmitate, medium with sweeteners and medium with added sweeteners and palmitate. Ctrl-control, P-Na-palmitate, Nat-Natreen Classic, Erit-Erythritritol, Hux-Huxol Original and Stev-Stevia Sugarel

Also, with the exception of one sample, the sweeteners increased the expression of CPT2, as shown in Figure 2. The following changes in gene expression occurred between the samples of sweeteners in the medium and the cells in the control medium: Natreen Classic 1.4 \pm o.1-fold up-regulation, erythritol sweetener 2.3 \pm 0.2 -fold up-regulation, Huxol Original sweetener 2.5 \pm 0.1 -fold up-regulation, Stevia Sugarel sweetener 0.7 \pm 0.3 -fold down-regulation. Comparison of the samples with added sweetener in the presence of palmitate and those with added palmitate alone showed that the expression increased for all four sweeteners. Similar to the expression of CPT1A, Stevia Sugarel alone downregulated the expression but caused an upregulation in the presence of palmitate. The highest effect was observed for Huxol original, where Huxol alone caused approximately 2 -fold upregulation, but in the presence of palmitate, the upregulation by Huxol was 5.7 \pm 0.5 -fold. Palmitate itself had no significant effect, the CPT2 gene upregulation was only 1.2 \pm 0.1-fold. 


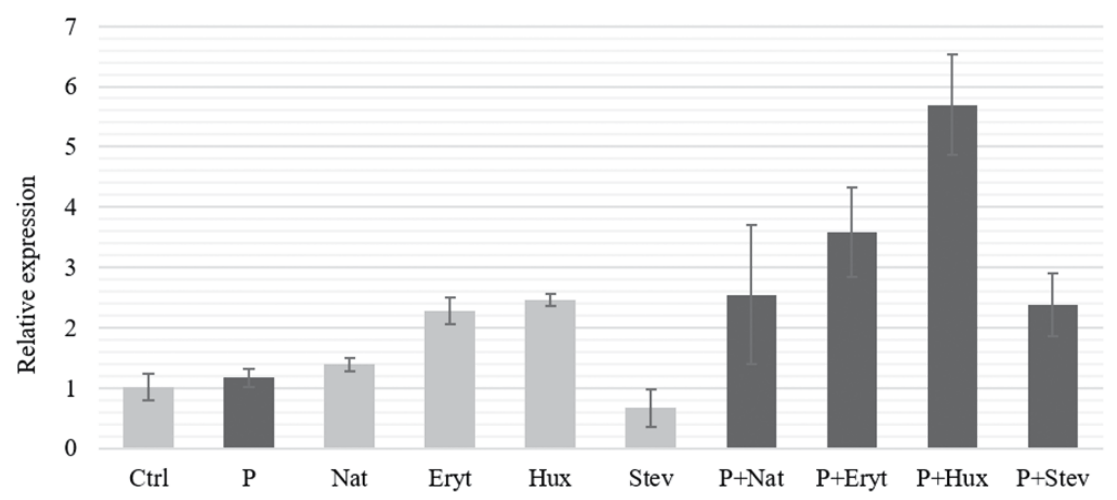

Figure 2: Relative expression of the CPT2 gene in medium, medium with added palmitate, medium with sweeteners and medium with added sweeteners and palmitate. Ctrl-control, P-Na-palmitate, Nat-Natreen Classic, Erit-Erythritritol, Hux-Huxol Original and Stev-Stevia Sugarel

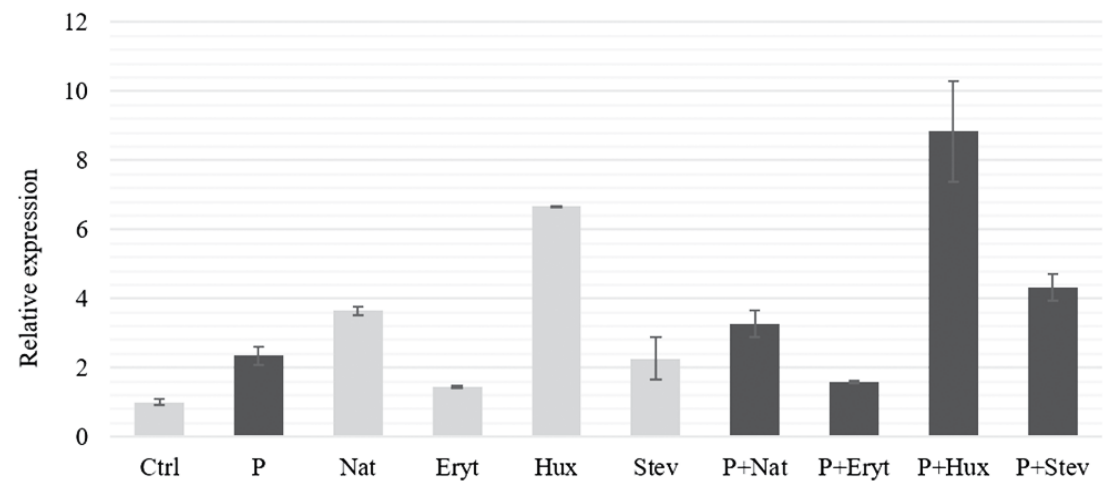

Figure 3: Relative expression of the DGAT2 gene in medium, medium with added palmitate, medium with sweeteners and medium with added sweeteners and palmitate. Ctrl-control, P-Na-palmitate, Nat-Natreen Classic, Erit-Erythritritol, Hux-Huxol Original and Stev-Stevia Sugarel

Analysis of DGAT2 gene expression, presented in Figure 3, showed an increased gene expression with the addition of all four sweeteners. There was the following increase in gene expression between samples of sweeteners in medium and cells in control medium without additives: Natreen Classic 3.6 \pm 0.1 -fold up-regulation, Erythritol sweetener 1.4 \pm 0.0 -fold up-regulation, Huxol sweet-

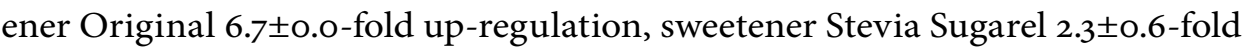
up-regulation. With the addition of the Erythritol sweetener to the palmitate medium (2.4 \pm 0.3 -fold upregulation compared to control), compared to that in

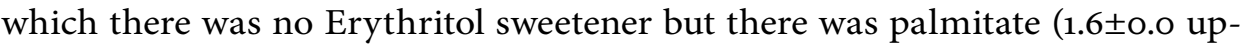
regulation compared to control), we can observe inhibited expression of this gene by this particular sweetener. A similar situation was observed for Stevia 
Sugarel, where gene expression was slightly lower when added to the medium alone $(\mathrm{F}=2.3 \pm 0.6)$ compared to the cells in the palmitate medium $(\mathrm{F}=2.4 \pm 0.3)$, but later an increase of gene expression in medium with sweetener and palmitate $(F=4.3 \pm 0.4)$ occurred. The greatest effect was observed with the sweetener Huxol Original, where there was a $6.7 \pm 0.0$ and $8.8 \pm 1.5$-fold up-regulation in DGAT2 gene expression.

As shown in Figure 4, the sweeteners with the exception of stevia slightly increased the expression of perilipin-2 (PLIN2). The following changes in gene expression occurred between the samples of sweeteners in the medium and the cells in the control medium without additives: in the case of Natreen Classic 1.6 \pm 0.2 -fold up-regulation, Erythritol 2.4 \pm 0.5 -fold up-regulation, Huxol Original 2.2 \pm 0.4 -fold up-regulation, Stevia Sugarel 0.5 \pm 0.1 -fold down-regulation. There was a slight decrease in expression when comparing the cell sample in the medium and the medium with added palmitate, but it was negligible. When cells were grown in the media containing palmitate, the results were similar. The comparison of samples with added sweetener and those with added sweetener and palmitate, there were major changes in the two samples; with the addition of palmitate, the expression of PLIN2 in the sweetener Huxol Original almost halved (from $F=2.2 \pm 0.4$ to $F=1.3 \pm 0.0$ ), which is the only example in our study, where sweetener alone had a stronger effect than the sweetener in combination with palmitate. The opposite occurred with the sweetener Stevia Sugarel, where expression greatly increased (from $\mathrm{F}=0.5 \pm 0.1$ to $\mathrm{F}=$ $2.6 \pm 0.1)$ in the presence of palmitate.

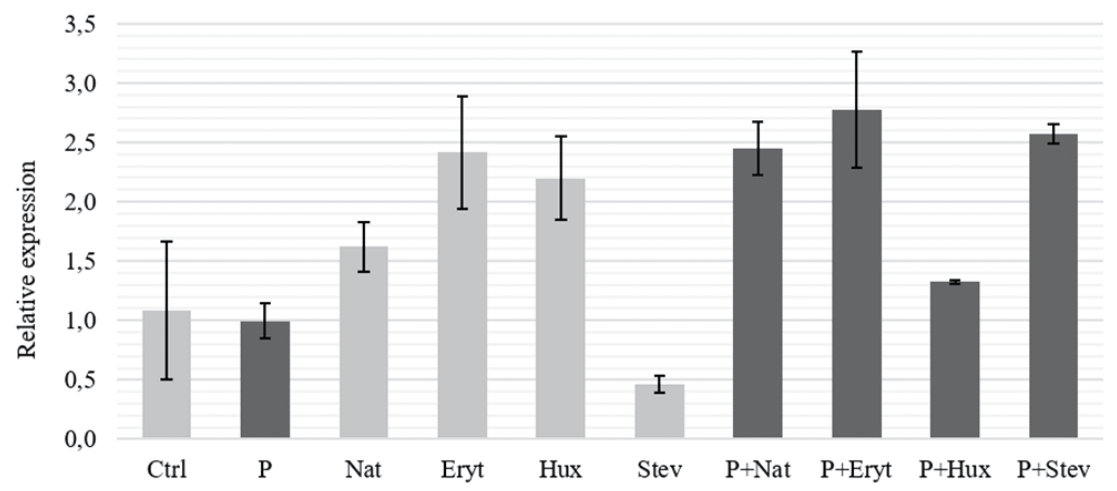

Figure 4: Relative expression of the PLIN2 gene in medium, medium with added palmitate, medium with sweeteners and medium with added sweeteners and palmitate. Ctrl-control, P-Na-palmitate, Nat-Natreen Classic, Erit-Erythritritol, Hux-Huxol Original and Stev-Stevia Sugarel 


\section{Accumulation of lipid droplets}

In the analysis of cell staining with Oil Red $\mathrm{O}$, the amounts and spatial distribution of fat infiltration of visibly stained lipids were observed under a microscope. The spectrophotometrically measured absorbances of the samples are shown in Figure 5. The difference between the cell sample in the control medium and the cells where palmitate was added to the medium is statistically significant, in the later it is $1.9 \pm 0.04$-fold higher $(\mathrm{p}<0.05)$. In line with our expectations, there are no statistically significant differences between the cells in the control medium and the cells where sweeteners are added to the medium, which is also consistent with the previously performed visual analysis of the samples.

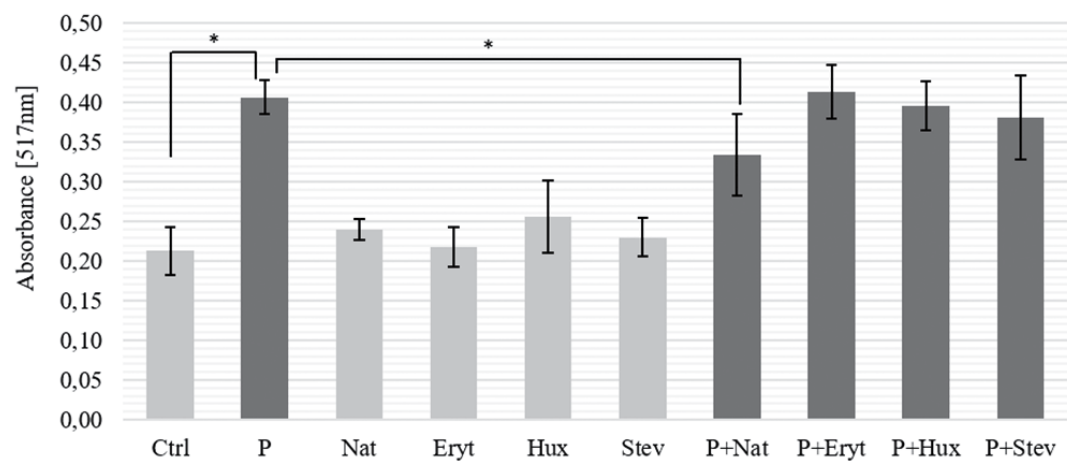

Figure 5: Results of spectrophotometric analysis of fat accumulation in HepG2 cells in the presence of sweetener and sweetener and palmitate. Ctrl-control, P-Na-palmitate, Nat-Natreen Classic, Erit-Erythritritol, Hux-Huxol Original and Stev-Stevia Sugarel, ${ }^{\star} p<0.05$

Significant differences in fat accumulation in samples with added sweeteners Erythritol, Huxol Original and Stevia Sugarel compared to cells where palmitate was added to the cells were not confirmed, but a statistical difference ( $p=0.01$ ) was shown in the treatment of cells with sweetener Natreen Classic. In the case when cells were treated with both Natreen Classic sweetener and palmitate, $0.8 \pm 0.06$-fold lower infiltration of fat into the cells was observed. The results show that the amount of lipid droplets in the cells is significantly increased with the addition of palmitate to the medium compared to the control medium and that the addition of selected sweeteners to the samples in HepG2 cells does not increase fat accumulation in the droplets. In the case of Natreen Classic fat accumulation is even slightly reduced.

\section{Discussion}

In the present study we show that sweeteners stevia, Huxol, Natreen and erythritol have an effect on the expression of genes, related to lipid metabolism. Analysis of gene expression showed that selected sweeteners exert such effect 
in a positive way, as expression of the genes involved in beta-oxidation CPT1A and $\mathrm{CPT}_{2}$ was increased, but also in a negative way, since genes involved in the storage of lipids (DGAT and PLIN2) were upregulated too. These effects, despite some difference, were found for all four studied sweeteners. As expected, the expression of all genes was higher in the presence of palmitate, which served as a source of fatty acids. However, the effect of sweeteners alone was similar also in the environment without added palmitate, where the only fatty acids in the cells are those endogenously produced from glucose.

On the other hand, a functional assay, showing the total accumulation of lipids in hepatic cells, did not confirm any major effect of the sweeteners. In the spectrophotometric analysis of the amount of lipid droplets, we found that the accumulation remained the same or decreased slightly. It should be noted that the analysis of gene expression can only give an estimate that the sweetener acts on a certain mechanism, and that overall accumulation of fat is influenced by other pathways that we have not studied. We conclude that the consumption of selected sweeteners, despite the effect on gene expression, does not affect the increased accumulation of fat in the liver. This is in agreements with the study of Ma et al. (2015), where NAFLD-related markers were not associated with the daily intake of drinks containing non-caloric sweeteners. Further, the investigated sweeteners were found to be non-cytotoxic in tested concentrations, which were calculated from a predicted high daily intake and considering complete absorption, and are thus presumably higher than actual physiologically relevant concentrations. Without a thorough understanding of the absorption and the metabolism of the sweeteners, accurate concentrations of a sweetener in the blood stream reaching liver cells in vivo is difficult to predict.

Although many studies describe the effect of sweeteners on NAFLD and obesity, the mechanisms by which sweeteners affect the human body are not yet entirely clear. According to Schiffman (2012), too little is known about the health effects of sweeteners. They propose the need for further studies in nine different areas, including the need to determine the role of transport molecules in the absorption of sweeteners, the identification of sweetener metabolites, metabolic enzymes and potential toxicity of metabolites, the effect of the sweetener itself on nutrient absorption and weight management, effects of sweeteners on acute and chronical brain activation, neuroplasticity and taste receptor interactions in the brain, checking whether sweeteners have clinically relevant genetic effects, determining long-term effects on the gut microbiota. Of these, only the cytotoxicity and gene-expression analysis were studied here.

Based on the results obtained, we cannot advise against the use of non-caloric sweeteners as an alternative to sugar for NAFLD prevention and other health complications. However, in the analysis of gene expression, we observed significant effects on lipid metabolism that were not previously known. Those are likely not causally related to the development of NAFLD, but confirm that sweeteners are not metabolically inert, as was suggested previously by Pepino (2015) and as such merit further research. 


\section{Conclusions}

Treatment of liver cells with the selected non-nutritive sweeteners did not reflect in altered lipid accumulation. The observed changes in gene expression, however, point to their important impact on lipid metabolism. As genes related to the beta-oxidation as well as those related to the fat storage were up-regulated, long-term effects should be further investigated to confirm their safe use in terms of liver health.

\section{References}

BUTCHKO, H.H., STARGEL, W.W., COMER, C.P., MAYHEW, D.A., BENNINGER, C., BLACKBURN, G.L., DE SONNEVILLE, L.M.J., GEHA, R.S., HERTELENDY, Z., KOESTNER, A. et al., 2002. Aspartame: Review of Safety. Regulatory Toxicology and Pharmacology. April 2002. Vol. 35, no. 2, p. S1-S93. [viewed 13 July 2021]. Available from: http://dx. doi.org/10.1006/rtph.2002.1542.

GREEN, C.H. and SYN, W-K, 2019. Non-nutritive sweeteners and their association with the metabolic syndrome and non-alcoholic fatty liver disease: a review of the literature. European Journal of Nutrition. August 2019. Vol. 58, no. 5, p. 1785-180o. [viewed 13 July 2021]. Available from: http:// dx.doi.org/10.1007/so0394-019-01996-5.

LEBDA, M.A., TOHAMY, H.G. and EL-SAYED, Y.S., 2017. Long-term soft drink and aspartame intake induces hepatic damage via dysregulation of adipocytokines and alteration of the lipid profile and antioxidant status. Nutrition Research. May 2017. Vol. 41, p. 47-55. [viewed 13 July 2021]. Available from: http://dx.doi.org/10.1016/j.nutres.2017.04.002.

MA, J., FOX, C.S., JACQUES, P.F., SPELIOTES, E.K., HOFFMANM, U., SMITH, C.E., McKEOWN, N.M., 2015. Sugar-sweetened beverage, diet soda, and fatty liver disease in the Framingham Heart Study cohorts. Journal of Hepatology, Vol. 63(2), p. 462-469. Available from: https://doi. org/10.1016/j.jhep.2015.03.032

PEPINO, M. Y., 2015. Metabolic effects of non-nutritive sweeteners. Physiology \& Behavior, Vol. 152(Pt B), p. 450-455. Available from: https://doi. org/10.1016/j.physbeh.2015.06.024

SCHIFFMAN, S.S., 2012. Rationale for Further Medical and Health Research on High-Potency Sweeteners. Chemical Senses. October 2012. Vol. 37, no. 8, p. 671-679. [viewed 13 July 2021]. Available from: http://dx.doi. org/10.1093/chemse/bjso53.

SWITHERS, S.E, 2016. Not-so-healthy sugar substitutes? Current Opinion in Behavioral Sciences. June 2016. Vol. 9, p. 106-110. Available from: http:// dx.doi.org/10.1016/j.cobeha.2016.03.003.

SYLVETSKY, A.C. and ROTHER, K.I., 2016. Trends in the consumption of low-calorie sweeteners. Physiology \& Behavior. October 2016. Vol. 164, p. 446-450. [viewed 13 July 2021]. Available from: http://dx.doi. org/10.1016/j.physbeh.2016.03.030 



\title{
Nutrition of the elderly with atherosclerosis
}

\author{
Tilen Dolinar, Saša Kastelic, Andreja Kvas \\ University of Ljubljana: Faculty of Health Sciences, Ljubljana, Slovenia \\ tilen.dolinar@gmail.com; sasakast@gmail.com; andreja.kvas@zf.uni-lj.si
}

\begin{abstract}
Introduction and purpose: Atherosclerosis is a disease of the vascular wall of the aorta and the middle and large arteries of the muscular and elastic type. It is an advanced process that can remain without symptoms and signs for a long time, and in the advanced stage it is manifested by one or more manifestations, such as coronary heart disease, stroke or peripheral vascular disease. It can begin in childhood and progress with age, but it is also accelerated by risk factors. The main risk factors include hypercholesterolemia, hyperlipidemia and increased concentration of low-density lipoproteins, arterial hypertension, obesity, diabetes, smoking, lack of physical activity. Although the developed atherosclerotic changes are irreversible, we can influence the rate of disease progression, especially with a healthy lifestyle, ie a healthy balanced diet and regular physical activity. Content presentation: Atherosclerosis is a disease affecting the vascular aortic wall and the middle and large elastic and muscular arteries. It is a progressive condition whose symptoms and signs may not occur for a longer period of time while the progressive stage may manifest itself via one or several of its manifestations, including coronary artery disease (CAD), a brain stroke, or Peripheral arterial disease (PAD). The disease may develop in childhood and progress with age, although the risk of the latter may be dramatically increased by certain risk factors. The main risk factors include hypercholesterolemia, hyperlipidemia and increased concentration of low-density lipoproteins, arterial hypertension, obesity, diabtes, smoking, and a lack of physical activity. Although atherosclerosis causes irreversible changes, one can significantly influence the progression of the latter with a healthy, balanced diet and regular physical exercise. Conclusions: The occurrence of atherosclerosis is associated with many factors that we can influence and factors that we cannot influence ourselves. In our article, we focused mainly on
\end{abstract}


the impact of proper diet. In reviewing the articles, we found that the authors mention a number of diets, such as the DASH diet, the TLC diet, the Mediterranean diet. The most appropriate diet for patients with atherosclerosis is one that includes foods from all groups of the food pyramid in moderation. An important factor is prevention and awareness of people, as cardiovascular disease as a result of atherosclerosis is one of the main factors of premature morbidity and mortality in the developed world, and thus also the financial burden of the health system.

Keywords: aging, cardiovascular diseases, physical activity, prevention

\section{Introduction}

Atherosclerosis is a disease of the vascular wall of the aorta and the middle and large arteries of the muscular and elastic type. It is an advanced process that can remain without symptoms and signs for a long time, and in the advanced stage it is manifested by one or more manifestations, such as coronary heart disease, stroke or peripheral vascular disease. It can begin in childhood and progress with age, but it is also accelerated by risk factors. The main risk factors include hypercholesterolemia, hyperlipidemia and increased concentration of low-density lipoproteins, arterial hypertension, obesity, diabetes, smoking, lack of physical activity.

Although the developed atherosclerotic changes are irreversible, we can influence the rate of disease progression, especially with a healthy lifestyle, ie a healthy balanced diet and regular physical activity (Petek Šter, 2017).

\section{Structured sections}

Atherosclerosis is a disease affecting the vascular aortic wall and the middle and large elastic and muscular arteries. It is a progressive condition whose symptoms and signs may not occur for a longer period of time while the progressive stage may manifest itself via one or several of its manifestations, including coronary artery disease (CAD), a brain stroke, or Peripheral arterial disease (PAD) (American Heart Association, 2017). The disease may develop in childhood and progress with age, although the risk of the latter may be dramatically increased by certain risk factors. The main risk factors include hypercholesterolemia, hyperlipidemia and increased concentration of low-density lipoproteins, arterial hypertension, obesity, diabtes, smoking, and a lack of physical activity (NIJZ, 2014).

The Mediterranean-type diet is primary and secondary prevention of Cardiovascular Disease. It may be considered not one specific diet, but rather a collection of eating habits traditionally followed by people bordering the Mediterranean sea and consisting of a plant-centered diet with high intakes of vegetables and fruits, whole-grain cereals, extra-virgin oil, nuts, moderate consumption of fish and poultry, low intake of dairy products, red meat, sweets and 
moderate consumption of red wine for usual drinkers. The Scientific Advisory Committee of the American Heart Association stated that the Mediterranean-style diet has impressive effects on Cardiovascular Disease. Atherosclerosis is one of the most important risk factors for the development of Cardiovascular Disease. Thus, several pharmacological strategies have been used to decrease or prevent the development of atherosclerosis. Interestingly, in recent years several studies have emphasized the role of several dietary nutrients and bioactive compounds in the mechanisms of the processes around the plaque formation. Nutrients such as saturated fatty acid and trans-fatty acids, among others, are associated with an increase in the development of atherosclerosis. On the other hand, nutrients such as soy, omega-3 fatty acids, several vitamins, and polyphenols reduce or attenuate the appearance of atherosclerotic lesions. The activity of these compounds is associated with a reduction in the inflammatory response, in the antioxidant capacity to prevent oxidation of LDL particles, leukocyte migration, adhesion molecules, in the viability of VSMCs and reduction in blood pressure among others (Torres, Guevara-Cruz, 2015; Velázquez-Villegas and Tovar, 2015).

Nutrition is far more important in stroke risk than most physcians suppose. Healthy lifestyle choices reduce the risk of stroke by $80 \%$. A Cretan Mediterranean diet, high in olive oil, whole grains, fruits, vegetables and legumes, and low in cholesterol and saturated fat, can reduce stroke by $40 \%$ or more in high-risk patients. The role of the intestinal microbiome in cardiovascular risk is emerging. High levels of toxic metabolites produced by intestinal bacteria from meat (particularly red meat) and egg yolk are renally excreted. Patients with renal impairment, including the elderly, should limit red meat and avoid egg yolk, as should other patients at high risk of stroke. Salt intake should be limited to 2-3 grams per day. Metabolic B12 deficiency is common and usually missed. It has serious neurological consequences, including an increase in the risk of stroke. It now clear that B vitamins to lower homocysteine reduce the risk of stroke, but we should probably be using methylcobalamin instead of cyanocobalamin (Spence, 2019). Several conditions associated with the development of cardiovascular disease (CVD) such as diabetes, obesity, hypertension, and dyslipidemia are known to be modifiable by changes in lifestyle. Among lifestyle factors, our diet, including both the nutritional quality and our acquired eating patterns, constitutes a major target of CVD prevention strategies. Eating patterns are highly dependent on cultural, social and psychological determinants, as people integrate them into their daily life routines. A particular habit that might have a significant effect on CVD health is breakfast consumption, as it is associated with factors such as satiety, daily energy intake (EI), metabolic efficiency of the diet, and appetite regulation. A number of studies have reported associations between the habit of omitting breakfast and increased cardiometabolic health markers, including obesity, diabetes and unfavorable lipid profile. Although there are some studies linking skipping breakfast with coronary heart disease risk, to the best of our knowledge, 
no studies have investigated the association with this dietary habit on the presence of subclinical atherosclerosis. The aim of our study was to characterize the association between different breakfast patterns and CVD risk factors, and in particular, whether regularly skipping breakfast is associated with subclinical atherosclerosis, by investigating the presence of atherosclerotic plaques in the carotid arteries, aorta, and iliofemoral arteries or coronary artery calcium, in a population with no previous history of CVD (Spence, 2019).

Clinical studies report that consuming a high-calorie meal in the morning would result in a significant decrease in fasting glucose and insulin, as well as reduced plasma ghrelin concentrations, a hormone associated with food perception, leading toward lower energy foods preference. Moreover, studies linking breakfast consumption with overall diet quality and regulation of appetite, reported that not only micronutrient-rich breakfast but the morning meals in general were potentially satiating and had a beneficial effect on appetite regulation, which would help to balance the energy intake throughout the day and prevent overeating and subsequent obesity. Considering the importance of regular breakfast consumption for primary CVD prevention, our findings are important for health professionals and might be used as an important key, and simple message for lifestyle-based interventions and public health strategies, as well as informing dietary recommendations and guidelines (Spence, 2019).

Skipping breakfast could serve as a marker of unhealthy dietary and lifestyle behavior and is associated with the presence of noncoronary and generalized atherosclerosis independent of conventional CVD risk factors in a sample of middle-aged asymptomatic individuals. Our findings highlight the message of the importance of healthy eating, including an energetic breakfast (Uzhova, et.al., 2017).

Evidence of interaction between genetic markers and dietary components has helped shed light on the inconsistencies that have been reported between diet-related studies and sometimes genetic analyses among different populations. The knowledge from gene-environment (diet) interactions will enable more effective and specific interventions for CVD prevention based on "personalized" nutrition. It is important to emphasize, however, that although many published investigations often indicated strong nutrientgene interactions that underlie variability of phenotypes, with nutrient intake potentially modulating risk factors of CVD, it is difficult at this time to apply these data to clinical practice. Indeed each of these nutrigenetic studies considered individually only one or at most two gene variants, neglecting the possible global interactions between a wide array of gene variants with different nutritional interactions. Nutrigenetics and nutrigenomics are still in their infancy with respect to cardiovascular disease prediction and therapy! The road of personalized medicine requires much more robust and sophisticated characterization of the functional implications of a growing set of new polymorphisms and CVD risk factors, supported by well-controlled dietary intervention studies that yield highly consistent results. Atherosclerotic CVD is as much a metabolic as it is an in- 
flammatory disease. The power of nutrigenetics and nutrigenomics can be further enhanced with the coapplication of metabolomics, another rapidly emerging discipline. Management and prevention of CVD will benefit tremendously from personalized medicine including individualized nutritional therapy. The public health implications of nutritional therapy are enormous. Integration of the progress in the omics, such as metabolomics, lipidomics, transcriptomics, and proteomics, coupled with advances in nutrigenomic and nutrigenetic research will make personalized medicine a reality. In the meantime, nutritionists, medical practitioners and genetic counselors need to embrace the new nutrigenetics/nutrigenomics revolution to help bring the nutritional component of preventive medicine from the dangerous stage of "generalization“ toward the new era of „personalized medicine“ (Merched and Chan, 2013).

Atherosclerosis, which causes approximately half of all deaths of adults over age 60 in industrialized nations, is a pandemic among inappropriately nourished and/or physically hypoactive children, adolescents, and adults world wide. Although nowadays statins are widely prescribed to middle age and elderly adults with high blood lipid levels as pharmacological prevention for the late complications of atherosclerosis, from a critical point of view statins seem not to solve the problem, especially when compared with certain natural ingredients of our nutrition like micronutrients as alternative strategy. Statin ingestion is associated with lowering of serum cholesterol and low-density lipoprotein concentrations; some prospective studies have shown statistical associations with subsequent modest reduction of mortality from cardiovascular disease. However, specific biochemical pathways and pharmacological roles of statins in prevention of atherosclerosis, if any, are unknown. Moreover, there have been no systematic cost-benefit analyses of life-style prophylaxis versus statin prophylaxis versus combined life-style plus statin prophylaxis versus neither life-style nor statin prophylaxis for clinically significant complications of cardiovascular diseases in the elderly. Further, in the trials of effectiveness statins were not compared with management of nutrition, which is the most appropriate alternative intervention. Such studies seem to be important, as the ever increasing world population, especially in developing countries, now demand expensive statins, which may be unaffordable for mitigating the pandemic. Studies of this kind are necessary to identify more precisely those patients for whom cardiovascular benefits will outweigh the risks and costs of the statin treatment in comparison with nutritional interventions.

Against the background of the current pathogenetic concept of atherogenesis some of its possible risk factors, particularly the roles of cholesterol and homocysteine, and the effects of statins versus nutritional (micronutrients) interventions in prevention and treatment of the disease are discussed. The prevailing opinion that serum cholesterol as a mediator of the disease is increased by eating saturated fats and decreased by eating polyunsaturated fats is being challenged. Evidently, the beneficial effects of statins in atherosclerosis are not mainly due to its cholesterol lowering effect, rather than to its "pleiotropic ef- 
fects". Other pathogenetic factors in atherosclerosis are involved, like inflammatory and immunologic processes, that can be modulated by statins as well as by other drugs or by the Mediterranean-style nutrition and by micronutrients (folate, B-vitamins) (Gebbers, 2007).

Some recent published studies indicate again the marked clinical benefit of the ,Mediterranean nutrition' on cardiovascular function, including that of the elderly, which is associated with improved endothelial function in persons with metabolic syndrome. If we want to make the best of what common micronutrients and statins may offer in the prophylaxis of atherosclerosis, we should try to learn more about how to assess the positive effects of statins against their potential toxic risks in individual patients. Additionally, titrating lipid-lowering therapy to reduce LDL cholesterol to very low levels by statins can be difficult, costly, is not without risk and no solid evidence appears to support this recommendation of the National Cholesterol Education Program (Gebbers, 2007).

The potential effect of reducing the intake of industrially produced trans fatty acids on the incidence of coronary heart disease in the United states was calculated. The authors estimated on the basis of reported relations between trans fat intake and coronary heart disease events in prospective studies 10\% to $19 \%$ of coronary heart disease events could be averted by reducing the intake of trans fat. Thus, given the 1.2 million annual myocardial infarctions and deaths from coronary heart disease in the United States, near-elimination of industrially produced trans fats might avert between $72,000(6 \%)$ and 228,00o (19 \%) coronary heart diseases each year (Gebbers, 2007).

The unequivocal beneficial effects of long term caloric restriction on the blood pressure, the ratio of cholesterol/HDL-cholesterol, and the body mass index (BMI), which have been demonstrated recently, must carry some especially important lessons for public health and educational policies in our obesity-ridden, low exertion, industrialized societies, which should surely be at least as useful to us in the long run as is the ongoing education of our affluent population about the availability and cost of prophylactic statins. A recently published hypothesis indicates the possible fact that statins are analogues of vitamin D, since several effects of statins match well with those of that vitamin particularly the anomalous results, such as unexpected benefits of statins like the modulation of inflammations and immune states.

Nowadays, we have to face our dependence on results of studies sponsored by the industry, particularly we have become too dependent on manufacturers as the predominant source of our scientific knowledge about the effects of medications (Gebbers, 2007).

With pharmaceutical costs increasing faster than most other health care expenditures, we require studies that will meet the needs of evidence-based presriptions and treatments and not just the needs of the pharmaceutical industry. These trials must not only be conducted involving combination thera- 
pies of the company's own products or the test drug against a placebo but rather against nutritional regimens. The conduct of such equivalence or non-inferiority studies imposes markedly higher methodological demands compared with traditional studies to prove the superiority of a treatment vs. placebo or standard therapy. It is not a question of whether we can afford to pay for our own drug and nutritional trials; it is increasingly evident that we cannot afford not to do so (Gebbers, 2007).

\section{Conclusions}

The occurrence of atherosclerosis is associated with many factors that we can influence and factors that we cannot influence ourselves. In our article, we focused mainly on the impact of proper diet. In reviewing the articles, we found that the authors mention a number of diets, such as the DASH diet, the TLC diet, the Mediterranean diet. The most appropriate diet for patients with atherosclerosis is one that includes foods from all groups of the food pyramid in moderation.

An important factor is prevention and awareness of people, as cardiovascular disease as a result of atherosclerosis is one of the main factors of premature morbidity and mortality in the developed world, and thus also the financial burden of the health system (Benedičič, 2016).

\section{References}

AMERICAN HEART ASSOCIATION, 2017. What is cardiovascular disease? [viewed 15 March 2021]. Available from: https://www.heart.org/en/ health-topics/consumer-healthcare/what-is-cardiovascular-disease.

BEDENČIČ, M., 2016. Prehrana. Živeti z aterosklerozo: Priročnik za bolnike s koronarno boleznijo in drugimi oblikami ateroskleroze [online]. Nacionalni inštitut za javno zdravje, pp. 37-40. Available from: http://skupajzazdravje.nijz.si/media/ziveti.z.aterosklerozo.pdf.

GEBBERS, J., 2007. Atherosclerosis, cholesterol, nutrition, and statins - a critical review. German Medical Science, vol. 5, ISSN 1612-3174.

MERCHED, A. J., \& CHAN, L., 2013. Nutrigenetics and Nutrigenomics of Atherosclerosis. Current Atherosclerosis Reports, vol. 15, no. 6.

NIJZ, 2014. Srčno-žilne bolezni [online]. [viewed 15 March 2021]. Available from: https://www.nijz.si/sl/srcno-zilne-bolezni.

PETEK ŠTER, M., 2017. Preventivni pregled $\mathrm{z}$ oceno tveganja za bolezni srca in ožilja. Izvajanje integrirane preventive kroničnih nenalezljivih bolezni $\mathrm{v}$ referenčnih ambulantah družinske medicine: Priročnik za zdravnike družinske medicine [online]. Ljubljana: NIJZ, pp. 58 - 62. [viewed 15 March 2021]. Available from: http://skupajzazdravje.nijz.si/media/splet-. zdm.prirocnik.pdf.

SPENCE, J., 2019. Nutrition and Risk of Stroke. Nutrients, vol. 11 no.3, pp. 647. 
TORRES, N., GUEVARA-CRUZ, M., VELÁZQUEZ-VILlEGAS, L. A., \& TOVAR, A. R., 2015. Nutrition and Atherosclerosis. Archives of Medical Research, vol. 46 no. 5, pp. 408-26.

UZHOVA, I., FUSTER, V., FERNÁNDEZ-ORTIZ, A., ORDOVÁS, J. M., SANZ, J., FERNÁNDEZ-FRIERA, L.,PEÑALVO, J. L., 2017. The Importance of Breakfast in Atherosclerosis Disease. Journal of the American College of Cardiology, vol.7o, no. 15, pp.1833-42. 


\title{
Nutrition support teams in social care institutions
}

\author{
Kemal Ejub, Alen Mahmutović, Valentina Syla, Andrej Starc \\ University of Ljubljana, Faculty of Health Science, Ljubljana, Slovenia \\ Ejub.kemal@gmail.com, alenmahmutovic88@gmail.com, tina.syla@gmail.com, andrej.starc34@gmail.com
}

\begin{abstract}
Introduction: The number of elderly people in Western countries has been increasing over the past years. The proper nutrition status among the elderly is very important because malnourished elderly people have five times higher mortality on admission compared to well nourished. Nutritional malnourishment in social care institutions is present in a range of $35-85 \%$. Detecting malnutrition is key to establishing systemic nutritional screening. Adequate nutritional support, which can be provided by various experts (dietitian, nurse, doctor), is of greatest importance when dealing with malnourished people. Unfortunately, the presence of a nutrition team in social care institutions is a rarity rather than a normal practice. Methods: A systematic review of scientific literature was conducted using PubMed, Cochrane Library, ScienceDirect and Google Scholar databases. The keywords used were: nutrition support teams, nursing care, nutritional care, mobile nutrition support team, mobile health clinics. The literature that was included had to be written in English language, published between 1995 and 2020 and needed to provide free and full access to the text. A methodological 'PRISMA approach' was used to review and select the proper articles. Results: In the literature review, our search resulted in 1354 articles. After taking into account all inclusion and exclusion criteria only 17 studies were included. When reviewing the literature, we found out that the presence of malnutrition among patients in social care institutions ranged between $35-38 \%$. Identifying and preventing malnutrition in social care institutions can involve different approaches (individual, multidisciplinary and with the help of a mobile nutrition team). Discussion and conclusion: Nutritional treatment in social care institutions can be carried out with the help of an individual, multidisciplinary or mobile nutrition team. Regardless of the approach chosen in the patient's nutritional treatment, teamwork (physician,
\end{abstract}


dietitian, nurse, cooks) is the most important. When planning a diet, it is important to take into account age-related changes and the presence of various diseases. An early dietary approach has been found to reduce complications during treatment, reduce hospital stays with disease exacerbation, and reduce morbidity and mortality among the elderly. Nutritional support arrangements require certain financial resources. Due to the lack of financial resources, we propose arrangement of nutrition support with the help of mobile nutrition teams as it requires lower operating costs in the long run compared to conventional nutrition support systems in social welfare institutions.

Keywords: nutrition support, nutrition support arrangements, social care institutions

\section{Introduction}

The number of elderly people in Western countries is increasing over the years. The importance of good nutrition among the elderly is of great importance. It has been found that protein-energy malnutrition is very common in sick elderly people. Between $35-85 \%$ of the elderly in social care institutions are malnourished. Malnutrition means great economic costs to society. Early detection is important because malnourished seniors are more likely to need health and social services and have more hospitalizations, higher morbidity and mortality rates. The elderlies in nursing homes are at greatest nutritional risk, with malnutrition more likely in those in need of a higher level of care (Guyonnet and Yves, 2015). Depression, disability and poor physical performance have been found to be significantly associated with the risk of malnutrition. Assessing nutritional status and the presence of risk factors associated with malnutrition is also important for achieving effective prevention and planning a better intervention strategy (Donini et al., 2020). The concept of nutrition support with appropriate staff was introduced at the end of the 2 oth century in both the United States and European countries. Nutrition support teams are composed mostly of many experts of various specialties (dieticians, nurse, gastroenterologist and others). The essence of nutrition support teams is the timely implementation of nutritional screening, the establishment of nutritional interventions, and counseling of health care providers in the case of nutritional interventions). The optimal team that provides adequate nutritional support to caregivers are: nurses, physicians, clinical dietitians, dieticians, and cooks (Berg et al., 2021). However in some places nutrition teams get lost in the system itself, due to savings, in others they are formed in terms of cost and quality. The challenge for nutrition teams in smaller hospitals is primarily to find a balance between the cost of services itself and their benefits. The concept of a mobile nutrition team becomes attractive in cases where the hospital facilities themselves are reluctant to fund the services of these teams and when the number of patients on parenteral nutrition is low. The existence of a mobile nutri- 
tion team that provides service to multiple hospitals or operates within a specific city network effectively reduces their operating costs (Orr, 1995).

\section{Methods}

A quantitative descriptive research method with critical review of English scientific and professional literature was performed using the following databases PubMed, Cochrane Library, ScienceDirect and GoogleScholar. The keywords we used were: nutrition support teams, nursing care, nutritional care. Literature inclusion criteria were articles published between 1995 and 2020, open and free access and articles with clearly defined objectives and methods in English language. We reviewed 17 articles, the excluded ones that didn't match our criteria. The literature search took place in March 2021. Data analyzed using a content analysis method. We used a prizma methodological diagram (Figure 1) to show the course of the decision criteria for determining the suitability of sources for inclusion in the literature review.

Figure 1: Prizma methodological diagram

\section{Results}

The results of literature review are presented in Table 1. Literature review based on keywords related to the implementation of nutritional support in social care institutions. Nutrition support can be organised in different way. In social care institutions is provided by nurses, dietitian, or doctors (Ali, 2007; Boeykens and Hecke, 2018). Nutrition support needs to be systematic and consistent (Power et al., 2019). 
Taking your show on

Orr , 1995 the road: the concept of a mobile nutrition support team

The concept of mobile nutrition teams is becoming attractive, when hospitals are not willing to provide financial aid or when the number of patients on parenteral support is low. The cost reduction of a mobile team is obtained by a joint use of several hospitals or by sustaining larger urban and rural area.

Recognition of malnutrition and initiation of adequate nutritional support care of critical importance in newl hospitalised patients is between $8 \%$ and $38 \%$. Patients who are not

An European survey of structure and organisa-

Shang et al., 2005 tion of nutrition support teams in Germany, Austria and Switzerland
Evaluation documentation an interview questions malnourished at the time of screening may develop during their hospital stay. Constant monitoring and screening patients is required during the hospitalization. Poor nutritional status and treatment outcomes as well as increased healthcare cost. Since establishment they noted less complications in $88 \%$ and cost savings in $98 \%$.

Malnutrition in nursing homes can be managed through consultation with a dietitian, the provision of appropri-

Managing under-nutri-

Ali, 2007 tion in a nursing home setting
Review ate feeding assistance, environmental adaptations, and the assessment and monitoring of nutritional status. Nurses can quickly identify any changes in a patient's nutritional status.

The nutrition support team should assess and manage patients who require nutrition support therapy. Nutrition support team are associated with improved patients outcomes and with decreased length of hospitalization and can improve cost effectiveness. Nutrition team can organize nutrition support services with different education (dietitian, nurse, physician, pharmacist, administration of nutrition support therapy).

Screening for malnutrition is recommended in all elderly subjects and must be carried out at least once a year in general practice, and once monthly in institutions, and during each hospital stay. Screening may be done using a questionnaire which must include at the very least a search for risk factors and body weight changes, such as the MNA (Mini Nutritional Assessment) and using a combination with a nutritional examination. 
Protein-energy malnutrition is a clinical condition due to the imbalance between needs, intake and utilization of nutrients, leading to increased morbidity and mortality and to the impairment of quality of life. Malnutrition can involves elderly people and different diseases like cancer and others. . Donini et al., 2013 $\begin{aligned} & \text { Nutritional Care in a } \\ & \text { Nursing Home in Italy }\end{aligned}$
Systematic review

The incidence of complications in malnourished people in nursing homes is $27 \%$ compared to patients in well nourished patients ( $16 \%)$, and mortality is three times higher.

Malnutrition affects the function of organs and systems, it decreases muscles maas and muscle strengt, increasing the incidence of hospital infections, increases the incidence of thrombosis and delays healing of surgical wounds and pressure sores.

Multidisciplinary nutritional support for the elderly in nursing homes and home care with an emphasis on individual treatment of potentially vari-

Multidisciplinary nutritional support for un-

Beck et al., 2016 dernutrition in nursing home and home-care: A cluster randomized con-

A cluster trolled trial

randomized trial in factors with a nutrition verification scheme and, where appropriate, the involvement of physiotherapists, dietitians and occupational therapists can have a positive impact on quality of life, muscle strength and oral care.

The developed model for nutritional support in nursing homes included seven areas: food supply, human focus, access to food and drink, tools, resources and environment, attitude towards others in food and drink, participation in activities, consistency of care and provision of information .

The United States of America began with educating nurses with special skills in the 2oth century. Europe is behind with development and imAdvanced practice nurs-

Boeykens and ing: Nutrition Nurse

Hecke, 2018 Specialist role and function
Systematic review plementation of Advanced Practice Nursing. Nutrition support also can be provided by a nurse with expert knowledge, skills, and clinical competencies for nutritional support. 
To determine the effectiveness of multidiscipli- Systematic

Rasamussen, et al., 2018 nary nutritional support in elderly hospitalized patients review and meta-analyses

Approach to malnutrition patients must be multidisciplinary. The intervention they introduced includes oral nutritional supplements, improved nutritional care and support, and diatics counseling. The results of the introduction of a multidisciplinary team and the above-mentioned interventions in the care of the elderly are an improvement in the quality of life and a reduction in mortality.

Four mobile health teams provided different health care services in remote/hard-to-reach communities in

Integrating nutrition services into mobile health Qarizada et al., teams: Bringing compre2019 hensive services to an underserved population in Afghanistan.

Pilot study Afghanistan. They also provided nutrition education and management of malnutrition. Between February and December 2018 they screened 19.187 children, out of which 1586 were severely malnutritioned and were successfully treated in $94 \%$.

Development and application of a scoring system to rate malnutrition Power et al., 2019 screening tools used in older adults in community and healthcare settings - A MaNuEL study

Systematic review

For screening malnutrition healthcare institutes can use their own health checklist for the community setting; the nutritional Form for Elderly, short Nutritional Assessment Questionnaire Residential Care; Malnutrition Screening Tool (MST) and Mini nutritional Assesment (MNA).

Mobile diabetes clinics provide high-quality patient care and are economical accessible to countries with limited resources. The mobile approach to diabetes treatment affected HbA1c, serum creatinine, BMI, and blood pressure values. Research has proven the effectiveness of a mobile clinic in an otherwise inefficient Palestinian health care system.

In malnourished patients, the use of individual nutritional support during hospital stays improved significant clinical outcomes, including survival, compared to standard hospital meals.

Individualised nutrition-

Schuetz et al., 2019 al support in medical inpatients at nutritional risk: a randomised clinical trial
Randomised clinical trial These findings strongly support the concept of systematic screening of patients on admission to the hospital for nutritional status, regardless of their medical condition, followed by nutritional assessment and the introduction of individual nutritional support for at-risk patients. 
Individual nutrition intervention for residents of nursing homes at risk of

An Individualised Nutritional Intervention ConSeemer et al., cept for Nursing Home 2020
Residents with or at Risk of Malnutrition: An enable Study malnutrition was based on the everyday concept of patient care with food and two intervention modules (different food texture, enrichment model). The model was well received and applied. To better track malnutrition in nursing homes, it makes sense to involve multidisciplinary nutrition support teams.

\section{Discussion}

The problem of malnutrition consists of several activities that require a combination of several approaches to address, and above all, each resident is treated individually. The nurse has a key help in managing malnutrition, as she spends the most time with the patient and is aware of their wishes and needs. The information held by nurses offered by others involved in the patient care process (including the kitchen where she prepares meals) can positively affect the nutritional status of nursing home residents (Ali, 2007). In the UK, an evidence-based model of person-centered nutritional care has been developed. They found that nutritional status is influenced by the cessation of dementia, the presence of concomitant diseases, psychosocial, cultural, and generational factors. Professionals need to consider factors in order to use good nutritional care for residents (Murphy et al., 2017). In Switzerland, guided individualized dietary support for gaining protein and calorie intake, provided within 48 hours of hospital admission, has been found to have quite a few advantages. Namely, it reduces the risk of adverse clinical outcomes in hospitalized patients at nutritional risk, including complications requiring intensive care and mortality. The intervention is also cost effective (Schuetz et al., 2019).

Recognizing malnutrition has a significant impact on the course of treatment, prolongs hospitalization time, and increases treatment cost (Ferrie, 2020). Shang et al. (2005) found out that $8 \%$ and $38 \%$ of all hospitalized patients have malnutrition. When malnutrition is not present, it is necessary to implement nutritional screening at least once per week. Malnutrition can be detected using screening forms such as MST and MNA. Power et al. (2019) found out that healthcare institutions can use their own method of nutrition assessment of patients, which includes a health checklist, a nutrition screening form for eldrely and a short nutrition assessment questionnaire. Several studies have found that malnutrition in the elderly is increasing and can be detected in the early phase of developmening malnutrition by using simple tools, however nutritional screening is not routine procedure. Nutritional support in social care institutions should be organized in a way to provide nutritional prevention and nutritional interventions in patients where malnutrition is already 
present. Nutritional support should be offered to patients with a multidisciplinary approach, when a multidisciplinary approach is not available it is necessary to provide nutritional support with the interdisciplinary team. Nutritional support includes a set of activities which depends what kind of medical problems a patient has. Nutritional support can be provided by different health profiles (nurse, dietitian, physician, pharmacist) (Ukleja et al., 2010). In the United States, special education in nursing care began in the early zoth century. In European countries with special knowling about dietetics by nurses is not developed like in the United States (Boeykens and Hecke, 2018).

In nursing homes in Denmark, a team of multidisciplinary nutritional support has been developed to treat malnutrition or the risk of malnutrition, which includes physiotherapists, dieticians and occupational therapists. It has been found to have positive effects on quality of life, muscle strength, and oral care in the elderly (Beck et al., 2016). A positive link between the introduction of multidisciplinary nutrition support teams and the quality of life of the elderly was also confirmed by Rasmussen and colleagues (2018). They also found lower mortality among residents of nursing homes who were under the control of the said teams. Seemer et al. (2020) found that multidisciplinary teams that provide nutritional support in nursing homes are effective. Namely, the study successfully introduced a series of interventions (eating pattern, nutritional supplements, improved food structure) to improve the nutritional status of malnourished elderly and those with risk factors for malnutrition.

Mobile diabetes clinics provide high-quality patient care and are also economically accessible to countries with limited resources. The mobile team could be funded jointly by network hospitals, or be funded by a single institution and provide services to everyone else in the network for agreed fees. These fees should cover at least the costs and, if possible, provide revenue. In return, the mobile nutrition team should very clearly document the impact of its services in terms of cost, results and quality of performed work. Their action to promote the appropriate use of nutritional supportive therapy and with implementation of nutritional screening will have a positive impact on the costs of care for patients who require nutritional support. Managed care payers will also be interested in the impact of the mobile nutrition team on hospitals, as well as the experience gained at home (Orr, 1995).

\section{Conclusions}

Every person has their own nutritional needs. In the elderly, nutritional needs vary even more due to more associated diseases and poorer physical performance. In social care institutions, it is essential to introduce regular nutritional screening, which will serve as a basis for the design of protective and therapeutic diets of the elderly. Part of the health team will also have to become a dietitian who will take the lead in planning and achieving nutrition support goals. Due to the constant presence of the patient, the nurse plays an important role in detecting eating problems and acting quickly with the help of a multidisci- 
plinary nutrition team that can provide the patient with comprehensive nutritional care. Due to the lack of the presence of adequate staff to deal with nutritional support in social care institutions, we see advantages in the organisation of work a mobile nutritional team, which is economically more economical to countries facing financial constraints. With adequate nutritional support, we will ensure adequate energy and nutritional intake of food, improve the nutritional status of the patient and reducing morbidity and mortality in sick elderly people.

\section{References}

AL-HALAWEH, A.A., ALMDAL, T., O'ROURKE, N. and DAVIDOVITCH, N., 2019. Mobile care teams improve metabolic control for adults with Type II diabetes in the Southern West Bank, Palestine. Clinical research \& Reviews, vol. 13, no. 1, pp. 782-785. https://doi.org/10.1016/j.dsx.2018.11.066 ALI, PA (2007). Managing under-nutritiion in a nursing home setting. Nursing older people, vol. 19, no. 3, pp. 33-36.

BECK, AM., Gøgsig Christensen A., Stenbæk Hansen B., Damsbo-Svendsen S. and Kreinfeldt Skovgaard Møller, T., 2016. Multidisciplinary nutritional support for undernutrition in nursing home and home-care: a cluster randomizide controlled trial. Nutrition, vol. 32. no. 2, pp. 199-205.

BOEYKENS, K. and HECKE, AV., 2018. Advanced practice nursing: Nutiriton Nurse Specialist role and function. Clinical Nutrition, vol. 26, pp. 72-76.

DONINI LORENZO, M., NERI, B., CHIARA, S., POGGIOGALLE. and MUSCARITOLI, M., 2013. Nutritional Care in Nursing Home in Italy. Plos One, vol. 8, no. 2, pp. 1-10.

DONINI, LM., STEPHAN, B., ROSANO, A., MOLFINO, A., POGGIOGALLE, E., LENZI, A., SIERVO, M., and MUSCARITOLI, M., 2020. What are the risk factors for malnutrition in older-aged institutionalized adults? Nutrients, vol. 12, no. 9, pp: 2857

FERRIE, S., 2020. What is nutritional assessment? A quick guide for critical care clinicians. Australian Critical Care, vol. 33, pp. 295-299.

GUYONNET, S. and ROLLAND, Y., 2015. Screening for malnutrition in older people. Clinics in Geriatric Medicine, vol. 31, no. 3, pp. 429-437.

ORR, M., 1995. Taking your show on the road: the concept of a mobile nutrition support team. Nutrition in Clinical Practice, vol. 10, no. 6, pp. 233-236.

MURPHY JL., HOLMES, J. and BROOKS, C., 2017. Nutrition and dementia care: developing an evidence-based model for nutritional care in nursing homes. BMC Geriatrics, no.17, vol. 1, pp. 55.

RASMUSSEN, N., BELQAID, K., LUNGET, K., NIELSEN, A., RASMUSSEN, HH. and BECK, AM., 2018. Effectiveness of multidisplinary nutritional support in older hospitalised patients: a systematic review and meta-analyses. Clinical nutritional ESPEN, vol. 27, pp. 44-45. 
RAYNUD, SA, REVEL DELHOM, C. and HEBAUTERNE, X., 2011. Clinical practice guidelines from French health high authority: nutritional support strategy in protein energy malnutrition in the elderly. Clinical $\mathrm{Nu}$ trition, vol. 30, pp. 312-319.

SCHUETZ, P., FEHR, R., BAECHIL, V., GEISER, M., DEISS, M. and GOMES, F., 2019. Individualised nutritional support in medical inpatients at nutritional risk: a randomised clinical trial. The Lancet, vol. 393, no. 10188, pp. 2312-2321.

SEEMER, J., KIESSWETTER, E. and BLAWERT, A., 2020.an individualised nutritional intervention concept for nursing home residents with or at risk of malnutrition: an enable study. Geriatrics, vol. 6, no. 1, pp. 2.

SHANG, E., HASENBERG, T., SCHLEGEL, B., STERCHI, AB., DRUML, W., KOLETZKO, B. and MEIR, R., 2005. An European survey of structure and organisation of nutrition support teams in Germany, Austria and Switzerland. Clinical nutrition, vol. 24, no. 6, pp. 1005-1013.

QARIZADA, AN., GALLAGHER, LM., BAQAKHIL, AQ., and GOERGEN, M., 2019. Integrating nutrition services into mobile health teams: Bringing comprehensive services to and underserved population in Afghanistan [online]. [viewed 15 June 2021]. Available from: https://www.ennonline.net/attachments/3496/FEX_61_web_version_62-64.pdf.

UKLEJA, A., GILBERT, K., MOGENSEN, K.M., WALKER, R., WARD, T.C., YBARRA, J., and HOLCOMBE, B., 2018. Standards for Nutrition Support: Adult Hospitalized Patients. Nutrition in Clinical Practice, vol. 33, no. 6, pp. 906-920. 


\title{
Attitudes towards smart technologies among older people and their informal carers in Slovenia
}

\author{
Simona Hvalič-Touzery, Vesna Dolničar \\ University of Ljubljana, Faculty of Social Sciences, Centre for Social Informatics \\ Simona.Hvalic-Touzery@fdv.uni-lj.si
}

\section{Abstract}

Introduction: Despite the growing body of evidence of smart solutions' positive outcomes on older people and their informal carers, the use of these solutions is still low, even more so in Slovenia. Moreover, in recent years, mostly single smart solutions have been developed, covering only a small range of applications. The international project i-evAALution evaluated the acceptance and the impact of the bundle of several single solutions (emergency watch, tablet and smart home devices) on community-dwelling older people and their informal carers. We present the preliminary results of only one segment of the whole study focusing on the results of a baseline questionnaire conducted in Slovenia. Methods: The randomised control trial was conducted in 2019-2O21 in the Central Slovenia region. A total of 55 dyads, including older care recipients (PE) and their primary informal carers (SE), were recruited and completed the baseline questionnaire. Care recipients were on average 78.6 years old $(\mathrm{SD}=7.79)$ and $43.6 \%$ had fallen in the past year. Carers were on average 52.8 years old $(\mathrm{SD}=11.58)$. On average, they provided 5.8 hours of care per week $(\mathrm{SD}=10.41)$ and had been doing so for an average of 6.6 years $(\mathrm{SD}=7.69)$. The majority $(71 \%)$ of carers were the children of the care recipient. Participants completed questionnaires at three or four measurement time points: at baseline (before randomisation to test or control group), post-installation (test group only), after 4-5 months (both groups), and after 12 months (control group only). Data were processed using the statistical package SPSS 20.0. Results: We observed a significant difference in technology competence between care recipients and carers $(\mathrm{MPE}=2.63, \mathrm{MSE}=2.12, \mathrm{p}=0.000)$ and the interest in technology $(\mathrm{MPE}=3.12, \mathrm{MSE}=3.70, \mathrm{p}=0.004)$. In addition, the most important features of a tested i-evAALution bundle recognised by both carers and care recipients were safety (MPE $=$ 4.32, $\mathrm{MSE}=4.46)$, emergency services $(\mathrm{MPE}=4.17, \mathrm{MSE}=4.41)$ and 
technical services $(\mathrm{MPE}=4.17, \mathrm{MSE}=4.36)$. The least important feature was leisure activities $(\mathrm{MPE}=1.98, \mathrm{MSE}=2.35)$. On average, it was more important to informal carers that care recipients could use the tablet to call family members or friends $(\mathrm{MSE}=3.27, \mathrm{p}<.05)$ than it was to care recipients $(\mathrm{MPE}=2.65)$. It was also more important for carers that the tablet reminded care recipients to take their medications $(\mathrm{MSE}=3.67)$ than for care recipients $(\mathrm{MPE}=2.94, \mathrm{p}<.05)$. Discussion and conclusions: This study contributes to a limited empirical evidence on the acceptance and attitudes of older people and their informal carers in Slovenia towards smart solutions in health and social care. Understanding their perceptions of technology and needs can also help the developers of such solutions, as well as the providers in the market, and support better deployment of such smart solutions in health and social care.

Keywords: assistive technologies, technology acceptance, technology attitudes, randomised control trial

\section{Introduction}

"Ageing in place", i.e. enabling people to live in their homes and communities for as long as possible, rather than in an institution, is the prevailing concept in current ageing policy (Wiles et al., 2012). However, in most EU countries, this concept is not sufficiently supported by social policies (Kröger et al., 2018) and pressures on informal carers are high and increasing (Spasova et al., 2018). Despite differences in long-term care (LTC) systems, informal care accounts for the majority of care hours in all European countries which is even more pronounced with the rising number of people in need of care and the lack of accessible formal LTC services and personnel (Kröger et al., 2019; Spasova et al., 2018). Despite these trends, in some countries, including Slovenia with its fragmented LTC system, the needs of informal carers are poorly met (Hlebec et al., 2021), although Slovenian Active Ageing Strategy (Bednaš and Kajzer, 2018) recognises the importance of improving support for informal carers and their integration into the LTC system.

According to Slovenian Public Opinion Survey (SJM) 2021, $30.6 \%$ of the population (aged 18 and over) provide at least 4 hours of unpaid informal care per week to a person aged 65 or over (Hafner-Fink et al., 2021; Dolničar et al., 2021). This refers to the provision of personal care activities (ADL) and/or activities related to independent living (IADL) and/or emotional support. The proportion of carers increases with age while they are still of working age (Tur-Sinai et al., 2020; Zigante, 2018), as also found in the Slovenian survey using an Online Access Panel 2021 (Dolničar et al., 2021). The proportion of informal carers of older people reported in these two Slovenian studies is significantly higher than in some other studies (Eurofound, 2017; Eurostat, 2019; Tur-Sinai et al., 2020). In 2013, $75.54 \%$ of Slovenian people aged 65 years or older, who received some type of care at home, received only informal care, $6.66 \%$ received only formal care, and $17.79 \%$ received a combination of the two (Hlebec et al., 
2016). As Dolničar et al. (2021) found, pressure on informal carers increased during the Covid 19 pandemic.

One way to address some of these challenges is to harness the potential of new technologies to support LTC and informal carers (Eurocarers, 2019), which is increasingly being proposed in European policy (Eurocarers, 2018, 2019; European Ageing Network, 2019; European Commission, 2021). A recent European Commission report calls for deployment of different ICT solutions for informal carers and older people and for addressing the lack of digital skills and mistrust of new technologies (Social Protection Committee (SPC) \& European Commission (DG EMPL), 2021; Zigante, 2021).

Despite evidence of the positive impact of these new technologies on older people (e.g., improved quality of life, increased safety, independence, reduced social isolation) (Khosravi et al., 2016; Siegel and Dorner, 2017)) and their informal carers (e.g. increased peace of mind and reassurance) (Andersson et al., 2017, Smole-Orehek et al., 2019, D'Onofrio et al., 2017), the prevalence of their use is still low, which is particularly pronounced in Slovenia.

The aim of this paper is to assess:

- which telecare functionalities are the most important for community-dwelling care receivers aged 65 and over (PE) and their informal carers (SE);

- $\quad$ technology competence among PEs and SEs and differences between them.

\section{Methods}

The present study was conducted as part of the i-evAALution project and is part of the randomised control trial (RCT), which ran from 2019 to 2021 in Slovenia, Austria, Italy and the Netherlands. For this paper, only the selected baseline section of RCT (i. e. before randomisation to test or control group and before installation of the bundle of AAL solutions), which relates to the Slovenian pilot site, is presented and discussed. The study has received ethical approval from the University Innsbruck Ethical Review Board (28/2019). Descriptive statistics and bivariate analyses were calculated.

\section{Instruments}

The Technology Commitment Scale (TC scale) (Neyer et al., 2012) was found to be moderately reliable, with a Chronbach Alpha of 0.662 for PE and 0.620 for SE. Other questions presented in this paper were developed by the project consortium. 


\section{Sample}

The Slovenian sample consisted of 55 dyads from PE and their SE. Both PEs (74.5 $\%$ ) and SEs (63.4 \%) were predominantly female. PEs were on average 78.4 years old and a higher proportion (67.3\%) lived in a single-person household. All but one SE owned a smartphone and a computer, while $67.3 \%$ of PEs owned a computer and 58.2\% owned a smartphone. A large proportion of PEs (70.4 \%) considered themselves independent, but $43.6 \%$ had experienced a fall in the past year. SEs were on average 52.8 years old $(S D=11.58)$. SEs in the sample were well educated, with nearly three-quarters having a university degree or more. Those who cared for PE did so for an average of 5.8 hours per week $(\mathrm{SD}=10.41)$ and an average of 6.6 years $(\mathrm{SD}=7.69)$. The majority $(71 \%)$ were children of SEs, followed by partners $(14.5 \%)$. Just over a quarter of SEs $(27.3 \%)$ lived in the same building as PEs and another fifth lived within walking distance. The remaining half of SEs were 15 minutes or more drive from PEs, and half of them were up to 30 minutes away.

Results

Importance of telecare functionalities

Table 1. Importance of eight main areas of telecare functionalities

\begin{tabular}{lcccc}
\multirow{2}{*}{\multicolumn{1}{c}{ Telecare functionalities }} & \multicolumn{2}{c}{$P E$} & \multicolumn{2}{c}{$S E$} \\
\cline { 2 - 5 } & $M$ & $S D$ & $M$ & $S D$ \\
\hline Safety and security & 4.32 & 0.687 & 4.46 & 0.482 \\
\hline Technology-related services & 4.17 & 1.052 & 4.36 & 0.841 \\
\hline Emergency services & 4.17 & 1.065 & 4.41 & 0.885 \\
\hline Services in case of need & 4.04 & 1.095 & 4.14 & 1.073 \\
\hline Health and care & 3.33 & 1.343 & 3.66 & 1.107 \\
\hline Living environment & 2.65 & 1.262 & 2.87 & 1.25 \\
\hline Information and communication & 2.57 & 1.202 & 2.98 & 1.102 \\
\hline Leisure activities & 1.98 & 1.201 & 2.35 & 1.377 \\
\hline
\end{tabular}

Legend: $M=$ Mean; $S D=$ Standard deviation

Note: Perceived importance of TC functionalities was measured on a 5-point scale:

1-not important, 2-slightly important, 3-moderately important, 4-significant, 5-significantly important.

All but three participants in the study had no experience with telecare services. However, participants were introduced to telecare services during the project's introductory session. After the introduction, participants rated a range of functionalities of telecare services in eight main areas (safety, technology-related services, emergency services, services in case of need, health and care, living environment, information and communication, leisure) according to how important they perceived them to be. When observing eight main areas of telecare functionalities, we found no statistically significant differences between the responses of PEs and SEs. Both, PEs and SEs, identified provision of safety 
$(\mathrm{MPE}=4.32, \mathrm{MSE}=4.46)$, provision of emergency services $(\mathrm{MPE}=4.17, \mathrm{MSE}$ = 4.41), and technology-related services (e.g., installation, maintenance) (MPE $=4.17, \mathrm{MSE}=4.36)$ as the most important functionalities of telecare services. The least important functionality was leisure activity $(\mathrm{MPE}=1.98, \mathrm{MSE}=2.35)$ (Table 1).

Beside studying main areas of telecare functionalities, we also investigated the importance of specific functionalities, which were measured with a battery of 29 indicators within eight main areas of functionalities. We found a statistically significant difference in responses between PEs and their SEs on only two indicators. On average, it was more important to the SEs that PE could use the tablet to call family members or friends $(\mathrm{MSE}=3.27, \mathrm{SD}=0.184$ ) than it was to PEs $(\mathrm{MPE}=2.65, \mathrm{SD}=0.193, \mathrm{t}(107)=-2.342, \mathrm{p}<.05)$. It was also more important for the SEs that $\mathrm{PE}$ has a medication reminder $(\mathrm{MSE}=3.67, \mathrm{SD}=0.173)$ than for $\mathrm{PE}(\mathrm{MPE}=2.94, \mathrm{SD}=0.213, \mathrm{t}(105)=-2.640, \mathrm{p}<.05)$.

\section{Technology competence}

We found a statistically significant difference in the technology competence of PEs and SEs $(\mathrm{MPE}=2.61, \mathrm{MSE}=\mathbf{2 . 1 2}, \mathrm{p}=0.000)^{1}$ as well as in their interest in technology $(\mathrm{MPE}=3.12, \mathrm{MSE}=3.70, \mathrm{p}=0.004)$. Both PEs and SEs showed interest in technological developments, with the proportion of SEs who fully or largely agreed with this statement $(78.2 \%)$ being significantly higher than the proportion of PEs (47.3\%). The data also shows that more than one-third of PEs find dealing with new technologies challenging and difficult. In addition, more than half of SEs agreed that dealing with technological innovations is usually overwhelming for them.

We were interested also in participants' self-perceived ability to use new technologies compared to the general technology skills of their peers. $85.5 \%$ of SEs and half (50.9 \%) of PEs rated them as very good or good. A significant proportion (30.9 \%) of PEs rated their ability to use new technologies as average and $\mathbf{1 8 . 2} \%$ rated their ability as poor or that they were complete novices. No correlation was found between PEs' ability to use new technologies and their assessment of the importance of individual telecare functionalities ( $p>0.05)$.

\section{Discussion}

A substantial proportion of the PEs in our study were still independent, although slightly less than half had a history of falls. However, regardless of health status, PEs and SEs both identified the provision of safety and emergency services as the most important functionalities of telecare services. These functionalities of telecare services provide security and rapid response in emergency situations, which are perceived benefits that may lead to the adoption of such

$1 \quad$ Technology competence and technology interest were each measured with 4 items as part of the TC scale. Technology competence was measured with negative-worded items; higher average score indicates lower competence. 
technologies among PEs and SEs, which has been discussed in several studies (Dolničar et al., 2017; Epstein et al., 2016; Hvalič Touzery et al., 2021; Jaschinski et al., 2021; Jaschinski and Ben Allouch, 2019; Mahoney, 2011; Olsson et al., 2012; Verloo et al., 2020; Williamson et al., 2017).

With regard to the second objective of the present study, it was found that although both participants have high ownership of everyday technologies (e.g., computers, smartphones), PEs have lower technology competence and interest in technology than SEs. This is also reflected in a low percentage of PEs and SEs who rated their ability to use new technologies as poor. Present study also found that some SEs find dealing with technological innovations overwhelming and PEs find dealing with new technologies challenging and difficult. Therefore, the importance of external support from telecare providers when using a telecare solution (e.g. installation, maintenance, technical support) is paramount and this was also expressed by the PEs and SEs in our study who ranked this support among the top three features of telecare services. These findings confirm the need to support both PEs and SEs in using telecare solutions. As evidenced by many studies, successful use of telecare solutions requires both initial training and continuous technical support during use, characterised by high quality, responsiveness and user - friendliness (Epstein et al., 2016; Gibson et al., 2019; Jaschinski and Ben Allouch, 2019; Sriram et al., 2019; Verloo et al., 2020; White et al., 2020; Williamson et al., 2017).

A recent study by Steils et al. (2021) concludes that informal carers are often an important source of help for older people in using assistive technologies. A prerequisite for this type of assistance is sufficient technology competence and openness to new technologies. In our sample of SEs, we found high levels of technology competence and interest in new technologies, whereas this was lower in PEs. Therefore, we can conclude that it is important to involve family members of older individuals in technology adoption, as reported in previous studies (Jaschinski et al., 2021; Luijkx et al., 2015).

Finally, some difference was found between PEs and SEs in terms of their interest in the new technologies, with SEs expressing greater interest, which is consistent with the findings of other studies. As the use of telecare is often a joint decision between PE and SE (Cook et al., 2018; Jaschinski et al., 2021; Jaschinski and Ben Allouch, 2019; Luijkx et al., 2015), it is even more important that SEs support new technologies.

\section{Study limitations}

The study design affected the sample size. It is somewhat small, but the sample has the advantage of including dyads. We invited all interested parties to participate. This resulted in an unbalanced distribution of participants in the sample by educational background. In fact, we have a high proportion of highly educated SEs in the sample. Aditionally it is possible that individuals with greater 
interest in the new technology have decided to participate in the study so there can be a bias in the data on their technology competence and interest.

\section{Conclusions}

Our study confirms the potential of telecare services to address challenges related to LTC. There are many challenges that Slovenian society needs to address in order to realize the full potential of telecare solutions. As can also be seen in our sample, people are not familiar with telecare solutions and do not use them. However, as our study also shows, they recognize their potential and express interest in using them. Therefore, these technologies should be made available to informal carers and older people. In addition, public authorities need to recognize the role and care needs of informal carers and thus promote a policy framework for the creation of telecare services for informal carers and beyond. At the same time, familiarity with and acceptance of these technologies needs to be promoted not only among the general population but also among social and health care professionals.

\section{Acknowledgement}

The study was carried out in the framework of the project i-evAALution, supported by AAL JP and projects Factors influencing the intention to use smart technology-enabled care services among family caregivers of older people in the context of telecare and Programme Internet research, financially supported by the Slovenian Research Agency (J5-1785, P5-0399).

\section{References}

BEDNAŠ, M., and KAJZER, A. (Eds.), 2018. Active Ageing Strategy. Ljubljana: Institute of Macroeconomic Analysis and Development of the Republic of Slovenia; Ministry of Labour, Family, Social Affairs and Equal Opportunities [online]. [viewed 5 January 2020]. Available from http://www. umar.gov.si/fileadmin/user_upload/publikacije/kratke_analize/Strategija_dolgozive_druzbe/UMAR_SDD_ang.pdf

DOLNIČAR, V., PETROVČIČ, A., ŠETINC, M., KOŠIR, I., and KAVČIČ, M., 2017. Understanding Acceptance Factors for Using e-care Systems and Devices: Insights from a Mixed-Method Intervention Study in Slovenia. In J. Zhou and G. Salvendy (Eds.), Human Aspects of IT for the Aged Population. Applications, Services and Contexts (pp. 362-377). Cham: Springer International Publishing.

DOLNIČAR, V., TRKMAN, M., BERZELAK, J., BARTOL, J., and HVALIČ TOUZERY, S., 2021. Pomoč starejšim osebam s strani družinskih članov ali sorodnikov in njihov odnos do novih tehnologij: Sumarni pregled frekvenčnih porazdelitev in opisnih statistik zbranih podatkov (raziskovalno poročilo na ARRS projektu J5-1785). Fakulteta za družbene vede. Forthcoming publication. 
EPSTEIN, I., ALIGATO, A., KRIMMEL, T., and MIHAILIDIS, A., 2016. Older Adults' and Caregivers' Perspectives on In-Home Monitoring Technology. Journal of Gerontological Nursing, vol. 42, no. 6, pp. 43-50.

HAFNER-FINK, M., BRODER, Ž., DOUŠAK, M., FALLE ZORMAN, R., GERDINA, O., JAGODIC, A., KECMAN, I., KURDIJA, S., MIHELJAK, V., PAJNIK, M. et al., 2021. Slovensko javno mnenje 2021/1 - Poročilo o izvedbi raziskave in sumarni pregled rezultatov. Center za raziskovanje javnega mnenja in množičnih komunikacij, Univerza v Ljubljani, Fakulteta za družbene vede.

HLEBEC, V., RAKAR, T., DOLNIČAR, V., PETROVČIČ, A., and FILIPOVIČ HRAST, M., 2021. Intergenerational solidarity in Slovenia: Key issues. In I. Albert (Ed.), Families and family values in society and culture, (Perspectives on human development). Charlotte: Information Age, pp. 359380.

HLEBEC, V., SRAKAR, A., and MAJCEN, B., 2016. Determinants of Unmet Needs Among Slovenian Old Population. Slovenian Journal of Public Health, vol. 55, no. 1, pp. 78-85.

HVALIČ TOUZERY, S., SMOLE-OREHEK, K., and DOLNIČAR, V., 2021. Family carers' perspective on how older people perceive telecare. Presented at the Places, spaces and cultures of ageing - European Sociological Association's Research Network on Ageing in Europe Midterm conference, Jyväskylä. Retrieved from University.

JASCHINSKI, C., ALLOUCH, S. B., PETERS, O., CACHUCHO, R., and VAN DIJK, J.A.G.M., 2021. Acceptance of Technologies for Aging in Place: A Conceptual Model. Journal of Medical Internet Research, vol. 23, no. 3, e22613.

JASCHINSKI, C., and BEN ALLOUCH, S., 2019. Listening to the ones who care: Exploring the perceptions of informal caregivers towards ambient assisted living applications. Journal of Ambient Intelligence and Humanized Computing, vol. 10, no. 2, pp. 761-778.

KHOSRAVI, P., REZVANI, A., and WIEWIORA, A., 2016. The impact of technology on older adults' social isolation. Computers in Human Behavior, vol. 63, pp. 594-603.

KRÖGER, T., MATHEW PUTHENPARAMBIL, J., and VAN AERSCHOT, L., 2019. Care poverty: Unmet care needs in a Nordic welfare state. International Journal of Care and Caring, vol. 3, no. 4, pp. 485-500.

LILHOLT, P. H., HÆSUM, L. K. E., EHLERS, L. H., and HEJLESEN, O. K., 2016. Specific technological communication skills and functional health literacy have no influence on self-reported benefits from enrollment in the TeleCare North trial. International Journal of Medical Informatics, vol. 91, pp. 6o-66. 
MAHONEY, D., 2011. An Evidence-Based Adoption of Technology Model for Remote Monitoring of Elders' Daily Activities. Ageing International, vol. 36, no. 1, pp. 66-81.

NEYER, F. -J., FELBER, J., and GEBHARDT, C., 2012. Development and validation of a brief measure of technology commitment. Diagnostica, vol. 58, no. 2, pp. 87-99.

OLSSON, A., ENGSTRÖM, M., SKOVDAHL, K., and LAMPIC, C., 2012. My, your and our needs for safety and security: Relatives' reflections on using information and communication technology in dementia care. Scandinavian Journal of Caring Sciences, vol. 26, no. 1, pp. 104-112.

SIEGEL, C., and DORNER, T.-E., 2017. Review article: Information technologies for active and assisted living-Influences to the quality of life of an ageing society. International Journal of Medical Informatics, vol. 10o, pp. $32-45$.

SOCIAL PROTECTION COMMITTEE (SPC), and EUROPEAN COMMISSION (DG EMPL), 2021. 2021 Long-Term Care Report-Trends, challenges and opportunities in an ageing society. Volume I. Luxembourg: Publications Office of the European Union [online]. [viewed 15 June 2021]. Available from: https://ec.europa.eu/social/main.jsp?catId=738andlangId=enandpubId $=8396$

SPASOVA, S., BAETEN, R., COSTER, S., GHAILANI, D., PENA-CASAS, R., and VANHERCKE, B., 2018. Challenges in long-term care in Europe-A study of national policies. Brussels: European Commission, Directorate-General for Employment, Social Affairs and Inclusion [online]. [viewed 15 March 2019]. Available from: https://ec.europa.eu/social/BlobServlet?docId $=20225$ andlangId $=$ en

STEILS, N., WOOLHAM, J., FISK, M., PORTEUS, J., and FORSYTH, K., 2021. Carers' involvement in telecare provision by local councils for older people in England: Perspectives of council telecare managers and stakeholders. Ageing and Society, vol. 41, no. 2, pp. 456-475.

TUR-SINAI, A., TETI, A., ROMMEL, A., HLEBEC, V., and LAMURA, G., 2020. How Many Older Informal Caregivers Are There in Europe? Comparison of Estimates of Their Prevalence from Three European Surveys. International Journal of Environmental Research and Public Health, vol. 17, no. 24, 9531.

VERLOO, H., KAMPEL, T., VIDAL, N., and PEREIRA, F., 2020. Perceptions About Technologies That Help Community-Dwelling Older Adults Remain at Home: Qualitative Study. Journal of Medical Internet Research, vol. 22, no. 6. e17930.

WILES, J. L., LEIBING, A., GUBERMAN, N., REEVE, J., and ALLEN, R. E. S., 2012. The Meaning of "Aging in Place" to Older People. The Gerontologist, vol. 52, no. 3, pp. 357-366. 
WILliAMSON, B., APLIN, T., DE JONGE, D., and GOYNE, M., 2017. Tracking down a solution: Exploring the acceptability and value of wearable GPS devices for older persons, individuals with a disability and their support persons. Disability and Rehabilitation. Assistive Technology, vol. 12, no. 8 , pp. $822-831$.

ZIGANTE, V., 2018. Informal Care in Europe: Exploring Formalisation, Availability and Quality. Brussels: Publications Office.

ZIGANTE, V., 2021. The Role of New Technologies in Modernising Long-term Care Systems - A scoping review. Luxembourg: Publications Office of the European Union [online]. [viewed 30 April 2020]. Available from: https:// ec.europa.eu/social/BlobServlet?docId=23362 andlangId $=\mathrm{mt}$ 


\title{
Integrating the needs of LGBT+ older adults into health and social care education
}

\author{
Anže Jurček, Mojca Urek \\ University of Ljubljana, Faculty of Social Work, Ljubljana, Slovenia \\ anze.jurcek@fsd.uni-lj.si; mojca.urek@fsd.uni-lj.si
}

\begin{abstract}
Introduction: Non-normative sexual orientation, gender identity and gender expression at the intersection of old age, represent diverse risks of discrimination and social exclusion, and at the same time can include many negative consequences for a person's health and sense of security. In old age, the situation may worsen, as LGBT+ older adults are less likely to access various forms of support that could trigger coming out of the closet. Research shows that inequalities in health and social care of LGBT+ older adults persist due to the lack of inclusive services and cultural competence of health and social care practitioners. Methods: The partners of the European project "Being Me" took up the challenges presented and explored good educational practices on the needs and specific living conditions of LGBT+ older adults using the innovative participatory method "World Café" (a method of group dialog). In 2018, two "World Cafés" were organized with a total of 78 stakeholders (LGBT+ older adults, practitioners, researchers, students, professors and teachers). An evaluation of both events was conducted using questionnaires. The project also included research into the national contexts of the participating partners and the publication of two systematic literature reviews on approaches to education on LGBT+ older adults and the impact of such education on health and social care staff. Results: In the first World Café, participants shared their personal experiences of care, highlighted the role of teachers in health and social care, and formulated initial ideas about the knowledge and skills that future practitioners should be equipped with to provide more inclusive and safe care. The second World Café was dedicated to researching specific methods and useful resources for delivering trainings and using them in education. A systematic review of the literature and both World Cafés led to the development of online learning materials and principles of good practice for all who educate in the field of health and social care.
\end{abstract}


The World Café method has proved to be an effective approach to linking the diverse views of participants and the participatory development of learning content, as evidenced in the evaluation findings. Discussion and conclusions: LGBT+ older adults represent one aspect of an increasingly diverse group of people whose need for health and social care services is growing in an aging society. In the future, staff training in these areas will need to address the needs of LGBT+ older adults, as providers of these services have a key role in delivering friendly and inclusive care to LGBT+ older adults.

\section{Keywords: LGBT+ older adults, inclusive care, education, World Café}

\section{Introduction}

The number of people aged 60 years or older is increasing exponentially (United Nations World Population Aging, 2019) and with it the needs for health and social services in both informal and formal support systems (United Nations Population Fund and HelpAge, 2012). At the same time, lesbian, gay, bisexual, transgender and other non-normative sexual orientations, gender identities and gender expressions (LGBT+) are becoming more visible but face various risks of discrimination and social exclusion at the intersection of old age.

There are numerous reports that LGBT+ older adults face specific social problems similar to their younger peers, including isolation, economic challenges, employment and housing discrimination (Boggs et al., 2017; Fredriksen-Goldsen et al., 2017; Emlet, 2016; Equal Rights Center, 2014), and multiple health problems, such as higher risk of mental health issues, disability, and substance abuse (Yarns et al. 2016; Fredriksen-Goldsen et al. 2013). Compared to the general population, they report poorer health and have worse experiences of care (Westwood et al., 2020). In addition, LGBT+ older adults are more likely to be estranged from their families, have no children, and live alone compared to their heterosexual and same-sex peers. Consequently, they have to rely on other support systems such as friends and other caregivers (Zelle and Arms, 2015; Knauer, 2016).

Studies have shown that LGBT+ older adults are often afraid to disclose their sexual orientation or gender identity to health and social care providers due to their personal histories of discrimination and social exclusion, and are reluctant to access existing services (Sharek et al., 2015; Almack, 2019; Burton et al., 2019). Westwood (2019) notes that in the case of organizational abuse, LGBT+ older adults may be potentially mistreated by both service providers and other residents. In addition, the fear of and actual occurrence of discrimination based on sexuality and gender identity, which often co-occurs with ageism, has been linked to a higher likelihood of depression and anxiety in LGBT+ older adults (Tinney et al., 2015).

In order to understand the specific needs that arise from the diverse life experiences and histories of LGBT+ older adults, both practicing and future 
professionals must be educated to provide culturally competent and inclusive care (Dentato et al., 2014; Canon et al., 2017, Smith et al., 2019). A lack of cultural competency and knowledge about working with LGBT+ older adults is often observed among professionals (Portz et al., 2014; Simpson et al., 2018; Kortes-Miller et al., 2019) and is missing from curricula and textbooks (De Guzman et al., 2018)

\section{Methods}

Between 2018 and 2020, the partners of the European project "Being Me" (https://beingme.eu/) took up the challenges presented and explored good educational practices on the needs and specific living conditions of LGBT+ older adults. The innovative participatory method "World Café" (World Café Community Foundation, 2015), a group dialog method, was used to bring stakeholders (LGBT+ older adults, practitioners, researchers, students, professors and teachers) together to document their lived experiences, knowledge and resources. Two 'World Cafés' were organized in Amsterdam (June 2018) and Dublin (October 2018) with a total of 78 participants and both events were evaluated with a questionnaire (see Hafford-Letchfield et al., 2021). The project also included research into the national contexts of the participating partners and the publication of two systematic literature reviews on approaches to education on LGBT+ older adults and the impact of such education on health and social care staff (see Jurček et al., 2021; Higgins et al., 2019a).

\section{Results}

\section{Use of World Café method}

In the first World Café, participants shared their personal experiences of care, highlighted the role of educators in health and social care, and formulated initial ideas about the knowledge and skills that future professionals should be equipped with to provide more inclusive and safer care. A variety of approaches and methods were used during the event, including storytelling, mixed group discussions on relevant topics and arts-based sessions. The groups invariably included diverse stakeholders from different partner countries (UK, Ireland, Netherlands and Slovenia) and stakeholder groups. This led to more lively discussions and followed the principle of 'nothing about us, without us', meaning that discussions about the experiences and needs of LGBT+ older adults always included someone with personal experience. Smaller group discussions were later presented to the whole group and the results were documented and collated by members of the Being Me team.

The second World Café followed a few months later and was dedicated to exploring specific methods and useful resources that can be used in professional education and training. Participants, particularly researchers, policy makers, practitioners and educators, were asked to bring examples of good practice, which were then presented in smaller groups, evaluated and discussed with 
other stakeholders. Again, input from all stakeholders, but particularly LGBT+ older adults, was crucial in identifying good practices, which were collected and later disseminated (see Hafford-Letchfield et al., 2019).

\section{Evaluation and main results}

The evaluation conducted in both sessions found that the World Café method was useful in achieving the event objectives and resulted in a high level of participant satisfaction. The majority of participants agreed that the climate within the group was conducive to open discussions and, with the help of the facilitators, everyone had the opportunity to express their thoughts in a safe environment. The different methods and approaches used during the event enabled the sharing of ideas and the creation of new resources that can be used in practical and educational settings. Key outcomes from the World Cafés led to the development of online learning materials (https://beingme.eu/toolbox) and principles of good practice for all who educate in the field of health and social care (Higgins et al., 2019b). The learning materials developed as part of the project cover six overarching themes: 1) Readiness to learn, which aims to prepare institutions and educators to include and address LGBT+ issues in their curricula; 2) Human Rights, which helps learners understand the meaning, origins, and relevance to LGBT+ older adults; 3) Identities and Intersectionality, which introduces relevant terminology and intersectionality critical to understanding different life stories and the interplay of people's identities; 4) Relationships, Families, and Intimacies, addresses the diversity of networks and relationships of LGBT+ older adults; 5) Life Stories, provides guidance to educators on using LGBT+ stories in their teaching; 6) Good Care, aims to provide knowledge about inclusive and LGBT+ friendly care.

\section{Discussion}

The World Café method proved to be an effective approach to linking the different views of participants and the participatory development of learning content, as shown by the evaluation findings. Project outputs were also informed by two systematic literature reviews. The first review synthesised literature describing the pedagogical principles, curriculum content and methods used to educate health and social care professionals in relation to the experiences and needs of LGBT+ older adults (Higgins et al., 2019a) and was used in the development of principles for good practice and learning materials. The findings of the review are congruent with the findings of the World Cafés and other reviews such as that of Lecompte et al. (2021), which emphasize the importance of educating practitioners by increasing their knowledge of LGBT+ issues, changing their attitudes and working proactively to take action at institutional and personal levels to provide safe and inclusive care. In addition to providing an overview of existing content and methods that can be used in educational settings, our review also indicates that there is a need for in-depth exploration of curricular principles, assessment strategies, and strategies to overcome barriers 
to incorporating issues experienced by LGBT+ older adults into curricula (Higgins et al., 2019a). The second study in the Being Me project looked at the outcomes of interventions used to educate health and social care workforce on the experiences and needs of LGBT+ older adults, in particular what impact the interventions have on the knowledge, attitudes and skills of participants. The included studies showed some positive outcomes, such as an increase in knowledge among participants, but not necessarily a change in attitudes or newly acquired skills (Jurček et al., 2021), therefore more emphasis needs to be placed on the transfer of acquired knowledge into practice when delivering training targeted at professionals working with LGBT+ older adults in the future. The review has shown that longitudinal studies of the impact of educational interventions are needed and that diversification of intervention content, different methodologies and the involvement of the public (particularly LGBT+ individuals and organizations) at all stages of the design and delivery of educational interventions could lead to a more sustainable impact (Jurček et al., 2021).

\section{Conclusions}

LGBT+ older adults represent one aspect of an increasingly diverse group of people whose need for health and social care services is growing in an aging society. In the future, staff training in these areas will need to address the needs of LGBT+ older adults, as providers of these services have a key role to play in delivering friendly and inclusive care for LGBT+ older adults. The Being Me project addressed these issues using both participatory approaches to include personal experiences of LGBT+ older adults and reviewed existing literature with the intention of providing educators and practitioners with valuable resources to incorporate the needs of LGBT+ older adults into curricula and train practitioners in health and social care services.

\section{References}

ALMACK, K., 2019. ,I didn't come out to go back in the closet': Ageing and endof-life care for older LGBT people. In KING, A., ALMACK, K., SUEN Y.-T. and WESTWOOD, S., eds. Older lesbian, gay, bisexual and trans people: Minding the knowledge gaps. London and New York: Routledge, pp. 160-171.

BOGGS, J.M., PORTZ DICKMAN, J., KING, D.K., WRIGHT, L.A., HELANDER, K., RETRUM, J.H. and GOZANKSY, W.S., 2017. Perspectives of LGBTQ Older Adults on Aging in Place: A Qualitative Investigation. Journal of Homosexuality, vol. 64, no. 11, pp. 1539-156o.

BURTON, C.W., LEE, J.A., WAALEN, A. and GIBBS, L.M., 2019. “Things Are Different Now But": Older LGBT Adults' Experiences and Unmet Needs in Health Care. Journal of Transcultural Nursing, vol. 31, no. 5, pp. 492501. 
CANNON, S.M., SHUKLA, V. and VANDERBILT, A.A., 2017. Addressing the healthcare needs of older Lesbian, Gay, Bisexual, and Transgender patients in medical school curricula: a call to action. Medical Education Online, vol. 22, no. 1.

DE GUZMAN, F.L.M., NGALEE MOKOULOU, L.N., SCOTT, L.D. and ZERWIC, J.J., 2018. LGBT inclusivity in health assessment textbooks. Journal of Professional Nursing, vol. 34, no. 6, pp. 483-487.

DENTATO, M.P., ORWAT, J. and SPIRA, M., 2014. Examining Cohort Differences and Resilience among the Aging LGBT Community: Implications for Education and Practice among an Expansively Diverse Population. Journal of Human Behavior in the Social Environment, vol. 24, pp. 316328.

EMLET, C.A., 2016. Social, Economic, and Health Disparities among LGBT Older Adults. Journal of the American Society on Aging, vol. 40, no. 2, pp. 16-22.

EQUAL RIGHTS CENTER, 2014. Opening Doors: An Investigation of Barriers to Senior Housing for Same-Sex Couples. Washington D.C.: Equal Rights Center.

FREDRIKSEN-GOLDSEN, K.I., KIM, H.J., BARKAN, S.E., MURACO, A. and HOY-ELLIS, C.P., 2013. Health Disparities Among Lesbian, Gay, and Bisexual Older Adults: Results From a Population-Based Study, Research and Practice, vol. 103, no. 10, pp. 1802-1809.

FREDRIKSEN-GOLDSEN, K.I., BRYAN, A.E.B., JEN, S., GOLDSEN, J., KIM, H.J. and MURACO, A., 2017. The Unfolding of LGBT Lives: Key Events Associated With Health and Well-being in Later Life. Gerontologist, vol. 57, no. 1, pp. 15-29.

HAFFORD-LETCHFIELD, T., PEZZELLA, A., CONNELL, S., UREK, M., JURČEK, A., HIGGINS, A., KEOGH, B., VAN DER VAART, N., RABELINK, I., ROBOTHAM, G. and et. al., 2021. Learning to deliver LGBT aged care: Exploring and documenting best practices in professional and vocational education through the World Café method (in press). Ageing and Society, (viewed 3 August 2021). Available from: https://doi. org/10.1017/So144686X21000441

HAFFORD-LETCHFIELD, T., PEZZELLA, A., CONNELL, S., VAN DER VAART, N., RABELINK, I., BUS, E., HIGGINS, A., KEOGH, B., ROBOTHAM, G., UREK, M. and Jurček, A., 2019. Being me : project report on best practices in learning and education to support LGBT ageing care and wellbeing (online). (viewed 3 August 2021). Available from: https://beingme.eu/public/application/downloads/resources/being-mebest-practices-world-cafe-report.pdf.

HIGGINS, A., DOWNES, C., SHEAF, G., BUS, E., CONNELL, S., HAFFORD-LETCHFIELD, T., JURČEK, A., PEZZELLA, A., RABELINK, I., ROBOTHAM, G. and et. al., 2019a. Pedagogical principles and methods 
underpinning education of health and social care practitioners on experiences and needs of older LGBT+ people: Findings from a systematic review. Nurse Education in Practice, vol. 40, no. 7. (viewed 3 August 2021). Available from: https://doi.org/10.1016/j.nepr.2019.102625.

HIGGINS, A., KEOGH, B., BUS, E., CONNELL, S., HAFFORD-LETCHFIELD, T., JURČEK, A., PEZZELLA, A., RABELINK, I., ROBOTHAM, G., UREK, M. and et. al. 2019b. Best practice principles on developing LGBT cultural competence in health and social care education (online). (viewed 3 August 2021). Available from: https://beingme.eu/ public/application/downloads/resources/being-me-best-practice-principles-20200622.pdf.

JURČEK, A., DOWNES, C., KEOGH, B., UREK, M., SHEAF, G., HAFFORD-LETCHFIELD, T., BUITENKAMP, C., VAN DER VAART, N. and HIGGINS, A., 2021. Educating health and social care practitioners on the experiences and needs of older LGBT+ adults: findings from a systematic review. Journal of Nursing Management, vol. 29, no. 1, pp. 43-57.

KNAUER, N.J., 2016. LGBT Older Adults, Chosen Family and Caregiving. Journal of Law and Religion, vol. 31, no. 2, pp. 150-168. KORTES-MILLER, K., WILSON, K. and STINCHCOMBE, A., 2019. Care and LGBT Aging in Canada: A Focus Group Study on the Educational Gaps among Care Workers. Clinical Gerontologist, vol. 42, no. 2, pp. 192-197.

LECOMPTE, M., DUCHARME, J., BEAUCHAMP, J. and COUTURE, M., 2021. Inclusive Practices toward LGBT Older Adults in Healthcare and Social Services: A Scoping Review of Quantitative and Qualitative Evidence. Clinical Gerontologist, vol. 44, no. 3, pp. 210-221.

PORTZ, J.D., RETRUM, J.H., WRIGHT, L.A., BOGGS, J.M., WILINS, S., GRIMM, C., GILCHRIST, K. and GOZANSKY, W.S., 2014. Assessing Capacity for Providing Culturally Competent Services to LGBT Older Adults. Journal of Gerontological Social Work, vol. 57, no. 2-4, pp. 305-321.

SHAREK, D.B., MCCANN, E., SHEERIN, F., GLACKEN, M. and HIGGINS, A., 2015. Older LGBT people's experiences and concerns with healthcare professionals and services in Ireland. International Journal of Older People Nursing, vol. 10, no. 3, pp. 230-240.

SIMPSON, P., ALMACK, K. and WALTHERY, P., 2018. 'We treat them all the same': the attitudes, knowledge and practices of staff concerning old/er lesbian, gay, bisexual and trans residents in care homes. Ageing \& Society, vol. 38, no. 5, pp. 869-899.

TINNEY, J., DOW, B., MAUDE, P., PURCHASE, R., WHYTE, C. and BARRETT, C., 2015. Mental health issues and discrimination among older LGBTI people. International Psychogeriatrics, vol. 27, no. 9, pp. 1411-1416.

SMITH, R. W., ALTMAN, J. K., MEEKS, S. and HINRICHS, K. L. M., 2019. Mental health care for LGBT older adults in long-term care settings: 
Competency, training, and barriers for mental health providers. Clinical Gerontologist, vol. 42, no. 2, pp. 198-203.

UNITED NATIONS, DEPARTMENT OF ECONOMIC AND SOCIAL AFFAIRS, 2019. World Population Ageing 2019: Highlights. New York: United Nations.

UNITED NATIONS POPULATION FUND AND HELP AGE INTERNATIONAL, 2012. Ageing in the Twenty- First Century: A Celebration and a Challenge. UNFPA United Nations Population Fund and HelpAge International (UNFPA). New York, London: HelpAge International.

YARNS, B.C., ABRAMS, J.M., WEEKS, T.W. and SEWELL, D.D., 2016. The Mental Health of Older LGBT Adults (online). Current Psychiatry Reports, vol. 18, no. 6o. (viewed 3 August 2021). Available from: https://doi. org/10.1007/s11920-016-0697-y

ZELLE, A. And ARMS, T., 2015. Psychosocial Effects of Health Disparities of Lesbian, Gay, Bisexual, and Transgender Older Adults. Journal of Psychosocial Nursing and Mental Health Services, vol. 53, no. 7, pp. 25-30.

WESTWOOD, S., 2019. Abuse and older lesbian, gay bisexual, and trans (LGBT) people: a commentary and research agenda. Journal of Elder Abuse and Neglect, vol. 31, no. 2, pp. 97-114.

WESTWOOD, S., WILLIS, P., FISH, J., HAFFORD-LETCHFIELD, T., SEMLYEN, J., KING, A., BEACH, B., ALMACK K., KNEALE, D., TOZE, M. and et al., 2020. Older LGBT+ health inequalities in the United Kingdom: setting a research agenda. Journal of Epidemiology \& Community Health, vol. 74, no. 5, pp. 408-411.

WORLD CAFE COMMUNITY FOUNDATION, 2015. A Quick Reference Guide for Hosting World Café (online). (viewed 2 August 2021). Available from: http://www.theworldcafe.com 


\title{
A study on the experiences of hygiene requirements among older persons during the COVID-19 epidemic
}

\author{
Tjaša Kamnik, Mojca Jevšnik \\ University of Ljubljana, Faculty of Health Sciences, Ljubljana, Slovenia \\ t.kamnik@gmail.com; mojca.jevsnik@zf.uni-lj.si
}

\begin{abstract}
Introduction: The COVID - 19 epidemic has brought many challenges and changes into our lives. It has significantly changed our lifestyles, which is why many people can see it as a challenge to their mental and physical health. In our research, we were investigating the experiences of hygiene requirements among older persons during the COVID-19 epidemic. Methods: The study was based on a quantitative methodology. A questionnaire was used to carry out a survey. It contained socio - demographic data, data on behaviour in trade during COVID-19 epidemic, data on food handling during COVID-19 epidemic, data on hygiene during COVID-19 epidemic and data about overcoming disease COVID-19. We invited 80 older persons aged 65 or above. Results: Of all the invited older persons, 6 did not respond to the survey. There were 74 respondents, of which we excluded 16 surveys that were not fully completed. There were 58 respondents included in the study, of which $19(32,8 \%)$ men and $39(67,2 \%)$ women. The results showed that behaviour in store during COVID-19 epidemic has changed for $91 \%$ older persons. Respondents observed changes in wearing masks, keeping social distancing, hand disinfection, and infrequent visits to stores. Most respondents ( $78 \%$ ) go to the grocery store less often than before the COVID-19 epidemic, due to risk of infection. In stores, $98 \%$ respondents touch only those foods that they intend to buy, as they are afraid of infection and virus transmission. One-third of respondents do not carry a shopping bag into the kitchen and more than one-third (32 $\%$ ) of all respondents disinfect it, because in this way, they believe that they protect themselves from COVID-19 infection. We have also found that hand hygiene was improved. Due to the fear of infection, $86 \%$ of respondents wash and disinfect their hands more frequently. Almost all respondents ( $97 \%$ ) bought hand sanitiser during the epidemic. Of all respondents, 17 people overcame COVID-19 infection. We were not
\end{abstract}


able to detect a connection between more severe cases of the disease and changed attitudes towards hygiene measures. Discussion and conclusions: The results have shown that older persons are afraid of COVID-19 infection. The fear has an impact on food handling in stores as well as on food preparation at home. Fear of COVID-19 infection is also reflected in improved hand hygiene. People need clear information and directions regarding the handling of food during epidemic, and above all, a way of communication that empowers and reassures people.

Keywords: health, older persons, hygiene requirements, COVID-19 epidemic

\section{Introduction}

SARS-CoV-2 causes an infectious coronavirus disease called 'COVID-19'. The disease occurs in humans in different ways. In $80 \%$ of patients, it has a mild \& course with symptoms such as fever, cough, sore throat, cold, malaise, headache, muscle and joint pain, loss of taste and smell, and digestive problems. In $20 \%$ of patients, the disease is more severe, and $5 \%$ of patients become critically ill and need treatment in the intensive care unit (ICU) (NIJZ, 2020). Infectious disease is transmitted through direct and indirect contact. Directly, it can be transmitted through droplets, that are formed during speaking, coughing, or sneezing. Indirectly, it can be transmitted through touching contaminated surfaces or objects and then touching the eyes, nose, or mouth before cleaning hands (Girum et al., 2020).

The risk of hospitalization or death from COVID-19 infection is greater in the older persons. The older persons are a more vulnerable population as their immune systems weaken over the years, making them more susceptible to infections (NIJZ, 2012). The number of deaths increases with age. In Slovenia, the quantity of people over the age of 65 has doubled since 1981 and amounted to $20.2 \%$ by 2020 (Eurydice, 2021).

The youngest deaths per 100,000 population in Slovenia until 9.3.2021, were recorded in the age group 35-44 years $(n=4)$, followed by the age group $45-54$ years $(n=8)$, and $55-64$ years $(n=32)$. Greater deviation is observed in the age groups $65-74$ years $(n=162), 75-84$ years $(n=695)$ and 85 or older $(n$ = 2826) (Alpaka, 2021). The Center for Disease Control and Prevention (2020) in United States of America estimated that 8 out of 10 reported deaths in 2020 were among persons aged 65 and over. Older persons represent $80 \%$ of all hospitalizations that were caused by COVID-19 (Mueller et al., 2020). The older persons may represent a special group of high-risk patients for the development of COVID-19 with rapidly progressing clinical deterioration. It is more likely that the disease will cause life-threatening respiratory failure and multisystem involvement (Perrotta et al., 2020).

High levels of infection, asymptomatic cases, and uncertainty are the characteristics of infectious diseases, that make these types of disease induce 
more fear among older persons than other diseases. Due to its rapid transmission and unexpected deaths, fear of COVID-19 can become exacerbated (Koçak et al., 2021). Fear of COVID-19 has a major impact on anxiety, depression, and stress; infecting family members or friends can deepen this fear (Koçak et al., 2021).

The COVID-19 epidemic has changed the daily routines of the older persons, their care, and their abilities to remain socially connected. This has triggered new challenges, including anxiety and fear of infection (WHO, 2021), therefore, the purpose of our research was to gain insight into the experience of hygiene requirements during the COVID-19 epidemic among older persons.

\section{Methods}

The main aim of the current research was to discover whether and in what way the behaviour of older persons has changed during the COVID-19 epidemic. We were interested in how the older persons experience the COVID-19 epidemic, and if they are feared of the infectious disease COVID-19. The survey only includes people over the age of 65 . The survey was conducted using a questionnaire, that was to be completed in the respondents' homes. The questionnaire was divided to 4 parts. In the first part, questions focus on the behaviour of older persons in trades during the COVID-19 epidemic. The second part of the questionnaire collects data about food handling during the COVID-19 epidemic, third part includes data on the hygiene of older persons during the COVID-19 epidemic, and the last, fourth part, includes data about overcoming COVID-19 disease and demographic data.

Most questions were of the combined type, followed by closed-ended questions using the yes/no dichotomy (with an added subquestion for clarification), open-ended questions and one question with a measurement scale. Respondents answered the questions after receiving detailed instructions.

\section{Results}

Only persons over 65 years of age were included in the survey. 74 questionnaires were completed, of which 58 were valid. The survey included $66 \%$ women and $34 \%$ men (Table 1 ).

Table 1: Respondents'age

\begin{tabular}{lccccc} 
& \multicolumn{7}{c}{ Respondents' age } \\
Women & $65-70(n)$ & $70-74(n)$ & $75-80(n)$ & 80 or over $(n)$ & Total $(n)$ \\
\hline Men & 12 & 9 & 10 & 7 & 38 \\
\hline Women and men & 5 & 6 & 7 & 2 & 20 \\
\hline
\end{tabular}


The questionnaire gave us an insight into the changed behaviour of older persons as the result of experiencing hygiene requirements during the COVID-19 epidemic. The COVID-19 epidemic changed the behaviour of $91 \%$ of older persons. Respondents observed changes mainly in wearing masks, maintaining social distancing, disinfecting their hands, and visiting stores less frequently. Of the older persons who experienced altered behaviour, $85 \%$ of respondents reported going to the grocery store less often than before the COVID-19 epidemic, due to an increased risk of infection. To avoid more frequent visits to the grocery stores, they buy larger quantities of products, or their relatives make a purchase for of them instead. In stores, $98 \%$ respondents touch only those foods that they intend to buy, as they are afraid of infection and virus transmission. The majority ( $91 \%$ ) of respondents believe that it is easier to keep their distance from other people (in the grocery store) with the wheeled shop\& $\quad$ ping trolley, than the shopping cart.

Table 2 shows the results of the extent to which respondents agree with the claims that COVID-19 infection is transmitted through food or through its packaging, using the Likert rating scale (1 - I do not agree at all, 5 - I totally agree). The results show that majority of respondents are of the opinion that COVID-19 infection spreads with food packaging, but not with the food.

Table 2: Evaluation of COVID-19 disease transmission claims

\begin{tabular}{lccccc} 
& $\begin{array}{c}1-\text { I do not } \\
\text { agree at all } \\
(n)\end{array}$ & $\begin{array}{c}2 \\
(n)\end{array}$ & $\begin{array}{c}3 \\
(n)\end{array}$ & $\begin{array}{c}4 \\
(n)\end{array}$ & $\begin{array}{c}5 \text { - I totally } \\
\text { agree } \\
(n)\end{array}$ \\
$\begin{array}{l}\text { COVID-19 spreads } \\
\text { with food packaging }\end{array}$ & 7 & 3 & 26 & 8 & 14 \\
\hline $\begin{array}{l}\text { COVID-19 spreads } \\
\text { with food }\end{array}$ & 17 & 11 & 19 & 5 & 6 \\
\hline
\end{tabular}

Legend: $n$ - number of respondents

One-third of respondents do not carry a shopping bag into the kitchen and more than one-third ( $32 \%)$ of all respondents disinfect it, because in this way, they believe that they protect themselves from COVID-19 infection.

We were interested in how and in what proportion of older persons' hand hygiene changed (Table 3). We observed a significant interaction between fear of infection and increased hand hygiene. Older persons are aware of the importance of hand hygiene in preventing the disease, but still, more than one-third of respondents $(38 \%)$ are not taught about the correct order of hand washing and disinfection. 


\begin{tabular}{lcc} 
& $\begin{array}{c}Y E S \\
(n)\end{array}$ & $\begin{array}{c}\text { NO } \\
(n)\end{array}$ \\
$\begin{array}{l}\text { Do you wash your hands more often than before } \\
\text { the COVID-19 epidemic? }\end{array}$ & 50 & 8 \\
\hline $\begin{array}{l}\text { Do you disinfect your hands more often than before } \\
\text { the COVID-19 epidemic? }\end{array}$ & 49 & $\mathbf{8}$ \\
\hline $\begin{array}{l}\text { Did you disinfect your hands before the COVID-19 } \\
\text { epidemic? }\end{array}$ & 56 & 2 \\
\hline $\begin{array}{l}\text { Did you buy a hand sanitizer during the COVID-19 } \\
\text { epidemic? }\end{array}$ & 56 & 2 \\
\hline
\end{tabular}

Legend: $n$-number of respondents

Of all respondents, $94 \%$ of older persons wash their hands more often than before the epidemic, as this makes them feel safer. The majority (94\%) have a common fear of infection with the COVID-19. They believe that by washing their hands, they prevent the possibility of the infection spreading. Fear of infection is the main reason that $86 \%$ of older persons disinfect their hands more often than before epidemic. Before the COVID-19 epidemic, $79 \%$ respondents did not disinfect their hands, the rest of respondents disinfect them after seeing a doctor to prevent infections. Almost all respondents (96\%) bought a hand sanitizer to prevent infection with the infectious disease COVID-19.

\section{Discussion}

With our research, we assess the experiences of hygiene requirements among older persons. As we expected, older persons were found to have changed their lifestyles in terms of hygiene measures during the epidemic. They do not socialize, they are lonely, they leave their homes less often, and they feel afraid of being infected with the infectious COVID-19. Measures, such as social distancing, are necessary to reduce the spread of the virus that causes the infectious COVID-19, but at the same time, those measures have a strong impact on the psychological state of older persons, who may feel lonely and feel the fear of getting the disease. Fear of illness, of virus transmission or fear of death as the consequence of COVID-19 disease, can be caused by a variety of psychological states such as depression, anxiety, and stress (Koçak et al., 2021).

Most older persons are afraid of contracting the disease while shopping, so they go to the grocery stores less often and they touch only the products which they intend to buy. The findings of the study showed that COVID-19 epidemic caused fear of contracting the disease among older persons. Most respondents agree that the infectious COVID-19 is transmitted through food packaging. In order for the older persons to buy products safely, National Institute of Public Health NIJZ (2020) recommends cautious behaviour in the grocery store. They recommended wearing masks, keeping social distancing, grocery shopping with 
a shopping list (enabling faster product choice decisions), disinfection of hands on entering and leaving the store, not touching unnecessary products, paying with a pay card, and not touching the face without washing hands.

In China, SARS-CoV-2 was found in early July 2020 on imported food products. It was detected on frozen foods, including their packaging materials. Han and co-researchers (2021) assumed that there is a risk of SARS-CoV-2 transmission between countries and regions. Despite evidence of transmission of the virus through food, there is no evidence that humans become infected by ingesting the virus through food or drink (Food Standards Australia New Zealand, 2021). Food packaging may be contaminated, but that does not pose a particular risk of transmitting the infection. Currently, there is no reliable evidence of virus transmission in contact with contaminated objects (German Federal Institute for Risk Assessment , 2021). So far, there is no more precise data on how long the virus survives or remains on surfaces. Studies show that ¿ it can take hours or weeks, depending on the type of surface, temperature and humidity of the environment (Food Standards Australia New Zealand, 2021). The World Health Organization (2021) states that the virus needs a living host (human or animal) to survive, and that it cannot reproduce on food packaging. They state that food packaging does not need to be disinfected, but recommend washing hands after handling the packaging.

The important interaction between fear of infection and increased hand hygiene is reflected in more frequent hand washing and disinfecting than before the COVID-19 epidemic. Hand hygiene is important in preventing the spread of infectious diseases (Gammon et al., 2020). Various campaigns around the world (e.g. national campaigns COVID-19 - nalezimo se dobrih navad (COVID 19 - Infect yourself with good habits), Higiena rok za vse (Hand hygiene for everyone), and international campaigns Clean your Hands, Seconds save lives clean your hands) in the field of public health have placed the greatest emphasis on hand hygiene practices such as washing and disinfection. Despite informing the public, the target group of respondents is still not entirely sure about the correct order of hand washing and disinfection. After washing hands and before disinfectng them, the drying phase of hands is also important, as in this way we prevent the resistance of microorganisms to alcohol.

There is no such research in Slovenia yet, so it would be sensible to modify it with a larger sample of respondents. The study has some limitations, as the infectious disease COVID-19 has not yet been fully investigated. However, the research is certainly a good basis for further research and a better understanding of the experiences of hygiene requirements among older persons during the COVID-19 epidemic

\section{Conclusion}

The COVID-19 epidemic is a huge challenge for humanity, because it has changed the lifestyles of many older persons. The results of the research show 
that older persons are afraid of infection with infectious disease COVID-19, which affects their changed way of handling food in stores and at home. Fear of infection with COVID-19 is reflected in more often washing and disinfecting hands. On one hand, measures such as social distancing prevent the spread of infectious disease, but on the other hand, can cause psychological distress to older persons. People need clear information and directions regarding the handling of food during epidemic, and above all, a way of communication that empowers and reassures them.

\section{References}

ALPAKA PROJEKT. 2021. Analiza podatkov in vizualizacija širjenja COVID-19 v Sloveniji. Covid19.alpalaka.si. [online]. [viewed: 9. March 2021]. Available from: https://covid19.alpaka.si/.

ASSESSMENT, GERMAN FEDERAL INSTITUTE FOR RISK. 2021. Can the new type of coronavirus be transmitted via food and objects? BfR. [online]. [viewed: 10. March 2021]. Available from: https://www.bfr.bund.de/ $\mathrm{cm} / 349$ /can-the-new-type-of-coronavirus-be-transmitted-via-food-andobjects.pdf.

EURYDICE. 2021. Prebivalstvo: demografsko stanje, jeziki in veroizpovedi. European Commission. [online]. [viewed: 10. March 2021]. Available from: https://eacea.ec.europa.eu/national-policies/eurydice/content/population-demographic-situation-languages-and-religions-77_sl.

FOOD STANDARDS AUSTRALIA NEW ZEALAND. 2021. Transmission of COVID-19 by food and food packaging. [online]. [viewed: 10. March 2021]. Available from: https://www.foodstandards.gov.au/consumer/safety/Pages/Can-COVID-19-be-transmitted-by-food-or-food-packaging.aspx.

GAMMON, J and HUNT, J. 2020. COVID-19 and hand hygiene: the vital importance of hand drying. NIH National Library of Medicine National Center for Biotechnology Information PubMed.gov. [online]. [viewed: 24. June 2021]. Available from: https://pubmed.ncbi.nlm.nih.gov/32972218/.

GIRUM, T., LENTIRO, K., GEREMEW, M., MIGORA, B. and SHEWAMARE, S. 2020. Global strategies and effectiveness for COVID-19 prevention through contact tracing, screening, quarantine, and isolation: a systematic review. BMC Part of Springer Nature, Tropical Medicine and Health. [online]. [viewed: 10. March 2021]. Available from: https://tropmedhealth.biomedcentral.com/articles/10.1186/s41182-020-00285-W.

HAN, J., ZHANG, X., HE,S. and JIA,P. 2020. Can the coronavirus disease be transmitted from food? A review of evidence, risks, policies and knowledge gaps. SpringerLink. [online]. [viewed: 10. March 2021], Available from: https://link.springer.com/article/10.1007/s10311-020-01101-X.

KOÇAK , O., KOÇAK , Ö. E. and YOUNIS, M. 2021. . The Psychological Consequences of COVID-19 Fear and the Moderator Effects of Individuals' 
Underlying Illness and Witnessing Infected Friends and Family. PMC US National Library od Medicine. [online]. [viewed: 24. June 2021]. Available from: https://www.ncbi.nlm.nih.gov/pmc/articles/PMC7917729/.

MUELLER, A.L., MCNAMARA, M.S. and SINCLAIR, D. 2020. Why does COVID-19 disproportionately affect older people? PMC US National Library of Medicine National Institutes of Health. [online]. [viewed: 9. March 2021]. Available from: https://www.ncbi.nlm.nih.gov/pmc/articles/PMC7288963/.

NIJZ. 2020. Koronavirus - pogosta vprašanja in odgovori. Z znanjem do boljšega zdravja. [online]. [viewed: 15.March 2021]. Available from: https:// www.nijz.si/sl/koronavirus-pogosta-vprasanja-in-odgovori\#kako-poteka-bolezen\%2C-kaksni-so-simptomi-in-znaki\%3F.

NIJZ. 2020. Priporočila za starejše v času epidemije nove virusne bolezni COVID-19. Nacionalni inštitut javnega zdravja. [online]. [viewed: 10. March 2021]. Available from: https://www.nijz.si/sites/www.nijz.si/files/uploaded/priporocila_za_starejse_v_casu_epidemije_nove_virusne_bolezni_ covid19.pdf.

NIJZ. 2012. Varnost živil v prehrani nosečnic, otrok in starostnikov. Z znanjem do boljšega zdravja. [online]. [viewed: 15. April 2021]. Available from: https://www.nijz.si/sl/varnost-zivil-v-prehrani-nosecnic-otrok-in-starostnikov.

PERROTTA, F., CORBI G., MAZZEO G., BOCCIA M., ARONNE L., D‘AGNANO V., KOMICI K., MAZZARELLA G., PARRELLA R. and BIANCO A. 2020. COVID-19 and the elderly: insights into pathogenesis and clinical decision-making. SpringerLink. [online]. [viewed: 15. April 2021]. Available from: https://link.springer.com/article/10.1007/s40520-02001631-y.

CENTER FOR DISEASE, CONTROL AND PREVENTION. 2020. Older adults At greater risk of requiring hospitalization or dying if diagnosed with COVID-19. Older Adults. [online]. [viewed: 9. March 2021]. Available from: https://www.cdc.gov/coronavirus/2019-ncov/need-extra-precautions/older-adults.html .

WHO. 2021. Coronavirus (COVID-19) Dashboard. World Health Organization. [online]. [viewed: 10. March 2021]. Available from: https://covid19.who.int/?gclid=CjwKCAiAu8SABh AxEiwAsodSZCmNYHOZtMC_W_6WZuNpvQb-7-6QiuJUA3PCY9oatdTH99LLB2ZnphoCOmIQAvD_Bw. 


\title{
Is the ICT use for health purposes in Slovenia linked to better health?
}

\author{
Andrej Kirbiš \\ University of Maribor, Faculty of Arts, Maribor, Slovenia \\ andrej.kirbis@um.si
}

\section{Abstract}

Introduction: In recent years, the use of ICT for health purposes has become increasingly common and popular among the residents of developed societies, including the elderly. The development of ICT in health and health care can contribute to disease prevention and control for those who need health information and services the most - the elderly and those with poor health. For this reason, it is vital to examine whether the search for information using ICT technology is associated with better health. Methods: In our study, we were interested in: 1) the frequency of searching for information with ICT; 2) the link between ICT seeking health information and health status; 3 ) the moderating role of age for the link between the frequency of searching for health information and the health status of the individual, and 4) whether the search for health information is related to the health status after controlling the sociodemographic determinants of ICT use. We used a representative national sample of the adult population of Slovenia from $2018(\mathrm{~N}=1047)$. We performed descriptive and multivariate analyses. Results: We found that in Slovenia, 1) the majority of the population uses ICT to obtain health information; 2) those with poorer health most often use ICT for health purposes; 3) age impacts the link between information seeking and health status; and 4) when controlled for sociodemographic determinants in the multivariate model, health status proved not to be statistically significantly associated with ICT use for health purposes. Discussion and conclusions: ICT can potentially improve the Slovenian population's health and access to health services. At the same time, we emphasise that better health can also enable easier and more efficient access, search and use of ICT health information. Further research is needed to examine whether there is a causal effect of ICT search and use of health information on health outcomes. It is also crucial that future studies examine whether the health effects are 
mainly for specific dimensions of health or whether they improve overall health status. The paper concludes with a discussion on the importance of ICT in health services and its importance for positive population health outcomes, especially for vulnerable groups. We also provide suggestions for achieving a more well-informed population concerning the opportunities offered by ICT in health promotion and disease prevention.

Keywords: health inequalities, eHealth, ICT use for health purposes, the elderly.

\section{Introduction}

The use of information and communication technology (ICT), including the Internet and smartphone apps, is becoming an important source of information related to health. The term electronic health ("E-health or eHealth) refers to measures to support health care through ICT (Rockmann and Gewald 2015: 505). In modern societies, eHealth services are increasingly becoming patient and consumer-oriented, enabling consumers to actively engage in their health and well-being by accessing health resources via the Internet (Rockmann and Gewald 2015). As early as 2009, for example, 61\% of adults in the United States used the Internet to access information about their illnesses and treatment options (Fox and Jones, 2009; in Rockmann and Gewald 2015: 510).

An analysis of the use of eHealth solutions in Slovenia (Rant and Stanimirović 2020) before the COVID-19 pandemic showed that between 2016 and 2019, the use of eHealth services increased. For example, the proportion of e-prescriptions and e-referrals in 2019 exceeded $90 \%$ of the total number of prescriptions and referrals. The share of e-referrals doubled during the period under review, from $45 \%$ to $94 \%$. The use of the zVEM web portal also increased during the same period.

Research on the use of ICT shows that many factors influence the search for health-related information. The frequency of information search varies, among other things, according to age and gender, but also health status, which is the main factor of interest in our study.

Besides other factors, it is vital to examine whether the use of ICT for health purposes is unequally distributed according to users' health status. From the point of view of equity in health services, one of the goals is equality of access and use of ICT for health purposes (regardless of individual's characteristics such as age, gender, socioeconomic status or health). However, evidence suggests that there are inequalities in access to health care services. For example, socially deprived groups have worse health and poorer access to health services (Riley 2012; Thomas 2017; Committee on Health Care Utilization and Adults with Disabilities 2018).

Research on ICT use similarly indicates a link between one's health and health-related ICT use. A survey of a sample of Norwegians aged 40 and over 
found that respondents who reported having a disease were more likely to use the Internet for health information (Wynn et al. 2020). In several other studies, poorer health has similarly been positively associated with the frequency of health-related use of the Internet. A U.S. survey of 21-year-olds and older found that those with two, three, or more chronic illnesses were more likely to use the Internet to seek health information (Wagner et al. 2004). Those with poorer subjective health also more frequently search for health information on the Internet (Baker et al. 2003). Similar findings were detected in a study of type 1 and type 2 diabetes; ICT use for health purposes was more common among those with poorer self-rated health (Hansen et al. 2019).

It needs to be noted that the results of the studies are not entirely consistent. In the aforementioned Norwegian study, for example, self-rated health did not prove to be statistically significantly related to the frequency of use of eHealth services (Wynn et al. 2020). In a study of seven European countries, Andreassen and colleagues (2007) found that respondents with poorer subjective health reported less frequent health-related Internet use. On the other hand, those with long-term chronic illness or disability reported more frequent health-related Internet use.

Research in some countries indicates that individuals with poorer health use the Internet for health purposes more frequently than their healthier counterparts. We examine whether this also holds in Slovenia. We also analysed the potential moderating role of age for the relationship between the frequency of seeking health information and an individual's subjective health status.

\section{Methods}

In the present study, we examined the frequency of searching for health-related information online and in smartphone apps. We compared three age groups: young people (18-34 years), adults (35-64 years) and the elderly (aged 65 and over).

We analysed a representative sample of the population of Slovenia using the Slovenian Public Opinion survey (Hafner Fink et al. 2019). Survey data were collected between 14 March 2018 and 12 June 2018. The sample included individuals over 18 living in private households, regardless of their nationality, citizenship, language or legal status in Slovenia. We performed bivariate analyses with chi-square tests and multivariate analysis.

The following dependent variable was examined: "How often did you search for health-related information online or in apps?" ( $1=$ never; 2 = less than once a month; $3=$ at least once a month; $4=$ at least once a week; $5=\mathrm{ev}$ ery day; $6=$ almost every day several times a day). Due to the uneven distribution of answers, values from 4 to 6 were recoded into a single category (at least once a week).

We included several control variables in our multivariate model. Specifically, we included age, gender, and partner status. Respondents' age in years 
was recoded into three age categories (18-34 years, 35-64 years, and 65 years and older). In addition to gender ( $1=$ male; $2=$ female), partner status was also added in our model, which was measured with the question: "Are you married or do you have a permanent partner? Do you share a joint household?" (1= yes, I live in a joint household with my spouse or permanent partner; $2=\mathrm{I}$ am married or have a permanent partner, but we do not live in a joint household; 3 $=$ no, I am not married, I do not have a permanent partner). Values were recoded into two categories $(1=$ respondent has a permanent partner; $2=$ respondent has no permanent partner).

Finally, we were interested in whether the subjective health status of respondents was related to the frequency of use of health information online or in applications. We measured health with a standard self-rated health indicator: "Would you say your health in general, is ...? ( $1=$ poor; $2=$ satisfactory; $3=$ good; 4 = very good; $5=$ excellent). Values were recoded into three groups $(1=$ poor/satisfactory; 2 = good; 3 = very good/excellent).

\section{Results}

Figure 1 shows the frequency of searching for health information online or in applications by the Slovenian public. In 2018 , more than $14 \%$ of Slovenians never searched for health information online or in applications. The largest proportion of respondents $(33.7 \%)$ searched for information at least once a month. The second largest group reported weekly or more frequent searches for information, followed by searching for information less than once a month (each of the two answers was chosen by about one in four respondents).

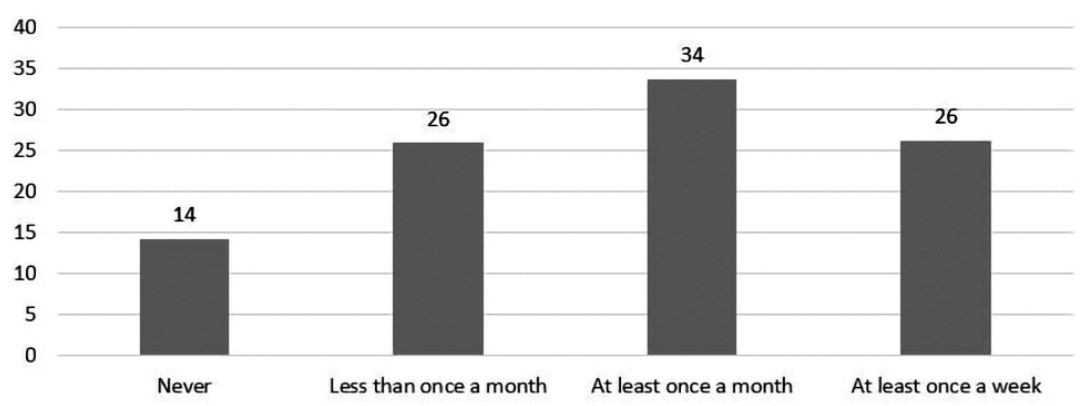

\section{Figure 1: Frequency of searching for health information online or applications among the Slovenians population Source: Slovenian Public Opinion 2018/1 (Hafner Fink et al. 2019).}

Figure 2 shows the frequency of information search by age group. We see that the proportion of those who never use the Internet/apps to search for health information increases with age. While this share is the lowest in the youngest age group (10.5\%), it increases to $13.4 \%$ in the adult group, with the highest proportion of non-users being among the elderly, with more than twice 
as many non-users (26.5\%) as among young people. At the same time, the categories of the most frequent information seekers are very comparable by size between age groups; the youngest age group has the largest proportion of most frequent users (27.9\%), followed by the oldest age group (26.5\%) and the middle-age group (25.4\%). The chi-square test showed that differences between age groups in the frequency of health-related information search were statistically significant $(\mathrm{p}<0.05)$.

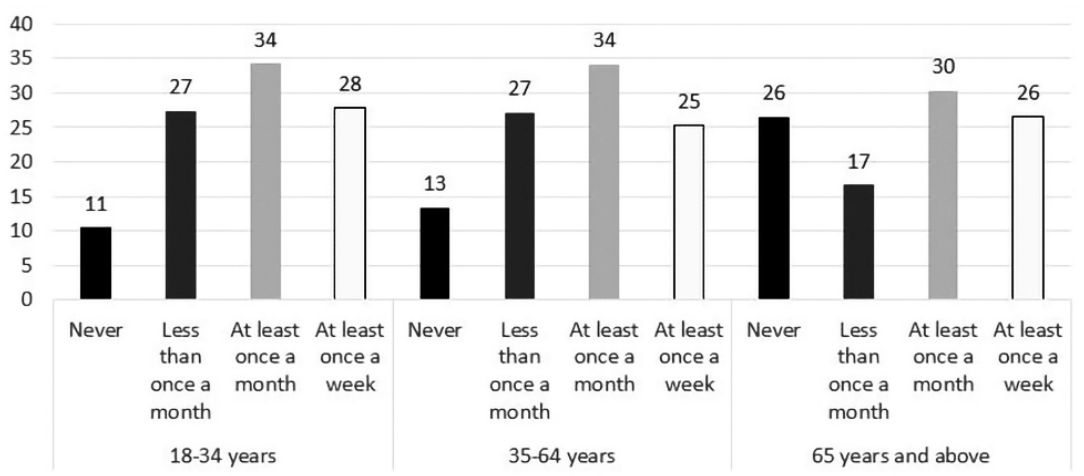

Figure 2: Frequency of searching for information by age group

Source: Slovenian Public Opinion 2018/1 (Hafner Fink et al. 2019).

Figure 3 shows the frequency of information search according to the respondents' self-rated health. The results show that the proportion of those who never use the Internet/apps to search for health information decreases with better health, indicating that among the healthiest respondents, there is the smallest proportion of non-users. On the other hand, the proportion of the most frequent searchers (who search for information at least weekly) is among the least healthy group (30.5\%), and the lowest proportion of frequent searchers is in the two remaining groups (around 1 in 4 in each group). The chi-square test showed that differences between health groups were statistically significant $(\mathrm{p}<0.05)$.

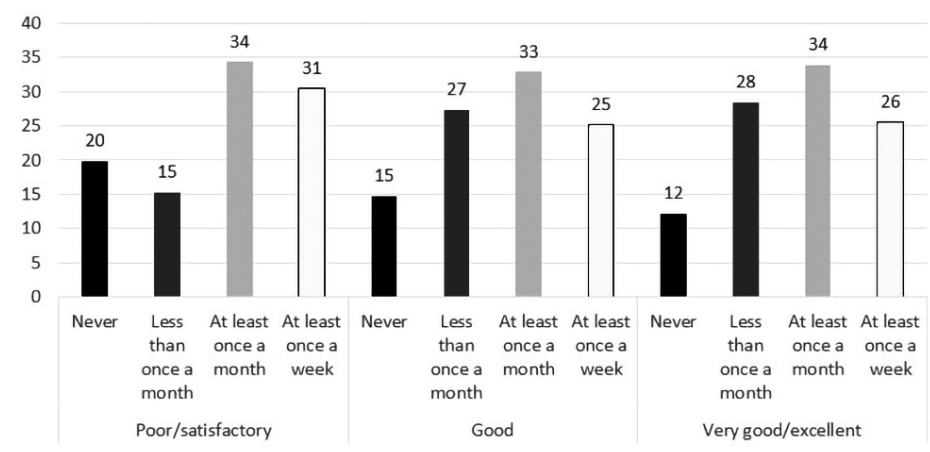

Figure 3: Frequency of searching for information by self-rated health status Source: Slovenian Public Opinion 2018/1 (Hafner Fink et al. 2019). 
Figure 4 shows the moderating role of age for the relationship between the frequency of health-related search and an individual's health status. The results show that in the youngest and oldest age group, the search for health information is associated with better health (see positive coefficients in Figure 4) and in the middle age group with poorer health. We note that none of the associations reached the level of statistical significance ( $p>0.05)$.

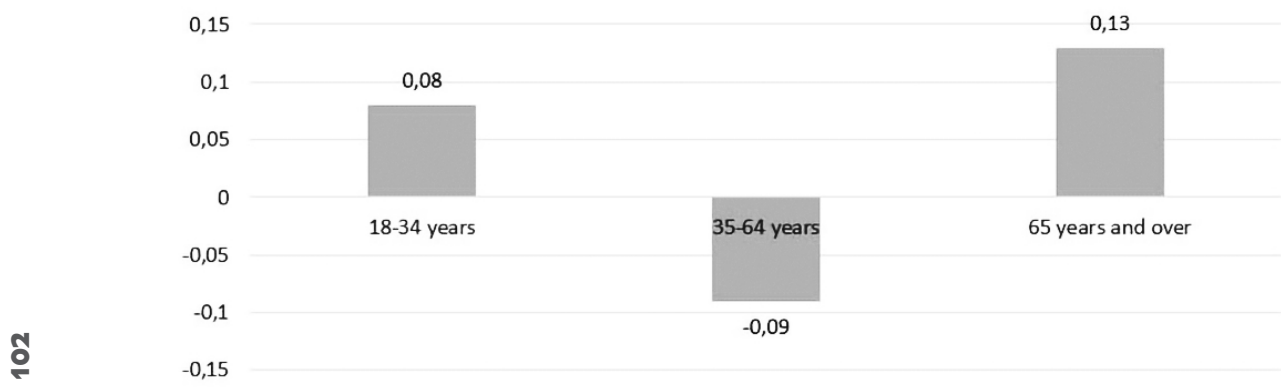

\begin{abstract}
Figure 4: Moderating role of age for the relationship between the frequency of searching for health information and the self-rated health Source: Slovenian Public Opinion 2018/1 (Hafner Fink et al. 2019). Note: Data indicates coefficient between health information search and self-rated health.
\end{abstract}

We also performed a regression analysis predicting the frequency of health-related information searches while controlling for the demographic variables. We were interested in whether better health was associated with more frequent search for health information when controlling for other variables. The analysis showed that of the four variables included in our model, the only statistically significant predictor of more frequent health information search was female gender $(\beta=0.09 ; \mathrm{p}<0.05)$. The other three predictors did not prove statistically significant, including self-rated health.

\title{
Discussion
}

Based on our study, we can summarize that there are differences in the frequency of searches for health information online and on apps by some determinants in Slovenia. Three out of five people search for health information online or apps at least monthly, and just under $15 \%$ of the population are non-seekers. Information is more often searched for by the elderly (but their group also has the largest proportion of non-seekers), women and those with poorer health (the largest proportion of non-seekers is also among them). We also find that age moderates the relationship between the frequency of health information seeking and the health status of the individual. In the youngest and oldest age groups, the search for health information is associated with better health (though statistically insignificantly). Multivariate analysis of the factors pre- 
dicting information search revealed that the female gender was the only significant predictor impacting the frequency of health information search.

Based on our results research, we can conclude that it is important to raise awareness of decision-makers and the public about the importance of access to the Internet, about the resources needed to search for health-related information online or via apps and to inform decision-makers on demographic and other factors contributing to inequalities in ICT use for health purposes. It is also necessary to be aware that ICT use can contribute to improving the health of the Slovenian population and access to health services. On the other hand, better health can also help (enable) an individual to more easily access and efficiently use ICT for health information proposes. In any case, future research is needed to examine the causal effect of ICT use and the use of health information on personal and public health. At the same time, researchers should examine whether the (potential) positive effects hold mainly for particular dimensions of health (e.g., physical symptoms, mental health) or overall health.

Strengthening intergenerational cooperation, e.g. through various programs, where young people would share their ICT knowledge with the elderly, while the latter could share their life experiences and knowledge with young people, could also encourage improvements in the health of both age groups.

\section{Conclusions}

We can conclude that the development and use of ICT in health information and healthcare services has played an important role in healthcare in recent years. Evidence suggests it may contribute to better health, including for more vulnerable groups. Proposals for strengthening the access to information with the possibilities and potential offered by ICT in the area of health promotion include informing the public in various popular media outlets, but also by personal physicians and other health professionals, for example, by health workers in reference clinics. In this way, older and other more vulnerable groups could be informed in more detail about how the use of ICT can improve their access to healthcare services and help maintain and enhance patients' health, and potentially even prevent disease.

\section{References}

ANDREASSEN, H. K., BUJNOWSKA-FEDAK, M. M., CHRONAKI, C. E., DUMITRU, R. C., PUDULE, I., SANTANA, S., VOSS, H., \& WYNN, R. (2007). European citizens' use of e-health services: A study of seven countries. BMC Public Health, 7(1), 53. https://doi.org/10.1186/1471-2458-7-53

BAKER, L., WAGNER, T. H., SINGER, S., \& BUNDORF, M. K. (2003). Use of the internet and e-mail for health care information: Results from a national survey. JAMA, 289(18), 2400-2406. https://doi.org/10.1001/jama.289.18.2400 
COMMITTEE ON HEALTH CARE UTILIZATION AND ADULTS WITH DISABILITIES. (2018). Health-care utilization as a proxy in disability determination. Consensus study report. The National Academies Press. https://doi.org/10.17226/24969

HAFNER FINK, M., HOČEVAR, M., GROŠELJ, D., URŠIČ, M., ZAVRATNIK, S., \& MEDVED, P. (2019). Slovensko javno mnenje 2018/1. https:// doi.org/10.17898/ADP_SJM181_V1

HANSEN, A. H., BRADWAY, M., BROZ, J., CLAUDI, T., HENRIKSEN, Ø., WANGBERG, S. C., \& ÅRSAND, E. (2019). Inequalities in the use of ehealth between socioeconomic groups among patients with type 1 and type 2 diabetes: Cross-sectional study. Journal of Medical Internet Research, 21(5), e13615. https://doi.org/10.2196/13615

RANT, Ž., \& STANIMIROVIĆ, D. (2020). Analiza uporabe rešitev ezdravja v sloveniji: Izzivi in prihodnje usmeritve. In 39th international conference on organizational science development (pp. 645-661). University of Maribor Press. https://doi.org/10.1869o/978-961-286-388-3.51

RILEY, W. (2012). Health disparities: Gaps in access, quality and affordability of medical care. Transactions of the American Clinical and Climatological Association, 123, 167-174.

ROCKMANN, R., \& GEWALD, H. (2015). Elderly people in ehealth: Who are they? Procedia Computer Science, 63, 505-510. https://doi.org/10.1016/j. procs.2015.08.376

THOMAS, L. (2017). Poor health: Poverty and scarce resources in U.S. Cities. Pittsburgh Post-Gazette. https://newsinteractive.post-gazette.com/longform/stories/poorhealth/1/

WAGNER, TODD, BAKER, LAURENCE, C., BUNDORF, KATE, \& SINGER, S. (2004). Use of the internet for health information by the chronically ill. Preventing Chronic Disease, 1.

WYNN, R., OYEYEMI, S. O., BUDRIONIS, A., MARCO-RUIZ, L., YIGZAW, K. Y., \& BELLIKA, J. G. (2020). Electronic health use in a representative sample of 18,497 respondents in Norway (the seventh TROMS $\varnothing$ study part 1): Population-based questionnaire study. JMIR Medical Informatics, 8(3), e13106. https://doi.org/10.2196/13106 


\title{
Apps that help the elderly with dementia
}

\author{
Adriana Kozina, Valentina Rok, Andrej Starc \\ University of Ljubljana, Faculty of Health Sciences, Ljubljana, Slovenia. \\ E-mail:adri.kozina@gmail.com; ms.valentina.rok@gmail.com; andrej.starc@zf.uni-lj.si
}

\begin{abstract}
Introduction: In the year 2018, it was estimated that at the global level were 50 million patients diagnosed with dementia, and the cost of their treatment had risen to over one billion US dollars. With the growth of the elderly population, that number shall only grow higher in the future. Research shows that specific mobile apps on smart devices could be used to help patients with dementia. The usage could reduce the financial cost of this illness, also. On the other hand elderly people do not have sufficient knowledge of the apps, and dementia influences their cognitive functions. Methods: We used a descriptive method with critical analysis of English scientific literature, using databases Cochrane Library, Google Scholar, PubMed, ScienceDirect and Wiley Online Library. The keywords used were: apps for dementia, apps for elderly with dementia, apps for dementia prevention. Between the words was used the Boolean logical operator AND. We included the literature published between 2013 and 2020, which were free and fully accessible. Results: We detected 1140 articles after the inclusion of all criteria. Only 8 scientific papers met the inclusion criteria and were about apps for patients with dementia. In the smart mobile marketplace exist several mobile apps, which are used for: diagnosing people with dementia, prevention for developing dementia, enhancing cognitive functions and apps for helping patients with everyday activities. Most free and accessible apps do not cover all the specific needs of people diagnosed with dementia. We expect that soon, there shall be a rise in such mobile apps development. Discussion and conclusions: Based on the appropriate design and the technology, app's could be used for improvement of physical, mental and social aspects of persons diagnosed with dementia. Mobile apps used for preventive strengthening of cognitive functions or for control and slowing the progress of dementia have proved to be an adequate tool for quick and efficient assessment of dementia. The development of such
\end{abstract}


apps is requires inclusion of healthcare workers as well as technological scientists and patients. More research should be done concerning app efficiency and adjustments of their functions for the specific patients' needs.

Keywords: Apps for dementia, elderly with dementia, apps for elderly with dementia

\section{Introduction}

Dementia is a syndrome for which it is typical a progressive lessening of the cognitive and behavioural abilities and memory and aggravation of doing everyday activities, which usually afflicts the elderly. In 2018, there was an estimation that around the world, there were 50 million people with dementia and treatment costs were a billion American dollars; however, the number of afflicted will increase till the year 2050 for a third (ADI - Alzheimer's Disease International, 2018). Research shows that specific mobile apps, meant for people with dementia and their caretakers, could lower their physical and psychological burden. At the same time, they could also reduce the costs to the Healthcare systems, higher the chances of the patients' independence and acceptance of their chronic disease while also slower its' development (Klimova, 2017). On the market, we can find a variety of apps. They can work preventively, meaning that they can serve as a diagnostic tool or quicker detection of developing dementia (Klimova, 2017).

On the other hand, apps can also work as a helping tool, making patients' lives more manageable and help them to cope in their everyday life (Klimova, 2017). Mobile apps could be beneficial at controlling dementia in five areas. Firstly, on detection and assessment of dementia disease, secondly at cognitive training of people with this diagnosis, thirdly for the evaluation of health and safety of people with dementia, fourthly in socialisation and relaxation and fifthly in long-distance health assessment of patients by a health professional (Yousaf et al., 2019)

It is necessary to know the limitation of usage of apps by the elderly since they are known to have limited knowledge of using technology, and dementia is known to cause further cognitive decline. Consequently, the usage of apps must be adjusted to the users - they need to be simple to use and calculate their needs and disadvantages. It is essential to add that all apps are not made by experts and are, therefore not adequate for use (Choi, 2020).

\section{Methods}

In this research it was used the descriptive method with critical appraisal of English scientific literature with the assistance of the diKUL portal (Digital library of University of Ljubljana). We used next keywords with Boolean logical operator AND: Apps for dementia, elderly with dementia, apps for elderly with dementia. The included literature needed to correspond with the following requirements: published between the years 2013 and 2021, the paper required to 
be recessed, be in full text, had open access and be written in either English or Slovenian language. On Figure 1 it is shown the process of selecting suitable articles.

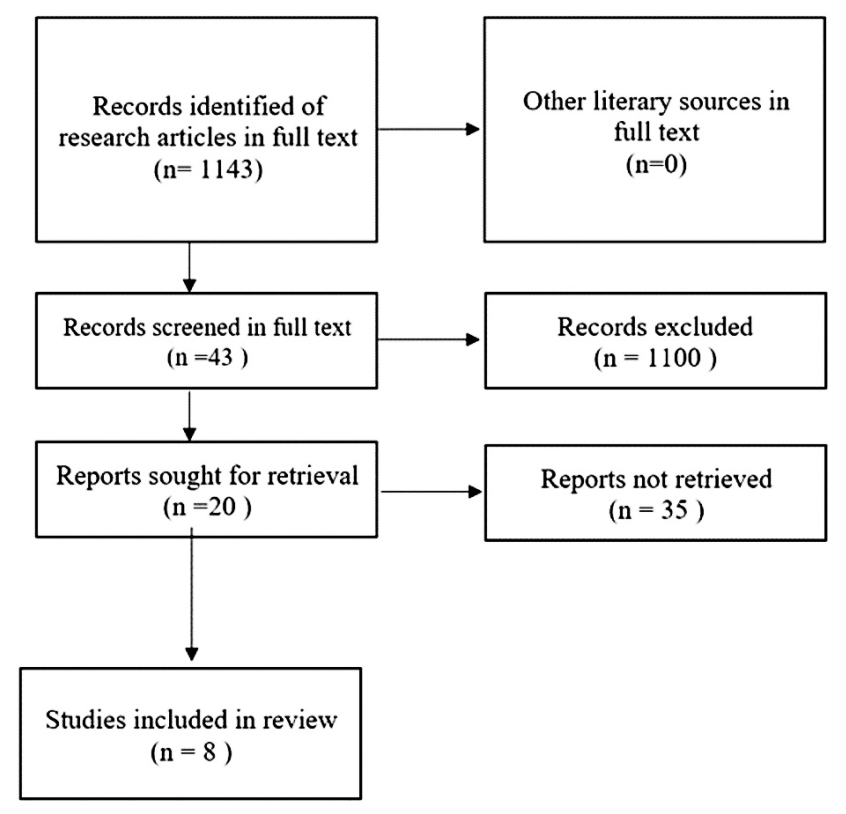

Figure 1: PRISMA diagram

\section{Results}

In Table 1, there are descriptive results of the studies that were included in this research. What we found noteworthy is the similarity between the results of these eight studies.

\section{Table 1: Results of literature review}

\section{Authors} ical applications in the field of

Identify key areas of technological develop-

Astell et al., 2019 ment in the field of dementia treatment and propose guidelines for future work
Overlook of recent research findings. dementia are:

a) diagnosis, assessment and monitoring,

b) maintenance of operation,

c) leisure and activities,

d) care and management. A holistic approach to the problem is needed. 
9 studies were included. Tech-

Review the findings of

Brown, O'Connor, 2020. recent qualitative studies to date on the use of mobile applications for peoQualitative literature overview. nology can improve some aspects of the physical, mental and social health of people with dementia. It can serve to promote cognitive functions and communication skills in people with dementia.

Applications differ from each other in quality and usability. $41.7 \%$ of the examined applications were not developed by healthcare professionals and were of lower quality information compared to the applica-

Overview and evaluation tions developed by healthcare of the features, content and technical aspects of 36 applications aimed at Google Play and the App store in the USA. Applications were coded and rated using a mobile app rating scale. plications for people with dementia. More than $50 \%$ of the
Review existing applications that contain information on Alzheimer's disease and other dementias and assess their usefulness professionals. This suggests the need for collaboration between healthcare professionals and IT professionals in developing apapplications were aimed at caregivers of people with dementia. Only one-third of the applications contain a reminder function for patients or caregivers. Applied with a proper design, applications can go a long way in making dementia management easier.

Currently, accessible apps do not cover all the complex needs of people with dementia and can be difficult for patients to use due to reduced abilities as a result of the disease. The authors emphasize that it would be necessary to develop properly designed, high-quality applications that could make it easier for patients to cope with the disease and help them to be more independent in managing the disease, while facilitating the work of their caregivers and families.

Studies have shown that mobile apps can be an excellent tool for quickly and accurately assessing dementia. They also reduce the psychological and financial burden on patients and their carers. More research should be done on the effectiveness of applications and, in collaboration with designers, their functions should be adapted to the specific needs of people with cognitive deficits. 
First study: The most frequent-

The first study identified important activities for people with dementia in the past and present, and the second study explored the needs, wants, and capabilities of us-

Kerkhof, 2017 ing mobile apps to help manage dementia. Findings could help to develop a tool to facilitate selecting suitable applications for the individual according to his abilities and needs. ly mentioned meaningful activity was 'being socially active'. Researchers have also found that an individual's activities before dementia carry essential information about important activities to the present. The most frequently mentioned needs for disease self-management by sufferers related to the support of memory functions. In another study, the authors detected some wishes of patients that had not previously been seen in the literature - minimal need to type to use applications, the ability to adjust the language, the ability to rotate the displayed image.

The first study implements a systematic and methodological approach in the development of a particular application. The created application has been well received by users and needs some updates and customisation of certain features.
A systematic approach to mobile application development.
The CAIDE Risk score app is the first app to predict the risk of dementia with the help of an evidence-based tool. It can be used by healthcare professionals in their work or by individuals suspected of having dementia. was developed based on the CAIDE Dementia

Risk scale. scale accessible to all users who want to determine whether they have dementia.

\section{Discussion}

Mobile apps have become quite accessible to users of mobile phones and tablets these days. The number of the latter is multiplying. Based on this, we can conclude that, as a result, new possibilities are opening up for reaching people with dementia and for preventive action in this area. Based on current studies, we can conclude that appropriately designed mobile apps can be an effective tool for dementia management (Klimova, 2017; Choi, 2020). The use of apps is possible in different areas. The researchers classified technological applications into four main groups, according to their purpose or content: apps that serve to facilitate the diagnosis, assessment and monitoring of patients, applications that support their operation, applications for activities and leisure and apps for care and disease management (Astell et al., 2021). The main positive effects of the applications identified by various researchers are reduction of the psychological and financial burden on patients and carers, the reduced financial burden of disease for the health system, rapid diagnosis and assessment of 
condition, assistance to patients and carers in everyday life, maintenance of social contacts and maintenance cognitive abilities - cognitive training (Klimova, 2017; Yousaf et al., 2020; Cindy et al., 2015; Rai et al., 2020a).

Due to the nature of the disease, applications must also be adapted accordingly. Studies have shown that many apps are not created in collaboration with health professionals and people with dementia. The latter announces questionable quality. Some do not have good information value, do not cover the specific needs of users, and do not take into account cognitive decline (Rai et al., 2020b; Klimova, 2017; Kerkhof et al., 2017).

There are many apps available to users, which differ in quality. Each also contains only certain content and functions, which may mean that patients would need an even more significant number of different apps to cover all their needs. To date, no apps have been developed that would be well-suited for people with dementia and would include all the necessary features and information. Researchers warn that adequately designed, high-quality apps should be developed to make it easier for patients to cope with the disease in the future. This will help them become more independent in managing the disease, while making it easier for their carers and family (Guo et al., 2020).

\section{Conclusion}

Research has shown that appropriately designed apps correlated with intelligent technology can be used as a preventive tool in dementia management and aid for people who already have a dementia. Currently, no quality apps have been developed that would be adapted to such people's complex needs. We believe that collaboration between healthcare professionals, technology professionals and patients is key to producing such apps. Further research should be done on the importance and effectiveness of apps, and their functions should be adapted to the specific needs of older people with cognitive deficits.

\section{References}

ALZHEIMER'S DISEASE INTERNATIONAL, 2018. World Alzheimer Report 2018 The state of the art of dementia research: New frontiers. London: Alzheimer's Disease International. Available at: https://www.alzint.org/ resource/world-alzheimer-report-2018/

ASTELL, A., BOURANIS, N., HOEY J et al., 2019. Technology and dementia. The future is now. Dementia and geriatric cognitive disorders, vol. 47, pp. 131-139. doi: 10.1159/000497800 .

BROWN, A. and O'CONNOR, S., 2020. Mobile health applications for people with dementia. A systematic review and synthesis of qualitative studies. Informatics for health and social care, vol. 45, no. 4, pp. 343-59. doi: 10.1080/17538157.2020.1728536 . 
CHOI, S.K., YELTON, B., EZEANYA, V.K., KANNALEY, K., FRIEDMAN, D.B., 2018. Review of the Content and Quality of Mobile Applications About Alzheimer's Disease and Related Dementias. Journal of applied gerontology, vol. 39, no.6, pp: 601-608. doi: 10.1177/0733464818790187.

GUO, Y., YANG, F., HU, F., LI, W., RUGGIANO, N., LEE, H.Y., 2020. Correction: Existing Mobile Phone Apps for Self-Care Management of People With Alzheimer Disease and Related Dementias: Systematic Analysis. Journal of medical internet research ageing, vol. 3, no. 1, e18754. doi: 10.2196/18754.

KERKHOF, Y., BERGSMA, A., GRAFF, M., DRÖES, R., 2017. Selecting apps for people with mild dementia: Identifying user requirements for apps enabling meaningful activities and self-management. Journal of rehabilitation and assistive technologies engineering, no. 4. doi: $10.1177 / 2055668317710593$.

KLIMOVA, B., 2017. Mobile phone apps in the management and assessment of mild cognitive impairment and/or mild-to-moderate dementia: An opinion article on recent findings. Frontiers in neuroscience, no. 11, pp: 461. doi: 10.3389/fnhum.2017.00461.

RAI, K.H., SCHNEIDER, J., ORRELL, M., 2020 a. An individual cognitive stimulation therapy app for people with dementia. Development and usability study of thinkability. Journal of medical internet research ageing, vol. 3, no. 2. doi: 10.2196/17105 .

RAI, K.H., CAVALCANTI BARROSO, A., YATES, L., SCHNEIDER, J., ORRELL, M. 2020 b. Involvement of People With Dementia in the Development of Technology-Based Interventions: Narrative Synthesis Review and Best Practice Guidelines. Journal of medical internet research, vol. 22, no. 12, e17531. doi: 10.2196/17531.

SINDI, S., et al., 2015. The CAIDE Dementia Risk Score App. The development of an evidence-based mobile application to predict the risk of dementia. Alzheimer's \& Dementia: diagnosis, assessment \& disease monitoring, no. 1, pp: 328-333. doi: 10.1016/j.dadm.2015.06.005.

YOUSAF, K., MEHMOOD, Z., SABA, T., REHMAN, A., MUNSHI, A., ALHARBEY, R., RASHID, M., 2019. Mobile-Health Applications for the Efficient Delivery of Health Care Facility to People with Dementia (PwD) and Support to Their Carers: A Survey. BioMed research international, vol. 2019, 1-27. doi: 10.1155/2019/7151475. 



\title{
Use of personal protective equipment during the COVID-19 epidemic in nursing homes - a students' perspective
}

\author{
Adriana Kozina', Jožica Čehovin Zajc², Marija Milavec Kapun \\ 'University of Ljubljana, Faculty of Health Sciences, Ljubljana, Slovenia \\ 2 University of Ljubljana, Faculty of Social Sciences, Ljubljana, Slovenia \\ E-mail: adri.kozina@gmail.com; jozica.cehovin-zaj@@fdv.uni-lj.si; marija.milavec@zf.uni-lj.si
}

\begin{abstract}
Introduction: Spreading of the new coronavirus among the community after spring 2020 considerably impacted the lives of residents and the work of staff in Slovenia's nursing homes. Infections were detected in $99 \%$ of all nursing homes, with their residents accounting for $58 \%$ of deaths due to COVID-19 in 2020. Even before the epidemic, nursing homes were understaffed - the epidemic exacerbated this problem (more work with strict protective measures and less staff due to illness). Those who were still working also faced a bigger workload following the introduction of many additional preventive measures. Consistent and proper use of personal protective equipment is vital for managing infections and keeping residents and staff healthy, which may prove challenging for them both. The use of personal protective equipment and implementation of measures to limit the spread of the virus also seriously constrains residents' ability to socialise. The aim of this paper is to explore the challenges and issues encountered by residents, staff and students in nursing homes while using personal protective equipment and implementing other measures to limit the spread of infection. Methods: In spring 2021, in-depth interviews were conducted with ten nursing and medical students who had worked or were working in nursing homes as part of 'Covid expeditions'. The interviews were transcribed and then coded using NVivo software. Content analysis was performed and key findings were supported with interviewee quotes. Results: Students found the nursing home staff and residents have faced several challenges in combating COVID-19. They identified the lack of resources and information, the organisational and psychological burdens on staff, the social isolation and the lack of personal contact with caregivers as the biggest problems for residents. Discussion: While personal protective equipment use and the application of other measures to limit the spread of the virus is very important to prevent the
\end{abstract}


transfer of diseases such as COVID-19, if their implementation is to be effective, conditions like sufficient resources, adequate organisation and guidelines, enough staff knowledge and the consistent use of appropriate personal protective equipment must be ensured. It is important to consider the importance of the residents' social life and and prevent excessive social isolation. Conclusions: To effectively control diseases like COVID-19, it is necessary to study the problems that arise in such situations among the staff and residents of nursing homes, especially those occurring while implementing infection-prevention measures and using personal protective equipment so as to help manage similar situations in the future. Our findings may serve as a basis for both recommendations for better and safer working and living in these facilities for staff and residents alike and for future research in this field.

Keywords: Coronavirus, problems, elderly, Covid expedition, social welfare institutions

\section{Introduction}

In 2020, COVID-19 had a major impact on life and work in nursing homes in Slovenia. Most (58\%) deaths in Slovenia due to COVID-19 in that year were among nursing home residents (UKOM, 2020). By November 2020, more than $85 \%$ of nursing homes had already experienced a coronavirus outbreak.

Nursing homes across the country already faced staff shortages before the epidemic, with the problem then only worsening (Zbornica-Zveza, 2020). The staff had to use considerable amounts of personal protective equipment (PPE) (NIJZ, 2020), which requires great consistency at work and is physically demanding. They also had to implement many other measures to prevent/limit the spread of the virus, overall creating more difficulties for both them and the residents (White et al., 2021).

Some research has already shown that PPE and measures to contain the coronavirus such as physical distancing, respiratory hygiene etc. play a key role in fighting diseases like COVID-19, given that transmission is largely airborne (Lotfi et al., 2020). We must consider many factors that affect virus infection prevention/control to spare problems for staff and to avoid errors by them. Some have already been highlighted by researchers around the world (Szczerbinska, 2020; Thompson et al., 2020), such as sufficient staff resources with appropriate knowledge, appropriate building design, precise work guidelines, adequate and quality material resources, and plans for residents' safe social contacts. The importance of healthcare workers' perception and knowledge about COVID-19 for better outcomes has also been noted (Bhagavathula et al., 2020).

Not much research can be found on the challenges staff and residents of nursing homes have faced during the COVID-19 epidemic. Therefore, the aim of our study was to examine the issues encountered by residents, staff and students in nursing homes while using PPE and applying other measures to lim- 
it the spread of the virus. The research question is: which kinds of problems did the students observe in Slovenia's nursing homes among the staff and residents arising from PPE use and the other measures to limit the virus' spread with a focus on resources, staff knowledge, consistent use of PPE and associated errors.

\section{Methods}

In spring 2021, we conducted in-depth interviews with ten nursing and medical students who had worked during the first wave and/or were working during the second wave of the epidemic across Slovenia as part of 'Covid expeditions' in nursing homes, places most impacted by the epidemic. The coronavirus situation meant the interviews were performed using the Zoom interface. Interviews were recorded, transcribed and then coded in NVivo.

Content analysis was carried out to answer the research question. Students were asked to describe issues arising at work they had noticed among the students, staff and residents in nursing homes while implementing measures to limit the virus' spread and using PPE. We asked them about material shortages, organisational problems and epidemic-related situations in the nursing homes where they were working. We asked them how they assessed the knowledge of staff and consistency in PPE use.

We summarised the main themes and supported the key findings with quotes from the interviewees and translated them into English. Students labelled with numbers $1-5$ had worked in nursing homes during the first wave, while students labelled 6-10 had done so during the second wave of the COVID-19 epidemic.

\section{Results}

We coded the text and designed the themes. The focus of analysis followed the aim of our research by considering the observed availability of resources (staff and PPE), knowledge and consistency of PPE use by staff, errors made while using PPE and implementing preventive measures to limit the spread of the coronavirus, and the problems encountered by residents during the epidemic.

\section{Staff shortage and exhaustion}

Almost all the students who had worked in both waves reported staff shortages: "In terms of staff, there was a general shortage anyway" (S2), and an increase in staff working hours: "They have been working to such a schedule for a very long time. Regardless of weekends, holidays. 12 hours, 12 hours..." (S1). It is also more difficult to work while using a lot of PPE.

Consequently, staff shortages and work overload create difficulties for the implementation of virus control measures: "There was supposed to be a team of people, who were meant to work only in the red zone and the rest, who were 
supposed to work in the grey zone, but it all got mixed up because there was a staff shortage" (S4).

The staff's mental and physical exhaustion was also reported to a large extent during both waves: "Exhaustion, depression" (S7).

\section{The availability and quality of PPE}

Differences between the results for the first and second waves mean that this set of data is divided into two parts.

First wave: In contrast to mass media reports, students generally reported a sufficient level of PPE: "Basically, we were not missing anything" ( $\left.\mathrm{S}_{1}\right)$.

Still, some students also reported a lack of PPE and the dangerous consequences of reusing it. If PPE items are stored for later reuse, undisinfected areas pose a risk when staff collect the PPE again. There is also a greater risk of contamination when clothing is reworn.

I think the biggest problem was PPE. We had it, but we were a little more frugal. We saved these coats when we went to lunch. We took them off, didn't throw them away, and then we put them back on again, and there was a risk of becoming infected. $\left(\mathrm{S}_{5}\right)$

In some nursing homes, the staff did not have Tyvek (i.e. a disposable, highly protective coat) to use for their protection, even while working in the red zone.

Q: So, you were working in the red zone, and you didn't have a Tyvek?

A: No, no. We had that blue coat, with a rubber band on the sleeves. I know they already had those 'space suits' at the end, but in testing they found out that they were leaky, so we didn't use them, they said it didn't make sense. $\left(\mathrm{S}_{2}\right)$

Second wave: Students had varied experiences regarding the availability of PPE and its quality. Mostly sufficient quantities were reported, but poorer quality. This could pose a risk of infection transmission to both staff and residents. PPE that tears and is made of poor material can create a bigger transmission risk because staff are wearing deficient protection. Awareness of the equipment's weaknesses also affects the mental state of the staff because they do not feel safe at work.

Umm, the material was there, but it was bad. The gloves I swear, every other one did... I said... This will be filmed now, but if condoms were like this, population growth would be $100 \%$. They were old, it was a batch of bad gloves, just porous. And we used washable coats. Washable coats!!! (Sg). 


\section{Knowledge and consistency among employees regarding PPE use}

In both waves, most students reported that the staff did not possess adequate knowledge about PPE use and did not use it consistently. Among the main reasons for this inconsistency, about half of them saw staff ignorance as $S$ the biggest problem: Q: "What was the biggest problem with PPE in the nursing home you were working at" A: "Careless wearing" $\left(\mathrm{S}_{4}\right)$, and a lack of knowledge: "Very, very poorly trained staff, including the management" (S9).

Just one student reported organised training for staff on proper PPE use. He also positively assessed the staff's knowledge: “They had these trainings, they came to them, and they refreshed their knowledge; I think they were just familiar with PPE" (S10).

The students also noted the lack of clear guidelines on PPE use and implementation of the measures for containing the virus.

It has been said for a while that we have nitrile gloves up and ones over, you treat the lower ones as your skin and disinfect them, and you change the upper ones. Then they said: 'It's better if you have two layers and you put both up and down'. Then they said: 'It makes no sense at all to use two layers'. I am unsure which is correct. I didn't quite understand that. Obviously, it's not that important if the guidelines change so often. (S2)

They also missed checks on compliance with the measures and proper PPE use.

No (i.e. no checking), due to exhaustion, I think the checking has also dropped. There was too much to do. So, if I had decided not to wear the vizor, no one would have said anything to me. Even if I said that I would only wear a Tyvek without a mask and a vizor, no one would say anything. (S5)

The second set of reasons for inconsistent PPE use and implementation of other measures to limit the coronavirus involved fatigue and tiredness: "There was a lot of equipment but, due to exhaustion, they did not wear it" ( $\left.\mathrm{S}_{4}\right)$.

Finally, an underestimation of the seriousness of the situation was also noted among the staff along with a false sense of security due to overcoming the disease: "But she, because she got over it ( COVID-19), she said: 'I think I'm good, I'm over, I don't need a mask and a vizor"' (S7).

Only one student reported organised checking and therefore greater staff consistency: "Yes, in the first nursing home, we twice had a check. Q: Do you think this has improved the consistency in the use of PPE? A: Yeah, basically it has, yeah" (S10). 


\section{Most common mistakes with PPE use}

The students noticed quite a few mistakes at work that should be pointed out and prevented in the future. In most nursing homes, staff saved for reuse the same protective coats during lunch. The coats made contact with different surfaces (chairs, tables etc.) and, after grabbing them again, they did not disinfect those surfaces. Such a surface (fomite), poses a risk for transmission of the virus.

In the ward, we took it off (the coat), like everyone, with or without disinfection, we usually left it on a chair in the dining room and went up stairs to the main dining room without it. Later, we put the coat back on, as well as the hat and vizor we had worn before. This could be better. Q: Did you later disinfect the chair? A: No.(S4)

Students also observed that the staff often did not follow the correct wiping techniques and took faster, more dangerous shortcuts.

It seems to me, that the biggest mistake came when taking off the coats that we had to constantly put on and off, and the employees didn't care to touch them where it was clean, they took them off with their bare hands, they just placed them down, and would then disinfect their hands a little bit.

Unclear guidelines meant that the use of gloves varied. In some places, staff wore single gloves, which they changed, and then they disinfected their hands, which is supposed to be the correct way. Others wore double or even triple gloves and changed only the top layer. Such gloves become permeable and carry the risk of infection transmission, while it is also impossible to disinfect one's hands regularly. Errors were observed in the exchange of disposable PVC coats between patients and in some nursing homes, even the complete absence of them: "But sometimes they didn't have any at all. They thought: 'Tyvek is protection anyway'; But it is protection for you, and you can still transmit!" (S10).

It was similar regarding equipment like a trolley and dry bath foam. These were intended for the whole department and were not disinfected between use by different residents.

The mixing of staff from different zones was observed. This may create the possibility of infection transmission and should thus be avoided. Many errors were observed during the time for resting and meals - inconsistent adherence to safety distance, non-use of PPE, many people in a small space, the lack of ventilation.

They had lunch and coffee together, not separately. The nurses were eating together, talking without masks. So I think those who were infected got it from other staff, not from the residents. I was there, I had 
a mask, and they used to say: 'come on, you will have coffee, take this mask off sometime' (S9).

In one case, it was also observed that asymptomatically infected staff were still working: "At the end, the whole house got infected, everyone was infected, all of the staff, people were working who were infected, asymptomatic and symptomatic, as it seemed to someone to be working" (S9).

The same student also noticed the worrying careless attitude of those in charge: "Because to say: yes, the best way is that everyone gets infected and then it will get better. You can't say that, speaking about people aged 80 and more!" (S9).

\section{PPE use and the residents}

The students reported that the staff's use of PPE was also a big problem for the elderly, who already had their social contacts drastically reduced and fewer daily activities. The staff were also so busy that they did not have time to talk etc. Students noticed that personal contact between the staff and residents was greatly impaired by the use of PPE and that users often felt distressed: "Social contacts suffered at the expense of everything else. There were also many (residents) who could not even recognise such staff in this equipment at all" (S1).

They detected that PPE had reduced the quality of communication: "There is less contact, even eye contact is worse, you hear worse, while touch in the Tyvek and gloves is not the same as without them..." (S8).

There was a lack of understanding of the situation by people with dementia: "One lady thought she was in jail and was apologising to us all the time" (S10).

One student, who had worked at a nursing home with enough staff, reported they were able to devote enough time to the residents' social contacts.

We took those who were in bed all the time in front of the glass door, to be seen through it, we lifted the bed for them to see, and then we held the phone to their ears so they could talk live to their loved ones. Yeah, we improvised a little. And we also made video calls for them. (S10)

\section{Discussion and conclusion}

We may conclude from our results that the staff and residents in Slovenia's nursing homes encountered similar problems to those described by other researchers abroad - a shortage of staff, poor quality PPE, the lack of clear guidelines for work, and deficient knowledge among the staff (Szczerbinska, 2020, Thompson et al., 2020). A lack of PPE can prove to be very dangerous - staff is consequently under greater psychological pressure and, when PPE is reused, life-threatening mistakes can occur very quickly. Good quality PPE is also es- 
sential for safe work. The students also noticed the lack of checking of staff's consistency at work, reduced personal contact between staff and residents due to the PPE, lack of knowledge regarding proper PPE use as well as virus properties. Based on a quote from a student who concluded that the changing guidelines mean it probably does not matter how gloves are used, we can underscore the importance of clear guidelines for ensuring awareness of the value of certain measures. Another student report shows that external checking of PPE use and compliance with the measures can make staff more consistent in those areas. Better knowledge about the virus and PPE use can also lead to greater consistency. This also affects staff's perception of the seriousness of the situation. The findings allow us to confirm that staff shortages impact the work and well-being of staff as well as the residents' quality of life. Enough staff means less workload and less exhaustion for staff, and this positively affects the quality of work and number of mistakes made. When there are enough staff, it is also easier to organise proper social activities and contacts for residents, which considerably impact the residents' health and well-being (Simard and Volicer, 2020). Shortcomings that surfaced during the COVID-19 epidemic should be pointed out, along with errors in the work process. Further research on these issues in our environment could assist our nursing home systems in being better prepared for potential, similar situations. Our findings may serve as a starting point for that. They could also serve as a starting point for recommendations for better and safer working and living in these facilities for both staff and residents.

\section{References}

BHAGAVATHUlA, A.S., ALDHALEEI, W.A., RAHMANI, J., MAHABADI, M.A. and BANDARI, DK., 2020. Knowledge and Perceptions of COVID-19 Among Health Care Workers: Cross-Sectional Study. Public Health and Surveillance, vol. 6, no. 2, pp. e1916o. Available from: https://publichealth.jmir.org/2020/2/e1916o/.

LOFTI, M., HAMBLIN, M.R. and REZAEI, N., 2020. COVID-19: Transmission, prevention, and potential therapeutic opportunities. Clinica Chimica Acta, no. 508, pp. 254-266. Available from: https://pubmed.ncbi.nlm. nih.gov/32474009/.

NIJZ (2020). Priporočila za preprečevanje in zajezitev okužb z virusom SARSCOV-2v socialnovarstvenih zavodih. [online]. [viewed 21 November 2020]. Available from: https://www.nijz.si/sites/www.nijz.si/files/uploaded/priporocila-za-preprecevanje-in-zajezitev-okuzb-z-virusom-sars-cov-2-16.10.2020.pdf.

SIMARD, J. and VOLICER, L., (2020). Loneliness and isolation in long-term care and the COVID-19 pandemic. JAMDA, vol. 2020, no. 21, pp. $966 e 967$. Available from: https://doi.org/10.1016/j.jamda.2020.05.006. 
SZCZERBIŃSKA, K., (2020). Could we have done better with COVID-19 in nursing homes? European geriatric medicine, no. 11, vol. 4. pp. 639-43. Available from: https://link.springer.com/article/10.1007/s41999-02000362-7.

THOMPSON, D.C., BARBU, M.G., BEIU, C., POPA, L.G., MIHAI, M. M., BERTEANU, M., POPESCU M. N., 2020. The Impact of COVID-19 Pandemic on Long-Term Care Facilities Worldwide: An Overview on International Issues. Biomed research international, vol. 2020, no. 4, pp. 8870249 . Available from: https://www.hindawi.com/journals/bmri/2020/8870249/.

UKOM (2020). Država v domove starejših občanov ni vlagala, zato je veliko smrti stanovalcev. [online]. [viewed 17 February 2020]. Available from: https://www.gov.si/novice/2021-01-11-drzava-v-domove-starejsih-obcanov-ni-vlagala-zato-je-veliko-smrti-stanovalcev/ <17. 2. 2021 $\rangle$.

WHITE, E. M., WETLE, T. F., REDDY, A. and BAIER, R.R., 2020. Front-line nursing home staff experiences during the COVID-19 pandemic. Journal of the american medical directors association, vol. 22, no.1, pp. 199-203. Available from: https://pubmed.ncbi.nlm.nih.gov/33321076/.

ZBORNICA-ZVEZA (2020 ). Kdo bo skrbel za paciente, ko medicinskih sester ne bo več? [online]. [viewed 3 January 2020]. Available from: https:// www.zbornica-zveza.si/clanek/kdo-bo-skrbel-za-paciente-ko-medicinskih-sester-ne-bo-vec/. 



\title{
Elderly and dietary supplements: Benefits and Risks
}

\author{
Katja Kramberger, Darja Barlič-Maganja \\ University of Primorska, Faculty of Health Sciences, Izola, Slovenia \\ katja.kramberger@fvz.upr.si, darja.maganja@fvz.upr.si
}

\section{Abstract}

Introduction: A large percentage of older adults do not receive recommended amounts of many nutrients from food alone. Due to increased awareness of the importance of nutrition to health, along with the advertising and over-the-counter accessibility of the dietary supplements, their use is increasing among the elderly. The purpose of this review is to determine the major benefits of dietary supplementation specific to older adults, as well as to highlight the potential risks that may occur with their use. Methods: PubMed database and the world wide web were searched with mesh terms "prehranska dopolnila" »dietary/food supplements«, »starostniki« - »elderly«, »zakonodaja« - »legislation«, »interakcije« - »interactions« and their combinations. English language articles published after 2000 were included in narrative review, as well as electronic sources regarding legislation in Slovenia and Europe. Results and discussion: Under certain circumstances, i.e. nutrient deficiencies, older adults may benefit from supplementation. Clinical studies have indicated a possible reduction in the risk of developing age-related diseases among older people who reported long-term use of multivitamin supplements. Higher plasma levels of omega-3 polyunsaturated fatty acids have also been associated with fewer cardiovascular deaths in older people taking omega-3 supplements. Dietary protein supplementation combined with physical activity had a strong effect in preventing age-related muscle mass attenuation and leg strength loss in older people. Finally, beneficial effects of purified flavonoids on cognitive function have been reported in some studies. Although there are potential benefits to taking supplements, there are also potential drawbacks. In addition to the increased risk of nutrient overdose, concomitant use of dietary supplements and prescription medications is common in this population and can increase the risk for drug-nutrient interactions and adverse events. Particular caution 
should be taken when using herbal supplements containing St. John's Wort, grapefruit, pomegranate, or black pepper, as these can affect the metabolism of numerous drugs. Supplements containing cranberry, Ginkgo, garlic, coenzyme Q10, or omega-3 fatty acids, on the other hand, may increase the risk of bleeding when used together with anticoagulant medications.

Conclusion: Given the risks associated with dietary supplement use, decisions about the appropriateness of supplementation for older adults should be made by healthcare providers, who should work with patients to identify quality products and evaluate the benefits and risks of supplement use on a case-by-case basis.

Keywords: dietary supplements, elderly, indications, interactions

\section{Introduction}

Diet is known to play an important role in the prevention of many diseases, and the right choice of nutrients can help prevent them and improve quality of life. However, analysis of nationwide survey data has shown that a large percentage of older adults do not receive recommended amounts of many nutrients from food alone (Walrand, 2018). This is of particular concern because conditions prevalent in this population, can further compromise nutritional status and could have a negative impact on neurological and cardiovascular health, mood, immune function, vision, blood sugar control, and bone strength (Harris et al., 2017; Walrand, 2018). The main reasons for nutrient deficiencies and risk of malnutrition among the older adult population, can result from loss of appetite with aging, decreased oral intake, chewing or swallowing difficulty, and/or nutrient depletions from medication use, among many other social and medical factors (Harris et al., 2017). On the basis of this evidence, together with television and magazine advertisements, information obtained on the Internet, articles in the lay press, and the recommendations of their physicians, a large proportion of the Western population takes a variety of vitamin, mineral, and herbal supplements daily in the hopes of promoting good health, preventing chronic diseases (such as heart disease and cancer), limiting the ravages of aging, and ultimately extending life (Marik and Flemmer, 2012). Dietary supplements (DS) use among older adults is even higher, as National Health and Nutrition Examination Survey (NHANES) 2011-2012 reported that up to $72 \%$ of individuals aged 65 years and older use supplements. In addition, among older adults surveyed in NHANES 2011-2012, $21 \%$ reported using four or more supplements daily (Harris et al., 2017). The continued use and popularity of DS in recent years may be due to various factors, including perceived health-promoting properties, fear of adverse events associated with prescription medications, cost of prescription medications, over-the-counter availability of DS, and belief that DS are natural and therefore safe to use (Walrand, 2018). Although some DS may indeed have the expected benefits on human health, it would be unwise to assume that they are all efficacious and safe to use. 
In the following sections, we will define what are DS, when is it beneficial to take them and what risks might occur with their (unsupervised) use.

\section{Methods}

PubMed database and the world wide web were searched with mesh terms "prehranska dopolnila« - »dietary/food supplements«, »starostniki« - »elderly«, »zakonodaja« - »legislation«, »interakcije« - »interactions« and their combinations. English language articles published after 2000 were included in narrative review, as well as electronic sources regarding legislation in Slovenia and Europe.

\section{Results and discussion}

\section{Definition, regulation of DS and problematic related to it}

A DS is defined according to the National Institutes of Health (n.d.) as a product that is intended to supplement the diet, which contains one or more of the following dietary ingredients: vitamins, minerals, herbs or other botanicals, amino acids, and other substances or their components. It is intended to be taken by mouth as a pill, capsule, tablet, or liquid form. DS are not meant to be and therefore cannot be represented as a conventional food item or a sole item of a meal or diet. They are also not intended to "treat, diagnose, prevent, or cure disease" and must be identified as a DS on the label (Harris et al., 2017). In the European Union (EU), DS are regulated as foods under the The Food Supplements Directive (FSD) Directive 2002/46/EC, which establishes a definition for DS, a list of allowable vitamins and minerals, and sets labelling requirements. Substances other than vitamins and minerals are not directly covered by the directive, and rules regulating these substances are still governed by individual EU member states. The Directive calls for the establishment of harmonized minimum and maximum dosage amounts; however, this has yet to be done and remains a competence of EU member states (Sovereign Silver, n.d.). FSD allows the Member States to implement only a notification procedure by which DS are reported to the authorities at the time they are put on the market. However, some Member States have not considered it necessary to introduce a notification obligation (Coppens, 2018). In Slovenia, the legal requirements on DS are determined in Rules on food supplements - Pravilnik o prehanskih dopolnilih (Official Gazette of the Republic of Slovenia (RS) - Uradni list RS, No. 66/33) issued by the national Ministry of Health. From the 5th of August 2013, the Ministry of Health no longer accepts new applications for DS and no longer keeps a list of DS currently marketed in RS. DS are classified as foods and must comply with an umbrella law on food, which states that all DS put on the market, must be safe to use and not contain substances in a form or amount that could pose a risk for human health. DS can be put on a market only by the food business operators, that have the appropriately registered food plant in the RS. The compliance with the food law on all the levels from manufacturing, dis- 
tribution and marketing is performed by the Health Inspectorate of the RS (Ministrstvo za zdravje, 2014). Safety and efficacy of DS in the EU are evaluated by the European Food Safety Authority (EFSA), an entity set up in January 2002 as an independent source of scientific advice that produces opinions which then are used by the European Commission to adopt legislation. In Slovenia, National Institute for Public Health (Nacionalni inštitut za javno zdravje) has joined European linkage called Nutrivigilance, which is intended to identify the possible risks related to DS consumption and prevention of them. The main purpose of nutrivigilance is to ensure the information flow between the consumers, food business operators and regulatory institutions. It includes raising awareness and reporting of possible adverse events (Nacionalni inštitut za javno zdravje, n.d.). Nonetheless, legislation around DS is much more loose compared to drugs and regulation of quality and safety is mostly post-market, whereas efficacy of DS is not being verified (Harris et al., 2017).

\section{Benefits from taking DS}

Nutrient deficiencies and malnutrition among the older adult population are a concern and may be reduced by supplementation (Gariballa, 200o). DS can play a role in optimizing nutrient levels among older adults who have poor nutrient intake due to decreased appetite, dental issues, etc., are at risk of malnutrition, or experience nutrient depletions from medications. Approximately $34 \%$ of individuals over the age of 65 are nutritionally deficient in protein, calories, and multiple micronutrients. Specific micronutrients of concern include those that are consistently found to be deficient in the diet and/or nutrients for which the digestion, absorption, or metabolism declines with age (such as vitamins A, C, D, B6, B12, and folate plus calcium, zinc, and magnesium). Supplementation may also be beneficial among older adults prescribed medications that reduce or interfere with the absorption of nutrients, such as statins, antacids, antidepressants, antibiotics, oral hypoglycemic medications. Proton pump inhibitors have been associated with nutrient deficiencies such as vitamin B12, vitamin $\mathrm{C}$, calcium, iron, and magnesium and metformin has been shown to cause vitamin B12 and folate malabsorption, specifically when used at higher doses and for extended periods of time (Harris et al., 2017).

In general, various DS are used by older people mainly in the expectation of reducing the risk of developing cancer, cardiovascular diseases, cognitive impairment, or skeletal muscle loss (Walrand, 2018). The most common DS taken among elderly, can be grouped according to their chemical nature as follows: vitamin and mineral supplements, omega-3 polyunsaturated fatty acids (PUFAs) supplements, protein supplements and plant-based supplements.

Many clinical studies aimed to investigate positive effects of the administration of antioxidant vitamins and their possibility to decrease cell oxidative damage, thereby decreasing the incidence of degenerative diseases and cancer (Walrand, 2018). In a longitudinal population-based study high vitamin E intake was associated with better cognitive performance during aging (Morris et 
al., 2002). Vitamin D and/or calcium are important modifiable factors associated with optimal bone health. Kahwati et al. (2018) compiled 11 randomized controlled trials, and concluded that compared with placebo, supplementation with vitamin D decreased total fracture incidence. Several clinical studies also investigated multivitamin supplements intake and possible prevention of atherosclerosis and cardiovascular disease. These studies have pointed to potential reductions in the risk to develop age-related diseases among older people who reported long-term use of multivitamins (Walrand, 2018).

Both randomized clinical interventions and observational studies highlight the protective effects associated with diets supplemented with fish oil and omega-3 PUFA, particularly the longer chain fatty acids, eicosapentaenoic acid (EPA), and docosahexaenoic acid (DHA). EPA and DHA supplementations have been extensively studied therapeutically in a wide variety of disease conditions, though principally cardiovascular diseases (Walrand, 2018). Beside fewer cardiovascular deaths due to higher plasma levels of omega-3 PUFAs, recent studies suggest that they may be also associated with cognitive status in older people. Ammann et al. (2017) have reported that higher levels of blood DHA+EPA may help protect against the development of dementia in older women. Furthermore, omega-3 PUFAs may also modulate physical performance in the elderly, as has been shown that they enhance muscle anabolic responses (Lalia et al., 2017).

Milk protein consists of whey - a fast digested protein with a large amount of leucine, which has been suggested as being responsible for enhanced ability to stimulate muscle protein anabolism. In a systematic review by Liao et al. (2017), it was confirmed that, dietary protein supplementation combined with exercise had a strong effect in preventing age-related muscle mass attenuation and leg strength loss in older people. Results from the study by Koutsofta et al. (2019) showed that combined protein administration through supplemental proteins for a period of up to 12 months may positively affect osteoporosis in postmenopausal women.

A prospective study comprising 1640 aged participants showed that persons with high dietary intake of flavonoids maintained better cognitive functions at the baseline and showed slower cognitive decline over a period of 10 years (Letenneur et al., 2007).

\section{Risks associated with DS use}

Although supplement use provides potential benefits by increasing nutrient intake, there are potential drawbacks. Firstly, the concurrent use of prescription medications and DS has become more common among older adults which increases the risk of potential drug-nutrient interactions. Of particular concern is polypharmacy, or the concurrent use of more than five prescription medications, which is common in elderly. The most problematic common herb with a very high risk of drug-nutrient interactions is St. John's wort (Hyperi- 
cum perforatum), which can increase metabolism of drugs processed through the $\mathrm{CYP}_{3} \mathrm{~A}_{4}$ enzymes, making up 50\% of all drugs. Other common potential drug-nutrient interactions include grapefruit (Citrus $\times$ paradisi), pomegranate (Punica granatum), goldenseal (Hydrastis canadensis), and black pepper (Piper nigrum) due to the inhibition of CYP450. Another common interaction can occur between anticoagulant medications such as warfarin and supplements such as cranberry (Vaccinium oxycoccos), garlic (Allium sativum), Ginkgo (Ginkgo biloba), coenzyme Q10, and fish oil/omega-3 fatty acids, due to increased risk of bleeding (Harris et al., 2017).

Secondly, although users tend to be motivated by putative health benefits, there is no clear evidence that the use of dietary supplements affects age-related chronic diseases and mortality (Walrand, 2018). While a considerable body of evidence has been gathered showing a positive impact of consuming some DS, some studies also reported contradictive results. Marik and Flemmer (2012) reviewed 63 randomized controlled trials that evaluated the benefits and safety of DS such as $\beta$-carotene, vitamin A, B6, B12, C, D, E, folic acid, calcium, selenium, omega-3 fatty acids, glucosamine and some herbs (Ginkgo, saw palmetto, milk thistle). No benefit was recorded in 45 studies, with ten of these showing a trend toward harm and two showing a trend toward benefit. Four studies reported harm, with an increased risk of cancer and cancer deaths in the Carotene and Retinol Efficacy Trial and the Norwegian Vitamin Trial II studies, and an increased risk of fractures in the two studies that investigated high-dose once-yearly vitamin D. The Nutritional Cancer Prevention Study (selenium supplementation) demonstrated both benefit (less cancer) and harm (increased risk of type 2 diabetes). The lower risk of cancer with selenium supplementation, however, was not confirmed in the much larger selenium and Vitamin E Cancer Prevention Trial. Similarly, the Calcium Polyp Prevention Study demonstrated both a benefit (reduced fractures and reduced polyps) and harm (increased acute myocardial infarction). A beneficial outcome was reported in only three studies with omega-3 fatty acids and in six studies with vitamin $\mathrm{D}$, which appeared to be dose dependent.

\section{Conclusions}

As there are a lot of things that need to be taken into consideration to ensure safe and reasonable supplementation in older patients, it is recommended that they seek professional consultation before starting a new supplement regimen. Supplement recommendations by healthcare practitioners should be tailored to each individual patient with consideration of quality of diet, use of medications, and other medical/social factors. Ideally, nutrition screening should be conducted for every patient by a qualified provider, such as a registered dietitian nutritionist, in order to assess nutrient intake and risk of malnutrition. If supplementation is deemed beneficial, the quality, safety, and efficacy of the DS should be assessed and the best regimen for the given patient determined. 


\section{References}

AMMANN, E.M., POTTALA, J.V., ROBINSON, J.G., ESPELAND, M.A., HARRIS, W.S., 2017. Erythrocyte omega-3 fatty acids are inversely associated with incident dementia: Secondary analyses of longitudinal data from the Women's Health Initiative Memory Study (WHIMS). Prostaglandins, Leukotrienes, and Essential Fatty Acids, vol. 121, pp. 68-75. https://doi.org/10.1016/j.plefa.2017.06.006

COPPENS, P., 2018. Food Supplements in the European Union: the Difficult Route to Harmonization [online]. [viewed 8 August 2021]. Available from: https://www.raps.org/news-and-articles/news-articles/2018/7/food-supplements-in-the-european-union-the-diffic

GARIBALLA, S.E., 200o. Nutritional support in elderly patients. The Journal of Nutrition, Health \& Aging, vol. 4, no. 1, pp. 25-27.

HARRIS, S.R., MORROW, K., TITGEMEIER, B., GOLDBERG, D., 2017. Dietary Supplement Use in Older Adults. Current Nutrition Reports, vol. 6, no. 2, pp. 122-133. https://doi.org/10.1007/s13668-017-0198-6

KAHWATI, L.C., WEBER, R.P., PAN, H., GOURLAY, M., LEBLANC, E., COKER-SCHWIMMER, M., VISWANATHAN, M., 2018. Vitamin D, Calcium, or Combined Supplementation for the Primary Prevention of Fractures in Community-Dwelling Adults: Evidence Report and Systematic Review for the US Preventive Services Task Force. Journal of American Medical Association, vol. 319, no. 15, pp. 160o-1612. https://doi. org/10.1001/jama.2017.21640

KOUTSOFTA, I., MAMAIS, I., CHRYSOSTOMOU, S., 2019. The effect of protein diets in postmenopausal women with osteoporosis: Systematic review of randomized controlled trials. Journal of Women \& Aging, vol. 31, no. 2, pp. 117-139. https://doi.org/10.1080/o8952841.2018.1418822

LALIA, A.Z., DASARI, S., ROBINSON, M.M., ABID, H., MORSE, D.M., KLAUS, K.A., LANZA, I.R., 2017. Influence of omega-3 fatty acids on skeletal muscle protein metabolism and mitochondrial bioenergetics in older adults. Aging, vol. 9, no. 4, pp. 1096-1129. https://doi.org/10.18632/ aging.101210

LETENNEUR, L., PROUST-LimA, C., LE GOUGE, A., DARTIGUES, J.F., BARBERGER-GATEAU, P., 2007. Flavonoid intake and cognitive decline over a 10-year period. American Journal of Epidemiology, vol. 165, no. 12, pp. 1364-1371. https://doi.org/10.1093/aje/kwmo36

LIAO, C.-D., TSAUO, J.-Y., WU, Y.-T., CHENG, C.-P., CHEN, HUI-CHUEN, HUANG, Y.-C., CHEN, HUNG-CHOU, LIOU, T.-H., 2017. Effects of protein supplementation combined with resistance exercise on body composition and physical function in older adults: a systematic review and meta-analysis. The American Journal of Clinical Nutrition, vol. 106, no. 4, pp. 1078-1091. https://doi.org/10.3945/ajcn.116.143594 
MARIK, P.E., FLEMMER, M., 2012. Do dietary supplements have beneficial health effects in industrialized nations: what is the evidence? Journal of parenteral and enteral nutrition, vol. 36, no. 2, pp. 159-168. https://doi. org/10.1177/0148607111416485

MINISTRSTVO ZA ZDRAVJE RS, 2014. Napotki glede področja prehranskih dopolnil v Republiki Sloveniji in skladnosti tovrstnih izdelkov Z veljavno zakonodajo [online]. [viewed 8 August 2021]. Available from: https://www.gov.si/assets/ministrstva/MZ/DOKUMENTI/Preventiva-in-skrb-za-zdravje/varnost-zivil-in-hrane/napotki_s_podrocja_ prehranskih_dopolnil_2015.pdf

MORRIS, M.C., EVANS, D.A., BIENIAS, J.L., TANGNEY, C.C., BENNETT, D.A., AGGARWAL, N., WILSON, R.S., SCHERR, P.A., 2002. Dietary intake of antioxidant nutrients and the risk of incident Alzheimer disease in a biracial community study. Journal of American Medical Association, vol. 287, no. 24, pp. 3230-3237. https://doi.org/10.1001/jama.287.24.3230

NACIONALNI INŠTITUT ZA JAVNO ZDRAVJE, n.d. Varno uživanje prehranskih dopolnil in poročanje o neželenih dogodkih [online]. [viewed 8 August 2021]. Available from: https://www.nijz.si/sl/varno-uzivanje-prehranskih-dopolnil-in-porocanje-o-nezelenih-dogodkih-o

NATIONAL INSTITUTES OF HEALTH, n.d. Dictionary of Dietary Supplement Terms [online]. [viewed 4 June 2021]. Available from: https://ods. od.nih.gov/HealthInformation/dictionary.aspx

SOVEREIGN SILVER, n.d. How Dietary Supplements are Regulated in Europe [online]. [viewed 8 August 2021]. Available from: https://sovereignsilver. com/pages/how-dietary-supplements-are-regulated-in-europe

WALRAND, S., 2018. Dietary supplement intake among the elderly: hazards and benefits. Current Opinion in Clinical Nutrition and Metabolic Care, vol. 21, no. 6, pp. 465-470. https://doi.org/10.1097/MCO.00ooooooooooo512 


\title{
The impact of oral cancer on the quality of life of older patients
}

\author{
Marjeta Logar Čuček \\ Ljubljana University Medical Centre, Department of Oral and Maxillofacial Surgery, 1000 Ljubljana, Slovenia \\ marjetalogar@gmail.com
}

\begin{abstract}
Introduction: Oral cancer is one of the most severe illnesses of the oral cavity. It is predominantly caused by smoking and alcohol consumption. Poor oral hygiene could also be one of the causes. In younger patients and non-smokers, the human papilloma virus has been identified to cause the disease, moreover, hereditary and environmental factors also play an important role. Due to their lifestyle, men suffer from the disease more frequently, however, it also affects women and people under 50 . The treatment process is typically multimodal with a view to recovery, lowering the occurrence of complications and achieving patient independence. The objective of the study was to make a review of literature dealing with connections between oral cancer in older patients and their way of life, as well as to assess their quality of life after their return to their work and social environments. Methods: A review literature in both Slovenian and English language, published between 2015 and 2020, has been carried out. Relevant databases of scientific and professional literature, webpages of professional organisations and various other digital and printed sources have been used. The search included words and phrases such as cancer, lifestyle, prevention, quality of life. To achieve a more precise searching procedure, the PRISM scheme has been used. Results: The identified hits have been described, analysed and evaluated. The results demonstrate a partial connection between the incidence of oral cancer in older patients and their lifestyle. The recovery process of patients after an oral cancer operation does not include only satisfying their physiological needs but also taking care of their psychological, social and mental needs in order to improve the quality of their lives. Discussion and conclusion: There are many important factors that significantly influence lowering the risk of oral cancer. Among the most important ones are lifestyle, taking care of health, prevention activities, timely action when noticing changes that
\end{abstract}


would lower the recovery chances in more advanced stages. In the treatment process, the psychological preparation of the patient is of vital importance, as well as their understanding of the disease. Patients' reintegration into their environment, development of communication skills and accepting themselves is frequently a long process that demands the cooperation of professionals, patient and their family members. There is no price that is too high to pay if the desired result is quality life.

\section{Keywords: cancer, lifestyle, prevention, quality of life}

\section{Introduction}

Mouth cancer can affect the area of lips, oral cavity and larynx. It is one of the most widespread malign diseases in Slovenia since it accounts for $54 \%$ of all cases of head and neck cancer. The incidence of lip cancer is decreasing, whereas the cancer of the oral cavity and larynx is on the rise. (Blatnik et al., 2019).

Alcohol consumption and smoking are largely responsible for oral cavity cancer (Blatnik et al., 2019; Logar Čuček, 2020), combining the two adds even more to the development of cancer - the negative effects of use grow exponentially (Radoï and Luce, 2013; Strojan et al., 2018). Another factor linked with the development of the disease and growing in the developed world, is infection with the human papilloma virus (HPV) in younger patients where other risk factors are present only to a smaller extend or are not present at all (Strojan et al., 2015; Blatnik et al., 2019 ). Other factors contributing to the development of oral cavity cancer are poor oral hygiene, lower socio-economic status, unhealthy diet, exposure to harmful chemicals in the work environment, ultraviolet radiation, weakened immune system, hereditary and environmental factors (Radoï and Luce, 2013; Didanovič, 2015; Blatnik et al., 2019; Dovšak, 2019).

In the last decade, men are three times more likely to suffer from oral cavity cancer; their average age is 50 years (Blatnik et al., 2019; Montero and Patel, 2015). Changes in smoking and drinking habits significantly contribute to rising incidence of oral cavity cancer in women and population younger than 50 years. Similar to other types of cancer, with age the chances of developing oral cavity cancer increase (Dovšak, 2019).

Oral cavity cancer is predominantly diagnosed in an advanced stage (Dovšak, 2006). Therefore, it is of vital importance for the oral cavity to be regularly checked, irrespective of patient's complaints. All changes in the oral cavity, for example ulcers that do not heal in two weeks, white or red patches in the lining of the mouth call for an immediate visit to the doctor or dentist, who decides what the best course of action should be, for example more frequent monitoring or referral to a specialist. Most cancer diseases start with precancerous changes, the most common being cutaneous squamous cell carcinoma (Kansky, 2015; Blatnik et. al, 2019).

Oral cavity cancer treatment requires a multidisciplinary approach and includes experts from different fields. It is comprised of three parts: diagnosis, 
treatment and monitoring. The two key entry points for patients are the outpatient clinic where the diagnostic procedure starts, and the multidisciplinary consilium where the course of treatment is determined. Various support services help in all stages in the form of clinics or wards, but mostly unconnected to them: pain therapy, rehabilitation of voice, speech and swallowing, clinical nutrition, dental care and rehabilitation; also other services might be involved, on recommendation of the consilium (Strojan et al., 2021). Patients' quality of life after removing oral cavity cancer is largely dependent on including them in the process of communication, boosting their self-acceptance and helping them to reconnect with their living and work environment. The process tends to be long-lasting and requires the cooperation of professionals, patient and their family (Logar Čuček, 2020).

The objective of the research was to study the interconnection between oral cavity cancer in older adults and their way of life, and the quality of life of patients after different stages of cancer treatment.

The first goal of the research was to study the connection between the way of life and its influence on the incidence of oral cavity cancer in older adults.

The second goal of the research was to assess the quality of a patient's life after rehabilitation and their inclusion in their social and work environment.

The following research question was posed:

How does lifestyle influence physical and mental quality of life in patients with oral cavity cancer?

\section{Methods}

\section{Review methods}

A descriptive method with a review of professional and scientific literature was used. We used relevant databases, websites of professional organizations, electronic and printed sources. The search for literature was conducted using the following key phrases and words: oral cancer, lifestyle, prevention, quality of life. The inclusion criteria for the selection of literature were articles in Slovene and English, published from 2015 to 2020 , freely available in full text with content matching the topic of the research. A source published before 2015 clearly states the consequences of alcohol consumption, smoking and the influence of other factors on the development of oral cancer. Payable articles and those that did not provide access to the full text were excluded.

Contents analysis of 6 professional and scientific articles from the field of the interdependence of factors for the development of cancer in the oral cavity was performed. The second step was a descriptive analysis of articles on the quality of a patient's life during treatment and preparation for inclusion into their work and social environment. 


\section{Review results}

The review of the databases came up with 60 sources. Subsequently, 28 sources were excluded and 32 texts were selected. The final set of sources includes 6 texts. For a more detailed process of searching the literature in databases, we used a customized schematic presentation, as enabled by PRISM scheme (Moher et al., 2009).

\section{Data processing description}

We focused on professional and scientific articles that contained at least two key search phrases. The texts were analysed using the "principle of qualitative content analysis". The central process of text analysis is open coding (Vogrinec, 2008).

\section{Results}

Table 1 shows the sources included in the literature review (year of publication, author, typology and objectives of the research, sample and key findings). Using qualitative analysis of the contents of the sources, 6 categories with corresponding codes (Table 2) were identified: possible risk factors for oral cancer, awareness of risk factors, balanced diet and physical activity, patients' need for information during oral cancer treatment, reducing suicide risk. After re-checking the contents, codes and categories, we changed the identified categories into subcategories and placed them under a single category titled Quality of life with oral cancer, which best describes the objective of literature review.

Table 1: A review of the key findings of the research included in qualitative content analysis

\section{Author, year} veloping oral cavity cancer are poor oral hygiene and irregular dental care;

$\begin{array}{lll} & \begin{array}{l}\text { To assess different } \\ \text { risk factors for oral } \\ \text { cavity cancer; the } \\ \text { Observation- } \\ \text { al study: case } \\ \text { study-reference. } \\ \text { Case-control study }\end{array} \\ & \begin{array}{l}\text { influence of factors } \mathrm{n}=128 / 320 \\ \text { on the recurrence } \\ \text { or appearance of a } \\ \text { new second prima- } \\ \text { ry tumour. }\end{array}\end{array}$
Excessive alcohol consumption (recurrence risk) and smoking (possible connection with death in simultaneous diseases; there is a strong connection between human papilloma infection and cancer, higher probability of recurrence. 
Other risk factors: tobacco chew-

To ensure preventive behaviour be-

Montero and $\mathrm{Pa}$ Systematic literatel, 2015 ture review. fore the disease and proper rehabilitation after the surgical procedure.

ing, wood dust exposure, genetic illnesses, insufficient nutrition, immune system change. Vital to change lifestyle. Timely diagnosis and proper treatment.

Prevention is the strongest weapon against cancer: re-

To assess the con-

Latino-Martel et al., 2016

Systematic literature review. nection between

dietary factors and $\mathrm{n}=133$

cancer. duce the consump tion of alcoholic beverages, ensure a balanced diet, be physically active.

To evaluate the connection between patients needs for special

Schorn et al., 2020 Retrospective cotween social ties hort study.

care in terms of physiological re-

$\mathrm{n}=1359$ habilitation, family support and their impact on patients' quality of life.

To assess the connection between patients' need for information dur-

ing the treatment
Jehn et al, 2021

Retrospective cohort study.

of oral cancer and

$\mathrm{n}=1359$ the quality of life or the development of post-traumatic stress disorder.

To determine the incidence of suicide in patients suffer-

Twig et al., 2020 Systematic literature review. ing from head and

neck cancer.

$\mathrm{n}=63$

To evaluate the procedures for suicide reduction.
A correlation beand depression has been proved.

The needs for speech therapy, physiotherapy and breathing exercises have been fulfilled only minimally.

Lack of information regarding the surgery and possible complications. Established correlations between lack of information and post-traumatic disorders.

The risk of suicide in these patients differs from others with cancer.

There is no evidence of interventions to reduce suicidal thoughts and suicide risk. 


\begin{tabular}{|c|c|c|c|}
\hline Category & $\begin{array}{c}\text { Subcategories } \\
n=6\end{array}$ & $\begin{array}{l}\text { Codes } \\
n=25\end{array}$ & Authors \\
\hline \multirow{6}{*}{$\begin{array}{l}\text { Oral cavity cancer pa- } \\
\text { tients' quality of life }\end{array}$} & $\begin{array}{l}\text { Possible risk factors for } \\
\text { oral cavity cancer. }\end{array}$ & $\begin{array}{l}\text { Excessive alcohol con- } \\
\text { sumption. } \\
\text { Heavy, long-term smok- } \\
\text { ing, men - women. } \\
\text { Human papilloma virus } \\
\text { infection (HPV). } \\
\text { Disease recurrence. } \\
\text { Other primary tumours. } \\
\text { Simultaneous diseases. }\end{array}$ & $\begin{array}{l}\text { Rosenquist, } 2005 \\
\text { Tsai et al., } 2014 \\
\text { Druesne-Pecollo et al., } \\
2014 . \\
\text { Kansky, } 2017\end{array}$ \\
\hline & $\begin{array}{l}\text { Raising awareness of risk } \\
\text { factors. }\end{array}$ & $\begin{array}{l}\text { Assessing the disease. } \\
\text { Prevention. } \\
\text { Raising the awareness of } \\
\text { the disease. } \\
\text { Change of lifestyle. } \\
\text { Early diagnosis - ways of } \\
\text { treatment and rehabili- } \\
\text { tation. } \\
\text { Reducing the influence } \\
\text { of therapy on shape and } \\
\text { function. } \\
\text { Regular disease moni- } \\
\text { toring. }\end{array}$ & $\begin{array}{l}\text { Montero and Patel, } 2015 \\
\text { Giraldi et al., } 2017 \\
\text { Kansky, } 2017\end{array}$ \\
\hline & $\begin{array}{l}\text { Balanced diet and physi- } \\
\text { cal activity. }\end{array}$ & $\begin{array}{l}\text { Excessive weight. Obesi- } \\
\text { ty. Alcoholic beverages. } \\
\text { Red and processed meat. } \\
\text { Salty food. }\end{array}$ & $\begin{array}{l}\text { Montero and Patel, } 2015 \\
\text { Latino-Martel et al., } 2016\end{array}$ \\
\hline & $\begin{array}{l}\text { Patients' need for care } \\
\text { during oral cancer treat- } \\
\text { ment. }\end{array}$ & $\begin{array}{l}\text { Social connections re- } \\
\text { duce depression. } \\
\text { Speech therapy. } \\
\text { Breathing exercises. } \\
\text { Physiotherapy. }\end{array}$ & $\begin{array}{l}\text { Schorn, } 2 \mathrm{O} 2 \mathrm{O} \\
\text { Jehn et al., } 2021\end{array}$ \\
\hline & $\begin{array}{l}\text { Patients' need for infor- } \\
\text { mation during oral can- } \\
\text { cer treatment. }\end{array}$ & $\begin{array}{l}\text { Information during } \\
\text { treatment. } \\
\text { Post-therapy disorders. } \\
\text { Quality of life. }\end{array}$ & $\begin{array}{l}\text { Jehn et al., } 2021 \\
\text { Kansky, } 2017\end{array}$ \\
\hline & Suicide risk reduction. & $\begin{array}{l}\text { Mental problems. } \\
\text { Social support. } \\
\text { Emotional problems } \\
\text { during treatment. } \\
\text { Suicide prevention. }\end{array}$ & $\begin{array}{l}\text { Twigg et al., } 2020 \\
\text { Schorn, } 2020\end{array}$ \\
\hline
\end{tabular}

\section{Discussion}

Due to all the dimensions of the consequences for the patient and society, special attention should be paid to the management of oral cancer. Rosenquist (2005) used the results of a study a decade and a half ago to link the development of cancer in the oral cavity with poor oral hygiene, poor dental care, and defective complete dentures. The risk can be reduced with regular dental care and dental hygiene. Furthermore, excessive drinking and smoking do not only pose a high risk for developing the disease. Based on the results of the research, Rosenquist points to the possibility of recurrence; in heavy smokers there is a 
strong link with death due to simultaneous diseases. Patients at high risk for HPV infection showed a threefold increased chance of cancer recurrence or the appearance of a second primary tumour. The need for improving oral hygiene was also noted by the authors of the study (Tsai et al., 2014). Poor hygiene is associated with high risk of head and neck cancer - the highest risk group are alcohol consumers with the poorest oral hygiene. The importance of reducing alcohol consumption was also presented by researcher Druesne-Pecollo and colleagues (2014). They pointed out that drinking alcohol is associated with another primary risk of cancer of the oral cavity, throat, larynx and oesophagus. Alcohol consumption, smoking, and especially the combination of the two, is also cited by Kansky (2017) as an important factor for the development of squamous cell carcinoma in the mouth. Due to changes in smoking and drinking habits, the incidence of oral cancer among women has been on the rise recently (Blatnik, et al, 2019). The same authors also state in their research that HPV infections increase the incidence of oral cancer among younger people, especially men with higher socio-economic status. This was already pointed out by Kansky (2017), who, unrelated to alcohol and smoking, pointed out the relevance of HPV, namely in men aged $44-55$ years.

Montero and Patel (2015) emphasize the importance of disease awareness and education about inappropriate lifestyle which in most cases leads to various diseases, including oral cancer. In their study, Giraldi et al (2017) found that a low level of education, in addition to smoking and alcohol consumption, is an unfavourable prognostic factor for overall survival in patients with oral cancer (Giraldi et al., 2017).

The awareness of the importance of physical activity and a balanced diet to offset harmful effects on health and the consequent development of cancer is an important disease preventive step. Latino-Martel and colleagues (2016) state that to improve cancer prevention, three main goals need to be achieved: reducing alcohol consumption, having a varied and balanced diet, and being physically active.

How a patient will live or what their quality of life with oral cancer will be is determined as soon as the disease is diagnosed. Pre-surgical optimization, consultations with a reconstruction surgeon, involvement of various therapists, from speech therapist, to swallowing and lifestyle changes coach, as well as giving up smoking and excessive alcohol consumption, all lead to a better quality of life during treatment and after reintegration into the work and social environment (Montero and Patel, 2015). A study conducted by Schorn and colleagues (2020) showed that physical rehabilitation of patients took place only at the time of hospitalization, in the initial phase of treatment. During this time, patients also needed speech therapy, physiotherapy, and respiratory therapy, but received them infrequently, in contrast to post-surgery patient care requirements. Proper patient care shortens the time of hospitalization and reduces postoperative complications. The quality of life of the patient is undoubtedly also enhanced by being provided with proper information during the treat- 
ment of oral cancer; the lack of information consequently affects the patient's perception of post-traumatic disorders. Patients should be informed of the possible physical and psychological consequences of the operation; information is also needed before surgery (Jehn, 2021). The path of accepting the diagnosis, treatment, and re-socializing is difficult for patients, especially for those who do not have enough social support. They often suffer from emotional distress that occurs at any time during, or even more frequently, after the treatment. They represent a much higher suicide risk compared to a demographically comparable general population group (Twigg et al., 2020). The authors found that no specific procedures exist for reducing suicide risk in these patients. Schorn and colleagues (2020) state that strong family ties and meaningful friendships reduce problems with depression and anxiety.

Researchers Kell et al., (2018) point out that one of the most important factors with positive effects in the treatment process and later, is communication with nurses and doctors as well as in the home environment.

Treating oral cancer is demanding and never without consequences. It marks the patient for life (Kansky, 2017). The author states that it is of vital importance to offer support to the patients also as human beings, to encourage and listen to them, and in this way help their successful rehabilitation after treatment.

\section{Conclusion}

The reviewed literature on oral cancer in older adults clearly confirms the fact that it is of vital importance to put the quality of life of patients at the forefront.

Oral health is an integral part of the overall health and well-being of every individual and society. The contents of the reviewed research papers indicate the need to stop smoking and moderate alcohol consumption. These are key elements in preventing and controlling oral cancer. Improving oral hygiene can bring additional benefits, as can caring for healthy teeth. Due to the increasingly important role of HPV infection in the development of oral cancer, more attention needs to be paid to the younger generation and their protection against this type of infection.

Early detection is needed to successfully treat oral cancer and improve survival rates. This can be achieved by raising the awareness and knowledge of the consequences of the risk factors that lead to disease.

\section{References}

BLATNIK, J., ZADNIK, V. and ARTNIK, B., 2019. Rak ustnega predela V Sloveniji v letih 1985-1914. Zdravstveni Vestnik, vol. 88, no. 11-12, pp. 493508.

DIDANOVIĆ, V., 2015. Kirurško zdravljenje raka glave in vratu. In: LOGAR, M., ed. Celostna zdravstvena nega in oskrba pacienta z maligno boleznijo $\mathrm{v}$ področju glave in vratu: zbornik predavanj / 5. strokovni seminar iz- 
vajalcev ZN KO za maksilofacialno in oralno kirurgijo UKC Ljubljana. Brdo pri Kranju, 28. 11. 2015. Ljubljana: Združenje za maksilofacialno in oralno kirurgijo Slovenije, pp. 20-23.

DOVŠAK, D., 2006. Odkrivanje in zdravljenje predstopenj raka ter raka ustne votline in ustnega dela žrela. Radiology and oncoloy, vol. 40, no. 1, pp. 9-17.

DOVŠAK, T., 2019. Vpliv kirurškega zdravljenja in obsevanja na imunski status, stanje prehranjenosti ter vnetni odziv pri bolnikih $\mathrm{z}$ rakom ustne votline: doctoral thesis. Ljubljana: Univerza v Ljubljani, Medicinska fakulteta.

DRUESNE-PECOLLO, N,, KEITA, Y., TOUVIER, M., CHAN, D.S., NORAT, T., HERCBERG, S., et al., 2014. Alcohol drinking and second primary cancer risk in patients with upper aerodigestive tract cancers: a systematic review and meta-analysis of observational studies. Cancer epidemiology, biomarkers \& prevention, vol. 23, no. 2, pp. 324-31. doi: 10.1158/10559965.EPI-13-0779. PMID: 24307268.

GIRALDI, L., LEONCINI, E., PASTORINO, R., WUNSCH-FILHO, V, DE CARVALHO, M., LOPEZ, R., et al., 2017. Alcohol and cigarette consumption predict mortality in patients with head and neck cancer: a pooled analysis within the International Head and Neck Cancer Epidemiology (INHANCE) Consortium. Annals of Oncology, vol. 28, no. 11, pp. 2843-2851.

JEHN, P., KORN, P., GELLRICH, N.C., ZELLER, A.N., NEUHAUS, M.T., TAVASSOL, F., et al. 2021. Fulfillment of patients' information needs during oral cancer treatment and its association with posttherapeutic quality of life. Quality of life research, vol. 30, no.1, pp. 169-18o. doi: 10.1007/s11136020-02616-0. PMID: 32860572.

KANSKY, A., 2015. Rak ustne votline. In: LOGAR, M., ed. Celostna zdravstvena nega in oskrba pacienta $\mathrm{z}$ maligno boleznijo $\mathrm{v}$ področju glave in vratu: zbornik predavanj / 5. strokovni seminar izvajalcev ZN KO za maksilofacialno in oralno kirurgijo UKC Ljubljana. Brdo pri Kranju, 28. 11. 2015. Ljubljana: Združenje za maksilofacialno in oralno kirurgijo Slovenije, pp. $1-2$.

KANSKY, A., 2017. Zdravljenje malignih bolezni ustne votline. Kajenje in zdravje - nikoli končana zgodba, pp. 83 - 86. [online]. [viewed $1 \mathrm{Au}-$ gust 2021]. Available from: http://www.dlib.si/?URN=URN:NBN:SI:DOC-T2 $77 V_{5} C X$

KELL, M.A., GILMOUR, J. and VAN WISSEN., A., 2018. Nurses' experiences caring for patients surgically treated for oral cavity cancer. Nursing Praxis in New Zealand, vol. 34, no. 1, pp. 7-19.

LATINO-MARTEL, P., COTTET, V., DRUESNE-PECOLlO, N., PIERRE, F.H., TOUILLAUD, M., TOUVIER, M., 2016. Alcoholic beverages, obesity, physical activity and other nutritional factors, and cancer risk: A re- 
view of the evidence. Critical reviews in oncology/hematology, vol. 99, pp. 308-23. doi: 10.1016/j.critrevonc.2016.01.002. PMID: 26811140.

LOGAR ČUČEK, M., 2020. Rak ustne votline in urgentna stanja v maksilofacialnem in oralnem področju. Utrip, vol. XXVIII, no. 4, pp. 79-81.

MOHER, D., LIBERATI, A., TETZLAFF, J., ALTMAN, D.G. and PRISMA GROUP, 2009. Preferred reporting items for systematic reviews and meta-analyses: The PRISMA Statement. PLoS Medicine, vol. 6, no. 7, pp. 1-6.

MONTERO, P.H. and PATEL, S. G., 2015. Cancer of the oral cavity. Surgical Oncology Clinics of Nord America, vol. 24, no. 3, pp. 491-508.

RADOÏ, L. and LUCE, D., 2013. A review of risk factors for oral cavity cancer: the importance of a standardized case definition [online]. Community Dentistry and Oral Epidemiology, vol. 41, no. 2, pp. 97-109. [viewed $1 \mathrm{Au}-$ gust 2021]. Available from: https://doi.org/10.1111/j.1600-0528.2012.00710. xPMID:22882534

ROSENQUIST, K., 2005. Risk factors in oral and oropharyngeal squamous cell carcinoma: a population-based case-control study in southern Sweden. Swedish dental journal. Supplement. 179, pp. 1-66. PMID:

SCHORN, L., LOMMEN, J., SPROLL, C., KRÜSKEMPER, G., HANDSCHEL, J., NITSCHKE, J., PROKEIN, B., GELLRICH, N.C., HOLTMANN, H., 2020. Evaluation of patient specific care needs during treatment for head and neck cancer. Oral Oncology. 110:104898. doi: 10.1016/j.oraloncology.2020.104898. PMID: 32674039.

STROJAN, P., GRAŠIČ KUHAR, C., ČIZMAREVIĆ, B. and GALE, N., 2018. Raki glave in vratu. In: STROJAN., P. and HOČEVAR, M, eds. Onkologija: učbenik za študente medicine. Ljubljana: Onkološki inštitut, pp. 46o88.

STROJAN, P., ZADNIK, V., ŠIFRER, R., LANIŠNIK, B., DIDANOVIĆ, V., JEREB, S., et al., 2015. Incidence trends in head and neck squamous cell carcinoma in Slovenia, 1983-2009: role of human papillomavirus infection [online]. Eur Arch Otorhinolaryngol, vol. 272, no. 12, pp. 3805-3814. [viewed 1 August 2021]. Available from: https://doi.org/10.1007/s00405014-3459-7 PMID:25542247

STROJAN, P., ANIČIN, A., AZARIJA, J., BATTELINO, S., ČIZMAREVIĆ, B., DIDANOVIĆ, V. et al., 2021. Priporočila za obravnavo bolnikov z rakom glave in vratu v Slovenji. Onkologija, vol. XXV, no.1, pp. 78-84.

TSAI, S.T., WONG T.Y., OU, C.Y., FANG, S.Y., CHEN, K.C., HSIAO, J.R., et al., 2014. The interplay between alcohol consumption, oral hygiene, AL$\mathrm{DH}_{2}$ and $\mathrm{ADH} \mathrm{B}_{1} \mathrm{~B}$ in the risk of head and neck cancer. International journal of cancer, vol. 135, no. 10, pp. 2424-36. doi: 10.1002/ijc.28885. PMID: 24719202.

TWIGG, J.A., ANDERSON, J.M., HUMPHRIS, G., NIXON, I., ROGERS, S.N., KANATAS, A., 2020. Best practice in reducing the suicide risk in head and neck cancer patients: a structured review. The British journal 
of oral \& maxillofacial surgery, vol., 58, no. 9, pp. e6-e15. doi: 10.1016/j. bjoms.2020.06.035. PMID: 32682651.

VOGRINEC, 2008. Kvalitativno raziskovanje na pedagoškem področju. Ljubljana: univerza v Ljubljani, Pedagoška fakulteta. 



\title{
Prevention and rehabilitation in the context of long-term care (LTC) in Slovenia
}

\author{
Tatjana Pokrajac \\ University of Ljubljana, Medical faculty, Ljubljana, Slovenia \\ Tatjana.pokraja@@mf.uni-lj.si
}

\section{Abstract}

Introduction: Our work is a more extensive overview of the state of longterm care in Slovenia, describing existing social and health care, and preventive and rehabilitation services in the context of long-term care. Methods: A systematic review of the literature in that bibliographic COBISS database was used. The restrictive criteria were as follows: the literature was summarised from 2010 to 2020 , the authors included in the field of public health, title, summary and content containing content on long-term care. The key words for the search were „elderly“, „demography“ AND „elderly“, „long-term care“ AND „elderly“, „culture“ AND „elderly“, „prevention“ AND „elderly“, „prevention“ AND „longterm care“, „rehabilitation“ AND ”elderly”, „rehabilitation“ AND „longterm care“, „government“ AND „long-term care“, and „funding“ AND „long-term care“. The systematic review was carried out according to the Prisma (Preferred Reporting Items for Systematic Reviews and MetaAnalyses) guidelines. This work is a result of the findings of a European project called INTERLINKS (Engl. INTERfaces and LINKS between prevention, rehabilitation, quality of services and informal care), which deals with health systems and long-term care for older people in Europe. This article is adapted to the situation in Slovenia. Results: The reviewed literature covered 7320 articles, books, laws and results of national statistics, of which 27 were final. The results showed, firstly, that demographic development by 2050 includes both a relative and an absolute increase in older and very old people in Slovenia, and thus we expect an increasing number of people with long-term care needs. We already have a number of activities (e.g. help with personal hygiene at home, community care, social networking, etc.) and various providers (Community nurses, health technicians, social workers, etc.) who deal with issues that are elements of long-term care, but we do not yet have the full scope of this activity and the operators. Legislation on long-term 
care in Slovenia is currently being prepared at national level. Currently, activities are financed from a number of sources: central budget, municipal budget, direct payments and other sources such as voluntary contributions, grants and sponsorship. Discussion and conclusion: Longterm care in Slovenia is at the beginning of its operation. It is obvious that the system is very complex and fragmented, and still cannot meet all demand. Existing services and benefits are not linked to a single system. We hope that the system will be treated by legislation, a long-term care law, that has already been written and we are waiting for its adoption.

Keywords: demography; community nurse; social workers; home for older people; acute care

\section{Introduction}

Slovenia belongs to the countries with older population. In 2019, the proportion of people older than 65 years amounts to $20 \%$. Among all elderly citizens, the share of women lies at $30.2 \%$. In 2019, the total number of citizens aged 65 and above exceeded the total population from o to 15 years. Life expectancy for men in 2019 is 78.32 years and for women 83.98 years. In 2018, 20485 people died in Slovenia. An average year of death at the moment is 77.9 years. Thus, there will be a significant increase in the proportion of the population older than 80 years. Long-term population projections for 2050 indicate a further increase in the proportion of older people in Slovenia and an increase of $10.6 \%$ of the proportion of the population aged over 80 years (SORS, 2019). Slovenia does not have a single system for long-term care (LTC) for older people, chronically ill, disabled persons, who need partial or full assistance of another person. Instead, there is a variety of services and (cash) benefits providers, in the context of existing social protection systems and medical care (Prevolnik-Rupel, 2010; Toth, 2018). Social Security Act (SSA, 2007-2019) defines the available long-term care services in Slovenia, that are primarily intended for ill, handicapped and older persons. The Government of the Republic of Slovenia has announced a law, which will comprehensively regulate the activity of long-term care and provide a stable revenue collection by introducing a system of social (and voluntary) insurance scheme (GOV RS, 2019).

The aim of this article is to discuss the problems of long-term care in Slovenia, adding the knowledge and practice of prevention and rehabilitation within long-term care in Slovenia and contribute to the discussion and adoption of the Law on long-term care.

\section{Methods}

Descriptive research methodology was used to review peer-reviewed literature about prevention and rehabilitation within long-term care in Slovenia. The systematic review was carried out according to the PRISMA (Preferred Report- 


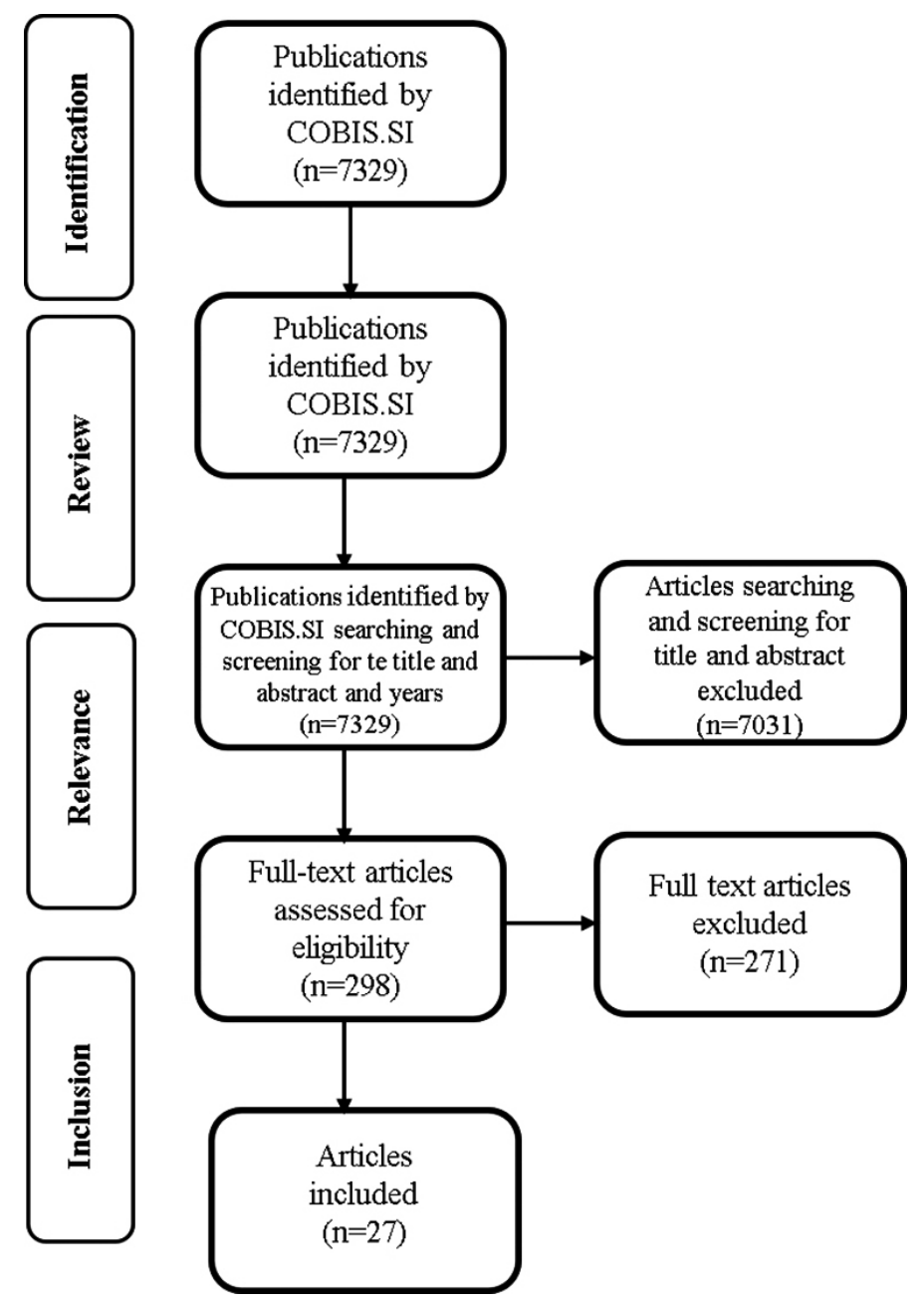

Figure 1: Flow chart of selection of researches

ing Items for Systematic Reviews and Meta-Analyses) guidelines (Welch, et al., 2012).

We searched the literature in the database COBIS.SI system in the period 1st of January 2000 to 30 d of November 2019. I used the search terms: " elderly', ' demography 'AND ' elderly', ' long-term care 'AND ' elderly', ' culture 'AND ' elderly ', ' prevention ' AND ' elderly ', 'prevention 'AND ' long-term care ', ' rehabilitation 'AND ' elderly', ' rehabilitation 'AND ' long-term care ', 'financing 'AND ' long-term care', government AND long-term care.

The websites of national and international organizations were also searched for data reporting long-term care published until 1st January 2010. These websites were selected on a discussion with all study authors including by project INTERLINKS (Kümpers, et al., 2010). Literature from Slovenian and other public health websites: "INTERLINKS", "National Institute of Public 
Level 1

Systematic review randomized clinic researches

$\mathrm{N}=5$

Level 2

Systematic review nonrandomized clinic researches

$\mathrm{N}=0$

Individual nonrandomized studies

$\mathrm{N}=0$

Level 3

Systematic review correlation / observational researches

$\mathrm{N}=4$

Level 4

Individual correlation / observational researches

$\mathrm{N}=0$

Level 5

Systematic review of descriptive / qualitatie / physiological researches $\mathrm{N}=2$

Level 6

Individual review of descriptive / qualitatie / physiological researches $\mathrm{N}=0$

Level 7

Opinions of authors, expert commissions

$\mathrm{N}=2$

\section{Figure 2: Hierarchy of evidence}

Health of the Republic of Slovenia" (NIPH RS), The Statistical Office of the Republic of Slovenia (SORS), Health Insurance Institute of Slovenia (HIIS), 2019 and "SHARE" (OECD, 2019). Laws has also been included in the review (CDA, 2006; FC, 2017-2019; PDIA -2, 2012 - 2020; Rules amending the Rules on the immunoprophylaxis and chemoprophylaxis Program for 2009; ReNSAP, 1320, 2013; SAA, 2007-2019).

The inclusion criteria were: the time window of the literatures in Slovene and English from 1st of January 2010 to 3ond of November 2019, qualitative and quantitative and scientific researches and reviews, at least one author was in the field of public health, thematic relevance according to the research area, fully accessible text.

Literature review from system COBISS was used for literature screening based on defined inclusion and exclusion criteria. We identified 7329 hits. We 
didn't have duplicates. We examined the hits for the title and abstracts and excluded $n=7031$ articles. Number of 271 full text articles are excluded. 27 hits corresponded to the inclusion criteria for the final analysis (Figure 1).

Evaluation of the quality of the review and description of data processing the quality of the literature review was determined by the example of Polita and Becka (Polita \& Becka, 2008). Two articles were based on a randomised clinical trial, four were based on a systematic review of correlation observation researches, one article was systematic review of descriptive/qualitative/physiological study and one was based as opinions of authors, expert commissions. The other articles were lower in terms of the hierarchy of evidence (Figure 2).

\section{Results}

We researched four sections within long-term care (prevention, rehabilitation, government and financing). The reason was, that the research is the part of the project of INTERLINKS which covered upper mentioned fields but is adopted on Slovenian environment. The characteristics of the individual scientific section included in the analysis are shown in Table 1 . Results are the principle of qualitative content analysis.

Table 1: A review of the key findings of the research included in qualitative content analysis

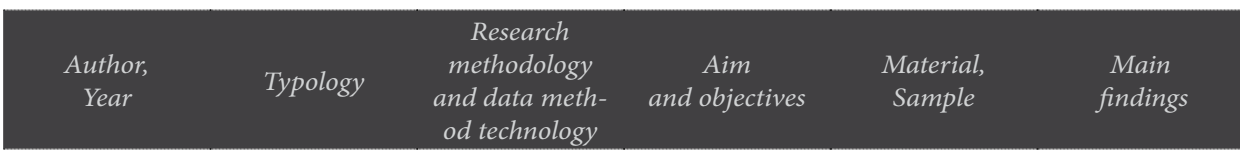

Cultural and political topics within LTC discourses in Europe; Governance: Col-

Descriptive vignettes; an EU quick-scan literature review;

Kümpers, et al., Project INTER2010 LINKS
Important thread in public and political debates focuses on the potential of prevention and rehabilitation for older people in European Union focus group discussions with the national Expert Panels and descriptive, national state of the art reports laboration versus competition; Embedding $\mathrm{P} \& \mathrm{R}$ in mainstream services; Embedding $\mathrm{P} \& \mathrm{R}$ in mainstream services; $\mathrm{P} \& \mathrm{R}$ across LTC pathways; Promoting self-determination and self-care in Europe; Special topic: Dementia. 


\begin{tabular}{|c|c|c|c|c|c|}
\hline $\begin{array}{c}\text { Author, } \\
\text { Year }\end{array}$ & Typology & $\begin{array}{c}\text { Research } \\
\text { methodology } \\
\text { and data meth- } \\
\text { od technology }\end{array}$ & $\begin{array}{c}\text { Aim } \\
\text { and objectives }\end{array}$ & $\begin{array}{l}\text { Material, } \\
\text { Sample }\end{array}$ & $\begin{array}{l}\text { Main } \\
\text { findings }\end{array}$ \\
\hline
\end{tabular}

Government

of the Repub-

lic of Slovenia,

2019 Conta-

gious Diseas-

es Act, 2006;

Rules amend-

ing the Rules

on the immu-

noprophylax-

is and chem-

oprophylaxis

Program for

2009, 2009; So- Law

The objective of

the long-Term

cial Assistance

Care Act is goal

to be accepted

Homemaking,

Help with personal hygiene,

Social network-

ing, Vaccina-

tion, Home

nursing (com-

munity nurs-

ing), Gener-

al practitioners

or family doc-

tor duties and

visits, Acute

care, history in

Slovenia, sub-

acute care, day

centers, insti-

tutional care,

home care, so-

sion and Disa-

bility Insurance

cial services.

2019. Fami-

ly Code, 2017-

2019

Statistical Of-

fice of the Re-

public of Slo-

venia (SORS),

2011; Statisti-

cal Office of the

Republic of Slo-

venia (SORS), National

2019; Outpa-

tient health-

care activities

(OHA) 2019;

Health Statis-

tical Yearbook,

2017; Hlebec,

2018 statistic

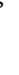

\begin{tabular}{|c|c|c|c|}
\hline $\begin{array}{l}\text { National } \\
\text { statistic }\end{array}$ & I & $\begin{array}{l}\text { Demographic } \\
\text { changes, num- } \\
\text { ber of home as- } \\
\text { sistance, num- } \\
\text { ber of nurses, } \\
\text { number of pre- } \\
\text { ventive visits, } \\
\text { number of cu- } \\
\text { rative visits, } \\
\text { number of so- } \\
\text { cial workers, } \\
\text { number of plac- } \\
\text { es at home for } \\
\text { older people, } \\
\text { number of shel- } \\
\text { tered housing. }\end{array}$ & $\begin{array}{l}\text { Slovenian pop- } \\
\text { ulation, } \\
\text { people older } \\
\text { than } 65 \text { years, } \\
\text { leaving in Slo- } \\
\text { venia, random } \\
\text { sample, as at } \\
\text { 3ond of June } \\
\text { the same year }\end{array}$ \\
\hline
\end{tabular}

Demographic

changes, num-

ber of home as-

ce, num -

number of $\mathrm{cu}$ -

rative visits,

number of plac-

es at home for

number of shel-

tered housing.
In 2019, the proportion of people older than 65 years amounts to 20\%; In 2017 the number of nurses was 853.55 we had 90.2 per 1000 population preventive visits and 489.2 per 1000 populations curative visits; in 2007 743 social workers carrying out home care; we have around 15.000 places at homes for older people. 


\begin{tabular}{|c|c|c|c|c|c|}
\hline $\begin{array}{c}\text { Author, } \\
\text { Year }\end{array}$ & Typology & $\begin{array}{c}\text { Research } \\
\text { methodology } \\
\text { and data meth- } \\
\text { od technology }\end{array}$ & $\begin{array}{c}\text { Aim } \\
\text { and objectives }\end{array}$ & $\begin{array}{c}\text { Material, } \\
\text { Sample }\end{array}$ & $\begin{array}{l}\text { Main } \\
\text { findings }\end{array}$ \\
\hline
\end{tabular}

\begin{tabular}{|c|c|c|c|c|c|}
\hline $\begin{array}{l}\text { Prevolnik-Ru- } \\
\text { pel et al., } 2010\end{array}$ & $\begin{array}{l}\text { Professional } \\
\text { monograph }\end{array}$ & $\begin{array}{l}\text { Review of the } \\
\text { literature, ob- } \\
\text { servational }\end{array}$ & $\begin{array}{l}\text { Long-term care } \\
\text { in Slovenia }\end{array}$ & $\begin{array}{l}\text { Slovenian pop- } \\
\text { ulation, } \\
\text { people older } \\
\text { than } 65 \text { years, } \\
\text { random sample }\end{array}$ & $\begin{array}{l}\text { Overview of the } \\
\text { system, assess- } \\
\text { ment of needs, } \\
\text { available LTC } \\
\text { services, man- } \\
\text { agement and } \\
\text { organization, } \\
\text { integration of } \\
\text { LTC, funding, } \\
\text { demand and } \\
\text { supply of LTC, } \\
\text { funding, LTC } \\
\text { policy }\end{array}$ \\
\hline $\begin{array}{l}\text { Hvalič Touzery, } \\
2014\end{array}$ & $\begin{array}{l}\text { Original scien- } \\
\text { tific article }\end{array}$ & $\begin{array}{l}\text { Statistics, bivar- } \\
\text { iant analysis }\end{array}$ & $\begin{array}{l}\text { Assessment of } \\
\text { satisfaction of } \\
\text { elderly in Slo- } \\
\text { venia }\end{array}$ & $\begin{array}{l}1306 \text { Slovenian } \\
\text { elderly }\end{array}$ & $\begin{array}{l}\text { The differences } \\
\text { between young } \\
\text { people and } \\
\text { the elderly in } \\
\text { terms of health, } \\
\text { well-being and } \\
\text { life satisfaction. } \\
\text { They found that } \\
\text { self-assessment } \\
\text { of health is as- } \\
\text { sociated with } \\
\text { age. The oldest } \\
\text { old people have } \\
\text { the most symp- } \\
\text { toms of vari- } \\
\text { ous diseases, } \\
\text { difficulty con- } \\
\text { centrating and } \\
\text { lacking ener- } \\
\text { gy and are most } \\
\text { limited in daily } \\
\text { activities. Posi- } \\
\text { tive attitudes to } \\
\text { life with age are } \\
\text { declining. }\end{array}$ \\
\hline
\end{tabular}




\begin{tabular}{|c|c|c|c|c|c|}
\hline $\begin{array}{c}\text { Author, } \\
\text { Year }\end{array}$ & Typology & $\begin{array}{c}\text { Research } \\
\text { methodology } \\
\text { and data meth- } \\
\text { od technology }\end{array}$ & $\begin{array}{c}\text { Aim } \\
\text { and objectives }\end{array}$ & $\begin{array}{c}\text { Material, } \\
\text { Sample }\end{array}$ & $\begin{array}{l}\text { Main } \\
\text { findings }\end{array}$ \\
\hline
\end{tabular}

The use of

(ICT) in the field of longterm care, in particular supply robotics, raises many serious concerns; the main is that the supply service of the robot is imperson-

Assessment of

Ramovš, 2019 Editorial

$\stackrel{ }{\circ}$ information

communica-

tion technology

(ICT) use
Review article al. The con-

cerns and fears are real. ICT is

not an appro-

priate substi-

tute for human

beings because

it embodies in-

ter-human co-

existence and

weakens in hu-

mans the social

immune im-

pulse of soli-

darity.

In Slovenia, the

health services

and social-ac-

tivity, and the

concept of

long-term care

are mixed, and

are not clearly

defined by law

and practice;

There are many

activities and

various con-

tractors, deal-

ing elements of

long-term care.

The long-term

care field is still

not able to cov-

er the needs.

Existing servic-

es and benefits

are not linked

into a single

system. 


\begin{tabular}{|c|c|c|c|c|c|}
\hline $\begin{array}{l}\text { Author, } \\
\text { Year }\end{array}$ & Typology & $\begin{array}{c}\text { Research } \\
\text { methodology } \\
\text { and data meth- } \\
\text { od technology }\end{array}$ & $\begin{array}{c}\text { Aim } \\
\text { and objectives }\end{array}$ & $\begin{array}{c}\text { Material, } \\
\text { Sample }\end{array}$ & $\begin{array}{l}\text { Main } \\
\text { findings }\end{array}$ \\
\hline Turk, 2008 & $\begin{array}{l}\text { Scientific re- } \\
\text { search article }\end{array}$ & Review & $\begin{array}{l}\text { Review of reha- } \\
\text { bilitation pro- } \\
\text { grams }\end{array}$ & $\begin{array}{l}\text { Slovenian pop- } \\
\text { ulation old- } \\
\text { er than } 65 \text { years } \\
\text { (random sam- } \\
\text { ple) }\end{array}$ & $\begin{array}{l}\text { Rehabilitation } \\
\text { measures in } \\
\text { case of injuries, } \\
\text { conic non-com- } \\
\text { municable dis- } \\
\text { eases; surgery, } \\
\text { early medical } \\
\text { rehabilitation, } \\
\text { home care, pal- } \\
\text { liative care }\end{array}$ \\
\hline $\begin{array}{l}\text { Government of } \\
\text { the Republic of } \\
\text { Slovenia (GRS), } \\
2019 .\end{array}$ & Speech & / & $\begin{array}{l}\text { Given the prob- } \\
\text { lem of frag- } \\
\text { mented and not } \\
\text { the entire sup- } \\
\text { ply of the elder- } \\
\text { ly, the objective } \\
\text { of the long- } \\
\text { Term Care Act } \\
\text { is goal to be ac- } \\
\text { cepted. }\end{array}$ & / & $\begin{array}{l}\text { On a national } \\
\text { level, long-term } \\
\text { car law is cur- } \\
\text { rently in prepa- } \\
\text { ration. }\end{array}$ \\
\hline $\begin{array}{l}\text { Social As- } \\
\text { sistance Act } \\
\text { (SAA)., 2007- } \\
\text { 2019; Health } \\
\text { Insurance In- } \\
\text { stitute of Slo- } \\
\text { venia (HIIS), } \\
\text { 2019; Pension } \\
\text { and Disability } \\
\text { Insurance Act } \\
\text { (PDIA -2), } 2012 \\
\text { - } 2019 . \text { OECD } \\
2018\end{array}$ & Law & / & $\begin{array}{l}\text { How do we } \\
\text { fund LTC ser- } \\
\text { vices? }\end{array}$ & / & $\begin{array}{l}\text { Long term care } \\
\text { in Slovenia is fi- } \\
\text { nanced from } \\
\text { multiple sourc- } \\
\text { es: } \\
\text { central budget, } \\
\text { municipal } \\
\text { budget, direct } \\
\text { payments and } \\
\text { other sources } \\
\text { like voluntary } \\
\text { contributions, } \\
\text { donations and } \\
\text { sponsorship }\end{array}$ \\
\hline
\end{tabular}

\section{Discussions}

According to our results, the article is a review description of the situation of long-term care in Slovenia, the special integration of prevention and rehabilitation within long-term care that would or would be carried out in Slovenia. The results obtained coincided with the results of the pre-European systematic researches (Kümpers et al., 2010).

Community nursing is organized as an independent organizational unit within primary health care institutions. Home visits are effective in reducing mortality, are effective in reducing admission to long-term institutional care/ nursing homes for older people and are effective in improving physical functioning or reducing physical decline in older people. Reference clinics are clinics of family medicine, reinforced by a graduate nurse. It is about strengthening the family medicine team and, he does, basic health activities, which is a health policy priority. In this way, the quality of work and patient satisfaction 
will be improved. The introduction of new staff will also allow for the reallocation of certain tasks and responsibilities (referencna-ambulanta.si/). The current Government wants to re-establish the Institute for gerontology and geriatric and adopted a document "Strategy care for the older by 2010 - solidarity, harmony and quality aging". The resulting gap is partially filled by the work of Institute Anton Trstenjak (http://www.inst-antonatrstenjaka.si/tisk/kakovostna-starost/stevilka.html). In Slovenia, virtually we do not have gerontologic hospital or institute, nor specialization on this field. Instead we have specialization for family doctors. In Slovenia after hospital discharge, many old people continue their treatment in the hospital with non-acute department - department of prolongation hospitalization and nursing department. The institutional care has the longest tradition in Slovenia and is the most spread in all Slovenian regions. Some institutionalized professional settings are performing activities in line of standards and procedures ISO 9001:2008 and E-Qualin (Prevolnik-Rupel, 2010).

Old age is marked with multimorbidity and greater frequency of injuries. Most common injuries are shaft fractures, osteoporotic vertebra fractures and hip fractures. Those decrease functional abilities and daily living quality. The current treatment for injuries include surgery, early medical rehabilitation and home care. Degenerative diseases, chronic diseases, diabetes, cerebrovascular diseases (CVD), arteriosclerosis, and osteoporosis, require a special form of rehabilitation, from early medical rehabilitation, immediately after the cerebrovascular insult, throughout to verticalization, spa treatment and home care. Oncological patients and palliative care for older people require special attention in the rehabilitation program. Artists are physiotherapists, occupational therapist and community nurses (Turk, 2010).

In the policy area on national level a law regarding long-term care are now in preparation stages for legislation (Prevolnik-Rupel, 2010).

According to the Social Security Act (UL 3/07) these sources are central budget, municipal budget, direct payments and other sources like voluntary contributions, donations and sponsorship money (Prevolnik-Rupel, 2010). A detailed estimation of expenditure for prevention and rehabilitation in LTC cannot be performed at the moment.

\section{Conclusions}

In Slovenia, health preventive measures in home environment are carried out by community nurses and GP/family doctors. GP/family doctors carry out the primary and secondary prevention of chronic non-communicable diseases. In 2007,743 social workers carried out social welfare measures. Rehabilitation services at home are almost not organized.

The rate of hospital treatment of older people in Slovenia is still growing. Non-acute hospitals have been operating for several years. Hospitals with departments of prolonged hospital treatment and nursing departments are be- 
ing implemented. The main task of non-acute departments is rehabilitation or continuation of rehabilitation, which the patient has already started on the sick ward. Daily centers are also undergoing preventive and rehabilitation programs: promoting healthy lifestyle, health education about diseases, exercises, working therapy, etc. In acute and non-acute hospitals social workers carry out organization of home environment, assisting in organizing the additional support at home or assist the installation of the older persons in the social security institutes.

\section{References}

CINZIA HROBAT, N., 2020. Zakonodaja in financiranje kot omejitve na področju razvoja oskrbovanih stanovanj:master thesis [on line]. Nova Gorica: FDŠ - Nova Univerza.

Fakulteta za državne in evropske študije [viewed 10. October 2020]. Available at: http://revis.openscience.si/info/index.php/slo/.

Contagious diseases act, 2006. Gazette of the Republic of Slovenia no. 33/2006.

Family code, 2017-2019. Official gazette of the Republic of Slovenia, no. 15, 21, 22/2017-2019.

Government of the Republic of Slovenia, 2019. Dolgotrajna oskrba. [on line]. [viewed 23. November 2019]. Available:at:https://www.gov.si/podrocja/ zdravje/dolgotrajnaoskrba/.

GovernmentoftherepublicofSlovenia,2019.PredlogZakona odolgotrajnioskrbi. [online]. [viewed 23. November2019].Availableat:https://www.google.com/ search?ei=slbZXabCBazokgWW9Yf4 BA\&q=predlog+zakona + o + dolgotrajni+oskrbi\&oq=Predlog+Zakona+o+dolgotrajni+oskrbi\&gs_l=psy-ab.1.o.oi19l2joi22i3oi19.4707.4707..6628...o.o..o.103.103.0j1..........2j1.. gws-wiz.c6lLvJ7ymG8\#spf=1574527214765].

Health insurance institute of Slovenia, 2019. Systems of Funding the Health Care Activities. [on line]. [viewed 23. November 2019]. Available at: http:// www.zzzs.si/index.html

HVALIČ TOUZERY, S., 2014. Zdravje, počutje in zadovoljstvo z življenjem najstarejših starih v Sloveniji. Teorija in praksa, vol. 51, no.2-3, pp. 458-474.

KÜMPERS, S., ALLEN, K., CAMPBELL, L., DIETERICH A., GLASBY. J., KAGIALARIS, G., et al., 2010. Prevention and rehabilitation within longterm care across Europe. Berlin, Copenhagen, Vienna: European Centre for Social Welfare and Research..

National institute of public health of the Republic of Slovenia, 2017. Health Statistical Yearbook. Ljubljana: NIJZ. [on line]. [viewed 10. 11. 2017]. Available at: http://www.zzzs.si/index.htmlAvailable at: https://www.nijz.si/sl/ publikacije/zdravstveni-statisticni-letopis-slovenije-2017. 
National institute of public health of the Republic of Slovenia, 2019. Zdrav življenjski slog. [on line]. [viewed 23. November 2019]. Available at: https:// www.nijz.si/sl/search/node/zdrav\%20\%C5\%BEivljenjski\%2oslog

National institute of public health of the Republic of Slovenia, 2019. Outpatient healthcare activities (OHA) 2019. [on line]. [viewed 23. November 2019]. Available at: https://www.nijz.si/sites/www.nijz.si/files/uploaded/podatki/podatkovne_zbirke_raziskave/zubstat_szbo/mn_kadri_in_ ure_2019_kon_a.pdf

OECD (EU), 2018. Health at a Glance: Europe 2018: State of health of the EU cycle. Paris: OECD Publishing, pp. 204. [on line]. [viewed 10. November 2018]. Available at: https://doi.org/10.1787/23056088

OECD (EU), 2019. Health at a Glance: Europe 2019; OECD Indicators. Paris: OECD Publishing. [on line]. [viewed 10. November 2019]. Available at: https://doi.org/10.1787/4dd50co9-en.

Pension and disability insurance act, 2012 - 2019. Official Gazette of the Republic of Slovenia, no. 96/12, 39/13, 99/13, 101/13, 44/14, 85/14, 95/14, 90/15, 102/15, 23/17, 40/17, 65/17 and 28/19 (2012-2019).

POLIT, D.F. and BECK, C.T. 2008 Nursing Research, Generating and Assessing Evidence for Nursing Practice. 8th ed, Philadelphia: Wolters Kluwer Health/Lippincott Williams \& Wilkins.

PREVOLNIK-RUPEL, V. and MAJCEN, B., 2010. Long term care system in Slovenia. Brussels: European Network of Economic Policy Research Institutes.

Referenčne ambulante družinske medicine. Referenčne ambulante družinske medicine.[on line]. [viewed 23. November 2020]. http://www.referencna-ambulanta.si/

Rules amending the rules on the immunoprophylaxis and chemoprophylaxis. program for 2009, 2009. Official Gazette of the Republic of Slovenia no. 24, 36/2009.

RAMOVŠ, J., 2019. Za kakovostno staranje in lepše sožitje med generacijami. Ljubljana: Inštitut Antona Trstenjaka za gerontologijo in medgeneracijsko sožitje.

Resolution on the national social assistance program 2013-2020. Official Gazette of the Republic of Slovenia no. 39/2013.

Social assistance act., 2007-2019. Official Gazette of the Republic of Slovenia, no. 3/o7, 23/07, 41/07, 61/10, 62/10, 57/12, 39/16, 52/16, 15/17, 29/17, 54/17, 21/18, 31/18and 28/19/2007-2019.

Statistical office of the Republic of Slovenia, 2011. The elderly in Slovenia. Ljubljana: Narodna in univerzitetna knjižnjica.

Statistical Office of the Republic of Slovenia (SORS), 2019. Novo v podatkovni bazi SiStat: Prebivalstvo, [on line]. [viewed 1. July 2019.]. Available at: https://www.program-svit.si/1. julij 2019. Available at: https://www.stat. si/StatWeb/News/Index/8498. 
TOTH, M., 2018. Dolgotrajna oskrba, kot nova in posebna veja socialne varnosti. Socialni izziv, vol. 23, no. 39, pp. 44-46.

TURK, Z., JESENŠEK PAPEŽ, B., TURK, E., 2008. Specifičnost rehabilitacije starostnikov. Zdravniški Vestnik, vol. 77, pp. 833-838.

World health organization, 2019. Nursing. [on line]. [viewed 23. November 2019.]. Available at: https://www.who.int/topics/nursing/en/

WElCH, V., PETTICREW, M., TUGWELl, P., MOHER, D., O`NEILL, J., WATERS, E., ET AL., 2012. PRISMA-Equity 2012 Extension: reporting Guidelines for systematic reviews with a focus onhealth equity. Public Library of Science Medicine, vol. 9, no.10. Availabke at; https://doi. org/10.1371/journal.pmed.1001333 



\title{
Comparison of applications used to help the elderly
}

\author{
Liza Privošnik, Maša Sedej Knezović, Lara Šinkovec, Andrej Starc \\ University of Ljubljana, Faculty of Health Sciences, Ljubljana, Slovenia
}

\section{Abstract}

Introduction: The COVID-19 pandemic has radically changed the existing infrastructure of medical practice, as clinics and hospitals around the world have focused on virtual resources to help care for patients. Technology has become critical to our wellbeing. Specifically, the technology for older adults is addressed for content that the elderly have the most needs in. The aim of this literature review is to present a comparison of mobile applications designed to help older adults in their basic life activities. Methods: A quantitative descriptive research method with critical review of English scientific and professional literature was performed using the following databases DiKul, PubMed, Researchgate and SienceDirect. The literature search took place from March 2021 to April 2021. Literature inclusion criteria were articles published between 2016 and 2021, open and free access and articles with clearly defined objectives and methods in English language. The exclusion criteria were articles published before 2016 , articles with paid access and articles that were not in English language. We reviewed 51 articles and excluded 35 articles that didn't match our criteria. We included 16 articles. Data was analyzed using a content analysis method. Results: The results showed that there are a few different mobile applications for different conditions in the market. All of them are designed to make life easier for elderly. There is evidence that mobile applications are helping elderly population as much as they help health workers. The benefits of reviewed mobile applications are to help reduce rates of forgetting and of medication errors, and also increases perceived independence in managing medication. However, currently available applications for smart mobile terminals used by the aged, which serve as the important carrier of various internet services for elderly people, have obvious defects in quantity, service range, and charm. Results show that in any mobile application that we included in this review there is room for 
improvement. Discussion and conclusions: It is important to bridge the gap between the elderly people and modern technologies, which is achieved through more products designed based on emotional care and construction, and by providing an appropriate training program for the elderly population to use a smartphone. In the future, research should focus on testing mobile health interventions in patients at risk for poor adherence and on standardizing alerts and protocols for clinicians.

Keywords: elderly, technology, mobile application, ICT

\section{Introduction}

The COVID-19 pandemic has radically changed the existing infrastructure of medical practice, as clinics and hospitals around the world have focused on virtual resources to help care for patients. Various professional associations emphasize the importance of the transition to telemedicine whenever possible (Lakkireddy et al., 2020). Technology has become critical to our wellbeing. Technology also presents many opportunities for expanding the possibilities of having a good life, and consequently is now somehow a necessity (Uysal et al., 2016).

The interest and needs of older adults are mainly focused around employment, housing, health and social care (Özsungur, 2019). Specifically, the technology for older adults is addressed for content, that the elderly have the most needs in. That includes programs and mobile applications for healthcare monitoring needs (medication instruction), social needs, and also safety and privacy needs (Klimova, Karesova, 2016).

The aim of this literature review is to present a comparison of mobile applications designed to help older adults in their basic life activities.

\section{Methods}

A quantitative descriptive research method with critical review of English scientific and professional literature was performed using the following databases DiKul, PubMed, Researchgate and SienceDirect. The keywords we used for searching literature were: elderly, technology, mobile application and ICT. Literature inclusion criteria were articles published between 2016 and 2021, open and free access and articles with clearly defined objectives and methods in English language. We reviewed 51 articles and excluded 35 articles that didn't match our criteria. We included 16 articles. The literature search took place in March 2021. Data was analysed using a content analysis method.

\section{Results}

The results of the review are presented in Table 1, where the first author and year of publication, methods and main results are written. 
A preliminary analysis was made by in-

Qi, 2016 terviewing 20 elderly people between $60-70$ years old on their usage of the mobile applications.

181 patients with diverse cancers who were prescribed oral therapy were randomized to receive either the smartphone mobile application or stand-

Greer, 2020 ard care. Linear regression was used to assess intervention effects on adherence and change in self-report outcomes from baseline to week 12, controlling for baseline scores and social support.

This retrospective cohort study included patients with diabetes recruited to the Lilly Connected Care Program (LCCP) platform for 8 months. According to the number of diabetes education courses they had completed, the patients were divided into three groups. Univariate and multivariate linear regression analyses were used.
Currently available mobile applications for smart mobile terminal used by the aged, which serve as the important carrier of various defects in quantity, service, range and charm.

Although the mobile application may not improve outcomes for all patients prescribed oral cancer therapy, the intervention may be beneficial for those with certain risk factors, such as difficulties with adherence or anxiety.

LCCP application-based diabetes education is effective for glycemic control and SMBG behavior improvement in patients with type 2 diabetes receiving insulin therapy.
41 participants performed three CMJs assessed via a contact mat and the My Jump application. The intraclass corre-

Cruvinel-Cabral, 2018 lation coefficient was used to verify the relative reliability, the coefficient of variation and the typical error of measurement were used to verify the absolute reliability.

The aim was to determine whether a prevention mobile application "Aachen fall prevention App" (AFPA) would be accepted and downloaded voluntarily by persons in the target population.

A quasi-experimental design was employed. Seventeen older people self-reported health concerns via Interaktor twice a week for 3-months and answered questionnaires at baseline, the end of the intervention and at a 6 -month follow-up.

Authors conducted semi-structured interviews in two groups to uncover their recommendations and requirements of application, the one was patients who never used applications that related to diabetes and another group was patients who ever used it.
Results suggest that the My Jump application is a valid and reliable tool compared to the contact mat for evaluating vertical jump performance in the elderly.

This field study revealed the AFPA as a promising tool to raise older adults awareness of their individual fall risk by means of a low-threshold patient-driven fall risk assessment tool.

The high application usage showed that an application may be a suitable tool for some older people living alone and receiving home care. The results indicate that the usage of Interaktor can support older people by significantly improving their communicative and critical health literacy.

A total of 24 empty nest elderly were interviewed, among them, 11 patients use smartphone and 13 not. Four themes were formed including knowledge of diabetes, record and reminders of medicine taking, blood glucose tests, appointments, communicate with peers and health service providers, feedback from health service providers. 
Researchers wanted to investigate to what extent two-week device-supported cycle training (modified version of the THERA-Trainer tigo ${ }^{\circ}$ and application-based fall risk assessment (certified medical application Lindera Mobilitätsanalyse) are feasible measures for fall prevention in older people living at

Fuchs, 2020 home. They used one-group pre-post design over a two-week intervention period. A questionnaire assessed participants'motivation, and a fall risk score was calculated pre- and post-intervention. The qualitative interviews were carried out retrospectively among two expert service providers after the intervention study.

Zhao, 2020

Zhong, 2020

Isaković, 2016 wait-list control group or the intervention group according to a random number. A smartphone training program was developed and was then made up of two modules. The first training module was easiest and focused on theoretical aspects. The second was focused on practical aspects, covering various smartphone applications.

A single-blind randomized controlled trial was conducted with a control and an experimental group in Spain in 2013. The characteristics of application called ALICE were specified based on the suggestions of 3 nominal groups with a total of 23 patients and a focus group with 7 professionals.

Authors recruited a total of 148 community-dwelling older adults aged 60 years and older from two cities in China: Beijing and Chongqing. User acceptability was measured by a questionnaire including four quantitative measures.

A nonequivalent control group with a non-synchronized design was utilized, and 60 participants were recruited from Chungnam National University Hospital from March to August 2018. Data were analysed using the $\chi^{2}$-test, the t-test, the repeated-measures ANOVA, and the $\mathrm{McNemar}$ test.

Authors perform subsequent usability evaluations on end users alone. The users were all older than 50 , with the average age of 64.2 years.
344 participants were included. The participants were randomly assigned to the
The results showed a high subjective motivation during the training and a slight reduction of the fall risk. Both the training and the assessment are feasible and well-received interventions. The respondents' self-assessed affinity for technology was moderate.

A significant improvement in smartphone usage competency for participants in the intervention group compared with the wait-list control group was reported. In the intervention group was presented a significant increase in smartphone application proficiency. However, that did not occur in wait-list control group. The intervention group showed big improvement in quality of life compared to the wait-list control group.

The ALICE application improves adherence, helps reduce rates of forgetting and of medication errors, and increases perceived independence in managing medication. Also elderly were able to use this application without any knowledge of computer skills.

This mobile phone application is a health management tool for older adults to self-manage their gait quality and prevent adverse outcomes.

The mobile- application-based self-management program developed in this study increased the sick-role behavior, basic psychological needs, and self-efficacy of elderly hemodialysis patients, while physiological parameters were maintained within the normal range.

The results show, that applications developed for the general population are not necessarily suitable for elderly users, which can be a significant problem, especially if they address the issues of the elderly users specifically. 
This study was a nonprobabilistic pilot trial using convenience sampling. An intervention was implemented among a group of 22 older adults between 60

Martínez-Alcalá, 2018 and 80 years of age over 12 weeks. Half of the older adults were stimulated with the mobile application and the other half followed the traditional paper and pencil training.

A randomized controlled study was conducted in subjects aged 6o years and older with food insecurity, identified at 17

Rodrigues, 2017 primary care centers in the Lisboa e Vale do Tejo health region in Lisbon, Portugal. The primary outcome was the changes in participants' food insecurity score at 3 months.

The subjects of the study were elderly people who wanted to check their weight and cardiac status. For this purpose, two mobile applications were used to measure energy expenditure based on physical activity and heart rate during controlled walking at specific speeds.
The intervention data show that the experimental group obtained better results in the postevaluation given that the participants were able to execute the exercises repetitively.

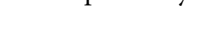

This study assesses the efficacy of this innovative tool for disseminating relevant health information, modifying behaviors, and decreasing food insecurity in an easy, low-cost, and massive way.

\section{Discussion}

In this information era, mobile applications have become an important tool in our work, life and entertainment. Third-party mobile applications that provide us with various convenient services have gradually become an essential part of our daily lives. Elderly people have been gradually becoming an important strength supporting the internet economy. However, currently available mobile applications for smart mobile terminals used by the aged, which serve as the important carrier of various internet services for elderly people, have obvious defects in quantity, service range, and charm (Qi et al., 2016). As Qi et al. (2016) point out, bridging the gap between elderly people and modern technologies requires more products designed based on emotional care and construction. Fields such as the design of intelligent mobile terminals and mobile applications for elderly still need further development.

It is important for creators that are developing mobile application used by the elderly people, to be aware of the shortcomings and problems that the elderly people face when using previously mentioned applications. If the mobile application is created well, used by in our case elderly people, helps reduce rates of forgetting and of medication errors, can also increase perceived independence in managing medication, reduction of fall risk, and also improving their communicative and critical health literacy.

An analysis of the mobile application for diabetes DeStress Assistant (DeSA), which was developed within the EU project and tested in a hospital by Isaković and colleagues (2016), showed that with a limited amount of modi- 
fications, an existing mobile application can be significantly improved to better suit elderly users. This could also be facilitated by creating different profiles to optimize the mobile application for different accessibility groups (e.g., poor eyesight and limited dexterity). A user could simply select their profile and the mobile application would be configured to their preferences. Such personalization features would of course have significantly larger impact and reach, if they were consistently implemented in all of the major mobile device operating systems.

When creating a mobile application designed for older adults with diabetes, creators need to focus on four important points: 1) The patient's knowledge of diabetes; 2) Record and reminders of medicine taking, blood glucose test, appointments; 3) Communicate with peers and health service providers; 4) Feedback from health service providers (Lv et al., 2018). In view of all the above, the mobile applications in question can also help healthcare professionals. Patients would not need frequent doctor's appointment, as only through the application used by their patients, could they find out how well the patient knows and works within the aforementioned four points.

Fall incidents are also a major problem for elderly patients and also healthcare. The Aachen Fall Prevention application (AFPA) represents the first mobile Health application empowering older patients (persons 50+ years) to self assess and monitor their individual fall risk. Rosche et al. (2017) conducted a study that revealed that AFPA is a promising tool to raise older adults' awareness of their individual fall risk by means of a low-threshold patient-driven fall risk assessment tool.

\section{Conclusions}

Mobile applications have become an important tool of our everyday life. There are a few different mobile applications for different conditions on the market. All of them are designed to make life easier for elderly. It is important to bridge the gap between the elderly people and modern technologies, which is achieved through more products designed based on emotional care and construction, and by providing an appropriate training program for the elderly population to use a smartphone.

Well-created mobile applications help reduce rates of forgetting and of medication errors, can also increase perceived independence in managing medication, reduction of fall risk, it improves knowledge about their disease and how to control it, and also improving their communicative and critical health literacy.

In the future, research should focus on testing mobile health interventions in patients at risk for poor adherence and on standardizing alerts and protocols for clinicians. 


\section{References}

BOUKHENNOUFA, I., AMIRA, A., BENSAALI, F. and ESFAHANI, S.S., 2020. A novel gateway-based solution for remote elderly monitoring. Journal of biomedical informatics, vol. 109, pp. 1-11. Available from: http://dx.doi. org/10.1016/j.jbi.2O20.103521

CRUVINEL-CABRAL, R.A., OLIVEIRA-SILVA, I., RICARTE MEDEIROS, A., CLAUDINO, J.G., JIMÉNEZ-REYES, P. and BOULLOSA, D.A., 2018. The validity and reliability of the "My Jump App" for measuring jump height of the elderly. Peer J, vol. 6, pp. e5804. Available from: https://doi. org/10.7717/peerj.5804

DAMANT, J. and KNAPP, M., 2015. What are the likely changes in society and technology which will impact upon the ability of older adults to maintain social (extra-familial) networks of support now, in 2025 and in 2040 ? London, 2015 [online]. [viewed 10 April 2021]. Available from: https:// core.ac.uk/download/pdf/35436349.pdf

FUCHS, D., TIEBEL, J. and FRIEDRICH, P., 2020. Device-supported training and assessment for fall prevention of community-dwelling elderly: a pre-post mixed methods study. Procedia Computer Science, vol. 176, pp. 2322-31. Available from: https://doi.org/10.1016/j.procs.2020.09.293

GÖRANSSON, C., WENGSTRÖM, Y., HÄLLEBERG-NYMAN, M., LANGIUS-EKLÖF, A., ZIEGERT, K. and BLOMBERG, K., 2020. An app for supporting older people receiving home care - usage, aspects of health and health literacy: a quasiexperimental study. BMC Medical Informatics and Decision Making, vol. 20, no. 1, pp. 226. Available from: https://doi. org/10.1186/s12911-02O-01246-3

GREER, J.A., JACOBS, J.M., PENSAK, N., NISTOEL, L.E., FISHBEIN, J.N., MACDONALD, J.J., REAM, M., WALSH, E.A., BUZAGO, J., MUZIKANSKY, A., et al., 2020. Randomized trial of a smartphone mobile app to improve symptoms and adherence to oral therapy for cancer. Journal of the National Comperhensive Cancer Network, vol. 18, no. 2., pp. 133-41. Available from: https://doi.org/10.6004/jnccn.2019.7354

IANCU, I. and IANCU, B., 2020. Designing mobile technology for elderly. A theoretical overview. Tehnological Forecasting and Social Change, vol. 155, pp. 1-9. Available from: https://doi.org/10.1016/j.techfore.2020.119977

ISAKOVIĆ, M., SEDLAR, U., VOLK, M. and BEŠTER, J., 2016. Usability pitfalls of diabetes mHealth apps for the elderly. Journal of diabetes research, vol. 2016, no. 2, pp. 1-9. Available from: http://dx.doi.org/10.1155/2016/1604609

KLIMOVA, B., and MARESOVA, P., 2016. Elderly people and their attitude towards mobile phones and their applications - a review study. In: PARK. J.H., CHAO, H.C., ARABNIA, H.R., YEN, N.Y, ed. Advanced Multimedia and Ubiquitous Engineering [online]. New York: Springer. [viewed 10 March 2021]. Available from: 10.1007/978-3-662-47487-7 
LAKKIREDDY, D.R., CHUNG, M.K., GOPINATHANNAIR, R., PATTON, K.K., GLUCKMAN, T.J., TURAGAM, M., CHEUNG, J.W., PATEL, P., SOTOMONTE, J., LAMPERT, R., HAN, J.K., et al., 2020. Guidance for cardiac electrophysiology during the COVID-19 pandemic from the Heart Rhythm Society COVID-19 Task Force; Electrophysiology Section of the American College of Cardiology; and the Electrocardiography and Arrhythmias Committee of the Council on Clinical Cardiology, American Heart Association. Hearth Rhythm Society, vol. 17, no. 9, pp. e233e241. Available from: https://doi.org/10.1016/j.hrthm.2020.03.028

LV, X., XIA, J., FU, L. and CAO, Y., 2018. Design of a mobile APP for empty nest elderly patients with T2DM. Studies in health technology and informatic, vol. 250, pp. 146-147. [viewed 10 April 2021]. Available from: https://pubmed.ncbi.nlm.nih.gov/29857411/

MARTÍNEZ-ALCALÁ, C.I., ROSALES-LAGARDE, A., HERNÁNDEZ-ALONSO, E., MELCHOR-AGUSTIN, R., RODRIGUEZ-TORRES, E.E. and ITZÁ-ORTIZ, B.A., 2018. A mobile app (iBeni) with a neuropsychological basis for cognitive stimulation for elderly adults: pilot and validation study. Journal of medical internet research, research protocols, vol. 7, no. 8. Available from: http://dx.doi.org/10.2196/resprot.9603

MIN, Y. and PARK, M., 2020. Effects of a mobile-app-based self-management support program for elderly hemodialysis patients. Healthcare informatics research, vol. 26, no. 2, pp. 93-103. Available from: http://dx.doi. org/10.4258/hir.2020.26.2.93

MIRA, J.J., NAVARRO, I., BOTELLA, F., BORRÁS, F., NUÑO-SOLINÍS, R., OROZCO, D., IGLESIAS-ALONSO, F., PÉREZ-PÉREZ, P., LORENZO, S. and TORO, N., 2014. A Spanish pillbox app for elderly patients taking multiple medications: randomized controlled trial. Journal of medical internet research, vol. 16, no. 4. Available from: http://dx.doi.org/10.2196/ jmir.3269

ÖZSUNGUR, F., 2019. Gerontechnological factors affecting successful aging of elderly. The aging male, vol. 23 , no. 5, pp. 520-532. Available from: http:// dx.doi.org/10.1080/13685538.2018.1539963

QI, X., ZHANG, W. and HAO, F., 2016. Design of emotional constructionBased life service APP for elderly people. 2016 Intl IEEE Conferences on Ubiquitous Intelligence \& Computing, Advanced and Trusted Computing, Scalable Computing and Communications, Cloud and Big Data Computing, Internet of People, and Smart World Congress (UIC/ ATC/ScalCom/CBDCom/IoP/SmartWorld), Toulouse, France 18.- 22. July 2016 [online]. Piscataway: IEEE pp. 1045-51. Available from: https://doi. org/10.1109/UIC-ATC-ScalCom-CBDCom-IoP-SmartWorld.2016.0163

RAMIREZ LOPEZ, L.J., GUILLEN PINTO, E.P. and RAMOS LINARES, C.O., 2018. Effective validation model and use of mobile-health applications for the elderly. Healthcare informatics research, vol. 24, no. 4, pp. 276-282. Available from: http://dx.doi.org/10.4258/hir.2018.24.4.276 
RASCHE, P., MERTENS, A., BROHL, C., THEIS, S., SEINSCH, T., WILLE, M., PAPE, H.C. and KNOBE, M., 2017. The "Aachen fall prevention App" - a Smartphone application app for the self assessment of elderly patients at risk for ground level falls. Patient Safety in Surgery, vol. 11, no. 14. Available from: https://doi.org/10.1186/s13037-017-0130-4

RODRIGUES, A.M., GREGÓRIO, M.J., GEIN, P., EUSÉBIO, M., SANTOS, M.J., DE SOUSA, R.D., COELHO, P.S., MENDES, J.M., GRAÇA, P., OLIVEIRA, P., BRANCO, J.C. and CANHÃO, H., 2017. Home-based intervention program to reduce food insecurity in elderly populations using a TV app: study protocol of the randomized controlled trial Saúde. Come Senior. Journal of medical internet research, research protocols, vol. 6, no. 3. Available from: http://dx.doi.org/10.2196/resprot.6626

UYSAL, M., SIRGY, M.J., WOO, E. and KIM, H.L., 2016. Quality of life (QOL) and well-being research in tourism. Tourism management, vol. 53, pp. 244-261. Available from: http://dx.doi.org/10.1016/j.tourman.2015.07.013

ZHANG, Y., LIU, C., LOU, S., HUANG, J., LI, X. and ZHOU, Z., 2020. Effectiveness of Lilly Connected Care Program (LCCP) App-Based Diabetes Education for Patients With Type 2 Diabetes Treated With Insulin: Retrospective Real-World Study. JMIR Mhealth and Uhealth, vol. 8, no. 3, pp. e17455. Available from: https://doi.org/10.2196/17455

ZHAO, X., WANG, L., GE, C., ZHEN, X., CHEN, Z., WANG, J. and ZHOU, Y., 2020. Smartphone application training program improves smartphone usage competency and quality of life among the elderly in an elder university in China: A randomized controlled trial. International journal of medical informatics, vol. 133, pp. 1-8. Available from: http://dx.doi. org/10.1016/j.ijmedinf.2019.104010

ZHONG, R. and RAU, P.P., 2020. A mobile phone-based gait assessment app for the elderly: development and evaluation. Journal of medical internet research, Mhealth and Uhealth, vol. 8, no. 5. Available from: http://dx.doi. org/10.2196/14453 



\title{
The importance of educating older adults with diabetes
}

\author{
Kristina Rakuša Krašovec \\ University of Novo mesto, Faculty of Health Sciences Novo mesto, Novo mesto, Slovenia \\ kristina.rakusa-krasovec@uni-nm.si
}

\begin{abstract}
Introduction: Diabetes is a chronic non-communicable disease of modern times. At the same time, one can almost speak of a pandemic, because type 2 diabetes is one of the leading diseases of modern times. It affects adults after the age of 40 , and the cause of its morbidity is mainly inappropriate lifestyle. Therefore, it is extremely important here to properly educate both the older and younger generation so that they know how to prevent themselves. Method: The research is quantitative and based on descriptive and causal non-experimental method of work. The data for the analysis of the empirical work was obtained using a survey technique, which was processed and graphically displayed on a computer. The study included 90 patients treated for diabetes in Celje General Hospital. Results: Research has shown that diabetic patients are receptive to new information and knowledge as they are aware that this is the only way they can maintain their health as optimal as possible. They are aware that their health depends on following all the medical advice they receive from the medical staff with whom they are very satisfied. It was noted that it is the medical personnel who are concerned about supporting and motivating the diabetic patients and their relatives. Discussion and conclusion: The term training means education and to train diabetic patients properly, the medical staff must have a wide range of knowledge. Adequate training is extremely important in maintaining and preventing the deterioration of health of a patient with diabetes. Diabetic patients are usually elderly people who are often unaware of how severe the disease is and how important they themselves are in preventing the development of chronic complications from the disease. It is important that they cooperate and be involved in the treatment process itself, which will be even more successful with the right education.
\end{abstract}

Keywords: diabetes, training, health education, patient 


\section{Introduction}

Diabetes mellitus is a chronic metabolic disease characterized by hyperglycemia due to disturbances in the secretion and/or function of insulin, resulting in disturbances in the function of carbohydrates, fats, and proteins (Ryden et al., 2007). There are different types of diabetes: type 1, type 2, gestational diabetes (Khan et al., 2019), secondary type of diabetes, hybrid types of diabetes and unclassified types (World Health Organization, 2019). Diabetes can be termed as a non-communicable epidemic. The number of diabetics is increasing rapidly, especially type 2 diabetics. In the treatment of diabetics, medical education is of great importance. Its aim is to enable the patient to control his own disease, to take over self-control and thus prevent the complications of inadequately treated diabetes. Type 2 diabetes is primarily a disease of older adults, as it usually occurs after the age of 40 . It occurs after the age of 40. It accounts for $90-95 \%$ of all diabetes cases, although unfortunately it is also more common in young people, especially in developed countries (Weale et al., 2019). Sokolov (2012) explains that in this type of diabetes, the pancreas produces insulin, but in small amounts, or the body has developed a resistance to it. It occurs quite inconspicuously, as patients often do not become ill until they already have chronic complications due to the disease or. find out during a random examination. Risk factors for a person to develop this type of diabetes are: Age, obesity, physical inactivity, hypertension and dyslipidemia, hereditary predisposition, and women with gestational diabetes during pregnancy (American diabetes..., 2013; Mrevlje, 2005).

Education is part of general education and a basic task of nurses (Dolinar, 2016; Janjoš et al., 2012). The patient must actively participate in the treatment process, for which he must be properly informed, motivated and educated if he is to be able to properly manage his disease (Janjoš et al., 2012; Poljanec Bohnec, 2016). Education involves a multidisciplinary team whose goal is to achieve the highest possible quality of life and prevent exacerbation of the disease (Poljanec Bohnec, 2016). Most patients are overweight, have elevated triglycerides and often hypertension (Tomažin Šporar, 2012), so they need to learn to measure and control blood glucose and blood pressure and adjust therapy accordingly (Pandit et al., 2014). In this way, they increase their autonomy, prevent glycaemia and consequent complications (Grégoire and Philis, 2017; Volčanšek and Zaletel, 2016). Since many diabetics suffer from depression, it is important to prevent this (Kaučič, 2020).

\section{Methods}

The aim of the study was to determine the awareness of type 2 diabetics about their health status, the adequacy of health education provided by medical staff and the motivation of patients to accept new information. The research was based on a quantitative working method. For the purpose of the empirical work, primary and secondary sources were collected, analyzed and synthesized. Primary data for the analysis was obtained using a survey tech- 
nique. For the theoretical part, technical and scientific literature was used, which was obtained from international databases. For the purpose of the study, an open and closed-ended questionnaire was prepared based on a review of foreign and domestic literature. The first part of the questionnaire was dedicated to demographic data, while the second part was related to the research questions.

The research was conducted in the General Hospital of Celje. It included 83 patients. The survey was conducted in January and February 2020 in a diabetic clinic. Consent was obtained from the General Hospital of Celje. Participation in the survey was voluntary and anonymous. The collected data were analyzed computerized using Microsoft Office Excel and presented in the results. Ethical principles of research were followed at all stages of data collection and processing.

\section{Results}

Majority of the respondents were above 61 years old, 62 (75\%), 11 (13\%) were between 51 and 60 years old and $10(12 \%)$ were between 31 and 50 years old and participated in the survey.

Most of the respondents do not have normal body weight but are overweight. Only $17 \%$ of the respondents have normal diet. Regarding diabetes management, 50\% need tablets, 37\% need diet and $13 \%$ already need insulin. The majority of respondents say they are aware of their disease, $51 \%$. The same percentage say they have received most of the information about their disease from medical staff. Our respondents are highly motivated for health education, as many as $79 \%$ of them, the rest are not motivated. $83 \%$ of them answer that there is enough health education material about their disease. Majority of the respondents (66\%) also answered that medical staff provides adequate support in managing diabetes. When we determined how many patients perform blood glucose self-monitoring, we found a high percentage $(86 \%)$. When determining the normal fasting blood glucose, $82 \%$ responded that this value is less than $6.0 \mathrm{mmol} / \mathrm{l}$. When asked what problems occur with diabetes, there were several possible answers. That it is visual disturbances, answered $86 \%, 80 \%$ answered that the sensitivity of the feet to touch decreases, $64 \%$ indicated vascular problems, $45 \%$ decreased concentration, $37 \%$ difficulty urinating, $21 \%$ decreased appetite, $18 \%$ memory loss, $2 \%$ reported thirst and fatigue. In terms of causes of hypoglycaemia, where multiple responses were possible, $75 \%$ reported that the most common cause was inadequate food intake, $65 \%$ agreed that this was due to overdose of insulin or tablets, $20 \%$ reported alcohol consumption and $14 \%$ could not answer this question. What changes the respondents look out for when observing their feet, $91 \%$ answered that it was sore feet, $66 \%$ swollen feet, $65 \%$ nail changes, $46 \%$ blisters, $43 \%$ dry skin, $7 \%$ answered I don't know. Majority of the respondents answered that they are satisfied with the type of training provided in the diabetic clinic, $74 \%$ of them. 


\section{Discussion}

We find that majority of the respondents are well aware about their disease and are motivated to participate in the treatment in which they are actively involved. The educational work of the medical staff and their attitude towards patient education also plays an important role. The majority of participants rate this as good, they are satisfied with the work of the medical staff. However, there are obstacles in absorbing information, as the majority of respondents do not have a university degree, which leads to difficulties in understanding new information. Most of the respondents are over 61 years old, which is an additional barrier to receiving information. Problems can arise when medical professionals use terminology that is not understandable to most patients.

According to Starc (2003), the purpose of health education for diabetics is to change behavior, which would enable the patient to have the best possible quality of life despite diabetes. Teaching a patient about his or her illness is crucial to the course of a chronic illness and is an important part of treatment. The role of providers of health education content is counseling, learning, practical demonstration, testing of knowledge and motivating patients and relatives to achieve the best self-management of the disease (Curhalek, 2013). In modern times, patients are increasingly educated and informed due to the availability of information and also the desire for permanent education. Therefore, health education is becoming increasingly complex and demanding, which means that health professionals must also be properly educated and must upgrade their knowledge (Sajko and Ertl, 2009). Gjuran (2011) states that motivation is a key psychological function. The learning itself must be adapted to the patient and also to the health professional, his abilities and environment, and above all it is important that it is easy for the patient (Žerdoner, 2016). Today's approach in health education focuses on the patient, in his active role, that they know how to take care of their own health and prevention (Koprivnikar, 2008). A diagnosis of diabetes can have very negative psychological consequences for the patient and his relatives, so the proper health education is of utmost importance. When a patient gains care for his illness, his self-confidence and life optimism also grow (Vrtovec, 1999).

\section{Conclusion}

Diabetes is a major health problem in the developed world. The number of newly diagnosed patients with diabetes is increasing rapidly, so it is extremely important to raise public awareness about the risk factors that can lead to the onset of diabetes and the appropriate prevention. For patients with diabetes who already have the disease, it is important to provide consistent tertiary health education so that patients know how to manage their own disease, live with their disease, and prevent it from getting worse. It is very important that patients know how to prevent the occurrence of acute and chronic complications of diabetes. 


\section{References}

AMERICAN DIABETES ASSOCIATION, 2013. Diagnosis and Classification of Diabetes Mellitus [online]. Diabetes Care, vol. 36, no. 1, pp. 67-74. [viewed 15 June 2021]. Available from: https://care.diabetesjournals.org/ content/diacare/36/Supplement_1/S67.full.pdf

CURHALEK, V., 2013. Pasti pri posredovanju informacij in zdravstvenovzgojnih vsebin bolniku. In: FILEJ, B., eds. Celostna obravnava pacienta Kako daleč smo? Novo mesto: Fakulteta za zdravstvene vede Novo mesto, pp. 89-97.

DOLINAR, Š., 2016. Predlog modela edukacije za sladkorno bolezen. In: PEKLAJ, K., eds. Endokrinološki kongres zdravstvene nege. Ljubljana: Zbornica zdravstvene in babiške nege, pp. 11-12.

GJURAN, J., 2011. Motivacija pacientov s sladkorno boleznijo za sodelovanje pri zdravstveni obravnavi: diploma thesis. Maribor: Univerza v Mariboru, Fakulteta za zdravstvene vede, pp. 19.

GRÉGOIRE, J. and PHILIS, M. G., 2017. L'éducation nutritionnelle du patient diabétique [The nutritional education of patients with diabetes] [online]. Soins; la revue de reference infirmiere, vol. 62, no. 815, pp. 19-23 [viewed 16 June 2021]. Available from: https://doi.org/10.1016/j.soin.2017.03.006

JANJOŠ, T., KLAVS, J., KOSMLINA NOVAK, V., PETERNEJ, K., PEKLAJ, K., POLJANEC BOHNEC, M., SLAK, M., STRNAD, S., TOMAŽIN ŠPORAR, M. and ŽARGAJ, B., 2012. Kurikulum za edukacijo o oskrbi odraslih bolnikov s sladkorno boleznijo. Ljubljana: Zbornica zdravstvene in babiške nege Slovenije -Zveza strokovnih društev medicinskih sester, babic in zdravstvenih tehnikov Slovenije, Sekcija medicinskih sester in zdravstvenih tehnikov v endokrinologiji.

KAUČIČ, M., 2020. Težave in počutje bolnikov s sladkorno boleznijo tipa 2: master's thesis [online]. Maribor: Univerza v Mariboru, Fakulteta za zdravstvene vede, pp. 2. [viewed 21 June 2021]. Available from: https:// dk.um.si/Dokument.php?id=147355

KHAN, R., CHUA, Z., TAN, J. C., YANG, Y., LIAO, Z., and ZHAO, Y., 2019. From Pre-Diabetes to Diabetes: Diagnosis, Treatments and Translational Research [online]. Medicina (Kaunas, Lithuania), vol 55, no. 9, pp. 546 [viewed 15 June 2021]. Available from: https://doi.org/10.3390/medicina55090546

KOPRIVNIKAR, H., 2008. Vzgoja za zdravje za otroke in mladostnike v primarnem zdravstvu. Ljubljana: Inštitut za varovanje zdravja Republike Slovenije, pp. 8.

MREVLJE, F., 2005. Bolezni presnove. In: KOCJANČIČ, A., MREVLJE, F. and ŠTAJER, D., eds. Interna medicina. Ljubljana: Založba Littera Picta, d. o. o., pp. 682-716. 
PANDIT, A.U., BAILEY, S.C., CURTIS, L.M., SELIGMAN, H.K., DAVIS, T.C., PARKER, R.M., SCHILliNGER, D., DEWALT, D., FLEMING, D., MOHR, D.C. et al., 2014. Disease-related distress, self-care and clinical outcomes among low-income patients with diabetes [online]. Journal of Epidemiology and Community Health, vol. 68, no. 6, pp. 557-564. [viewed 22 June 2021]. Available from: https://pubmed.ncbi.nlm.nih. gov/24489044/

POLJANEC BOHNEC, M, 2016. Edukacija o telesni dejavnosti in kakovost življenja starejših bolnikov s sladkorno boleznijo: master's thesis [online]. Ljubljana: Univerza v Ljubljani, Pedagoška fakulteta, pp. 1. [viewed 14 June 2021]. Available from: https://repozitorij.uni-lj.si/IzpisGradiva. php?id=85972

RYDÉN, L., STANDL, E., BARTNIK, M., VAN DEN BERGHE, G., BETTERIDGE, J., DE BOER, M.J., COSENTINO, F., JÖNSSON, B., LAAKSO, M., MALMBERG, K. et al., 2007. Guidelines on diabetes, pre-diabetes, and cardiovascular diseases: executive summary. The Task Force on Diabetes and Cardiovascular Diseases of the European Society of Cardiology (ESC) and of the European Association for the Study of Diabetes (EASD) [online]. European Heart Journal, vol. 28, no. 1, pp. 88-136. [viewed 22 June 2021]. Available from: https://academic.oup.com/eurheartj/article/28/1/88/2887245

SAJKO, G. in ERTL, M., 2009. Pomen medicinskih sester. ISIS, vol. 18, no. 5, pp. 40.

SOKOLOV, V., 2012. Naravno zdravljenje: diabetes. Ljubljana: Begen, pp. 13.

STARC, A., 2003. Program zdravstvenega izobraževanja sladkornih bolnikov. Obzornik zdravstvene nege, vol. 37, no. 3, pp. 139-150.

TOMAŽIN ŠPORAR, M., 2012. Štetje ogljikovih hidratov. In: TOMAŽIN ŠPORAR, M. and POLJANEC BOHANEC, M., eds. Kurikulum za edukacijo o oskrbi odraslih bolnikov s sladkorno boleznijo. Ljubljana: Zbornica zdravstvene in babiške nege Slovenije, pp. 28-30.

VOLČANŠEK, Š. and ZALETEL, J., 2016. Spremljanje urejenosti glikemije v ambulantni obravnavi. In: ZALETEL, J. and RAVNIK OBLAK, M., eds. Slovenske smernice za klinično obravnavno sladkorne bolezni tipa 2. Ljubljana: Diabetološko združenje Slovenije, pp. 53-58.

VRTOVEC, M., 1999. Zdravstvena vzgoja bolnikov s sladkorno boleznijo tipa 2. In: KOSELJ, M., MEDVEŠČEK, M. and MREVLJE, F., eds. Sladkorna bolezen tipa 2, Priročnik za zdravnike. Ljubljana: Samozaložba, pp. 348-357.

WEALE, C.J., DAVISON, G.M., HON, G.M., KENGNE, A.P., ERASMUS, R.T. and MATSHA, T.E., 2019. Leucocyte Telomere Length and Glucose Tolerance Status in Mixed-Ancestry South Africans. Cells, vol. 18, no. 5, pp. 464 . 
WORLD HEALTH ORGANIZATION, 2019. Classification of Diabetes mellitus [online]. [viewed 15 June 2021]. Available from: file://C:/Users/ KRKRAS 1/AppData/Local/Temp/9789241515702-eng.pdf

ŽERDONER, L., 2016. Zdravstvena vzgoja bolnikov s KOPB. In: PRESTOR, L., eds. Zbornik predavanj z recenzijo. Strokovni seminar Astma in kronična obstruktivna bolezen, Zreče, 8.-9. april 2016. Ljubljana: Zbornica zdravstvene in babiške nege Slovenija -Zveza društev medicinskih sester, babic in zdravstvenih tehnikov Slovenije, pp. 61-66. 



\title{
Quality of life of the elderly in intergenerational cooperation and learning programs
}

\author{
Valerija Rotar', Tamara Poklar Vatovec ${ }^{2}$ \\ 'Community Health Centre Ormož, Ormož, Slovenia \\ 2University of Primorska Faculty of Health Sciences, Izola, Slovenia \\ valerija.rotar@gmail.com; tamara.vatovec@fvz.upr.si
}

\section{Abstract}

Introduction: Demographic change and the weight of an aging society require strategies and long-term solutions to ensure a quality life for the older generations and to maintain intergenerational solidarity at the level of sustainability of society as a whole. Healthy and active aging is not only an indicator of health status, but also means the inclusion of the elderly in social processes in the local and wider community, where they have opportunities and resources to develop new knowledge, skills and enrich their lives. Methods: The survey was conducted from March to April 2021, which included 6o self-employed elderly people from eastern Slovenia. A questionnaire on the frequency of food and beverage consumption was used to assess their eating habits and others related to their quality of life. Results: Most older people buy food and prepare meals regularly. Less than a quarter of the elderly gained weight during the pandemic. They often ate fried foods and rarely ate fish, porridge, and cereals. Most are concerned about the situation; half have been vaccinated and a fifth have survived the Covid-19 virus disease. Discussion and conclusions: The profession of dietitian is underrepresented in work processes, and the inclusion of dietitian in various programs, workshops and promotions is a great opportunity to participate and learn in the local and wider community. Through the transfer of professional knowledge and skills, dietitians can influence management of inappropriate eating habits that lead to malnutrition, fragility and other metabolic deficiencies, and thus significantly affect the quality of life of older people. In the process of learning and socializing, knowledge and interpersonal relationships deepen, which is of great importance for the elderly in making their lives meaningful. A dietitian can be involved as a professional associate at the primary level in the health system and in programs and projects aimed at raising awareness of importance of healthy eating. 
Keywords: healthy aging, intergenerational cooperation, food habits, covid-19 illness

\section{Introduction}

Slovenia is one of many countries with a rapidly aging population. In view of these demographic changes, some reforms are needed at the national level. To ensure the quality of life of aging citizens, remedies and solutions in the form of intergenerational cooperation and solidarity in a close community are needed (Hozjan, 2010).

As the human lifespan lengthens, the need to maintain and preserve the quality of life and independence of our elderly increases (Mihor et al., 2018).

As a result of the aging process, older people need help and a variety of services, either in a formal setting (institutional care, volunteer work, home care) or informally (relatives, neighbours, friends...) (Marjan Cugmas et al., 2021).

Chronic diseases are a major problem in old age (Cijan and Cijan, 2003). The interconnectedness of chronic diseases in elderly patients can lead to frequent hospitalizations, where treatment is prolonged and the recovery process worsens (Poredoš, 2004).

Intergenerational collaboration can have a major positive impact on people's well-being and health. For older people, engaging in such activities leads to minimizing potential problems as they generally improve mood, reduce isolation, strengthen their social network, sense of belonging and sense of importance to society (Macuh, 2019).

A healthy lifestyle is based on a balanced and planned diet and the right amount of physical activity, which in turn can lead to a longer and healthier life. The energy requirement of an elderly person is reduced due to slower basal metabolic rate and less physical activity, also the functions of internal organs are reduced, endocrine system and immune system are less efficient and all these factors can also lead to inadequate absorption of nutrients in the body (Pregelj et al., 2011). The immune system of a person depends on age, diet, metabolism and genetics (Rotovnik Kozjek, 2020).

Active and healthy aging is a process that promotes and strengthens the capabilities of health, safety, and inclusion in society with the long-term goal of improving the health and well-being of older people (Kenda, 2018).

A society's longevity strategy is based on the concept of active aging, i.e. people living active, healthy, independent and safe intergenerational lives in all areas of life, including older people (Bednaš and Kajzer, 2017).

\section{Methods}

The survey was conducted from March to April 2021 and included 60 independent elderly people (70\% women and 30\% men) from Eastern Slovenia. In 
the age group 65 to 75 years there were $68.3 \%$ and in the oldest age group $31.7 \%$ of the elderly. The research was conducted by means of a structured interview with individuals. A short questionnaire on healthy/unhealthy diet (Koch et al., 2014) was used to assess their eating habits and other aspects of their quality of life. For statistical analysis, we used the computer program SPSS version 26. Using the descriptive method, we describe the sample and results using the frequency distribution of responses and mean scores. Statistically significant differences in the variables were determined using the Mann Whitney test. For statistical inference, we considered 0.05 risk levels.

\section{Results}

Table 1 presents the results of the respondents in correlation with the risk factors of unhealthy diet. $16.7 \%$ of the elderly consume 2 meals or less per day. Less than once a day, $20.0 \%$ of the elderly consume vegetables and $25.0 \%$ fruit. 68.3 $\%$ of the elderly consume drinks with added sugar less often and $66.7 \%$ salt after eating meals. Once a week or more, $63.3 \%$ eat fried foods and $61.7 \%$ of the elderly use fat (margarine, butter, cream or lard) when preparing food.

\section{Table 1: The respondents in correlation with risk factors of unhealthy diet}

\begin{tabular}{|c|c|c|c|c|}
\hline Description of risk & Criteria for unhealthy behaviour & Answer & $n$ & $\%$ \\
\hline \multirow{2}{*}{ Number of daily meals } & \multirow{2}{*}{2 or less } & Yes & 10 & 16,7 \\
\hline & & No & 50 & 83,3 \\
\hline \multirow{2}{*}{ Frequency of breakfast } & \multirow{2}{*}{ Never } & Yes & 11 & 18,3 \\
\hline & & No & 49 & 81,7 \\
\hline \multirow{2}{*}{$\begin{array}{l}\text { Milk and dairy products consump- } \\
\text { tion frequency }\end{array}$} & \multirow{2}{*}{ Less than once a day } & Yes & 33 & 55,0 \\
\hline & & No & 27 & 45,0 \\
\hline \multirow{2}{*}{ Frequency of fruit consumption } & \multirow{2}{*}{ Less than once a day } & Yes & 15 & 25,0 \\
\hline & & No & 45 & 75,0 \\
\hline \multirow{2}{*}{ Frequency of vegetable consumption } & \multirow{2}{*}{ Less than once a day } & Yes & 12 & 20,0 \\
\hline & & No & 48 & 80,0 \\
\hline \multirow{2}{*}{ Frequency of red meat consumption } & \multirow{2}{*}{ Three times a week or more } & Yes & 29 & 48,3 \\
\hline & & No & 31 & 51,7 \\
\hline \multirow{2}{*}{$\begin{array}{l}\text { Frequency of fish and sea food con- } \\
\text { sumption }\end{array}$} & \multirow{2}{*}{ Three times a month or less } & Yes & 39 & 65,0 \\
\hline & & No & 21 & 35,0 \\
\hline \multirow{2}{*}{$\begin{array}{l}\text { Frequency of whole-grain cereals } \\
\text { consumption (groups of porridge, } \\
\text { groats...) }\end{array}$} & \multirow[b]{2}{*}{ Three times a month or less } & Yes & 30 & 50,0 \\
\hline & & No & 30 & 50,0 \\
\hline \multirow{2}{*}{$\begin{array}{l}\text { Frequency of fried food consump- } \\
\text { tion }\end{array}$} & \multirow{2}{*}{ Once a week or more } & Yes & 38 & 63,3 \\
\hline & & No & 22 & 36,7 \\
\hline \multirow{2}{*}{ Additional use of salt } & \multirow{2}{*}{ Adding salt without tasting food first } & Yes & 20 & 33,3 \\
\hline & & No & 40 & 66,7 \\
\hline
\end{tabular}


Fat in food preparation

Margarine, butter, cream, lard

\begin{tabular}{ccc} 
Yes & 37 & 61,7 \\
\hline No & 23 & 38,3 \\
\hline Yes & 19 & 31,7 \\
\hline No & 41 & 68,3
\end{tabular}

Drinks with added sugar (fizzy

drinks, still drinks, water with added One to three times a week or more

flavour, fruit syrup)

The questionnaire was used to determine the number of healthy eating habits (scale 1-12). Most elderly 23.3\% scored 7 points, and $3.3 \%$ all points. More than half of the possible points got to $66,6 \%$ seniors (Figure 1 ).

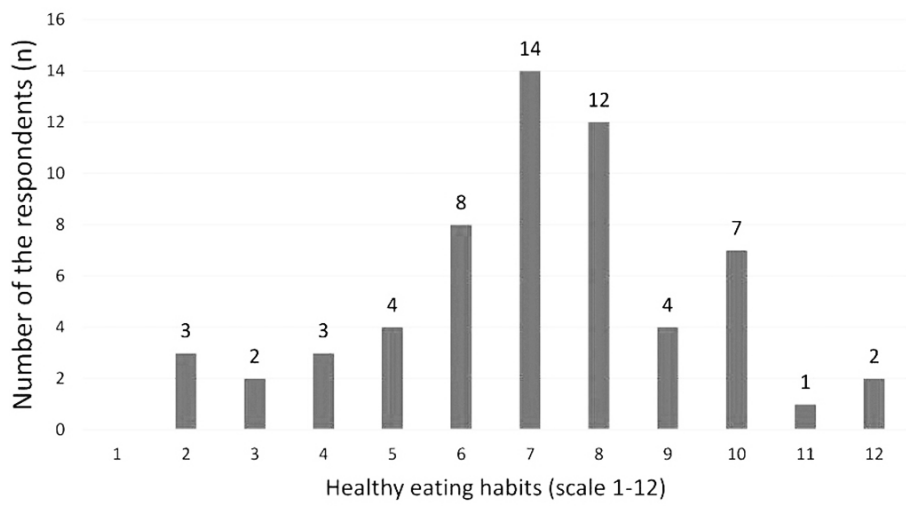

Figure 1: Proportion of elderly and their number of healthy eating habits

Table 2: Results of the questionnaire about life habits

\begin{tabular}{|c|c|c|c|}
\hline Questions & Answers & $n$ & $\%$ \\
\hline \multirow{2}{*}{$\begin{array}{l}\text { Frequency of water and unsweetened beverages. } \\
\text { Less than } 2 \text { glasses a day. }\end{array}$} & Yes & 8 & 13,3 \\
\hline & No & 52 & 86,7 \\
\hline \multirow{2}{*}{ Do you buy food alone? } & Yes & 49 & 81,7 \\
\hline & No & 11 & 18,3 \\
\hline \multirow{2}{*}{ Do you cook meals yourself? } & Yes & 46 & 76,7 \\
\hline & No & 14 & 23,3 \\
\hline \multirow{2}{*}{ You gained weight during Covid-19? } & Yes & 14 & 23,3 \\
\hline & No & 46 & 76,7 \\
\hline \multirow{2}{*}{ Did you have Covid-19? } & Yes & 7 & 11,7 \\
\hline & No & 53 & 88,3 \\
\hline \multirow{2}{*}{ Have you been vaccinated against Covid-19? } & Yes & 36 & 60,0 \\
\hline & No & 24 & 40,0 \\
\hline \multirow{2}{*}{ How do you feel during the Covid-19 pandemic? } & Same as before & 20 & 33,3 \\
\hline & I fell more worried & 40 & 66,6 \\
\hline
\end{tabular}


During the Covid-19 pandemic, $33.3 \%$ of the elderly felt the same as before the pandemic and $66.6 \%$ were a little or a lot more worried than before (Table 2). Those who felt the same during the pandemic as before scored $\mu=8.3$ points $(\mathrm{Me}=7,5)$ with the questionnaire, and the "I was more worried" group scored $\mu=6.6$ points $(\mathrm{Me}=7,0)$. We found a statistically significant difference using the Mann Whitney test $(\mathrm{U}=256,0 ; \mathrm{p}=0$,022). Those who have better eating habits and scored higher feel better and were less worried during a pandemic. Covid-19 disease was had by $11.7 \%$ of elders and $60 \%$ of them were vaccinated.

\section{Discussion}

Based on the questionnaire and their thoughts on the Covid-19 pandemic, we conducted an interview in the form of a dialogue to capture their eating habits and other habits related to a healthy lifestyle. Of concern was the fact that one-fifth of the participants consumed vegetables less than once a day and onefourth consumed fruits less than once a day, which are an important source of vitamins, minerals, fibre, and other health-promoting elements. $16.7 \%$ of older people eat fewer than two meals a day. However, due to the physiological processes of ageing, it is recommended to eat several smaller but nutrient-rich meals with controlled energy intake (Gabrijelčič Blenkuš, et al., 2010). $63.3 \%$ of the elderly consume fried foods once or more a week, and $61.7 \%$ of them also use fat (margarine, butter, cream, animal fat) in their preparation. $33.3 \%$ of the elderly additionally salt their food at the table and $32 \%$ drink sugared drinks 1-3 times a week.

The pandemic has strongly influenced the eating, shopping and living habits of the elderly. In addition, there are movement limitation, changes in physical functioning (decreased musculature, bone density, respiratory capacity, urination problems, vasomotor instability, sensory sensitivity), changes in mental health (depression, social isolation, sadness), as well as eating disorders, orientation difficulties, falls, acute infections, malnutrition and others. This is why a healthy, balanced diet planned according to expert guidelines is so important for a healthy and robust immune system (Skela et al., 2010). Limited access to food during the pandemic period, as well as lack of cooking skills and poor financial situation, are important factors contributing to inadequate and insufficient nutrition, which in turn can negatively affect health and subsequent treatment outcomes (Gregorič et al., 2020). One of the results showed that $33.3 \%$ of the participants felt the same as before the pandemic, but the rest, $66.6 \%$, felt somewhat or much more affected than before. A statistically relevant relationship was found between those who ate well and their worries, as they felt better and less worried than those who did not eat properly. We must point out that independence and quality of life are very important for older people when it comes to choosing food and preparing their own meals. After all, $76.7 \%$ of the participants prepare their own meals and $81.7 \%$ buy their own food. The data clearly shows that the elderly who participated in this research 
eat fried foods and red meat too often, use too much fat, and eat too little vegetables, fish, and seafood. They also tend to add extra salt to their meals. Consumption of grains and porridge is also inadequate. Nearly a quarter have increased body weight. For the elderly, it is important that meals are energetically tailored to their needs. Gender, age, diet, temperature, psychological factors, physical activity and general well-being all play a role (Kobentar and Marinič, 2000).

\section{Conclusions}

Slovenia and the whole of Europe are facing their greatest challenge yet: the demographic crisis and the aging of the population pose unique challenges to human coexistence, intergenerational cooperation and the foundations of solidarity.

In the light of the pandemic of the new coronavirus (Covid-19), the vulnerability of an aging population is becoming clear. The complex process of aging, the cost of chronic disease, impaired physiological function, psychological problems, disability, poverty, elder abuse, increased isolation, and more are frightening signs of the challenges facing our aging society.

Due to poor diet, our elderly do not consume enough fruits and vegetables and do not drink enough fluids. Due to physiological changes in their bodies, their appetite decreases and energy consumption decreases. Therefore, it is necessary to evaluate dietary habits and develop a diet plan based on research findings. This is the only way to prevent malnutrition, frailty syndrome and other diseases related to malnutrition. This is a very good initiative to involve dietitians in the health care system and other similar institutions (nursing homes, hospitals, rehabilitation centres, schools, etc.) where dietitians have not been involved in the work process so far. It is important to point out that we can address the health problems of older people and their unhealthy habits by promoting healthy lifestyles and prevention programs, which are included in many Slovenian nutrition policies.

It is obvious that dietitians are underrepresented in working processes. By including a dietitian in various programs, workshops and actions, we could set a precedent for collaboration and learning in the local community and beyond. With his expertise, a dietitian can address inappropriate eating habits that lead to malnutrition, frailty and other metabolic deficiencies. In this way, he can improve the quality of life of the elderly. Because of his training, a dietitian can participate in numerous projects to promote healthy and active lifestyles and use his knowledge to educate young and old alike about the importance of healthy eating. In addition, a nutritionist can explain the recommended guidelines for a balanced and energy-rich diet and warn against modern trends, marketing and advertising.

There are many programs and projects in Slovenia in which a dietitian can be involved. They may work in health care, as volunteers or in some other 
form of employment, as studies have shown that health is a high priority for the elderly population. Dietitians play an important role in promoting a healthy diet and lifestyle to prolong life and improve its quality, especially in old age. With their skills, they play a key role in intergenerational social interaction; lifelong learning and expanding the network of social relationships with the aim of helping older people find a meaningful role in society and a purpose in their lives.

\section{References}

BEDNAŠ, M. and KAJZER A. (ed.)., 2017. Strategija dolgožive družbe. Ljubljana: Urad Republike Slovenije za makroekonomske analize in razvoj: Ministrstvo za delo, družino, socialne zadeve in enake možnosti.

CIJAN, V. and CIJAN, R., 2003. Zdravstveni, socialni in pravni vidiki starostnikov. Maribor: Visoka zdravstvena šola.

CUGMAS, M., DREMELJ, P., KOGOVŠEK, T., FERLIGOJ, A. and BATAGELJ, Z., 2021. Socialna opora starejših, ki živijo v domačem okolju, v času prvega vala epidemije koronavirusa v Sloveniji. Ars \&Amp; Humanitas, 15(1), 73-90. Available from: https://doi.org/10.4312/ars.15.1.73-90 (Original work published 20. julij 2021)

GABRIJELČIČ BLENKUŠ, M., STANOJEVIĆ JERKOVIĆ, O., ĐUKIČ, B., PREZELJ, M., JEŠE, M., ŠKORNIK TOVORNIK, T.,FAJDIGA TURK, V.,DREV. A., JERIČ I. and TRATNJEK, P., 2010. Prehrana in telesna dejavnost pri starejših-pregled stanja. Ljubljana: Inštitut za varovanje zdravja Republike Slovenije. Available from: https://www.nijz.si/sites/www. nijz.si/files/uploaded/prehranaintelesnadejavnoststarejsih_4940.pdf

GREGORIČ, M., POLIČNIK, R., ĐUKIČ, B., BLAZNIK, U., FAJDIGA TURK, T. and KORDIŠ, T., 202O. Prehranski nasveti namenjeni posameznikom in družinam v času nove virusne bolezni covid-19. Ljubljana: Nacionalni inštitut za javno zdravje.

HOZJAN, T., 2010. Aktualne dejavnosti na področju medgeneracijskega sodelovanja v Sloveniji. Andragoška spoznanja, 16(4), 45-52. Available from: https://doi.org/10.4312/as.16.4.45-52

KENDA, A., 2018. Usmeritve na področju aktivnega staranja. In: TRATNIK VOLASKO, M. (ed.), Starejši kot sedanjost in prihodnost družbe .Ljubljana: Državni svet Republike Slovenije: Varuh človekovih pravic Republike Slovenije, pp. 21-30.

KOBENTAR, R. and MARINIČ, M., 20oo. Organske spremembe in motnje prehranjevanja $\mathrm{v}$ starosti Organic changes and nutritional disorders in old age. Obzornik zdravstvene nege 34(5-6), 209-214. Available from: https://obzornik.zbornica-zveza.si:8443/index.php/ObzorZdravNeg/article/view/2331 
KOCH, V., GABRIJELČIČ BLENKUŠ, M., GREGORIČ, M., KOSTANJEVEC, S., 2014. Risk Factors as a Result of Unhealthy Nutrition in the Adult Population in Slovenia With Regard to Sociodemographic Variables. Zdrav Var, (53), 144-155.

MACUH, B., 2019. Pomen medgeneracijskega sodelovanja za starostnike v tretjem in četrtem življenjskem obdobju. Revija za univerzalno odličnost $8(4), 328-337$.

MIHOR, A., DŽINIĆ, P., VENINŠEK, G. and GABROVEC, B., 2018. Obravnava starostne krhkosti na ravni posameznika - vloga prehrane. In: ARSENIJEVIĆ, O., PODBREGAR, I., ŠPRAJC, P.,TRIVAN, D. and ZIEGLER, Y. (ed.), Organizacija in negotovosti v digitalni dobi: konferenčni zbornik = Organization and uncertaintyin the digital age: conference proceedings 37. mednarodna konferenca o razvoju organizacijskih znanosti, 21-23. marec 2018, Portorož. Maribor: Univerzitetna založba univerze, pp. 732742. Available from: https://press.um.si/index.php/ump/catalog/book/326

POREDOŠ, P., 2004.Zdravstveni problemi starostnikov. Zdravstveni vestnik, 73(10), 753-756. Available from: http://www.dlib.si/details/URN:NBN:SI:doc-AJHRNSHX

PREGELJ, T., BIZJAK, M. IN POKLAR VATOVEC, T., 2011. Smernice in priporočila za zdravo prehranjevanje starostnikov. In: JURDANA, M., POKLAR VATOVEC, T. and PERŠOLJA ČERNE, M. (ed.), Razsežnosti kakovostnega staranja, Koper: Univerza na Primorskem, Znanstveno-raziskovalno središče, Univerzitetna založba Annales, pp. 63-77

ROTOVNIK KOZJEK, N., 2020. Vpliv epidemije covid-19 na zdrav življenjski slog-telesna neaktivnost. In: KRAJC, M. (ed.) Obvladovanje raka v času covida-19 v luči preventive XXVIII. seminar In memoriam dr. Dušana Reje, Ljubljana, 3 december 2020, Ljubljana: Zveza slovenskih društev za boj proti raku : Onkološki inštitut, pp. 51-65.

SKELA SAVIČ, B., ZURC, J. and HVALIČ TOUZERY S., 2010. Staranje populacije, potrebe starostnikov in nekateri izzivi za zdravstveno nego. Zdravstveni vestnik 44(2), 89-100. 


\title{
The influence of the covid-19 epidemic on the incidence of depression in the elderly in a reference dispensary
}

\author{
Tjaša Šarić, Karin Kramberger \\ 'Community Health Centre dr. Adolfa Drolca Maribor, Maribor, Slovenia \\ ${ }^{2}$ University of Maribor, Faculty of Health Sciences, Maribor, Slovenia \\ tjasa.saric@gmail.com; karin.krambergero7@gmail.com
}

\section{Abstract}

Introduction: Depression is an increasingly common mental disorder that is already facing more than 264 million people worldwide. The effects of depression can be long-lasting and recurrent, which greatly affects the quality of life. The main strategy to combat COVID-19 in most countries around the world is social distance, which is the main cause of increasing human loneliness, resulting in depression, especially in the elderly. Certainly, social distance is an important and effective measure to contain the epidemic, but we must be aware that it has psychological consequences for people. Methods: In writing the article, we used a descriptive methodological review of the literature on the impact of the COVID-19 epidemic on the development of depression in the elderly. Literature is searched using the COBISS bibliographic system, and literature is reviewed in foreign databases such as Medline, CINAHL, PubMed, Wiley, Sicris and EBSCOhost. We searched the literature for the period from 2016 to 2021. Keywords we used were: covid-19, depression, elderly, stress, loneliness. Discussion and conclusion: We found that the elderly are more exposed to risk factors such as loneliness, stress, and social distance during the COVID-19 epidemic. These factors are the main triggers for the development of depression. Media has a great influence on mental health of the elderly, which, in addition to doing useful work, informing the public, can also have a negative impact on the public by constantly reporting the spread of the disease and the number of deaths, which can lead isolated people to despair. It has been known for years that physical pain and illness often occur due to psychological problems. Depression, however, is most often caused by severe personal distress as a result of long economic, post-war crises, and so on. However, it also occurs when people are self-isolated, lonely and forgotten by everyone for a long time. We will be able to determine for months the consequences of the COVID-19 epidemic, not only economic, 
but also psychological, because everything we experience affects our body and soul. Upon review of foreign research, we found that there is a correlation between epidemic and epidemiological measures and depression. Depression in the initial phase is often not detected in time, which indicates the need for more effective preventive treatment in the Reference dispensary of Family Medicine with screening and counseling.

Keywords: covid-19, depression, elderly, stress, loneliness

\section{Introduction}

It is a fact that the epidemic negatively affects people's mental health. The most at risk group are definitely the elderly. It is therefore crucial that the first signs of psychiatric illnesses, including depression, are detected as soon as possible to prevent their development. The nurse in the Reference Clinic plays an important role in the immediate detection, as she recognizes the first signs of depression through screening tests and interviews and, based on the findings and documentation, refers the patient to the chosen personal physician in a timely manner. According to the authors, factors such as fear of infection, inadequate information, stigma, or financial loss were associated with major negative psychological impacts. These stressors, however, increase the risk of psychopathology such as anxiety or depression (Pfferbaum \& North, 2020). The World Health Organization (WHO, 2020) in its guidelines recommends strict social isolation of the geriatric population to control death in severely affected countries. As vulnerabilities increase, so do the fears, panic, and anxiety that have been talked about but little talked about among the elderly and their families. The purpose of the article is to find a correlation between the epidemic and the development of depression in the elderly through a systematic review of the literature.

\section{Methods}

A descriptive method of work was used - literature review using the COBISS bibliographic system, and literature review in databases such as: Medline, CINAHL, PubMed, Wiley, Sicris and EBSCOhost . We searched for literature for the period 2016 to 2021 . The key words we used were: covid-19, depression, old age, stress, loneliness in Slovenian or English (covid-19, depression, elderly , stress, loneliness). The following were considered as inclusion /exclusion criteria for the selection of literature: language, professionalism of literature, accessibility of literature in its entirety and age of literature.

\section{Depression}

Epidemics have historically negatively affected the mental health of the population (GAVI, 2020). The rapid growth of confirmed cases and deaths has created distress such as stress, anxiety, and depression in the general population (Picaza Gorrochategi, et al ., 2020). Recent research has shown that infection 
with SARS-CoV-2, the virus that causes COVID-19, can affect mental health. The study, published in The Lancet Psychiatry, analyzed the electronic medical records of 69.8 million patients in the U.S., which included 62,354 patients diagnosed with COVID-19. Within three months of positive testing, nearly $20 \%$ of people diagnosed with COVID-19 were then diagnosed with psychiatric disorders, including anxiety, depression, or insomnia. One in four of these people has not yet received a psychiatric diagnosis (GAVI, 2020). A study conducted in the Netherlands shows that individuals with chronic mental health disorders reported a greater impact of the epidemic on their mental health, had more fear of COVID-19, and coping with a pandemic on their own was not effective in these people (Pan, et al., 2020). There are major concerns about the impact of the global COVID-19 outbreak on mental health. Numerous studies show that mental health deteriorated in many countries before and during forced isolation, but it remains unknown how mental health changed from week to week during the COVID-19 epidemic (Fancourt, et al., 2020). Exposure to information leveled at people by social networks and the media, however, has been linked by experts to depression ( $\mathrm{Ni}$, et al., 2020).

\section{The impact of the epidemic on mental health}

Loneliness reflects subjective distress resulting from a mismatch between desired and perceived social relationships (Jeste, et al., 2020). Unfortunately, loneliness in an individual causes distress such as depression, anxiety, physical morbidity, and mortality. Although the evidence suggests that the social distance and measures envisaged to contain COVID-19 are effective, there is also a downside. Measures have a negative effect on people in terms of psychological, social and physical health. Among the vulnerable are mainly older people - older adults with multimorbidity. Elderly patients who have more chronic conditions have been found to be more lonely, anxious, and also experience insomnia. Also, their management of chronic diseases by a doctor or nurse is impaired due to the epidemic (Yeung Shan Wong, et al., 2020). Social distance is an important public health strategy to control the spread of the virus and reduce the impact on the elderly adult population. However, this comes at a price. Loneliness is associated with countless detrimental health outcomes. Older people are therefore at greater risk for effectively managing loneliness and social isolation. In an effort to limit social distancing, closures have varied across countries (Van Orden, et al., 2020). The presence of multimorbid conditions makes the elderly more susceptible to new infections and related psychological distress (Andreas, et al., 2017). Older people are prone to social isolation, even under normal circumstances, and this problem is exacerbated in the current situation. Most of them only have a close circle of friends and family with whom they communicate regularly. As most countries enforce strict blockades to control the spread of the epidemic, this issue has become even more important for older people. If such individuals are unable to provide a regular and 
permanent supply of medication, the problems will certainly recur or the current mental state will deteriorate (Philip \& Cherian, 2020).

\section{The impact of the epidemic on mental health in Slovenia}

Peoples exhaustion due to the epidemic is a response of people to a long-lasting public health crisis, which significantly interferes with the daily life of the individual. Symptoms appear gradually, influenced by emotions, experiences, and attitudes. The severity and scale of the COVID-19 epidemic and the introduction of strict measures to prevent the spread of the infection have a very large impact on the population, including that group of people not directly affected by the virus. Exhaustion causes compensatory mechanisms in people to manage the crisis situation and thus reduce the motivation to follow the recommended self- protection measures (NIJZ, 2021). When reviewing foreign research, we found that there is a correlation between epidemic and epidemiological measures and depressive symptoms, which is in contrast to the Slovenian study (SI-PANDA, 2021), which shows that the presence of these symptoms in the 12th wave of research decreased in of all age groups, and in general it was the lowest in the age group of 65 to 74 years. Depressive symptoms in the initial phase are often not detected in time in half of the persons, which indicates the need for more effective preventive treatment in the Reference dispensary of Family Medicine with screening and counseling. In the 13th wave of the SI-PANDA survey (2021), respondents were asked about how often they felt tense, stressed or under a lot of pressure in the last 14 days. Almost a quarter of respondents $(23.3 \%)$ experienced stress on a daily or frequent basis. The experience of stress decreases with age and is the lowest in the oldest age group from 65 to 74 years, approximately $9.1 \%$. Compared to the data from the CINDI survey, which took place about a year ago, the proportions of respondents are higher a year later, as in 2020 about $7 \%$ less $(16,3 \%)$ reported that they experience stress often or on a daily basis. As expected, stress is more often experienced by respondents who show signs of depressive disorder, the majority - almost 70\% compared to those who have mental health problems $(35.3 \%$ experience stress daily or often).

\section{Depression and Reference Clinic}

Reference dispensary of Family Medicine (hereinafter RDFM) plays an important role in the earliest possible detection. Communication between the patient and members of the healthcare team is of key importance in the RDFM, as all their tasks are focused on the well- being of patients (Projektna pisarna referenčnih ambulant, 2011). The implementation of preventive activities is in the domain of RDFM, which also includes the treatment of a depressed patient. It is therefore very important that the nurse at RDFM is well educated in this area so that she can detect the signs in time and alert the doctor to this. Often at the beginning of the signs of depression, we do not notice or confuse them with other illnesses, as they often appear slowly. Every sixth person will 
suffer from depression at least once in their life (Konec Juričič, 2014). No one is immune to this disease and can be affected at any stage of life. One of the reasons for the development of depression is also stress (Khan \& Khan, 2017). Appropriate treatment should be started as soon as possible, as this is how we can overcome depression (Berkow , 2005). Many times a patient with depression in the clinic complains of physical symptoms. Thus, we can conclude that these are the main reason why depressed individuals come to the family doctor at all (Strbad, 2012). The PHQ-9 scale is used in RDFM to aid in detection. The questionnaire was designed specifically for primary care and is also a diagnostic tool that can be used to monitor the adequacy of treatment. The main task of the nurse in RDFM is to determine disease exacerbation (Rifel, 2017). Treatment of a chronic patient with depression by the nurse in RDFM includes: treatment procedure - application of the PHQ-9 questionnaire; situation assessment and evaluation - evaluation of the questionnaire; conclusion (motivational conversation, information, health education, assessment of the patient's understanding of information, referral to a doctor, documentation, entry of results and health services) (Panikvar Žlahtič , et al ., 2016). When the nurse in RDFM deems it necessary to include the patient in psychoeducational workshops entitled Support in Coping with Depression, conducted by the Center for Health Promotion (CKZ), it does so. Workshops are held once a week and include counseling. During the epidemic, workshops take the form of telephone counseling. It is intended to identify the factors of depression, participants learn about the signs and symptoms, learn about the types of therapy, it is intended to increase flexibility of thinking and aimed at preventing exacerbations and great emphasis on non-activation with the support of relatives (Roškar \& Tančič Grum, 2016). We reviewed statistical data in one of the Reference dispensary of Family Medicine dr. Adolfa Drolca Maribor from November 2019 to January 2020, and compared them with data from November 2020 to January 2021. Data were obtained using the PHQ-9 questionnaire. Respondents were over 60 years of age, there were 60 respondents in both groups, and the results showed that in the period from November 2019 to January 2020, 3.3 $\%$ had risk factors for developing depression. The results from the period from November 2020 to January 2021 show that $18.3 \%$ of respondents had risk factors for the development of depression. From this, we concluded that the risk increased by $15 \%$ during the COVID-19 epidemic.

\section{Discussion}

Examining the results of foreign research in the field of the presence of a risk of developing depression during an epidemic, we see that the risk of developing depression increases significantly during an epidemic, especially with the introduction of "lockdown". Research (Ettman, 2020) showed that the prevalence of depressive symptoms in the U.S. increased more than three times during the COVID-19 epidemic, from $8.5 \%$ before COVID-19 to $27.8 \%$ during COVID-19. We humans are social beings who need contact, closeness, and when measures 
like lockdown are introduced, it is broken. That's when people become lonely, and loneliness is often the trigger for depression. During an epidemic, there is a lot of negative information that increases stress in people, so it is very important how the government of each country provides information to people. The elderly are the most vulnerable group of people, who are much more exposed to loneliness even under normal conditions than younger people. It is therefore necessary that we pay special attention to this group. Gerst-Emerson \& Jayawardhana (2015) state that social relationships are essential for people's well-being and research consistently documents that social integration and support have a protective effect on morbidity and mortality. An important role can also be played by the nurse in the Reference dispensary of Family Medicine, who detects the first signs through screening tests and counseling (Projektna pisarna referenčnih ambulant, 2011). For many, the doctor-patient relationship is one that provides social support and not just treatment. This possible explanation is confirmed by research confirming that people who are lonely do not visit a doctor for medical reasons, but to satisfy their needs for interaction and interpersonal stimulation (Gerst-Emerson \& Jayawardhana, 2015).

\section{Conclusion}

The main strategy in the fight against COVID-19 is social distancing and this is the main cause of depression. It is important that primary health care is included in the Reference Outpatient Clinics and that preventive activities are carried out, including the treatment of a depressed patient. In this way, it can detect the signs in time and prevent the development of depression. Experience from previous pandemics, such as SARS, has shown that regular telephone counseling, family contact, relevant and up-to-date information, care for general health and psychological needs, and respect for privacy and dignity are important components of mental health care ( $\mathrm{Wu}$, et al., 2009). We believe that the nurse in the referral clinic is key to detecting signs of depression, as patients usually go for regular check-ups in the referral clinic every year, which allows the nurse to recognize patients and detect possible abnormalities.

\section{References}

ANDREAS, S., SHULZ, H. \& VOLKERT, J., 2017. Prevalence of mental disorders in elderly people: the European MentDis_ICF65+ study. British Journal of Psychiatry, 210(2), pp. 125-131.

BERKOW, R., 2005. Veliki zdravstveni priročnik za domačo uporabo: najpopolnejši pregled medicinskih informacij. Ljubljana: Mladinska knjiga.

ETTMAN, K. K., ABDAllA, S. M. \& COHEN, G. H., 202o. Prevalence of Depression Symptoms in US Adults Before and During the COVID-19 Pandemic. Original Investigation, 3(9), p. 2019686.

FANCOURT, D., STEPTOE, A. \& BU, F., 2020. Trajectories of anxiety and depressive symptoms during enforced isolation due to COVID-19 in Eng- 
land: a longitudinal observational study. The Lancet Psychiatry, 8(2), pp. 141-149.

GAVI, 2020. Anxiety, depression and insomnia: the impact of COVID-19 on mental health. [Online] Available at: https://www.gavi.org/vaccineswork/anxiety-depression-and-insomnia-impact-covid-19-mental-health [Accessed 2512021 ].

GERST-EMERSON, K. \& JAYAWARDHANA, J., 2015. Loneliness as a Public Health Issue: The Impact of Loneliness on Health Care Utilization Among Older Adults. American Journal of Public Health, 105(5), pp. 10131019.

JESTE, D. V., LEE, E. E. \& CACIOPPO, S., 2020. Battling the modern behavioral epidemic of loneliness: Suggestions for research and interventions. JAMA Psychiatry, 77(6), pp. 553-554.

KHAN , S. \& KHAN, R., 2017. Chronic stress leads to anxiety and depression. Annalls of Psychiatry and Mental Health, 5(1), p. 1091.

KONEC JURIČIČ, N., 2014. Duševno zdravje: depresija. [Online] Available at: https://www.nijz.si/sl/depresija [Accessed 281 2021].

NI, M. Y., YANG, L. \& LEUNG, C. M., 2020. Mental health, risk factors, and social media use during the COVID-19 epidemic and cordon sanitaire among the community and health professionals in Wuhan, China. Journal of Medical Internet Research, 7(5), pp. 476-480.

NIJZ, 2021. Pandemija COVID-19 v Sloveniji. [Online] Available at: https:// www.nijz.si/sites/www.nijz.si/files/uploaded/panda_porocilo_po_4._valu.pdf [Accessed 135 2021].

PANIKVAR ŽLAHTIČ, K., VIDMAR, I., ISTENIČ, B. \& BENKOVIČ, R., 2016. Določitev zdravstvenih storitev diplomirane medicinske sestre v referenčni ambulanti - dopolnitev opisov. Ljubljana: Zbornica zdravstvene in babiške nege Slovenije - Zveza strokovnih društev medicinskih sester.

PAN, K.-Y., KOK, A. A. L. \& EIKELENBOOM, M., 2020. The mental health impact of the COVID-19 pandemic on people with and without depressive, anxiety, or obsessive-compulsive disorders: a longitudinal study of three Dutch case-control cohorts. The Lancet, 8(2), pp. 121-129.

PFFERBAUM, B. \& NORTH, C. S., 2020. Mental Health and the Covid-19 Pandemic. New England Journal of Medicine, 383(6), pp. 510-512.

PHILIP, J. \& CHERIAN, V., 2020. Impact of COVID-19 on mental health of the elderly. International Journal Of Community Medicine And Public Health, 7(6), pp. 2435-2436.

PICAZA GORROCHATEGI, M., EIGUREN MUNITIS, A. \& DOSIL SANTAMARIA, M., 2020. Stress, anxiety, and depression in people aged over 60 in the COVID-19 outbreak in a sample collected in Northern Spain. The American journal of geriatric psychiatry, 28(9), pp. 993-998. 
PROJEKTNA PISARNA REFERENČNIH AMBULANT, 2011. Referenčna ambulanta družinske medicine. [Online] Available at: http://www.referencna-ambulanta.si/ [Accessed 281 2021].

RIFEL, J., 2017. Preventivni pregled na področju depresije. V: J. Govc Eržen \& M. Petek Šter, eds. Priročnik za zdravnike družinske medicine: izvajanje integrirane preventive kroničnih nalezljivih bolezni v referenčnih ambulantah družinske medicine. Ljubljana: Nacionalni inštitut za javno zdravje, pp. 8o-83.

ROŠKAR, S. \& TANČIČ GRUM, A., 2016. Psihoedukativne delavnice podpore pri spoprijemanju z depresijo. V: N. Konec Jurčič, S. Roškar \& P. Jelenko Roth, eds. Prepoznavanje in obravnava depresije in samomorilnosti pri pacientih v ambulanti družinskega zdravnika: priročnik za strokovnjake na primarni zdravstveni ravni. Ljubljana: Nacionalni inštitut za javno zdravje, pp. 81-86.

ㅇ $\quad$ STRBAD, E., 2012. Ali depresija boli?. Farmacevtski vestnik, 63(1), pp. 38-39.

VAN ORDEN, K. A., BOWER, E. \& LUTZ, J., 2020. Strategies to promote social connections among older adults during 'social distancing' restrictions. The American Journal of Geriatric Psychiatry, 54(4), pp. 376-38o.

WU, P., FANG, Y. \& GUAN, Z., 2009. The psychological impact of the SARS epidemic on hospital employees in China: exposure, risk perception, and altruistic acceptance of risk. The Canadian Journal of Psychiatry, 54(5), pp. 302-311.

WORLD HEALTH ORGANIZATION, 2020. Depression. [Online] Available at: https://www.who.int/health-topics/depression\#tab=tab_1 [Accessed 26 1 2021].

YEUNG SHAN WONG, S., ZHANG, D. \& WING SHAN SIT, R., 2020. Impact of COVID-19 on loneliness, mental health, and health service utilisation: a prospective cohort study of older adults with multimorbidity in primary care. British Journal of General Practice, 70(700), pp. 818-824. 


\title{
The gut microbiota in the elderly
}

\author{
Karin Šik Novak, Zala Jenko Pražnikar \\ Faculty of Health Sciences, University of Primorska, Izola, Slovenia \\ karin.novak@fvz.upr.si, zala.praznikar@fvz.upr.si
}

\section{Abstract}

Introduction: The human gastrointestinal tract represents the biggest microbial community in the human body. Gut bacteria regulate extraction, synthesis and absorption of many nutrients and metabolites, such as bile acids, lipids, amino acids, vitamins, and short-chain fatty acids. Aging is a genetically-determined process that leads to a decline of physiological functions. One of the most recognized effects of aging is the age-associated immune deregulation. Gut dysbiosis can trigger the immune response and chronic low-grade inflammation, leading to age-related degenerative pathologies and unhealthy aging. An adequate nutritional status is important to maintain the functionality of the immune system and preventing frailty and cognitive function impairment in the elderly. Methods: A scientific literature search was performed by accessing the databases PubMed, GoogleScholar and ScienceDirect using the following keywords and their combinations: "gut microbiota«, »elderly«, »longevity«, »Alzheimer's disease«, "nutrition", limiting the search to the last 10 years. The review was focused on the changes of gut microbiota during aging, the effect of nutrition and its link to pathologies. Results: Gut microbiota diversity increases from birth and at about the age of three, the gut microbiota composition is mostly mature. In the elderly, changes in dietary habits, digestion, nutrient absorption and immune activity can affect gut microbiota composition. The microbiota-gut-brain axis is a bidirectional communication system that is connected via neural, immune, endocrine, and metabolic pathways and plays a key role in the modulation of brain functions. Research shows a link between the gut microbiota and Alzheimer's disease (AD), which is characterized by the accumulation of amyloid- $\beta$ and tau in the brain, leading to cognitive impairment. The increased gut and blood-brain barrier permeability induced by gut dysbiosis may affect pathogenesis of $\mathrm{AD}$ and other neurodegenerative 
disorders. Nutritional strategies aiming at microbiota and immune modulation in the elderly are especially relevant due to their higher susceptibility to disease, malnutrition, impairment of the gut microbiota and a pro-inflammatory status of the immune system. Animal studies show that interventions with antibiotics, microbial infections, prebiotics, probiotics and faecal microbiota transplantation not only affect gut microbiota composition, but also influence cognitive impairment related to AD. Analysis of the gut microbiota and its potential for modulation to improve health are important elements in the process of improving health of the elderly. Discussion and conclusions: Nutritional strategies for the elderly should consider the nutritional deficiencies and needs, but also the gut microbiota, the immune system and cognitive function. More research is needed to better understand the changes in gut microbiota over the lifespan and associated pathologies.

Keywords: gut microbiota, aging, elderly, intestine, nutrition

\section{Introduction}

The human gastrointestinal tract contains more than $10^{12}$ of microorganisms per millilitre and represents the biggest microbial community in the human body. Gut bacteria are key regulators of extraction, synthesis and absorption of many nutrients and metabolites, such as bile acids, lipids, amino acids, vitamins and short-chain fatty acids (SCFA) (Rinninella et al., 2019). Gut microbiota can affect distant organs by regulating the absorption of nutrients or the production of microbial metabolites such as SCFA or vitamins, by regulating the immune system and by translocating bacteria or their products through disrupted mucosal barriers (Shimizu, 2018). For the last two centuries the lifespan has been increasing by two years per decade in the developed countries (Salazar et al., 2017). Most western countries have experienced a significant increase in the proportion of elderly citizens (65 years and older) due to improved sanitation, hygiene and healthcare (O'Toole and Jeffery, 2015). One of the most recognized effects of aging is the age-associated immune deregulation (Salazar et al., 2017). Gut dysbiosis can trigger the innate immune response and chronic low-grade inflammation, leading to many age-related degenerative pathologies and unhealthy aging (Kim and Jazwinski, 2018). An adequate nutritional status is important to maintain the functionality of the immune system and preventing frailty and cognitive function in the elderly (Salazar et al., 2017). Analysis of the gut microbiota and its potential for modulation to improve health are important elements in the process of improving health of the elderly (O'Toole and Jeffery, 2015).

\section{Methods}

We performed a literature search accessing the databases PubMed, GoogleScholar and ScienceDirect using following keywords and their combinations: »gut microbiota«, »gut microbiome«, »elderly«, »longevity«, »Alzheimer’s dis- 
ease«. We limited the search to the last 10 years. The literature review was focused on the change of gut microbiota during aging, the effect of nutrition on gut microbiota and various nutritional and other interventions for microbiota manipulation and its link to neurodegenerative diseases and pathologies.

\section{Results and Discussion}

Gut microbiota shows wide inter-individual variation, but its within-individual variation is relatively stable over time (Kim and Jazwinski, 2018). Taxonomically, bacteria are classified according to phyla, classes, orders, families, genera and species (Rinninella et al., 2019). The dominant bacterial phyla are Bacteroidetes and Firmicutes, which constitute $90 \%$ of the total gut microbiota (Kim \& Jazwinski, 2018), with Actinobacteria, Proteobacteria, Fusobacteria, and Verrucomicrobia also frequently present. Microbiota diversity increases from birth and at about the age of three years, a child's gut microbiota composition is mostly adult-like (Rinninella et al., 2019). The composition of the intestinal microbiota in older people is variable between individuals and differs from the microbiota and diversity levels of younger adults (Claesson et al., 2012). In the elderly, changes in dietary habits, digestion, nutrient absorption and weaker immune activity can affect gut microbiota composition (Rinninella et al., 2019). Changes in diet could be attributed to the loss of taste and smell and difficulties with chewing food. This frequently leads to the increased intake of foods high in fat and sugar and decreased intake of plant foods (Mangiola et al., 2018). The loss of diversity in the common microbiota groups is associated with increased frailty and reduced cognitive performance (O'Toole and Jeffery, 2015).

The microbiota-gut-brain axis is a bidirectional communication system that is connected through neural, immune, endocrine and metabolic pathways. The gut microbiota plays a vital role in the modulation of brain functions (Jiang et al., 2017). Gut bacteria have been found to affect the maturation of the nervous, endocrine and immune systems in mice (Pluta et al., 2020). Research supports a possible link between the gut microbiota and Alzheimer's disease (AD), which is characterized by the deposition of amyloid- $\beta$ (A $\beta)$ and tau in the brain, leading to degeneration of cognitive function (Mangiola et al., 2018). Theories for the role of gut microbiota in AD pathophysiology include direct microbial action (microbial infection in AD), indirect action (hygene hypothesis) and processes related to aging of the immune system (Angelucci et al., 2019). The increased gut and blood-brain barrier permeability induced by microbiota dysbiosis may modulate AD pathogenesis and other neurodegenerative disorders, especially aging-related (Jiang et al., 2017). The inflammatory response from the gut along with aging and poor diet in the elderly have been found to contribute to the pathogenesis of AD (Pluta et al., 2020). Gut microbiota products, such as SCFA (butyrate, acetate, propionate), have specific functions in the gut and the brain where butyrate has been found to have protective properties in the brain. Gut microbiota also produces more than $90 \%$ of 
whole body serotonin, a metabolite that regulates cognitive functions (Shimi$\mathrm{zu}, 2018)$. Studies show reduced microbial diversity and a decrease in Firmicutes and Bifidobacterium, as well as an increase in Bacteroidetes and Proteobacteria in AD patients (Pluta et al., 2020; Rinninella et al., 2019). Changes in gut microbial composition and diversity are associated with biological or functional age. Gut microbial diversity inversely correlates with biological age, but not with chronological age. Transfer of the gut microbiota from old to young germ-free mice triggers inflammatory responses mimicking "inflammaging" (Kim and Jazwinski, 2018).

Unhealthy dietary patterns, drugs, reactive oxygen species (ROS), psychological stress and other pro-inflammatory factors contribute to gut dysbiosis and are linked to development of various pathologies. Gut dysbiosis due to antibiotics or a high-fat or high-carbohydrate diet is associated with metabolic disorders (Kim and Jazwinski, 2018). Diet is a controllable environmental factor that influences gut microbiota composition (Claesson et al., 2012) and has been shown to be involved in the development of AD (Pluta et al., 2020). Nutritional strategies aiming at microbiota and immune modulation in the elderly are especially relevant due to their higher susceptibility to disease, malnutrition, impairment of the gut microbiota and a pro-inflammatory status of the immune system (Salazar et al., 2017).

The Mediterranean diet (MD) involves a high intake of legumes, olive oil, fruits, nuts, vegetables and whole grains, moderate intake of fish, wine and dairy and a low intake of red meat, processed meat and sugar. Greater adherence to MD was associated with a reduced risk of developing AD (Botchway et al., 2018). Healthy dietary patterns with high probiotic and prebiotic intake, along with other nutrients, may delay cognitive decline (Angelucci et al., 2019). Probiotics are bacteria that are beneficial for host's health if consumed in adequate quantities, while prebiotics are fibre substances that act as food for these bacteria. The consumption of fermented milk product with probiotics not only affected normal brain activity, but also caused significant cognitive improvement in patients with AD (Pluta et al., 2020). A two week dietary intervention in elderly women with obesity improved the metabolic profile and reversed gut microbiota dysbiosis towards a profile associated with metabolic health. A combined use of balanced Mediterranean diet and probiotics could induce beneficial effects on the gut microbiota and metabolic profile (Cancello et al., 2019). The role of prebiotics and diet in modulating AD will need to be established more in the future (Leblhuber et al., 2018). In healthy older adults, probiotics promote mental flexibility and alleviate stress, along with changes in gut microbiota (Kim et al., 2021). An intervention with probiotic milk positively affected cognitive function and some metabolic markers (Akbari et al., 2016) and a multispecies probiotic influenced gut microbiota composition and tryptophan metabolism in AD patients (Leblhuber et al., 2018). A recent systematic review and meta-analysis showed that probiotics intervention improved general cognitive function, inflammatory profile, cellular biomarkers regulation 
and led to significantly increased brain-derived neurotrophic factor (BDNF) levels in humans, while in animals they improved cognitive status and spatial and non-spatial memory. The most widely used probiotic strains were from the genera Lactobacillus and Bifidobacterium, the most commonly used species were L. acidophilus, B. bifidum and B. longum (Ruiz-Gonzalez et al., 2021).

In addition to probiotic interventions, studies with germ-free animals, antibiotic interventions, microbial infections and faecal microbiota transplantation have been used to determine the role of the gut microbiota on cognition and AD. Studies on germ-free mice and disruption of the gut microbiota after antibiotic treatment in humans induce cognitive impairment and decreased BDNF levels in the brain (Jiang et al., 2017). Transfer and transplantation of the faecal microbiota from healthy mice into mice with AD ameliorated the formation of $A \beta$ plaques and cognitive impairment and reversed abnormalities in the colonic expression of genes related to intestinal macrophage activity (Kim et al., 2020). It's important to consider the intervention targets on the intestinal microbiota and the immune system in humans may differ among elderly groups from different environments or geographical locations (Salazar et al., 2017). Despite interventions with probiotics, other strategies have been largely unstudied in humans (Ruiz-Gonzalez et al., 2021).

\section{Conclusions}

Nutritional strategies for the elderly should consider the nutritional deficiencies and needs that differ from the needs in the adult life, but also the gut microbiota, the immune system and cognitive function. Gut microbiota profiling offers the potential for biomarker-based identification of individuals at risk for unhealthy aging and could be used as diagnostic criteria for AD. More research is still needed to better understand the changes in gut microbiota over the lifespan, its link to dietary changes and associated pathologies and to clarify whether a stable gut microbiota modification could be obtained and its longterm effects on frailty and cognitive decline.

\section{References}

AKBARI, E., ASEMI, Z., DANESHVAR KAKHAKI, R., Bahmani, F., Kouchaki, E., Tamtaji, O. R., Hamidi, G. A. and Salami, M., 2016. Effect of Probiotic Supplementation on Cognitive Function and Metabolic Status in Alzheimer's Disease: A Randomized, Double-Blind and Controlled Trial. Frontiers in Aging Neuroscience, vol. 8, pp. 256. https://doi.org/10.3389/ fnagi.2016.00256

Angelucci, F., Cechova, K., Amlerova, J. and Hort, J., 2019. Antibiotics, gut microbiota, and Alzheimer's disease. Journal of Neuroinflammation, vol. 16, no. 1, pp. 108. https://doi.org/10.1186/s12974-019-1494-4

Botchway, B. O. A., Moore, M. K., Akinleye, F. O., Iyer, I. C. and Fang, M., 2018. Nutrition: Review on the Possible Treatment for Alzheimer's Disease. 
Journal of Alzheimer's Disease: JAD, vol. 61, no. 3, pp. 867-883. https:// doi.org/10.3233/JAD-170874

Cancello, R., Turroni, S., Rampelli, S., Cattaldo, S., Candela, M., Cattani, L., Mai, S., Vietti, R., Scacchi, M., Brigidi, P. and Invitti, C., 2019. Effect of Short-Term Dietary Intervention and Probiotic Mix Supplementation on the Gut Microbiota of Elderly Obese Women. Nutrients, vol. 11, no. 12, pp. 3011. https://doi.org/10.339o/nu11123011

Claesson, M. J., Jeffery, I. B., Conde, S., Power, S. E., O’Connor, E. M., Cusack, S., Harris, H. M. B., Coakley, M., Lakshminarayanan, B., O’Sullivan, O., Fitzgerald, G. F., Deane, J., O’Connor, M., Harnedy, N., O’Connor, K., O’Mahony, D., van Sinderen, D., Wallace, M., Brennan, L., ... and O’Toole, P. W., 2012. Gut microbiota composition correlates with diet and health in the elderly. Nature, vol. 488, no. 7410, pp. 178-184. https://doi. org/10.1038/nature11319

Jiang, C., Li, G., Huang, P., Liu, Z. and Zhao, B., 2017. The Gut Microbiota and Alzheimer's Disease. Journal of Alzheimer's Disease, vol. 58, no. 1, pp. 1-15. https://doi.org/10.3233/JAD-161141

Kim, C.-S., Cha, L., Sim, M., Jung, S., Chun, W. Y., Baik, H. W. and Shin, D.-M., 2021. Probiotic Supplementation Improves Cognitive Function and Mood with Changes in Gut Microbiota in Community-Dwelling Older Adults: A Randomized, Double-Blind, Placebo-Controlled, Multicenter Trial. The Journals of Gerontology. Series A, Biological Sciences and Medical Sciences, vol. 76, no. 1, pp. 32-40. https://doi.org/10.1093/gerona/glaao9o

Kim, M.-S., Kim, Y., Choi, H., Kim, W., Park, S., Lee, D., Kim, D. K., Kim, H. J., Choi, H., Hyun, D.-W., Lee, J.-Y., Choi, E. Y., Lee, D.-S., Bae, J.-W. and Mook-Jung, I., 2020. Transfer of a healthy microbiota reduces amyloid and tau pathology in an Alzheimer's disease animal model. Gut, vol. 69, no. 2, pp. 283-294. https://doi.org/10.1136/gutjnl-2018-317431

Kim, S. and Jazwinski, S. M., 2018. The Gut Microbiota and Healthy Aging: A Mini-Review. Gerontology, vol. 64, no. 6, pp. 513-520. https://doi. org/10.1159/000490615

Leblhuber, F., Steiner, K., Schuetz, B., Fuchs, D. and Gostner, J. M., 2018. Probiotic Supplementation in Patients with Alzheimer's Dementia-An Explorative Intervention Study. Current Alzheimer Research, vol. 15, no. 12, pp. 1106-1113. https://doi.org/10.2174/1389200219666180813144834

Mangiola, F., Nicoletti, A., Gasbarrini, A. and Ponziani, F. R., 2018. Gut microbiota and aging. European Review for Medical and Pharmacological Sciences, vol. 22, no. 21, pp. 7404-7413. https://doi.org/10.26355/eurrev_201811_16280

O’Toole, P. W. and Jeffery, I. B., 2015. Gut microbiota and aging. Science, vol. 350, no. 6265, pp. 1214-1215. https://doi.org/10.1126/science.aac8469 
Pluta, R., Ułamek-Kozioł, M., Januszewski, S. and Czuczwar, S. J., 2020. Gut microbiota and pro/prebiotics in Alzheimer's disease. Aging, vol. 12, no. 6, pp. 5539-5550. https://doi.org/10.18632/aging.102930

Rinninella, E., Raoul, P., Cintoni, M., Franceschi, F., Miggiano, G. A. D., Gasbarrini, A. and Mele, M. C., 2019. What is the Healthy Gut Microbiota Composition? A Changing Ecosystem across Age, Environment, Diet, and Diseases. Microorganisms, vol. 7, no. 1. https://doi.org/10.339o/microorganisms7010014

Ruiz-Gonzalez, C., Roman, P., Rueda-Ruzafa, L., Rodriguez-Arrastia, M. and Cardona, D., 2021. Effects of probiotics supplementation on dementia and cognitive impairment: A systematic review and meta-analysis of preclinical and clinical studies. Progress in Neuro-Psychopharmacology \& Biological Psychiatry, vol. 108, pp. 110-189. https://doi.org/10.1016/j.pnpbp.2020.110189

Salazar, N., Valdés-Varela, L., González, S., Gueimonde, M. and Reyes-Gavilán, C. G. de los., 2017. Nutrition and the gut microbiome in the elderly. Gut Microbes, vol. 8, no. 2, pp. 82-97. https://doi.org/10.1080/19490976.2016.1 256525

Shimizu, Y., 2018. Gut microbiota in common elderly diseases affecting activities of daily living. World Journal of Gastroenterology, vol. 24, no. 42, pp. 4750-4758. https://doi.org/10.3748/wjg.v24.i42.4750 



\title{
Recognizing the importance of nutrition counseling for the elderly with COPD in primary care
}

\author{
Mateja Šimec \\ University of Novo mesto, Faculty of Health Sciences, Novo mesto, Slovenia \\ mateja.simec@uni-nm.si
}

\begin{abstract}
Introduction: Chronic obstructive pulmonary disease (COPD) alters a person's metabolic processes and increases the need for energy and protein intake, while metabolism and muscle wasting are also affected by the aging process. A patient with COPD is at risk of malnutrition, therefore the medical staff in the family practise also plays an important role in the orderly and well-managed disease. Methods: The studyh was based on a qualitative approach, the method of description. A semistructured interview template was used as a measurement tool to collect data for the empirical part of the study. The study was conducted among nurses and paramedics at a health center. There were 7 participants in the stusy who are involved in the treatment of COPD patients. Results: The study revealed that the respondents' perception of the importance of nutritional counseling for older adults with COPD was low, which was reflected in the inadequate information provided to COPD patients on appropriate nutrition for their disease. The findings of the study also revealed that the respondents were aware of their role as health educators in the management of COPD patients, but self-assessment to have inadequate knowledge about proper nutrition in COPD, citing lack of opportunities to attend training on the subject. Discussion and conclusion: Weight loss in a COPD patient is associated with an increased risk of complications and mortality. Therefore, it is critical to identify older adults COPD patients because of the dangers associated with malnutrition and to recognize those with a pre-existing condition. Nutritional support (alongside appropriate physical activity) is the foundation for quality rehabilitation of patients with COPD, with a key role played by competent healthcare professionals involved in the comprehensive management of patients with COPD.
\end{abstract}

Keywords: COPD, nutrition, health education, patient 


\section{Introduction}

Chronic obstructive pulmonary disease (COPD) is an incurable, progressive, not fully reversible disease that most commonly affects smokers. It is a chronic inflammatory obstruction of the small airways characterized by an accelerated decline in lung function and premature death. In Slovenia, approximately 500 to 600 people die each year as a result of COPD (Šuškovič et al., 2011). According to the World Health Organization, the disease is the fourth leading cause of death (Kristan Škrgat et al., 2009). COPD patient has chronic bronchitis and a feeling of heavy breathing, mucus secretion increases, breathing mechanics are impaired, resulting in a feeling of heavy breathing, which is exacerbated during physical exertion. According to a European study, $73 \%$ of people with severe COPD suffer from dyspnea, $64 \%$ from sputum, $59 \%$ from cough and $42 \%$ from wheezing (Burkhardt and Pankow, 2014). The disease has a chronic course with accompanying acute exacerbations. Early detection and treatment of the disease has implications for slower disease progression and better quality of life (Škrgat et al., 2017). COPD is a major health problem as it is a leading cause of morbidity and mortality in developed and developing countries and is not only a respiratory disease, but is characterized by systemic inflammation that can manifest itself through skeletal and cardiac involvement: muscle wasting, cachexia, anemia and accelerated atherosclerosis (Šorli, 2015).

The main goals of COPD treatment are to prevent disease progression, relieve disease symptoms, increase physical capacity, prevent and treat disease exacerbations, and improve the patient's quality of life. Among the important non-pharmacological treatment measures is proper nutrition (regular meals, more protein in the diet, sufficient fluids) (Škrgat et al., 2017).

\section{COPD patient and diet}

Despite great advances in medicine, COPD still cannot be completely cured with available medications, so treatment is usually symptomatic. Patients are advised to change their lifestyle with the help of appropriate medications. This certainly includes proper diet, which can have a significant impact on relieving the symptoms of shortness of breath. COPD patients have on average $20-50 \%$ higher energy requirements, which is why they are advised to eat foods rich in energy and nutrients, as the energy consumption in the respiratory process is even ten times higher than usual in COPD patients, which should be taken into account when determining the appropriate daily caloric intake. About 40$50 \%$ of patients with advanced COPD suffer from weight loss, especially lean muscle mass (Samaras et al., 2015).

Inadequate energy and nutrient intake leads to patient malnutrition, metabolic changes, and progressive lung disease to pulmonary cachexia, which is associated with increased mortality in patients with COPD. Frequent fatigue can lead to loss of appetite, chronic airway inflammation from coughing can affect the smell and taste of food, and accompanying depression further reduc- 
es the patient's need for regular food intake. A rapid feeling of fullness after a meal causes the diaphragm to flatten, constricting the abdominal organs and increasing pressure in the stomach. Chronic cough with cough and shortness of breath further increases energy consumption and promotes malnutrition (Širca Čampa, 2016).

In COPD patients, protein and energy malnutrition and weight loss are permanent and even more rapid during exacerbations, and the main causes are anorexia and increased metabolic activity of the body. A COPD patient's diet should maintain proper nutrition and improve well-being because patients lose weight due to increased respiratory muscle function and energy expenditure, while less physical activity and poor patient nutrition decrease muscle mass and contractility of respiratory muscles. The goals of nutritional support are to ensure adequate nutrient intake according to individual energy needs, and to prevent weight loss, daily supplements in the form of oral energy drinks with high protein content should be included in the daily diet in addition to inadequate daily energy intake (Košnik et al., 2011).

\section{Family doctor and COPD patient}

The general practitioner (GP) is responsible for the diagnosis of COPD, health care management and referral to a specialist (Kristan Škrgat et al., 2009). In the primary care referral clinic, a graduate nurse performs preventive measures and manages specific groups of patients with chronic diseases, including COPD. Smokers and ex-smokers over the age of 40 are actively sought out, and a known COPD patient is seen once a year by a team in a GP referral clinic. Patients with suspected COPD are managed according to a predetermined protocol that includes the use of a standard questionnaire and guidelines for action based on the outcome (Susuč Poplas et al., 2013). The biggest problem of a COPD patient suffering from nutrition is protein-energy malnutrition, which can develop with increased energy and nutrient needs due to impaired lung function on the one hand and poor appetite of the patient on the other (Mahan, 2011), and non-pharmacological treatment of COPD includes advice on proper nutrition in addition to advice on smoking cessation, vaccination and rehabilitation (Škrgat, 2017).

The aim of this study was to determine the importance of nutritional advice for elderly patients with COPD in primary care. For this purpose, we asked the following research questions:

What is the perceived importance of nutritional counseling for older people with COPD in primary care?

What is the nature of nutritional counseling for older patients with COPD in primary care? 


\section{Methods}

The study was based on a qualitative research method. Primary and secondary sources were collected, analyzed and synthesized for the empirical work. Primary data for the analysis was obtained using the interview technique. For the theoretical part, technical and scientific literature from international databases in the field of nutrition of patients with COPD was used.

A semi-structured interview questionnaire was prepared for the study based on a review of domestic and foreign literature (Benedik, 2012; Širca Čampa, 2016; Vrbica, 2019). The first part of the questionnaire is related to demographic data and the second part is related to research. The survey was conducted in February 2021 among 7 nurses of the health center involved in the treatment of COPD patients. Participation in the survey was voluntary, and participants were informed in advance of the purpose of the survey. The interview was recorded using a recording device, and a verbatim transcript of the audio recording was made and sent to the respondents for approval. Codes and categories were established. We recorded the results in the discussion section. Ethical research principles were followed at all stages of data collection and processing.

\section{Results}

7 respondents were included in the survey; 5 nurses and 2 graduate medical technician aged between 21 and 46 years.

We have usefully divided the codes into categories:

- Category 1: Nutritional advice consists of the codes: inhaled drugs, not relevant, less necessary, medicines, elderly patients.

- Category 2: Patient information is characterized by codes: no advice, a little explanation, sometimes or rarely I say, they know too little.

- Category 3: Health worker's role in health education is characterized by codes: explanation, healthy lifestyle, educate older patients, advise on healthy eating

- Category 4: Health professionals' knowledge about nutrition of COPD patients is characterised by the following codes: I know too little, I don't know the guidelines, healthy eating pyramid, I follow the news, I'm interested, more protein.

- Category 5: Health worker education is made of codes: heard at Golnik, no education, COPD school, insufficient education, not relevant

\section{Discussion}

We found that a low perception of the importance of nutritional advice was prevalent among the study participants, which is unfavorable for patients 
with COPD, as Mahan et al. (2011) found that the major nutritional problem in COPD patients is protein-energy malnutrition, which can develop with increased energy and nutrient requirements due to patients' impaired lung function and lower appetite. Collins et al. (2013) state that disease-related malnutrition is a major problem in $30-60 \%$ of COPD patients, so it is important to identify these patients and counsel them appropriately on how to eat.

A worrying figure shows that patients in primary care are poorly informed about the importance of proper nutrition in their lung disease, as our study found that COPD patients receive very little information from primary care providers, especially if they do not report any occupations. Green and Watson (2005) emphasize that nurses have close contact with patients and play a key role in assessing patients' nutritional status and identifying malnourished patients who need additional advice and support in planning and implementing appropriate nutrition. Numerous studies suggest that targeted individualized nutritional therapy for COPD patients is important in all patients, not just malnourished patients with advanced COPD and reduced muscle mass, and should be part of the regular rehabilitation of these patients (Sugawara, 2015).

The GP referral clinic also cares for patients with regulated COPD and treats deterioration in the health of these patients (Škrgat et al., 2017), and through patient medical history taking we should identify COPD risk patients (malnourished patients and those close to it) and involve them in counseling on the importance of adequate nutrition or refer them to a dietitian who will help the patient to establish a diet plan and perform a nutritional assessment. The role of graduate nurse in independent patients in need of health education is to control the disease, which we believe includes counseling about appropriate nutrition. In the family medicine reference clinic patient must be motivated to learn about COPD, the nature of the disease, the effects of smoking, proper breathing, proper use of medications, the effects of respiratory rehabilitation, the expected course of the disease, and the importance of nutrition in COPD. Patients must be strongly encouraged to eat properly and prepare appropriate meals, and the patient's mental state should also be checked, as depression often develops, which affects nutritional status (Bratkovič, 2011).

The research found that the majority of COPD patients are advised by health professionals at the primary care level about proper nutrition for their lung disease. We believe that all COPD patients should receive at least basic advice on proper nutrition and adequate intake of nutrients, especially protein, at the initial level of medical care. Protein found in meat, milk, and dairy products is a rich source of protein that is important for maintaining muscle mass in COPD patients, and they need to consume it daily, regularly, and in sufficient amounts because, as Baum et al. (2016) note, problems that accompany patients with COPD (decreased appetite, poor taste perception, nausea) often prevent adequate intake of nutrients, especially protein. Metabolic changes in old age also affect the need for micronutrients, making it necessary to provide an adequate amount of vitamins (D, B12, B6, E and C) and minerals (calcium, 
iron, zinc) (NIJZ, 2016). With the aggravation of COPD, body weight decreases rapidly, so good nutrition and attention to a regular and proper diet are very important. Outpatient screening at the primary health care level can contribute significantly to the detection of patients with COPD (Yawn et al., 2014), so we believe it is useful to assess the nutritional status at the primary health care level with the questionnaire "The Mini Nutritional Assessment « (MNA) with anthropometric measurements and bioimpedance measurements. According to Širca Čampa (2016), the basic nutritional problem is not only energy malnutrition, but also protein malnutrition, which leads to inadequate nutrient ratios (excessive carbohydrate content in the diet), which is why nutritional support for patients with COPD is an important part of a holistic therapeutic approach. Symptoms of the disease, improving quality of life and slowing the progression of the disease.

This study is important because it gives us insight into the non-pharmacological treatment of COPD patients in the area of nutrition at the primary level of health care. COPD is a serious health problem and is one of the major causes of morbidity and mortality in both developed and developing countries, so proper treatment of COPD patients is essential. It is advisable to pay attention to proper nutrition as chronic lung patients tend to lose weight which is bad. The life of COPD patients with below average weight is shorter than that of normal weight patients because the muscles that are important for breathing function worse. Our study has also shown that the participants in the study are not able to acquire the necessary knowledge in organized trainings (continuously), and the question remains why the staff does not receive more training on the importance of proper nutrition of patients with COPD.

\section{Conclusions}

At the primary level of health care, more intensive counseling on appropriate nutrition is needed in all COPD patients, especially the elderly. This obviously requires the employment of health professionals with appropriate skills and sufficient up-to-date knowledge in this area, as COPD patients often do not meet health professionals until the primary care level and it is all the more important that they already receive appropriate health education. work in the area of nutrition in COPD which can make a significant contribution to their quality of life.

\section{References}

BAUM, J.I., KIM, IL, Y. and WOLFE, R.R., 2016. Protein Consumption and the Elderly: What Is the Optimal Level of Intake? Nutrients, vol. 8, no. 6, pp. 359.

BENEDIK, B., 2012. Stanje prehranjenosti in telesna sestava bolnikov s KOPB. Magistrsko delo. Univerza v Mariboru, Fakulteta za zdravstvene vede. 
BRATKOVIČ, M., 2011. Zdravstvena vzgoja bolnikov s KOPB - Šola KOPB na Kliniki Golnik. Modul: Astma, KOPB, Alergijski rinitis. Program za medicinske sestre in zdravstvene tehnike, Golnik, 5.-11. maj 2011. Golnik: Univerzitetna klinika za pljučne bolezni in alergijo; pp. 49-51. Dostopno na: http://www.klinika-golnik.si/strokovnajavnost/referencne-ambulante/datoteke/prirocnik_RA_2011a.pdf (8.2.2021).

BURKHARDT, R. in PANKOW, W., 2014. The diagnosis of cronic obstructive pulmonary disease. Deutsches Arzteblat International, vol. 111, no. 49, pp. $834-845$.

COLLINS, P.F., ELIA, M. and STRATTON, R.J., 2013. Nutritional support and functional capacity in chronic obstructive pulmonary disease: a systematic reviwe and meta-analysis. Respirology, vol. 18 (no. 4): pp. 616-629.

GREEN, S.M. and WATSON, R., 2005. Nutritional screening and assessment tools for use by nurse: literature review. Journal of Advanced Nursing, vol. 50, pp. 69-83.

KOŠNIK, M., MREVLJE, F., ŠTAJER, D., KOŽELJ, M. and ČERNELIČ, P., 2011. Interna medicina, 4. izdaja. Ljubljana: Littera picta - Slovensko medicinsko društvo, pp. 758-76o.

KRISTAN ŠKRGAT, S., ŠIFRER, F., GUČEK KOPČAVER, N., OSOLNIK, K., ERŽEN, R., FLEŽAR, M., PETEK, D., ŠORLI, J. ML., TOMIČ, V., MUŠIČ, E. et al. 2009. Stališče do obravnave akutnega poslabšanja KOPB, Zdravniški vestnik; vol. 78: pp. 19-32.

MAHAN, K.L. and RAYMOND, J.L., 2017. Krause's Food and the Nutrition Care Process. 14th Edition. Elsevier, St. Louis, London.

NIJZ - Nacionalni inštitut za javno zdravje, 2016. Referenčne vrednosti za energijski vnos hranil: tabelarična priporočila za otroke (od 1. leta starosti naprej), mladostnike, odrasle, starejše, nosečnice ter doječe matere [online]. [viewed 8. Februar 2021]. Available from: http://www.mz.gov.si/ fileadmin/mz.gov.si/pageuploads/javno_zdravje_2015/foto_DJZ/prehrana/2016_referencne_vrednosti_za_energijski_vnos_ter_vnos_hranil_17022016.pdf

SAMARAS, N., SAMARAS, D., CHAMBELLAN, A., PICHARD, C. and THIBAULT, R., 2014. Pulmonary rehabilitation: the reference therapy for undernourished patients with chronic obstructive pulmonary disease. Biomed Research International. 3:248420. doi: 10.1155/2014/248420. Epub 2014 Feb 19. PMID: 24701566 ; PMCID: PMC3950477.

SUGAWARA, K., TAKAHASHI, H., KASHIWAGURA, T., YAMADA, K., YANAGIDA, S., HOMMA, M., DAIRIKI, K., SASAKI, H., KAWAGOSHI, A., SATAKE, M., et al., 2012. Effect of anti-inflammatory supplementation with whey peptide and exercise therapy in patients with COPD. Respiratory Medicine, vol.106, no. 11, pp. 1526-1534.

SUSUČ POPLAS, T., ŠVAB, I. in KERSNIK, J., 2013. Projekt referenčnih ambulant družinske medicine v Sloveniji, Zdravniški Vestnik vol. 82: pp. 635647. 
ŠIRCA ČAMPA, A., 2016. Pomen dobre prehranjenosti bolnikov s KOPB. V: PRESTOR, L. eds. Astma in kronična obstruktivna bolezen,.Ljubljana: Zbornica zdravstvene in babiške nege Slovenije - Zveza društev medicinskih sester, babic in zdravstvenih tehnikov Slovenije, Sekcija medicinskih sester in zdravstvenih tehnikov v pulmologiji. pp. 137-145.

ŠKRGAT, S., TRILLER, N., KOŠNIK, M., POPLAS SUSIČ, T., PETEK, D., VODOPIVEC JAMŠEK, V., HUDOKLIN, I., OGRIČ LAPAJNE, A., LETONJA, S., ŠORLI, J. et al. 2017. Recommendations for the management of patients with chronic obstructive pulmonary disease (COPD) at primary and specialist pulmonary levels in Slovenia. Zdravstveni vestnik; vol. 86 (no. 1-2): pp. 65-75.

ŠORLI, J., 2015. Rehabilitacija je edini nujni del zdravljenja KOPB. Pharmonia. vol.13: pp. 13-14.

ŠUŠKOVIČ, S., 2011. Bolezni dihalnih poti. In: KOŠNIK, M., MRAVLJE, F., ŠTAJER, D., ČRNELČ, P., KOŽELJ, M., ANDOLJŠEK, D., eds. Interna medicina. Ljubljana: Littera Picta, d. o.o., Slovensko medicinsko društvo.

VRBICA, Ž., 2019. Prehrana bolnikov s KOPB. [online]. [viewed 10. Februar 2021]. Dostopno na: https://www.plivazdravlje.hr/aktualno/clanak/32069/Prehrana-bolesnika-oboljelih-od-KOPB-a.html

YAWN, B.P., DUVALL, K., PEABODY, J., ALBERS, F., IQBAL, A., PADEN, H., ZUBEK, V.B. in WADLAND, W.C., 2014. The impact of screening tools on diagnosis of chronic obstructive pulmonary disease in primary care. American Journal of Preventional Medicine, vol. 47 (no. 5): pp. 563-575. 


\title{
Elderly's attitude towards information communication technology
}

\author{
Jasna Špehar, Dajana Glavan, Dijana Došen, Andrej Starc \\ University of Ljubljana, Faculty of Health Science, Ljubljana, Slovenia \\ jasnaspehar@gmail.com, glavan.dajana@gmail.com, dijana.dosen1@gmail.com, andrej.starc@zf.uni-lj.si
}

\begin{abstract}
Introduction: Information and communication technology (ICT) is advancing extremely fast and is present at all stages of life. The need for the inclusion of ICT has also appeared in the everyday life of the elderly, which enables them easier access to new information and resources. Most older people were not directly involved in the new age of the Internet or the ICT, as they did not use computers or the Internet often in their educational, work and / or personal lives. Despite the fear of how the elderly will accept this, desires for knowledge and use have also started to come from their side, as they are interested in the benefits of ICT. Methods: A descriptive method with a systematic literature review was performed. The units for analysis took place with the help of DiKUL in the international databases Medline, ScienceDirect, CINAHL with full text and Google Scholar. We also searched using the COBIB.SI database. The keywords "elderly", "information and communication technology" and "health" with Boolean operators "AND" and "OR" were used in Slovene and in English. The inclusion criterion was also the content relevance. 19 articles were reviewed and after the content analysis, we ranked 10 articles. Subsequently, we excluded those articles that did not meet the inclusion criteria. Results: The use of ICT benefits the elderly, improves and facilitates daily activities. When problems arise in the use of ICT, they want the support and help of relatives. The elderly expressed fear of invasion of privacy and related security in the use of ICT. In the case of technology upgrades, they are concerned about whether they will be able to keep up with progress. The latter may be particularly exposed, as they also fear discrimination from society, which makes it easier to follow the progress of ICT development. In promoting the use of ICT in the elderly, the design of the devices must be taken into account, but also their social context. Discussion and conclusion: The number of elderly ICT users has been increasing.
\end{abstract}


Studies suggest positive effects of using ICT, especially to reduce feelings of loneliness. Restrictions on the cognitive and physical limitations of the elderly need to be taken into account when designing ICTs for the elderly. Older people may face special barriers to learning about ICT, the Internet and computers due to age-related sensory, physical and cognitive changes. Elderly people are often concerned about privacy when using ICT, but using it could partially relieve the health care system and help to detect health complications earlier and consequently reduce costs in the health care system. The attitude of the elderly towards ICT has important implications for the design and implementation of adapted forms of ICT related to health. New technology can to some extent replace the person caring for the elderly and give them a greater sense of independence and security.

Keywords: elderly, information communication technology, health, safety.

\section{Introduction}

Currently, almost a fifth of the European population is over 65 years old. The use of information and communication technology (ICT) is increasing rapidly (Monaco et al., 2019) and has recently become an integral part of life. It offers new tools that enable and facilitate daily activities and also lead to health improvements, as ICT provides older people with access to new information and resources. Those who use this technology are more likely to report better health. They want health-related ICT that provides them with independence, security and protection, and enables them to socialize, manage their own health, and assist them in their day-to-day activities (Kim et al., 2020).

Understanding the willingness of older people to adopt new technologies is one of the key components in determining which older people would benefit from ICT. Technologies are increasingly seen as a potential resource to facilitate or improve everyday life, as it is about adapting to aging and a particular environment (Courtney et al., 2008). Most of the literature refers to only one accepted type of technology, ignoring the fact that the use of a particular technology is highly dependent on the availability and use of technological and non-technological alternatives (Peek et al., 2019).

The aim of the article is to present the attitude of the elderly towards ICT.

\section{Methods}

We performed a systematic review of the literature using a descriptive method. The collection of units for analysis took place in March 2021 with the help of DiKUL and the international databases Medline, ScienceDirect, CINAHL with full text and Google Scholar. We also searched using the COBIB.SI database. 
In Slovene the keywords „zdravje“, „informacijsko komunikacijska tehnologija“ and „zdravje“ with Boolean operators „IN“ and „OR“ were used for the search. The keywords used in English were "elderly", "information communication technology" and "health" with Boolean operators "AND" and "OR".

The search was limited to a ten-year period of published units from 2011 to 2021. We have also used the language criterion, as only Slovenian and English scientific and professional articles with accessible full text were included.

The inclusion criterion was content relevance. We have reviewed 19 articles and we have ranked 10 articles after the content review. Subsequently, we excluded those articles that did not meet the inclusion criteria.

\section{Results}

Taking into account the inclusion criteria, five articles were included in the systematic literature review (Table 1). The results showed that the use of ICT benefits the elderly, improves and facilitates daily activities.

When problems arise with the use of ICT, help should be easily accessible to older people, both during training and during practical use. Lack of privacy, security and stigma are some of the barriers that older people face in using ICT (Vassli and Farshchian, 2017). There are six main interrelated factors related to the frequency of technology use, namely emotional attachment, compatibility of needs, signs of use, ability to use, resource input, and support (Peek et al., 2019). To promote the use of ICT in the elderly, broader contextual issues need to be considered, not only the design of devices but also their socio-ecological context (Abdelrahman et al., 2021).

\section{Table 1: Overview of analyzed articles}

\begin{tabular}{|c|c|c|c|}
\hline $\begin{array}{l}\text { Author, } \\
\text { year }\end{array}$ & $\begin{array}{l}\text { The purpose } \\
\text { of the research }\end{array}$ & Methodology & Results \\
\hline Peek et al., 2019 & $\begin{array}{l}\text { To better understand the } \\
\text { changes and frequency } \\
\text { of the use of ICT tech- } \\
\text { nology in independent } \\
\text { seniors. }\end{array}$ & $\begin{array}{l}\text { Longitudinal qualitative } \\
\text { Interview }\end{array}$ & $\begin{array}{l}\text { Regarding the frequency of } \\
\text { ICT use, there are } 6 \text { main in- } \\
\text { terrelated factors: } \\
\text { - emotional attachment } \\
\text { - compatibility of needs } \\
\text { - signs for use } \\
\text { - ability to use } \\
\text { - input of resources } \\
\text { - support }\end{array}$ \\
\hline $\begin{array}{l}\text { Ramsden Marston } \\
\text { et al., } 2019\end{array}$ & $\begin{array}{l}\text { To examine the experi- } \\
\text { ences of older people in } \\
\text { the field of ICT and the } \\
\text { impact on their lives. }\end{array}$ & $\begin{array}{l}\text { Online survey Focus } \\
\text { group }\end{array}$ & $\begin{array}{l}\text { They confirmed two inter- } \\
\text { twining themes: incentives } \\
\text { and barriers to use. They rec- } \\
\text { ommend promoting the use } \\
\text { of ICT according to the skills } \\
\text { of the elderly and opportu- } \\
\text { nities to improve health and } \\
\text { well-being. }\end{array}$ \\
\hline
\end{tabular}




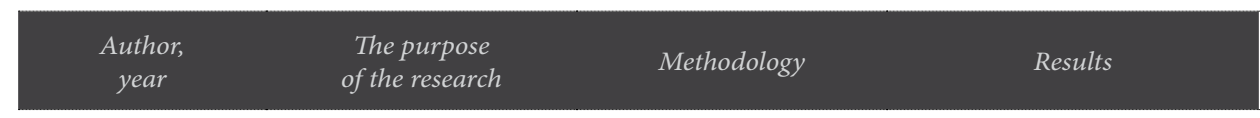

\begin{tabular}{|c|c|c|}
\hline $\begin{array}{l}\text { Abdelrahman et al., } \\
2020\end{array}$ & $\begin{array}{l}\text { To find out what are the } \\
\text { opinions about ICT re- } \\
\text { garding brain health in } \\
\text { healthy and independent } \\
\text { elderly people. Identify } \\
\text { the factors for the adop- } \\
\text { tion of ICT and its im- } \\
\text { portance for addressing } \\
\text { health issues. }\end{array}$ & $\begin{array}{l}\text { Qualitative research } \\
\text { method Focus groups } \\
\text { Content analysis }\end{array}$ \\
\hline
\end{tabular}

To find out what are the garding brain health in

Abdelrahman et al., the factors for the adopportance for addressing health issues.
Seven topics were identified: physical health, cognitive health, social engagement, information organization, desire to learn new technologies, technology development and privacy, and security. In order to promote the use of ICT in the elderly, it is necessary to take into account its socio-ecological context.

Caregivers perceived resistance, lack of interest, fear and their socio-social situation as an obstacle to ICT training in the elderly.

ICT instructors emphasized the importance of motivation, the instructor-elderly relationship, patience, self-confidence and mutual respect.

The elderly emphasized the achievements, challenges and sense of competence for ICT. An in-depth approach to addressing internal personal and external social barriers is crucial.

Older people want health-related ICT that provides them with independence, security and protection, enables them to socialize, manage their own health and helps them with their daily activities. Aid for the use of ICT must be easily accessible and adapted to the elderly. Barriers to the use of ICT are lack of privacy and security and stigma.

\section{Discussion}

Although most elderly people live in their own homes at an early age, they are not adapted to their changing needs. It is easier for ICT users to embrace it if it reminds them of a technology they have been using for many years (e.g. cable wires, standard telephones, etc.). Older people will invest energy and money for new technology as long as the latter is also beneficial to them (Lipar, 2014).

Recently, the number of elderly ICT users has been increasing. Studies suggest positive effects of using ICT, especially to reduce feelings of loneliness and depression. Little is known about the factors that would prevent the use of ICT in the elderly population, which may be at greater risk than those living in health and social care facilities (Rikard et al., 2018). 
The boom in ICT comes at a time of dramatic increase in life expectancy, which in turn leads to significant increases in healthcare costs. During this time, researchers are using the development and use of ICT in the healthcare environment, which would enable the improvement of health status and increase independence in everyday tasks.

ICT training can also encourage the elderly to increase the use of health and social care institutions, thus increasing the level of application skills, while promoting confidence in new technology and reducing the likelihood of discontinuing the use of ICT. A key factor that could contribute to the widespread applicability of ICT are designers and programmers, who should recognize limitations regarding the cognitive and physical limitations of the elderly (Rikard et al., 2018).

In a longitudinal survey on unobtrusive home monitoring and computer use, $72 \%$ of participants agreed with this type of study, but $60 \%$ expressed concerns about the privacy and security of personal data. The research included the installation of sensory technology at home and used it to determine the occurrence of cognitive decline and other health problems. The purpose of the study was to determine the level of readiness to share health and / or activity data with physicians or family members and to evaluate their privacy and data protection concerns (Boise et al., 2013). Concerns about data protection and security have been highlighted in several articles included in the systematic literature review. In a study by Boise et al. (2013) then, after one year, concerns about the potential risks to data privacy increased, while on the other hand, they perceived a high degree of agreement with such monitoring and sharing of information with the physician or family members.

Older people, to whom ICT is closer and more susceptible to it, could partially relieve the health care system by using it, thus helping to detect health complications earlier and consequently at a lower cost for the health care system. In healthcare, it is a well-known saying that prevention is better than treatment, not only in financial terms, but especially in terms of improving the quality of an individual's health, as prevention prevents many serious illnesses or injuries.

\section{Conclusions}

The older age group is not homogeneous in terms of display, income, or even the different types of disability that are often age-related. The elderly, like the group at greatest risk, will be excluded from the information societies. Most seniors were not directly involved in the development of the internet or ICT. Computers or the internet are not often used for their education, employees in / or personal life. Older people had to acquire ICT competencies in unfavourable conditions. Learn by having to collect with technologies that have so slowly supplanted manual activities in restaurants, shops, hospitals, and government affairs. Older people can earn age-related sensory, physical, and cog- 
nitive changes, encountering special hurdles in learning about ICT, the Internet, and computer science. There is a general belief that ICT can help older people improve their lives. They encourage them to stay healthier, live longer independently, if possible, to prevent impairment (Amaro and Gil, 2011). The attitude of the elderly towards ICT has important implications for the development of adapted forms of health-related ICT. New technology can make only a few substitutes that care for the elderly and give them more feelings of independence and security.

\section{References}

ABDELRAHMAN, N.G., HAQUE, R., POLVERENTO, M.E., WENDLING, A., GOETZ, C.M. and ARNETZ, B.B., 2021. Brain Health: Attitudes towards Technology Adoption in Older Adults [online]. Healthcare, vol. 9, no. 23, pp. 1-7. [viewed 1 April 2021]. Available from: http://dx.doi. org/10.3390/healthcarego10o23

AMARO, F. and GIL, H., 2011. ICT for Elderly People: »Yes, 'They' Can!«. In: 2011 e-CASE \& e-Tech International Conference, Tokyo, Japan, January 18-20, 2011. Toshi Center Hotel, pp. 3792-803. [viewed 1 April 2021]. Available from: https://www.researchgate.net/publication/277243287_ICT_ for_elderly_people_Yes_\%27They\%27_Can

ARTHANAT, S., VROMAN, K.G., LYSACK, C. and GRIZZETTI, J., 2019. Multi-stakeholder perspectives on information communication technology training for older adults: Implications for teaching and learning [online]. Disability and Rehabilitation: Assistive Technology, vol. 14, no. 5, pp. 453-61. [viewed 1 April 2021]. Available from: http://dx.doi.org/10.108 $\mathrm{o} / 17483107.2018 .1493752$

BOISE, L., WILD, K., MATTEK, N., RUHL, M., DODGE, H. H. and KAYE, J., 2013. Willingness of older adults to share data and privacy concerns after exposure to unobtrusive in-home monitoring [online]. Gerontechnology, vol. 11, no. 3, pp. 428-35. [viewed 1 April 2021]. Available from: https:// www.ncbi.nlm.nih.gov/pmc/articles/PMC3604979/pdf/nihms438588.pdf

COURTNEY, L.K., DEMIRIS, G., RANTZ, M. and SKUBIC, M., 20o8. Needing smart home technologies: the perspectives of older adults in continuing care retirement communities [online]. Informatics in Primary Care, vol. 16, no. 3, pp. 195-201. [viewed 1 April 2021]. Available from: http://dx. doi.org/10.14236/jhi.v16i3.694

KIM, J., LEE, J.H., WON, R.C., WON, R.C., BARR, T. and MERIGHI, J.R., 2020. Older adults technology use and its association eiyh health and depressive symptoms: Findings from the 2011 National Health and aging trends study [online]. Nursing Outlook, vol. 68, no. 5, pp. 56o-572. [viewed 1 April 2021]. Available from: https://dx.doi.org/10.1016\%2Fj.outlook.2020.05.001 
LIPAR, T., 2014. Tehnologija za starejše - gerontehnologija. Kakovostna starost [online], vol. 17, no. 1. [viewed 1 April 2021]. Available from: http://www. inst-antonatrstenjaka.si/tisk/kakovostna-starost/clanek.html?ID=1413.

MONACO, A., MAGGI, S., DE COLA, P., HASSAN, T.A., PALMER, K. and DONDE, S., 2019. Information and communication technology for increasing healthy ageing in people with non-communicable diseases: identifying challenges and further areas for development [online]. Aging Clinical and Experimental Research, vol. 31, no. 11, pp. 1689-1693. [viewed 1 April 2021]. Available from: https://dx.doi.org/10.1007/s40520019-01258-8

PEEK, S.T.M., LUIJKX, K.G., VRIJHOEF, H.J.M., NIEBOER, M.E., AARTS, S., VAN DER VOORT, C.S., RIJNAARD, M.D. and WOUTERS, E.J.M., 2019. Understanding changes and stability in the long-term use of technologies by seniors who are aging in place: a dynamical framework [online]. BMC Geriatrics, vol. 19, no. 236, pp. 1-13. [viewed 1 April 2021]. Available from: https://dx.doi.org/10.1186/s12877-019-1241-9

RIKARD, R.V., BERKOWSKY, W.R. and COTTON, R.S., 2018. Discontinued Information and Communication Technology Usage Among Older Adults in Continuing Care Retirement Communities in the United States [online]. Gerontology, vol. 64, no. 2, pp. 188-200. [viewed 1 April 2021]. Available from: https://www.ncbi.nlm.nih.gov/pmc/articles/ PMC5828954/pdf/nihms912583.pdf

RAMSDEN MARSTON, H., GENOE, R., FREEMAN, S., KULCZYCKI, C. and MUSSELWHITE, C., 2019. Older Adults' Perceptions of ICT: Main Findings from the Technology In Later Life (TILL) Study [online]. Healthcare, vol. 7, no. 86, pp. 1-27. [viewed 1 April 2021]. Available from: https://dx. doi.org/10.3390/healthcare7030086

VASSLI, L.T. and FARSHCHIAN, B., 2018. Acceptance of health-related ICT among elderly people living in the community: A systematic review of qualitative evidence [online]. International Journal of Human-Computer Interaction, vol. 34, no. 2, pp. 99-116. [viewed 1 April 2021]. Available from: https://dx.doi.org/10.1080/10447318.2017.1328024 



\title{
Association between dietary nutrient intake and sarcopenia in older adults
}

\author{
Felicita Urzi', Sandra Potušek', Laura lacolina',2, Elena Bužan' \\ ' University of Primorska, Faculty of Mathematics, Natural Sciences and Information Technologies, Koper, Slovenia \\ 2 Aalborg University, Department of Chemistry and Bioscience, Fredrik Bajers Vej 7H, 9220 Aalborg, Denmark \\ felicita.urzi@upr.si
}

\section{Abstract}

Introduction: There is increasing interest in modifiable factors that may be effective in both the prevention and treatment of sarcopenia. Although there is a growing evidence of the importance of nutrition in the treatment of sarcopenia, studies examining the relationship between nutrient intake and sarcopenia in older adults are limited. The aim of this study was to examine the association between nutrient intake and sarcopenia in older adults. Methods: The case-control observational study included 115 older adults ( $\geq 65$ years), 26 of whom were classified as sarcopenic. Sarcopenia was assessed according to the European Working Group on Sarcopenia in Older People (EWGSOP) diagnostic criteria. Habitual dietary intake was assessed with the 3-day weighed dietary record over two weekdays and one weekend day. The weight of food intake in grams was converted into energy, macronutrient and micronutrient amounts using the online OPEN (Open Platform for Clinical Nutrition) dietary assessment tool. The mini nutritional assessment (MNA) was used to assess the nutritional status. Differences in nutrient intake and nutritional status between the sarcopenic and non-sarcopenic groups were evaluated. Risk factors were determined using logistic regression with sarcopenic status as the outcome. Results: Seven nutrients (n-3 fatty acid, vitamin D, vitamin K, vitamin $\mathrm{C}$, vitamin $\mathrm{B} 1$, vitamin $\mathrm{B} 7$, and vitamin $\mathrm{B} 9$ ) were all statistically significantly lower in the sarcopenic compared to the non-sarcopenic group $(\mathrm{p}<.05)$. An increased risk of sarcopenia $\left(\mathrm{R}_{2}=.756\right)$ was found in older adults with low dietary intakes of n-3 fatty acids. After accounting for possible covariates, the evidence for an association between n-3 fatty acid and sarcopenia is partially explained by age, body mass index, presence of diabetes mellitus, hypertension, and physical activity level. Discussion and conclusions: Sarcopenic older adults differed in terms of intake of seven nutrients compared with non-sarcopenic older adults. 


\begin{abstract}
Adequate intake in some of these nutrients have been repeatedly shown to be valuable in preserving muscle mass and protecting against normal decline in the elderly, both in randomized controlled trials and in cohort analyses. Given that nutrition may influence the development of sarcopenia, nutrition intervention may represent a feasible measure for preventing or postponing age-related decline in muscle mass and function.
\end{abstract}

\begin{abstract}
Keywords: nutrition, sarcopenia, n-3 fatty acid, vitamin D, nutritional assessment
\end{abstract}

\title{
Introduction
}

Sarcopenia is defined as the presence of low muscle strength, low muscle quantity/quality and low physical performance (Morley et al., 2011; Cruz-Jentoft et al., 2019). Today it is recognized as an age-related disease with ICD-10-CM (M62.84) code (Anker et al., 2016). The overall estimates of prevalence of sarcopenia in older adults worldwide is $10 \%$ (Shafiee et al., 2017), while it may be as high as 30\% in community-dwelling populations and even higher than $30 \%$ for populations in long-term care (Cruz-Jentoft et al., 2014). The consequences of having sarcopenia are reflected in loss of independence due to impaired physical performance, increased risk of mobility disorders, falls and fractures and impaired ability to perform activities of daily living, leading to nursing home admission, depression, hospitalization, and even death (Landi et al., 2013; Correa-de-Araujo and Hadley 2014; Cruz-Jentoft and Sayer 2019). In addition, its presence is associated with other comorbidities, such as osteoporosis, diabetes mellitus, insulin resistance, obesity, and chronic kidney disease, which have an important impact on the public health burden (Beaudart et al., 2014; Kim et al., 2014; Pacifico et al., 2020).

Multiple risk factors contribute to the aetiology of sarcopenia. Changes in muscle morphology, neurodegenerative process, anabolic and sex hormone production or sensitivity, protein balance, increased oxidative stress, inflammation and genetic predisposition are important risk factors (Roubenoff, 2003; Fulle et al., 2004; Can et al., 2016; Coen et al., 2019; Bauer, 2021; Priego et al., 2021). which leads to reduced mobility, fragility and loss of independence. This process called sarcopenia is secondary to several factors such as sedentary lifestyle, inadequate nutrition, chronic inflammatory state and neurological alterations. However, the endocrine changes associated with aging seem to be of special importance in the development of sarcopenia. On one hand, advancing age is associated with a decreased secretion of the main hormones that stimulate skeletal muscle mass and function (growth hormone, insulin-like growth factor 1 (IGF[sbnd]IAlong with these changes in older adults, decreased basal metabolic rate and increased dietary protein needs are also detected (Wilson and Morley, 2003; Bauer et al., 2013; Boirie, 2014). Besides these endogenous factors, inadequate nutrition and a sedentary lifestyle also contribute to the complex aetiology of sarcopenia (Rolland et al., 2008; Walrand et al., 2011; 
Volkert et al., 2018; Beaudart et al., 2019). Many of them are not modifiable since they are caused by progressive, irreversible processes contributing to reduced muscle mass and strength (Rolland et al., 2008; Cruz-Jentoft nad Sayer 2019). Therefore, there is rising interest in studies that point to the influence of modifiable factors such as nutrition and lifestyle, because these factors may be effective for both the prevention and treatment of sarcopenia. Proper nutrition is an important determinant of health and can contribute to protection against the negative impact of age-related changes of body composition and muscle quality decline (Volkert et al., 2018; Beaudart et al., 2019). Evidences shows significantly lower dietary nutrient intakes of at least 3-6 nutrients in sarcopenic comparing to non-sarcopenic older adults (ter Borg et al., 2016; Beaudart et al., 2019). Results of some studies have led to the proposition that $n-3$ fatty acid along with vitamin $\mathrm{D}$, protein intake and physical activity as a combined intervention could be effective in the management of sarcopenia (Boirie et al., 2014; $\mathrm{Wu}$ et al., 2020). Antioxidant nutrients (carotenoids, selenium and vitamins $\mathrm{E}$ and $\mathrm{C}$ ) intake have also been associated with sarcopenia (Lauretani et al., 2007; Chen et al., 2014; Welch et al., 2020).

Studies that evaluate the association between nutrient intake and sarcopenia in older adults is limited. To fill this gap, this study aims to evaluate the differences in nutrition intake among sarcopenic and non-sarcopenic older adults.

\section{Methods}

\section{Study design and participants}

This case-control observational study is set to identify nutritional factors that differ in sarcopenic and nonsarcopenic groups of older adults.

Study participants were older adults ( $\geq 65$ years) selected from our previous study (Urzi et al., 2017). The sample was composed of 115 participants, 26 of whom had sarcopenia; 75 older adults living in a nursing home and 40 free-living older adults (29\% of men; average age $77.7 \pm 10.3$ years). Sarcopenia was assessed according to the EWGSOP diagnostic criteria (Cruz-Jentoft et al., 2010). For details on health-related data, body composition measurements and sarcopenia assessment see our original publication (Urzi et al., 2017). We conducted our study in compliance with the principles of the Declaration of Helsinki. The study was approved by the Republic of Slovenia National Medical Ethics Committee (No. 0120-313/2015-6 KME 105/06/16).

\section{Dietary Intake and Malnutrition Assessment}

Habitual dietary intake was assessed with the 3-day weighed dietary record over two weekdays and on one weekend day. The weight of food intake in grams was converted into energy, macronutrient and micronutrient amounts using the online OPEN (Open Platform for Clinical Nutrition dietary assessment tool (http://www.opkp.si)). 
The mini nutritional assessment (MNA) was used to assess the nutritional status. Malnutrition indication scores ranged from 17 to 30 points. Participants were classified according to achieved scores as follows: from 24 to 30 points (normal nutritional status), from 17 to 23.5 points (at risk of malnutrition), and less than 17 points (malnourished) (Vellas et al., 1999).

\section{Statistical analysis}

Data were analysed using SPSS version 25 (SPSS Inc., Chicago, IL). For continuous variables, we calculated mean values, standard deviations, and medians. Categorical variables are expressed as numbers and percentages.

Normality in the distribution of variables was tested with the Shapiro-Wilk test. The homogeneity of variances was tested by Leven's test for equality of variances. For continuous variables, differences in participant's characteristics between those with and without sarcopenia were examined using the unpaired Student's t-test or Mann-Whitney U test. For categorical variables, comparisons between groups were made using the $\chi^{2}$-test. Risk factors were determined using logistic regression with sarcopenic status as the outcome. Initially, those dietary factors that were significantly different between groups were included in a multivariate model to determine the best predictor of sarcopenic status. Those factors that were significant at the $\mathrm{p}=.05$ level were included in the multivariate model, having taken into consideration possible covariates, to determine whether the dietary intake differences between the groups were related to sarcopenia. The following covariates were included for the evaluation of dietary intake: sex, age, body mass index, MNA malnutrition category, energy intake, diabetes mellitus, hypertension, heart disease, depression, chronic obstructive pulmonary disease (COPD) and physical activity level. All statistical tests were 2-sided. A p value lower than .05 was considered statistically significant.

\section{Results}

Baseline characteristics of study participants in relation to the presence of sarcopenia according to EWGSOP (Cruz-Jentoft et al., 2010) diagnostic criteria are presented in Table 1 and Table 2 . We found lower body mass index $(\mathrm{t}(113)=$ 2.839, $\mathrm{p}=.005)$, skeletal muscle index $(\mathrm{U}=439, \mathrm{z}=-4.801, \mathrm{p}=<.001)$, gait speed $(\mathrm{U}=440, \mathrm{z}=-4.794, \mathrm{p}<.001)$, and grip strength $(\mathrm{U}=319, \mathrm{z}=-5.605, \mathrm{p}<.001)$ in the sarcopenic group. The sarcopenic participants also reported a lower level of physical activity than the nonsarcopenic older adults $(U=761, z=-2.792$, $\mathrm{p}=.005)$, and had significantly higher rates of diabetes mellitus $\left(\chi^{2}(1)=5.25, \mathrm{p}\right.$ $=.022)$, and hypertension $\left(\chi^{2}(1)=5.59, \mathrm{p}=.018\right)$. The risk of malnutrition was higher $\left(\chi^{2}(1)=10.45, \mathrm{p}=.001\right)$ in the sarcopenic $(42.3 \%)$ comparing to the nonsarcopenic group (13.5\%). None of the participants were malnourished. 
Table 1: Characteristic of study participants in relation to the presence of sarcopenia by EWGSOP diagnostic criteria

\begin{tabular}{lccc}
\multicolumn{1}{c}{ Variables } & $\begin{array}{c}\text { Non sarcopenic } \\
(n=89)\end{array}$ & $\begin{array}{c}\text { Sarcopenic } \\
(n=26)\end{array}$ & T-test / Mann-Whitney \\
\hline Mge (years) & $75.2(10.0)$ & $\mathrm{M}(\mathrm{SD})$ & $\mathrm{p}$-values \\
\hline Body height $(\mathrm{cm})$ & $163.0(8.7)$ & $86.2(5.98)$ & $<.001$ \\
\hline Body mass $(\mathrm{kg})$ & $74.0(13.0)$ & $159.3(8.9)$ & .063 \\
\hline $\begin{array}{l}\text { Body mass index }(\mathrm{kg} / \\
\text { m2) }\end{array}$ & $28.1(5.5)$ & $62.8(11.6)$ & .005 \\
\hline $\begin{array}{l}\text { Skeletal muscle index } \\
(\mathrm{kg} / \mathrm{m} 2)\end{array}$ & $7.79(1.22)$ & $24.7(3.8)$ & $<.001$ \\
\hline Gait speed $(\mathrm{m} / \mathrm{s})$ & $0.92(0.43)$ & $6.59(1.02)$ & $<.001$ \\
\hline Grip strength $(\mathrm{kg})$ & $28.0(9.34)$ & $0.46(0.18)$ & $<.001$ \\
\hline Physical activity level & $1.38(0.13)$ & $16.6(6.07)$ & .005 \\
\hline
\end{tabular}

Table 2: Nutritional and health status of study participants in relation to the presence of sarcopenia by EWGSOP diagnostic criteria

\begin{tabular}{|c|c|c|c|}
\hline Variables & Non sarcopenic & Sarcopenic & $\chi^{2}$-test \\
\hline & $\mathrm{n}(\%)$ & $\mathrm{n}(\%)$ & p-values \\
\hline \multicolumn{4}{|l|}{$\begin{array}{l}\text { Mini Nutritional Assess- } \\
\text { ment }\end{array}$} \\
\hline $\begin{array}{l}\text { Normal nutrition- } \\
\text { al status }\end{array}$ & $77(86.5)$ & $15(57.7)$ & .001 \\
\hline At risk of malnutrition & $12(13.5)$ & $11(42.3)$ & \\
\hline Malnourished & o (o) & $\mathrm{o}(\mathrm{o})$ & \\
\hline $\begin{array}{l}\text { Chronic obstructive pul- } \\
\text { monary disease }\end{array}$ & $3(3.4)$ & $1(3.8)$ & l \\
\hline Type 2 diabetes & $12(13.5)$ & $8(30.8)$ & .022 \\
\hline Hypertension & $29(32.6)$ & $14(53.8)$ & .018 \\
\hline Heart disease & $10(11.2)$ & $4(15.4)$ & .463 \\
\hline Other diseases & $35(39.3)$ & $13(50.0)$ & .365 \\
\hline
\end{tabular}

Note. EWGSOP = European Working Group on Sarcopenia in Older People. Sarcopenia: low muscle mass, cut off point $\leq 8.87 \mathrm{~kg} / \mathrm{m}_{2}$ (in men) and $\leq 6.42 \mathrm{~kg} / \mathrm{m} 2$ (in women) and low muscle strength (men <3o kg; women $<20 \mathrm{~kg}$ ) and/or low physical performance (gait speed $<0.8 \mathrm{~m} / \mathrm{s}$ ).

Comparison of dietary intake between sarcopenic and nonsarcopenic older individuals

The dietary intake of the sarcopenic and nonsarcopenic groups are shown in Table 2. Energy intake does not differ between the groups, but when expressed as energy intake per kg of body mass per day, the sarcopenic group shows higher values compared to the non-sarcopenic group (24.9 vs. $28.8 \mathrm{~g} / \mathrm{kg}$ per day; $U=1689, \mathrm{z}=3.544, \mathrm{p}<.001)$. The sarcopenic participants also have a higher protein intake (1.13 vs. $0.95 \mathrm{~g} / \mathrm{kg}$ bw/d; $\mathrm{t}(113)=-3.592, \mathrm{p}<.001)$. Compared with the PROT-AGE recommendations for dietary protein intake (Bauer et al., 2013), the proportion of older adults with dietary protein intake lower than 1.0 
$/ \mathrm{kg}$ bw/d were $19 \%$ and $57 \%$ for sarcopenic and non-sarcopenic older adults, respectively. Intakes lower than $1.2 \mathrm{~g} / \mathrm{kg}$ bw/d amounted to $69 \%$ for the sarcopenic and $89 \%$ for the non-sarcopenic group. Greater daily protein intake in the sarcopenic group was not reflected in the differences in branch chain amino acid (BCAA) $(\mathrm{p}=.981)$ or leucine $(\mathrm{p}=.931)$ intake between the two groups.

There were no significant differences in daily intake of carbohydrate $(\mathrm{p}=$ $.229)$, fat ( $\mathrm{p}=.583)$, and saturated fatty acid ( $\mathrm{p} \geq .24)$. Other nutrients like $\mathrm{n}-3$ fatty acid $(\mathrm{U}=544, \mathrm{z}=-4.099, \mathrm{p}<.001)$, vitamin $\mathrm{D}(\mathrm{U}=750, \mathrm{z}=-2.721, \mathrm{p}=.007)$, vita$\min \mathrm{K}(\mathrm{U}=691, \mathrm{z}=-3.116, \mathrm{p}=.002)$, vitamin $\mathrm{C}(\mathrm{U}=843, \mathrm{z}=-2.099, \mathrm{p}=.036)$, vi$\operatorname{tamin} \mathrm{B}_{1}(\mathrm{U}=69 \mathrm{o}, \mathrm{z}=-3.112, \mathrm{p}=.002)$, vitamin $\mathrm{B}_{7}(\mathrm{U}=68 \mathrm{o}, \mathrm{z}=-3.189, \mathrm{p}=.001)$, and vitamin $\mathrm{B} 9(\mathrm{U}=589, \mathrm{z}=-3.798, \mathrm{p}<.001)$ were all lower in the sarcopenic compared to the non-sarcopenic group. Intakes of all other nutrients did not differ between the two groups $(\mathrm{p} \geq .062)$. The proportion of individuals whose usual intake of n-3 fatty acid was below the RDA (Reference dietary values DACH, 2004) was $100 \%$ in the sarcopenic group and $83.1 \%$ in the nonsarcopenic group. Vitamin D intake was lower than the RDA in both the sarcopenic and nonsarcopenic group (in $100 \%$ and $87.6 \%$ of individuals, respectively). Folic acid intake was substantially lower than the RDA in the sarcopenic and nonsarcopenic group (in $100 \%$ and $89.9 \%$ of individuals, respectively). Thiamine intake was also lower than the RDA in both the sarcopenic and nonsarcopenic group (92.3\% and $53.9 \%$, respectively). Dietary supplement users in nonsarcopenic group was $9 \%$ (supplement: $9 \%$ vitamin D, $4 \%$ n-3 fatty acid, $2 \%$ vitamin C and $1 \%$ vitamin B), while none of the sarcopenic participants used supplements.

Table 3: Average daily dietary intakes by non-sarcopenic and sarcopenic older adults

\begin{tabular}{lccc}
\multicolumn{1}{c}{ Characteristic } & $\begin{array}{c}\text { Non sarcopenic } \\
(n=89)\end{array}$ & $\begin{array}{c}\text { Sarcopenic } \\
(n=26)\end{array}$ & T-test / Mann-Whitney \\
\hline Energy $(\mathrm{kcal})$ & $1809(375)$ & $\mathrm{M}(\mathrm{SD})$ & .392 \\
\hline $\begin{array}{l}\text { Energy }(\mathrm{kcal} / \mathrm{kg} \mathrm{BM} \\
\text { / day) }\end{array}$ & $24.9(6.03)$ & $1786(329)$ & $<.001$ \\
\hline Protein $(\mathrm{g} / \mathrm{kg} \mathrm{BM} / \mathrm{day})$ & $0.95(0.24)$ & $28.8(4.75)$ & $<.001$ \\
\hline Carbohydrates $(\mathrm{g})$ & $221(55.4)$ & $1.13(0.18)$ & .229 \\
\hline $\begin{array}{l}\text { \% Energy from Carbo- } \\
\text { hydrates }\end{array}$ & $48.9(6.92)$ & $211(50.5)$ & .172 \\
\hline Fat $(\mathrm{g})$ & $70.0(19.8)$ & $47.2(4.91)$ & .583 \\
\hline \multicolumn{1}{c}{$\%$ Energy from Fat } & $34.7(6.51)$ & $72.3(15.2)$ & .205 \\
\hline BCAA $(\mathrm{g})$ & $9.81(2.37)$ & $36.5(4.92)$ & .981 \\
\hline Leucine $(\mathrm{g})$ & $4.05(0.95)$ & $9.80(1.63)$ & .931 \\
\hline Palmitic acid $(\mathrm{g})$ & $10.5(3.20)$ & $4.03(0.67)$ & .249 \\
\hline Stearic acid $(\mathrm{g})$ & $4.57(1.55)$ & $11.2(2.20)$ & .489 \\
\hline $\mathrm{n}-3$ fatty acid $(\mathrm{g})$ & $1.04(0.76)$ & $4.74(0.98)$ & $<.001$ \\
\hline $\mathrm{n}-6$ fatty acid $(\mathrm{g})$ & $8.73(4.33)$ & $0.57(0.14)$ & .904 \\
\hline Vitamin D $(\mu \mathrm{g})$ & $4.40(6.59)$ & $8.36(3.07)$ & .007 \\
\hline Vitamin E $(\mathrm{mg})$ & $10.1(2.98)$ & $1.44(0.38)$ & .062 \\
\hline
\end{tabular}




\begin{tabular}{|c|c|c|c|}
\hline Characteristic & $\begin{array}{c}\text { Non sarcopenic } \\
(n=89)\end{array}$ & $\begin{array}{l}\text { Sarcopenic } \\
\quad(n=26)\end{array}$ & T-test / Mann-Whitney \\
\hline Vitamin K $(\mu g)$ & $138(112)$ & $77.7(27.2)$ & .002 \\
\hline Vitamin C (mg) & $76.6(39.8)$ & $57.7(18.5)$ & .036 \\
\hline Vitamin $\mathrm{B}_{1}$ (mg) & $0.97(0.33)$ & $0.76(0.11)$ & .002 \\
\hline Vitamin B2 (mg) & $1.27(0.31)$ & $1.24(0.23)$ & .714 \\
\hline Vitamin B5 (mg) & $3.91(0.97)$ & $3.51(0.63)$ & .072 \\
\hline Vitamin B6 (mg) & $1.34(0.44)$ & $1.15(0.19)$ & .091 \\
\hline Vitamin B7 $(\mu g)$ & $20.1(11.2)$ & $12.8(5.03)$ & .001 \\
\hline Vitamin B9 (mg) & $0.21(0.08)$ & $0.15(0.02)$ & $<.001$ \\
\hline Vitamin B12 $(\mu \mathrm{g})$ & $2.89(1.29)$ & $2.55(0.54)$ & .349 \\
\hline Potassium (g) & $2.54(0.58)$ & $2.31(0.39)$ & .131 \\
\hline Calcium (g) & $0.74(0.22)$ & $0.81(0.18)$ & .161 \\
\hline Magnesium (g) & $0.32(0.12)$ & $0.27(0.04)$ & .166 \\
\hline Phosphorus (g) & $1.02(0.25)$ & $0.99(0.20)$ & .570 \\
\hline Iron $(\mathrm{g})$ & $13.1(3.68)$ & $11.8(2.12)$ & .088 \\
\hline Copper (mg) & $1.37(0.40)$ & $1.30(0.24)$ & .290 \\
\hline Selenium $(\mu \mathrm{g})$ & $51.0(16.6)$ & $45.1(12.9)$ & .175 \\
\hline Zinc (mg) & $7.90(1.99)$ & $7.65(0.29)$ & .784 \\
\hline
\end{tabular}

\begin{tabular}{|c|c|c|c|}
\hline & & Model I & \\
\hline Factor & $\beta$-value & p-value & Odds ratio $(95 \% \mathrm{CI})$ \\
\hline n-3 fatty acid (g) & -3.232 & .035 & $0.039(0.002-0.793)$ \\
\hline Vitamin D $(\mu \mathrm{g})$ & -0.059 & .786 & $0.943(0.617-1.441)$ \\
\hline Vitamin K $(\mu \mathrm{g})$ & -0.006 & .386 & $0.994(0.981-1.007)$ \\
\hline Vitamin C (mg) & 0.010 & .529 & $1.010(0.980-1.040)$ \\
\hline Vitamin $B_{1}(\mu g)$ & -1.726 & .450 & $0.178(0.002-15.71)$ \\
\hline Vitamin $B_{7}(\mu \mathrm{g})$ & -0.007 & .895 & $0.993(0.897-1.100)$ \\
\hline Vitamin B9 $(\mu \mathrm{g})$ & -0.013 & .377 & $0.987(0.959-1.016)$ \\
\hline
\end{tabular}


In Table 5 the model after controlling for sex, age, body mass index, MNA malnutrition category, energy intake, diabetes mellitus, hypertension, heart disease, depression, COPD and physical activity level is shown. An increased risk of sarcopenia $\left(\mathrm{R}_{2}=0.756\right)$ was found in older adults with a low dietary intake of n-3 fatty acid (OR 0.002, 95\% CI 0.00o-0.461, p = .025), body mass in$\operatorname{dex}(\mathrm{OR}$ 0.611, 95\% CI 0.438-0.853, p = .004), physical activity level (OR o.001, 95\% CI 0.000-0.873, $\mathrm{p}=.048$ ), with the presence of diabetes mellitus (OR o.0o6, 95\% CI 0.000-0.170, $\mathrm{p}=.003$ ), hypertension (OR 0.063, 95\% CI 0.005-0.768, p $=.030$ ), and were older (OR 1.172, 95\% CI 1.016-1.352, $\mathrm{p}=.030)$. Sex, MNA malnutrition category, energy intake, heart disease, depression, and COPD did not achieve statistical significance in this model ( $\mathrm{p} \geq .092)$.

\section{Table 5: Regression coefficients and odds ratios (and 95\% CIs) for risk factors associated with sarcopenia}

\begin{tabular}{lccc} 
& & Model II & \\
\hline \multicolumn{1}{c}{ Factor } & $\beta$-value & -value & Odds ratio (95\% CI) \\
\hline $\mathrm{n}-3$ fatty acid $(\mathrm{g})$ & -6.226 & .025 & $0.002(0.000-0.461)$ \\
\hline Age (years) & 0.159 & .030 & $1.172(1.016-1.352)$ \\
\hline Physical activity level & -12.527 & .048 & $0.000(0.000-0.873)$ \\
\hline $\begin{array}{l}\text { Body mass index (kg/ } \\
\text { m2) }\end{array}$ & -0.492 & .004 & $0.611(0.438-0.853)$ \\
\hline $\begin{array}{l}\text { Diabetes mellitus (pres- } \\
\text { ence) }\end{array}$ & -5.039 & .003 & $0.006(0.000-0.170)$ \\
\hline Hypertension (presence) & -2.768 & .030 & $0.063(0.005-0.768)$ \\
\hline
\end{tabular}

Note. Binary logistic analyses were used to estimate the odds ratio (OR) and $95 \%$ confidence interval (CI) of factors related to sarcopenia. Adjusted model for sex, age, body mass index, MNA malnutrition categories, energy intake, diabetes mellitus, hypertension, heart disease, depression, COPD and physical activity level.

\section{Discussion}

Deficiencies in both macronutrients and micronutrients can be considered as a risk factor for sarcopenia, because such deficiencies can accelerate age-dependent changes in body composition, involving the loss of muscle mass, strength and function (Walrand et al., 2011; Volkert et al., 2018; Beaudart et al., 2019). We aimed to investigated nutritional factors that may be associated with the aetiology of sarcopenia by comparing the habitual dietary intake of the sarcopenic and nonsarcopenic groups of older adults.

The findings show that older adults in the sarcopenic group were more likely at risk of malnutrition (42.3\%) than those in the nonsarcopenic group (13.5\%) and demonstrate a higher rate of co-morbidities such as diabetes mellitus and hypertension. According to the MNA, although none of the participants was malnourished, $20 \%$ were at risk of malnutrition. The proportion of older adults who are malnourished or at risk of malnutrition vary depending on the cohort in the study. We found that the proportion of participants at risk of malnutrition was as high as $42.5 \%$ in the nursing homes (Lardiés-Sánchez et 
al., 2017), or 9\% among community-dwelling older adults (ter Borg et al., 2016). Although we observed significant differences in the MNA malnutrition category between the sarcopenic and nonsarcopenic group, as in other studies (ter Borg et al., 2016; Lardiés-Sánchez et al., 2017), it was not identified as a covariate for some of the observed nutrient intake differences.

The energy intake of the present population was 7.1-8.6MJ (1696.9 kcal $2055.4 \mathrm{kcal}$ ) including intake of carbohydrate 48-49 En\%, protein 15-16 En\%, and fat 33-35 En\%. These results are in line with the intake data of older adults from systematic literature review (ter Borg et al., 2015), and other studies (van Rossum et al., 2011; ter Borg et al., 2016) that indicates suboptimal macronutrient intakes among older adults. We did not observe significant differences in energy intake between the sarcopenic and nonsarcopenic group, similar to the results of Maastricht Sarcopenia Study (ter Borg et al., 2016).

Even though the greater proportion of the sarcopenic participants meet the lower range of evidence-based recommendations for optimal dietary protein intake of $1.0 \mathrm{~g} / \mathrm{kg}$ bw/d (Bauer et al., 2013), the inadequate nutrition pattern of this group was reflected in the insufficient daily amount of seven nutrients ( $\mathrm{n}-3$ fatty acid, vitamins D, K, C, thiamine, biotin and folic acid). Besides, the evidence shows that protein intake alone is not sufficient to preserve muscle quality but it is rather an interplay of group of nutrients that contribute to the prevention of sarcopenia (Verlaan et al., 2018). The literature suggests that adequate intake of proteins ( $1.2 \mathrm{~g} / \mathrm{kg}$ bw/d), n-3 fatty acids, and vitamin D, combined with physical exercise, forms part of an integrated management of sarcopenia (Boirie et al., 2014; Wu et al., 2020).

A significantly lower intake of thiamine, biotin, and folate $(21 \%, 36 \%$, and $28 \%$, respectively) was observed in our sarcopenic group compared to the nonsarcopenic group. The literature review (ter Borg et al., 2015; ter Borg et al., 2016; Beaudart et al., 2019) identified six nutrients (thiamin, riboflavin, vitamin D, $\mathrm{Ca}, \mathrm{Mg}$ and $\mathrm{Se}$ ) of potential concern as a result of a high prevalence of micronutrient inadequacy in diets among older adults in Europe. Furthermore, a possible link between vitamins B and the aetiology of sarcopenia was proposed (ter Borg et al., 2016; Bulut et al., 2017; Aytekin, 2018). The mechanisms are mainly related to the reduced activity of vitamin B1 dependent enzymes in mitochondria, and folate deficiency with hyperhomocysteinaemia. Deficiencies in these vitamins can include impairments in oxidative metabolism, and mitochondrial function, leading to inflammatory responses associated with increased production of reactive oxygen species and excitotoxicity, which causes muscle protein degradation (ter Borg et al., 2016; Aytekin, 2018).

The comparison of vitamin D intake between the groups showed a significantly lower vitamin D intake in the sarcopenic group of $67 \%$. Furthermore, none of the sarcopenic participants were supplemented with vitamin D. Supportive evidence shows the clinical relevance of vitamin D supplementation in the treatment and prevention of sarcopenia (Cangussu et al., 2015; Verlaan et al., 2018). 
We observed a 45\% lower n-3 fatty acids intake in the sarcopenic group compared to the nonsarcopenic group. The findings of our study show that a higher dietary intake of n-3 fatty acid in the nonsarcopenic group was associated with a significantly reduced risk of sarcopenia. The analyses considered possible covariates and indicated that the association between n-3 fatty acid and sarcopenia is partially explained by age, body mass index, presence of diabetes mellitus, hypertension, and physical activity level.

Various randomized controlled trials and cohort analysis shows a significant role of the dietary intake of n-3 fatty acids in preventing sarcopenia and muscle loss (Ganapathy and Nieves, 2020). Besides, it was shown that n-3 fatty acid supplementation directly stimulates muscle protein synthesis in older adults and may be effective for muscle mass gain (Smith et al., 2011). Some previous studies have discovered that the prevalence of chronic disease is interrelated with systemic chronic low-grade inflammation, which contributes to the loss of muscle mass, strength and function through several cytokine signalling pathways (Kim et al., 2014; Dalle et al., 2017). It was suggested that nutrients like n-3 fatty acids might have the potential of preventing and reducing numerous chronic conditions caused by inflammatory factors by decreasing the level of inflammatory cytokines, and prevent the loss of muscle mass, strength and function associated with age-related sarcopenia (Smith, 2016; Buoite et al., 2018).

Certain limitations must be taken into consideration. Based on the cross-sectional design of the study, no conclusion can be made on the cause-effect relationship between sarcopenia and nutrient factors. Therefore, research along with longitudinal design and controlled bias would be useful in providing further clarification on the effects of the differences in nutrient intake regarding the risk of sarcopenia.

\section{Conclusions}

Musculoskeletal health is important for the functionality and independence of older adults, and we showed that some nutrients as well as dietary patterns offer protective effects against age-related declines in muscle mass and function.

The present results suggest that sarcopenic older adults have important dietary deficiencies in n-3 fatty acids, vitamin D, vitamin $C$ and some vitamin B. The inadequate intake of these nutrients could be viewed as a risk factor for sarcopenia, although prospective studies are needed to confirm these findings.

\section{References}

ANKER, S.-D., MORLEY, J.-E., and HAEHLING, S., 2016. Welcome to the ICD-10 code for sarcopenia. Journal of Cachexia, Sarcopenia and Muscle, vol. 7, no. 5, p. 512-514.

AYTEKIN, N., MILEVA, K. N., and CUNLIFFE, A. D., 2018. Selected B vitamins and their possible link to the aetiology of age-related sarcopenia: 
relevance of UK dietary recommendations. Nutrition research reviews, vol. 31, no. 2, pp 204-224.

BAUER, J., BIOLO, G., CEDERHOLM, T., CESARI, M., CRUZ-JENTOFT, A.-J., MORLEY, J.-E., PHILLIPS, S., SIEBER, C., STEHLE, P., TETA, D., VISVANATHAN, R., VOLPI, E. and BOIRIE, Y., 2013. Evidence-Based Recommendations for Optimal Dietary Protein Intake in Older People: A Position Paper From the PROT-AGE Study Group. Journal of the American Medical Directors Association, vol. 14, no. 8, pp. 542-559.

BAUER, J.-M., 2021. Muscle Function and Sarcopenia: Clinical Implications of Recent Research. Journal of the American Medical Directors Association, vol. 22, no. 4, pp. 725-727.

BEAUDART, C., LOCQUET, M., TOUVIER, M., REGINSTER, J.-Y. and BRUYĖRE, O., 2019. Association between dietary nutrient intake and sarcopenia in the SarcoPhAge study. Aging Clinical and Experimental Research, vol. 31, no. 6, pp. 815-824.

BEAUDART, C., RIZZOLI, R., BRUYĖRE, O., REGINSTER, J.-Y. and BIVER, E., 2014. Sarcopenia: burden and challenges for public health. Archives of public health, vol. 72 , no. 1, pp. 45.

BEAUDART, C., SANCHEZ-RODRIGUEZ, D., LOCQUET, M., REGINSTER, J.-Y., LENGELÉ, L. and BRUYĖRE, O., 2019. Malnutrition as a Strong Predictor of the Onset of Sarcopenia. Nutrients, vol. 11, no. 12, pp. 2883.

BOIRIE, Y., MORIO, B., CAUMON, E. and CANO, N.-J., 2014. Nutrition and protein energy homeostasis in elderly. Mechanisms of Ageing and Development, vol. 136, pp.76-84.

BULUT, E.-A., SOYSAL, P., AYDIN, A.-E., DOKUZLAR, O., KOCYIGIT, S.-E. and ISIK, A.-T., 2017. Vitamin B12 deficiency might be related to sarcopenia in older adults. Experimental gerontology, vol. 95, pp.136-140.

BUOITE S.-A., GORTAN CAPPELLARI, G., BARAZZONI, R. and ZANETTI, M., 2018. Update on the impact of omega 3 fatty acids on inflammation, insulin resistance and sarcopenia: A review. International journal of molecular sciences, vol. 19, no. 1, pp. 218.

CAN, B., KARA, O., KIZILARSLANOGLU, M.-C., ARIK, G., AYCICEK, G.-S., SUMER, F., CIVELEK, R., DEMIRTAS, C. and ULGER, Z., 2016. Serum markers of inflammation and oxidative stress in sarcopenia. Aging Clinical and Experimental Research, vol. 29, no. 4, p. 745-752.

CANGUSSU, L.-M., NAHAS-NETO, J., ORSATTI, C.-L., BUELONI-DIAS, F.-N. and NAHAS, E.-A.-P., 2015. Effect of vitamin D supplementation alone on muscle function in postmenopausal women: a randomized, double-blind, placebo-controlled clinical trial. Osteoporosis International, vol. 26, no. 10, pp.2413-2421.

CHEN, Y.-L., YANG, K.-C., CHANG, H.-H., LEE, L.-T., LU, C.-W. and HUANG, K.-C., 2014. Low Serum Selenium Level Is Associated with Low 
Muscle Mass in the Community-Dwelling Elderly. Journal of the American Medical Directors Association, vol. 15, no. 11, pp.807-811.

COEN, P.-M., MUSCI, R.-V., HINKLEY, J.-M. and MILLER, B.-F., 2019. Mitochondria as a Target for Mitigating Sarcopenia. Frontiers in Physiology, [online]. [viewed 23 August 2021]. Available from: https://www.frontiersin.org/articles/10.3389/fphys.2018.01883/full

CORREA-DE-ARAUJO, R. and HADLEY, E., 2014. Skeletal Muscle Function Deficit: A New Terminology to Embrace the Evolving Concepts of Sarcopenia and Age-Related Muscle Dysfunction. The Journals of Gerontology Series A: Biological Sciences and Medical Sciences, vol. 69, no. 5, pp. 591-594.

CRUZ-JENTOFT, A.-J., BAEYENS, J.-P., BAUER, J.-M., BOIRIE, Y., CEDERHOLM, T., LANDI, F., MARTIN, F.-C., MICHEL, J.-P., ROLLAND, Y., SCHNEIDER, S.-M., TOPINKOVA, E., VANDEWOUDE, M. and ZAMBONI, M. Sarcopenia: European consensus on definition and diagnosis: Report of the European Working Group on Sarcopenia in Older People. Age and Ageing, vol. 39, no. 4, pp. 412-423.

CRUZ-JENTOFT, A.-J., LANDI, F., SCHNEIDER, S.-M., ZUNIGA, C., ARAI, H., BOIRIE, Y., CHEN, L.-K., FIELDING, R.-A., MARTIN, F.-C., MICHEL, J.-P., SIEBER, C., STOUT, J.-R., STUDENSKI, S.-A., VELLAS, B., WOO, J., ZAMBONI, M. and CEDERHOLM, T., 2014. Prevalence of and interventions for sarcopenia in ageing adults: a systematic review. Report of the International Sarcopenia Initiative (EWGSOP and IWGS). Age and Ageing, vol. 43, no. 6, pp. 748-759.

CRUZ-JENTOFT, A.-J. and SAYER, A.-A., 2019. Sarcopenia. The Lancet, vol. 393, no. 10191, pp. 2636-2646.

CRUZ-JENTOFT, A.-J, BAHAT, G., BAUER, J., BOIRIE, Y., BRUYĖRE, O., CEDERHOLM, T., COOPER, C., LANDI, F., ROLLAND, Y., SAYER, A.-A., SCHNEIDER, S.-M, SIEBER, C.-C, TOPINKOVA, E., VANDEWOUDE, M., VISSER, M., ZAMBONI, M., BAUTMANS, I., BAEYENS, J.-P., CESARI, M., CHERUBINI, A., KANIS, J., MAGGIO, M., MARTIN, F., MICHEL, J.-P., PITKALA, K., REGINSTER, J.-Y., RIZZOLI, R., SÁNCHEZ-RODRÍGUEZ, D. and SCHOLS, J., 2019. Sarcopenia: Revised European consensus on definition and diagnosis. Age and ageing, vol. 48, no. 1, pp.16-31.

DALLE, Sebastiaan, ROSSMEISLOVA, Lenka and KOPPO, Katrien, 2017. The role of inflammation in age-related sarcopenia. Frontiers in physiology, [online]. [viewed 23 August 2021]. Available from: https://www.frontiersin.org/articles/10.3389/fphys.2017.01045/full

FUlle, S., PROTASI, F., DI TANO, G., PIETRANGELO, T., BELTRAMIN, A., BONCOMPAGNI, S., VECCHIET, L. and FANÒ, G., 2004. The contribution of reactive oxygen species to sarcopenia and muscle ageing. Experimental gerontology, vol. 39, no. 1, pp. 17-24. 
Ganapathy, A. and Nieves, J.-W., 2020. Nutrition and sarcopenia-What do we know?. Nutrients, vol. 12, no. 6, pp. 1755.

KIM, J.-E., LEE, Y.-H., HUH, J.-H., KANG, D.-R., RHEE, Y. and LIM, S.-K., 2014. Early-stage chronic kidney disease, insulin resistance, and osteoporosis as risk factors of sarcopenia in aged population: The Fourth Korea National Health and Nutrition Examination Survey (KNHANES IV), 2008-2009. Osteoporosis International, vol. 25, no. 9, pp. 2189-2198.

LANDI, F., CRUZ-JENTOFT, A.-J., LIPEROTI, R., RUSSO, A., GIOVANNINI, S., TOSATO, M., CAPOLUONGO, E., BERNABEI, R. and ONDER, G., 2013. Sarcopenia and mortality risk in frail older persons aged 80 years and older: results from ilSIRENTE study. Age and Ageing, vol. 42, no. 2, pp. 203-209.

LARDIÉS-SÁNCHEZ, B., SANZ-PARÍS, A., PÉREZ-NOGUERAS, J., SERRANO-OLIVER, A., TORRES-ANORO, M.-E. and CRUZ-JENTOFT, A.-J., 2017. Influence of nutritional status in the diagnosis of sarcopenia in nursing home residents. Nutrition, vol. 41, pp.51-57.

LAURETANI, F., SEMBA, R.-D, BANDINELLI, S., RAY, A.-L, GURALNIK, J.-M and FERRUCCI, L., 2007. Association of low plasma selenium concentrations with poor muscle strength in older community-dwelling adults: the InCHIANTI Study. The American Journal of Clinical Nutrition, vol. 86, no. 2, pp. 347-352.

MORLEY, J.-E, ABBATECOLA, A.-M., ARGILES, J.-M, BARACOS, V., BAUER, J., BHASIN, S., CEDERHOLM, T., STEWART COATS, A.-J., CUMMINGS, S.-R, EVANS, W.-J, FEARON, K., FERRUCCI, L., FIELDING, R.-A, GURALNIK, J.-M, HARRIS, T.-B, INUI, A., KALANTAR-ZADEH, K., KIRWAN, B.-A., MANTOVANI, G., MUSCARITOLI, M., NEWMAN, A.-B, ROSSI-FANELLI, F., ROSANO, G.-M.C., ROUBENOFF, R., SCHAMBELAN, M., SOKOL, G.-H, STORER, T.-W, VELLAS, B., VON HAEHLING, S., YEH, S.-S. and ANKER, S.-D, 2011. Sarcopenia With Limited Mobility: An International Consensus. Journal of the American Medical Directors Association, vol. 12, no. 6, pp. 403-409.

Open Platform for Clinical Nutrition, OPEN, http://opkp.si/en, Ljubljana, Slovenia.

PACIFICO, J., GEERLINGS, M.-A., REIJNIERSE, E.-M., PHASSOULIOTIS, C., LIM, W.-K. AND MAIER, A.-B., 2020. Prevalence of sarcopenia as a comorbid disease: A systematic review and meta-analysis. Experimental gerontology, vol. 131, pp. 110801.

PRIEGO, T., MARTÍN, A.-I., GONZÁLEZ-HEDSTRÖM, D., GRANADO, M., LÓPEZ-CALDERÓN, A. and CARDALINI, D., 2021. Role of hormones in sarcopenia. Vitamins and Hormones, vol. 115, pp. 535-570.

Reference dietary values (DACH), German Nutrition Society (DGE), Austrian Nutrition Society (OGE), Swiss Society for Nutrition Research (SGE), Swiss Nutrition Association (SVE), Ministry of Health (2004), Ljubljana. 
ROLLAND, Y, CZERWINSKI, S, ABELLAN VAN KAN, G, MORLEY, J E, CESARI, M, ONDER, G, WOO, J, BAUMGARTNER, R, PILLARD, F, BOIRIE, Y, CHUMLEA, W M C and VELLAS, B, 2008. Sarcopenia: its assessment, etiology, pathogenesis, consequences and future perspectives. The journal of nutrition, health and aging, vol. 12, no. 7, pp. 433-50.

ROUBENOFF, R., 2003. Sarcopenia: Effects on Body Composition and Function. The Journals of Gerontology Series A: Biological Sciences and Medical Sciences, vol. 58, no. 11, pp. M1012-M1017.

SHAFIEE, G., KESHTKAR, A., SOLTANI, A., AHADI, Z., LARIJANI, B. and HESHMAT, R., 2017. Prevalence of sarcopenia in the world: a systematic review and meta- analysis of general population studies. Journal of Diabetes and Metabolic Disorders, vol. 16, no. 1, pp. 21.

SMITH, G.-I., 2016. The Effects of Dietary Omega-3s on Muscle Composition and Quality in Older Adults. Current Nutrition Reports, vol. 5, no. 2, pp.99-105.

SMITH, G.-I, ATHERTON, P., REED, D.-N, MOHAMMED, B.-S., RANKIN, D., RENNIE, M.-J and MITTENDORFER, B., 2011. Dietary omega-3 fatty acid supplementation increases the rate of muscle protein synthesis in older adults: a randomized controlled trial. American Journal of Clinical Nutrition, vol. 93, no. 2, pp.402-412.

TER BORG, S., DE GROOT, L.-C.P.G.M., MIJNARENDS, D.-M., DE VRIES, J.-H.M., VERLAAN, S., MEIJBOOM, S., LUIKING, Y.-C. and SCHOLS, J.-M.G.A., 2016. Differences in Nutrient Intake and Biochemical Nutrient Status Between Sarcopenic and Nonsarcopenic Older Adults-Results From the Maastricht Sarcopenia Study. Journal of the American Medical Directors Association, vol. 17, no. 5, pp. 393-401.

TER BORG, S., VERLAAN, S., HEMSWORTH, J., MIJNARENDS, D.-M., SCHOLS, J.-M.G.A., LUIKING, Y.-C. and DE GROOT, L.-C.P.G.M., 2015. Micronutrient intakes and potential inadequacies of community-dwelling older adults: a systematic review. British Journal of Nutrition, vol. 113, no. 08, pp. 1195-1206.

URZI, F., ŠIMUNIČ, B. and BUZAN, E., 2017. Basis for Sarcopenia Screening With the SARC-CalF in Nursing Homes. Journal of the American Medical Directors Association, vol. 18, no. 11, pp.991-e5.

VAN ROSSUM C.-T.M, FRANSEN H.-P, VERKAIK-KLOOSTERMAN J, BUURSMA-RETHANS E.-J.M, OCKE M.-C, 2011. Dutch National Food Consumption Survey 2007-2010: Diet of children and adults aged 7 to 69 years | RIVM. Report Number 350050006/2011. National Institute for Public Health and the Environment, [online]. [viewed 23 August 2021]. Available from: https://rivm.openrepository.com/handle/10029/261553

VELLAS, B., GUIGOZ, Y. GARRY, P.-J., NOURHASHEMI, F., BENNAHUM, D., LAUQUE, S. and ALBAREDE, J.-L., 1999. The mini nutritional as- 
sessment (MNA) and its use in grading the nutritional state of elderly patients. Nutrition, vol. 15, vol. 2, pp.116-122.

VERLAAN, S., MAIER, A.-B., BAUER, J.-M., BAUTMANS, I., BRANDT, K., DONINI, L.-M., MAGGIO, M., MCMURDO, M.-E.T., METS, T., SEAL, C., WIJERS, S.-L.J., SIEBER, C., BOIRIE, Y. and CEDERHOLM, T., 2018. Sufficient levels of 25 -hydroxyvitamin $\mathrm{D}$ and protein intake required to increase muscle mass in sarcopenic older adults - The PROVIDE study. Clinical Nutrition, vol. 37, no. 2, pp.551-557.

VOLKERT, D, BECK, A.-M, CEDERHOLM, T., 2018. ESPEN guideline on clinical nutrition and hydration in geriatrics. Clinical Nutrition, vol. 38 , no. 1 , pp. $10-47$.

WALRAND, S., GUILLET, C., SALLES, J., CANO, N. and BOIRIE, Y., 2011. Physiopathological Mechanism of Sarcopenia. Clinics in Geriatric Medicine, vol. 27 , no. 3, pp. 365-385.

WELCH, A.-A., JENNINGS, A., KELAIDITI, E., SKINNER, J. and STEVES, C.-J., C. J. (2020). Cross-sectional associations between dietary antioxidant vitamins $\mathrm{C}, \mathrm{E}$ and carotenoid intakes and sarcopenic indices in women aged 18-79 years. Calcified tissue international, vol. 106, no. 4, pp. 331-342.

WILSON, M.-M.G. and MORLEY, J.-E., 2003. Invited Review: Aging and energy balance. Journal of Applied Physiology, vol. 95, no. 4, pp. 1728-1736.

WU, P.-Y., HUANG, K.-S., CHEN, K.-M., CHOU, C.-P., TU, Y.-K., 202O. Exercise, nutrition, and combined exercise and nutrition in older adults with sarcopenia: A systematic review and network meta-analysis. Maturitas, [online]. [viewed 23 August 2021]. Available from: https://doi. org/10.1016/j.maturitas.2020.12.009 
Zdravje starostnikov

Health of the Elderly

Proceedings

Uredila / Edited by Ana Petelin

Recenzenti / Reviewers - Darja Barlič-Maganja, Ester Benko, Maša Černelič Bizjak,

Sara Fabjan, Sabina Ličen, Denisa Manojlović, Ana Petelin, Tim Podlogar, Tamara Poklar Vatovec, Patrik Pucer, Doroteja Rebec, Dea Salamon, Helena Skočir, Karin Šik Novak, Klemen Širok, Matej Voglar, Boštjan Žvanut

Oblikovanje in prelom / Design and Typesetting - Tanja Žuvela, Jonatan Vinkler

Izdajatelj / Published by - University of Primorska Press

Titov trg 4, si-600o Koper,

Koper 2021

Glavni urednik/Editor-in-Chief • Jonatan Vinkler

Vodja založbe/Managing Editor • Alen Ježovnik

ISBN 978-961-293-129-2

http://www.hippocampus.si//SBN/978-961-293-129-2.pdf

ISBN 978-961-293-130-8

http://www.hippocampus.si//SBN/978-961-293-130-8/index.html

DOI: https://doi.org/10.26493/978-961-293-129-2

(C) 2021 University of Primorska Press

\section{(G) BYSA}

Kataložni zapis o publikaciji (CIP) pripravili v Narodni in univerzitetni knjižnici v Ljubljani 


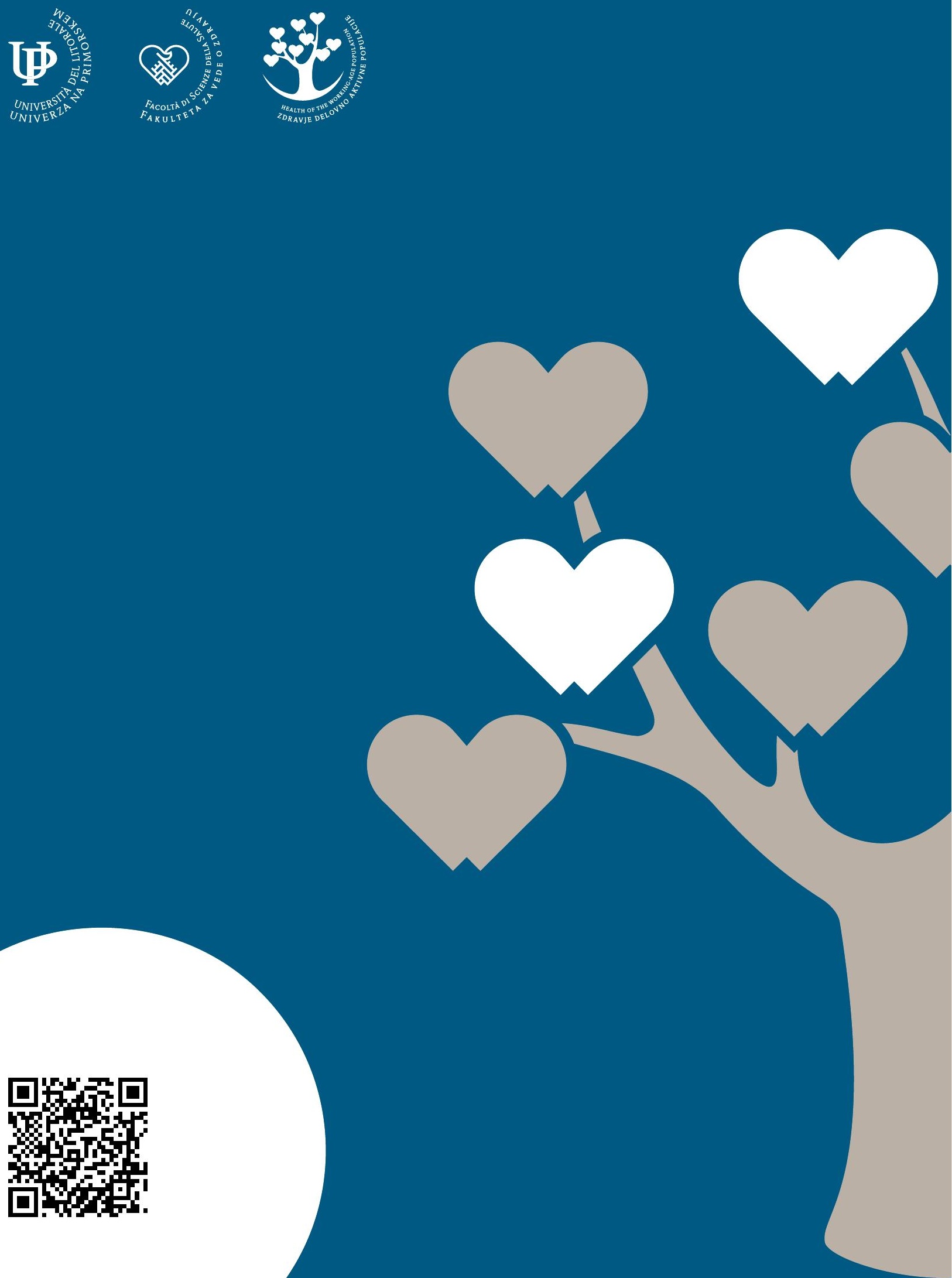